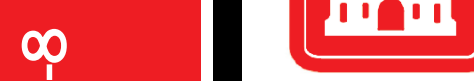

US Army Corps of Engineers $s_{\circledast}$

Engineer Research and

Development Center

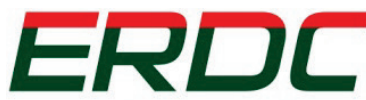

INNOVATIVE SOLUTIONS

for a safer, better world

Environmental Quality Technology Research Program

\title{
Aquatic Contaminant and Mercury Simulation Modules Developed for Hydrologic and Hydraulic Models
}

Zhonglong Zhang and Billy E. Johnson

July 2016
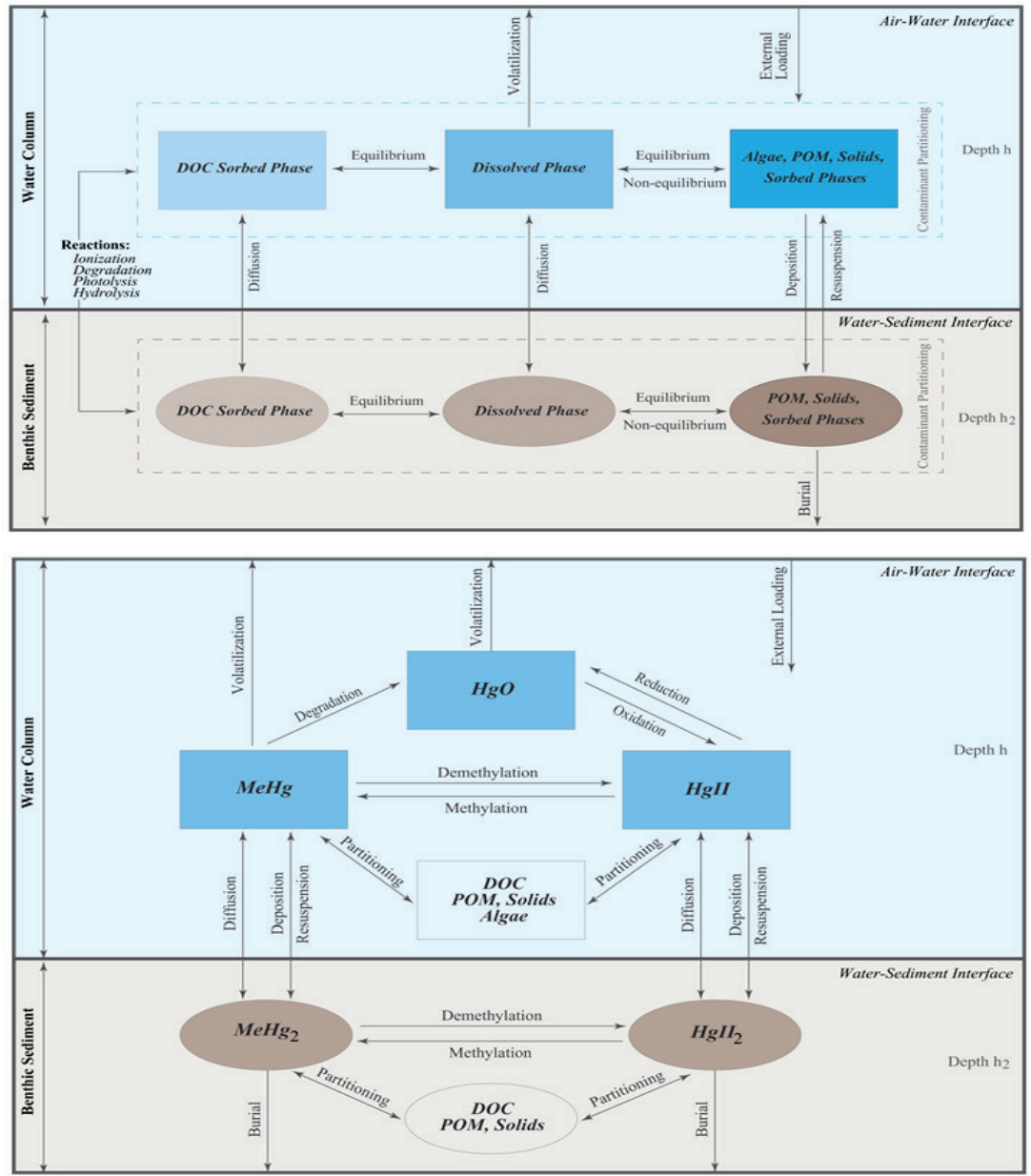
The U.S. Army Engineer Research and Development Center (ERDC) solves the nation's toughest engineering and environmental challenges. ERDC develops innovative solutions in civil and military engineering, geospatial sciences, water resources, and environmental sciences for the Army, the Department of Defense, civilian agencies, and our nation's public good. Find out more at www.erdc.usace.army.mil.

To search for other technical reports published by ERDC, visit the ERDC online library at http://acwc.sdp.sirsi.net/client/default. 


\section{Aquatic Contaminant and Mercury Simulation Modules Developed for Hydrologic and Hydraulic Models}

Zhonglong Zhang and Billy E. Johnson

Environmental Laboratory

U.S. Army Engineer Research and Development Center

3909 Halls Ferry Road

Vicksburg, MS 39180-6199

Final report

Approved for public release; distribution is unlimited.

Prepared for Headquarters, U.S. Army Corps of Engineers

Washington, DC 20314-1000 


\section{Abstract}

This report offers details regarding the theory and mathematical formulations implemented in the newly developed general constituent simulation module (GC), contaminant simulation module (CSM), and mercury simulation module (HgSM). The GC models simple kinetics for multiple size classes of solids and user-defined constituents in the water column. The CSM models the kinetics of user-defined contaminants in aquatic systems. The kinetic processes modeled in CSM include: ionization, multi-phase partitioning, degradation, photolysis, hydrolysis, volatilization, generalized second-order reaction, and transformations where one chemical species undergoes a reaction and is transformed to a daughter product. The HgSM models mercury species (elemental mercury, inorganic mercury, and methylmercury) and their cycling in aquatic systems. The three water quality modules only compute internal sources and sinks of each state variable for both water column and an underlying sediment layer. The GC, CSM and HgSM modules are written as "plug in" dynamic link libraries and compiled as GC.dll, CSM.dll and HgSM.dll respectively. These modules have been integrated into the HEC-RAS model and will also be integrated into other hydrologic and hydraulic models (e.g. AdH and SRH-2D).

DISCLAIMER: The contents of this report are not to be used for advertising, publication, or promotional purposes. Citation of trade names does not constitute an official endorsement or approval of the use of such commercial products. All product names and trademarks cited are the property of their respective owners. The findings of this report are not to be construed as an official Department of the Army position unless so designated by other authorized documents. 


\section{Contents}
Abstract ii

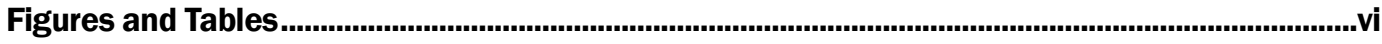

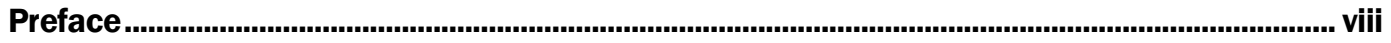
Unit Conversion Factors .......................................................................................................... ix

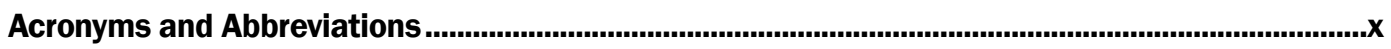

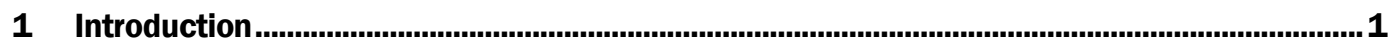

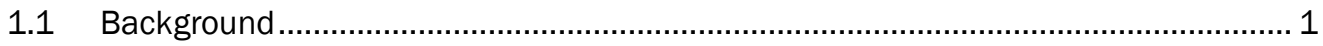

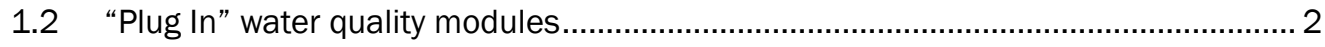
1.3 Report outline ................................................................................................. 3

2 General Constituent Simulation Module (GC) ......................................................................4

2.1 Solids characterization and conceptual model................................................. 4

2.2 Suspended solids .......................................................................................... 6

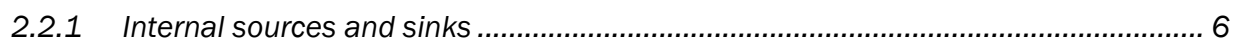

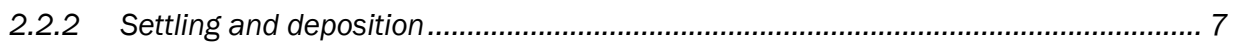

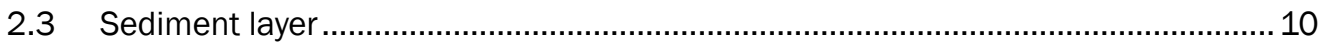

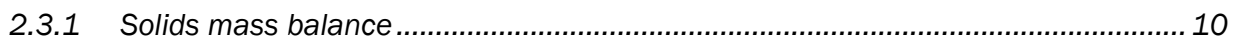

2.3.2 Sediment re-suspension ................................................................................. 11

2.3.3 Bottom shear stress.......................................................................................... 13

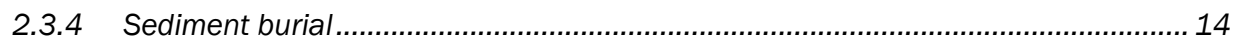

2.4 Solids and sediment layer parameters.......................................................... 14

2.5 Simple kinetics for user-defined constituents ................................................. 16

2.6 Water temperature correction equations ............................................................. 17

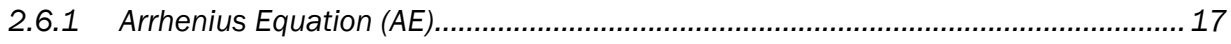

2.6.2 Modified Arrhenius Equation (MAE) ............................................................ 18

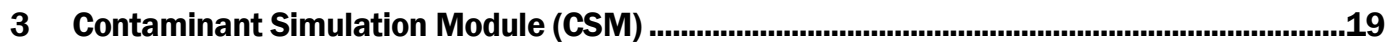

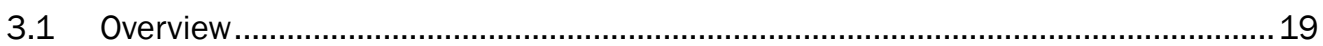

3.2 Contaminant ionization ............................................................................... 21

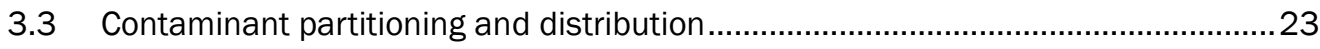

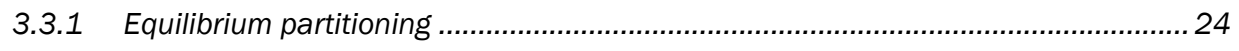

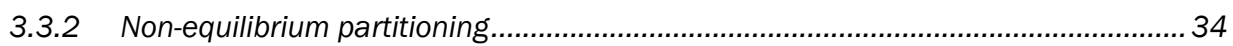

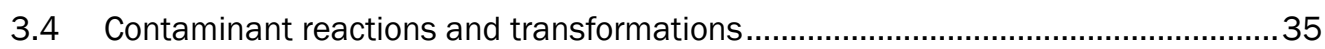

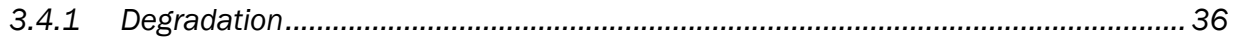

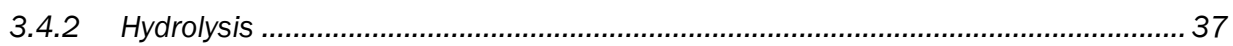

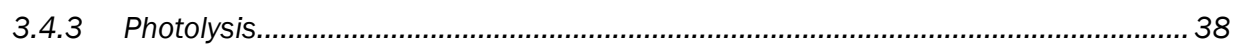

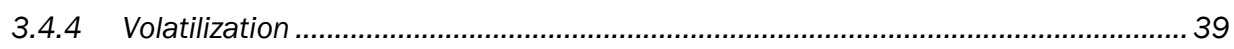

3.4.5 Generalized second-order reaction ................................................................... 42 


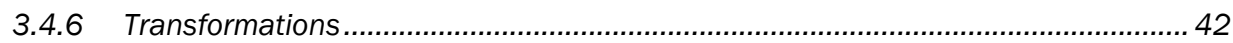

3.5 Contaminant air deposition, settling and sedimentation...................................43

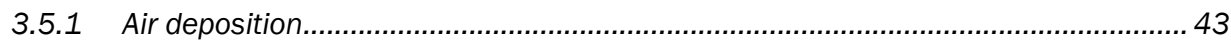

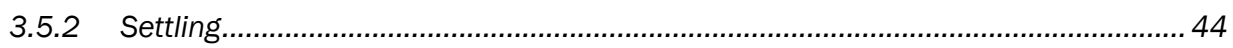

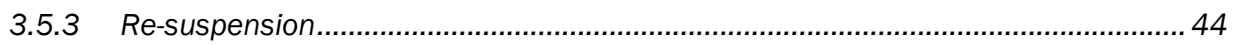

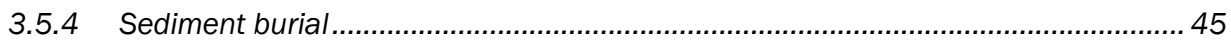

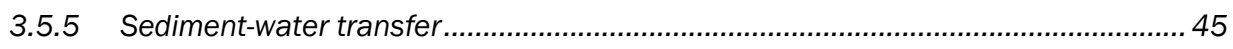

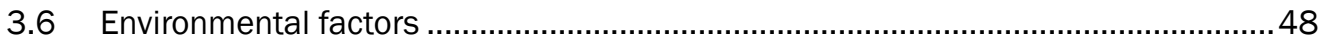

3.7 Water column contaminant source/sink equations ...............................................49

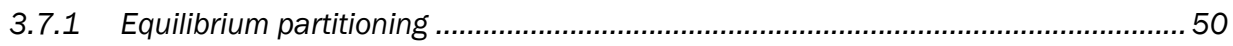

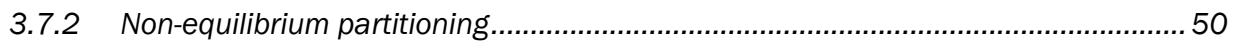

3.8 Sediment contaminant mass balance equations .............................................53

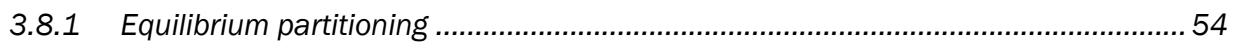

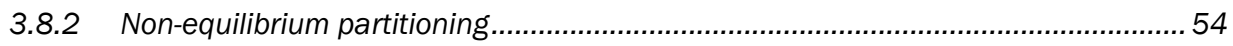

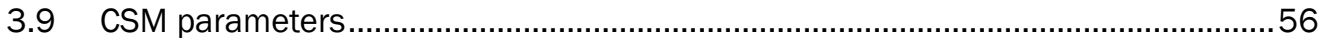

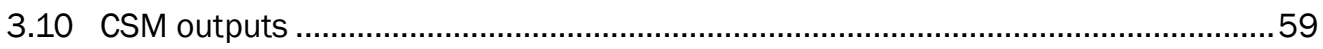

4 Mercury Simulation Module (HgSM)

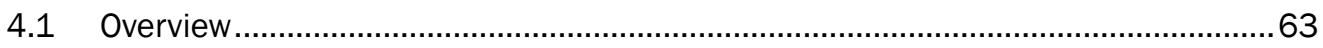

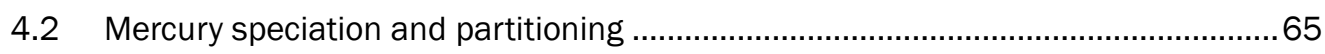

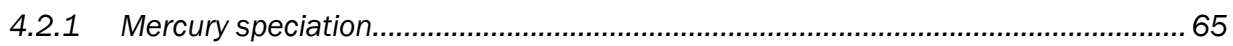

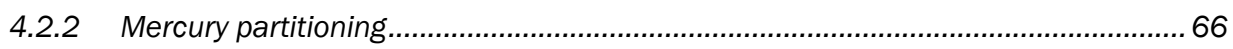

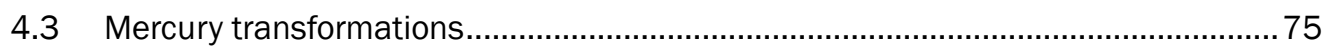

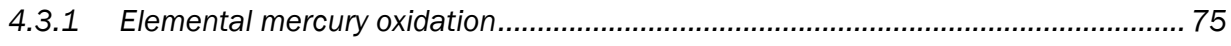

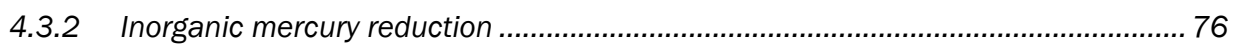

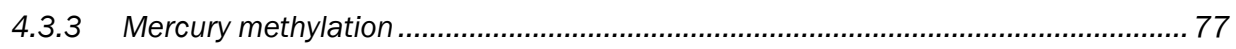

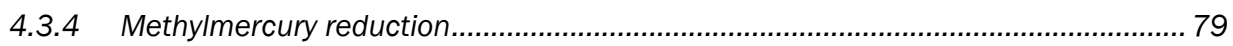

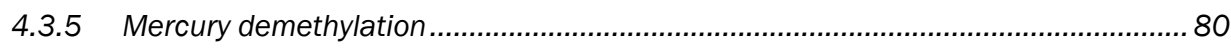

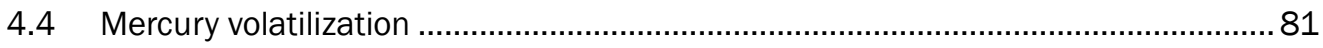

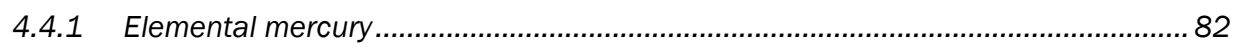

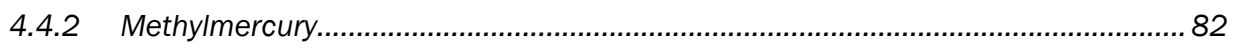

4.5 Mercury air deposition, settling and sedimentation ............................................... 82

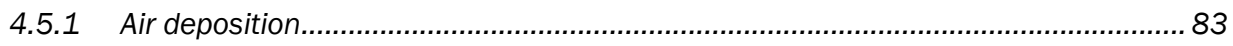

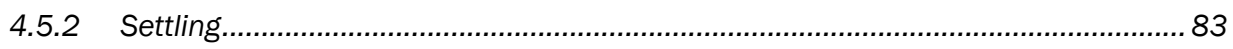

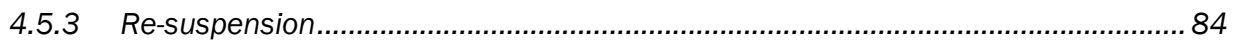

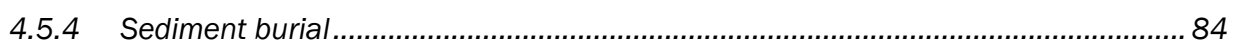

4.5.5 Sediment-water transfer ................................................................................ 85

4.6 Water column mercury source/sink equations................................................. 85

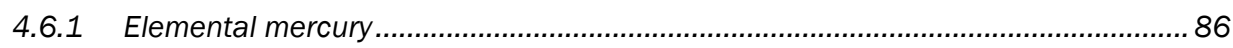

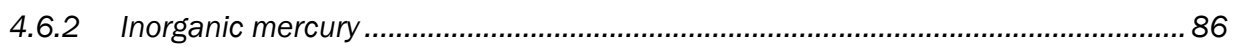

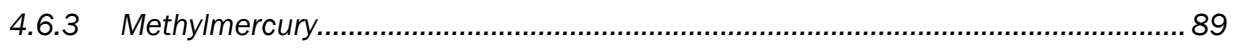

4.7 Sediment mercury mass balance equations ....................................................90

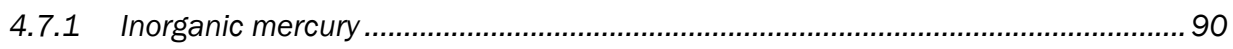

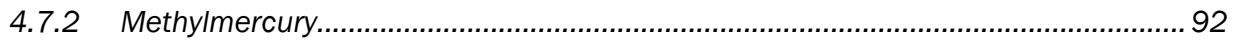

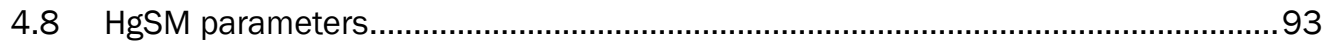

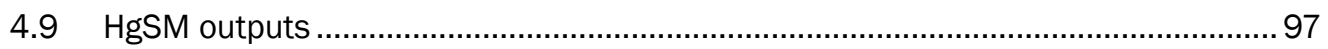




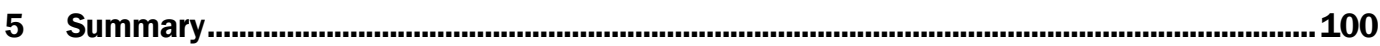

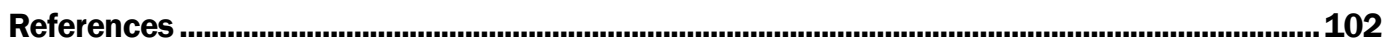

Appendix A: Definition of Mathematical Symbols used in the GC Module ...............................111

Appendix B: Definition of Mathematical Symbols used in the CSM Module ...........................113

Appendix C: Definition of Mathematical Symbols used in the HgSM Module ........................120

Report Documentation Page 


\section{Figures and Tables}

\section{Figures}

Figure 1. Conceptual model representation of water column and bed sediment interactions for solids

Figure 2. Relationship of the rate coefficient and temperature as defined in modified Arrhenius Equation

Figure 3. Conceptual representation of contaminant processes modeled in CSM...........................20

Figure 4. Three equilibrium sorption isotherms...........................................................................2

Figure 5. Schematic representation for soluble chemical release from bed sediment. .....................47

Figure 6. Conceptual representation of mercury speciation and processes modeled in HgSM.

Figure 7. Relationship between Hgll methylation and sulfate in sediments (Langer et al. 2001).

\section{Tables}

Table 1. Settling velocities $\left(\mathrm{m} \mathrm{d}^{-1}\right)$ for a range of solid sizes and densities........................................

Table 2. List of solids and user-defined constituent parameters. ......................................................15

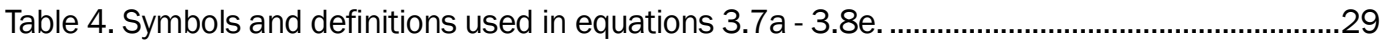

Table 5. Symbols and definitions of the contaminant concentrations in equations 3.9a-

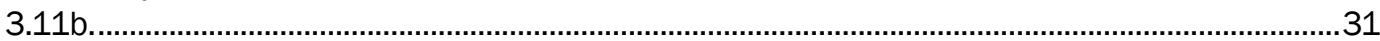

Table 6. List of environmental dependent variables and affected processes in CSM. .....................48

Table 7. Water column total contaminant source/sink terms and pathways under

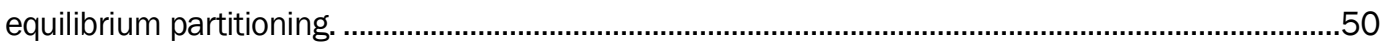

Table 8. Water column contaminant partitioning phase source/sink terms and pathways under non-equilibrium partitioning. ..............................................................................................

Table 9. Sediment total contaminant source/sink terms and pathways under equilibrium

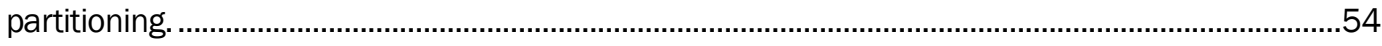

Table 10. Sediment contaminant partitioning phase source/sink terms and pathways under non-equilibrium partitioning. ...........................................................................................5

Table 11. List of CSM input parameters....................................................................................5

Table 12. List of contaminant concentrations computed in CSM. ....................................................61

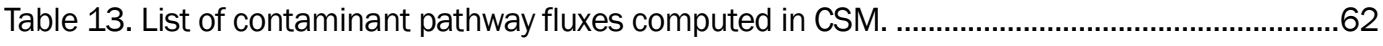

Table 14. Formulations of calculating Hgll and MeHg partitioning fractions in HgSM......................67

Table 15. Symbols and definitions used in Table 13. ..................................................................68

Table 16. Formulations of calculating Hgll and MeHg partitioning concentrations in HgSM............70

Table 17. Symbols and definitions of Hgll and MeHg concentrations used in Table 16. ...................70

Table 18. Mercury species and their transformations modeled in HgSM..........................................75

Table 19. Hg0 source/sink terms and pathways...................................................................................86 
Table 20. Water column total Hgll source/sink terms and pathways under equilibrium partitioning.

Table 21. Water column Hgll partitioning phase source/sink terms and pathways under non-equilibrium partitioning.

Table 22. Water column total MeHg source/sink terms and pathways under equilibrium partitioning.

Table 23. Sediment layer total Hgll source/sink terms and pathways under equilibrium partitioning. . .90

Table 24. Sediment layer Hgll partitioning phase source/sink terms and pathways under non-equilibrium partitioning.

Table 25. Sediment layer total MeHg source/sink terms and pathways under equilibrium partitioning. 93

Table 26. List of HgSM's input parameters. .93

Table 27. List of concentrations of mercury species computed in HgSM.. . .98

Table 28. List of pathway fluxes of mercury species computed in HgSM. 


\section{Preface}

This study was funded by the U.S. Army Environmental Quality Technology (EQT) Research Program. Dr. Elizabeth Ferguson was Technical Director, and William Jones was Program Manager.

The report was prepared by Dr. Zhonglong Zhang of LimnoTech, under contract to the U.S. Army Engineer Research and Development Center (ERDC) and Dr. Billy Johnson of the Water Quality and Contaminant Modeling Branch (WQCMB), Environmental Processes and Engineering Division (EPED), Environmental Laboratory (EL) of ERDC. The study was conducted under the general direction of Dr. Beth Fleming, Director, EL; Warren Lorentz, Chief, EPED; and Dr. Dorothy Tillman, Chief, WQCMB.

Dr. Kevin Farley of Manhattan College, Dr. James Martin of Mississippi State University, Dr. Junna Wang of the University of California at Davis, and Dr. Mark Dortch of WQCMB reviewed the report and provided valuable recommendations for the model development.

At the time of publication, COL Bryan S. Green, was the Commander of ERDC, and Dr. Jeffery P. Holland was the Director. 


\section{Unit Conversion Factors}

\begin{tabular}{|l|c|l|}
\hline Multiply & By & To Obtain \\
\hline degrees Fahrenheit $\left({ }^{\circ} \mathrm{F}\right)$ & $(\mathrm{F}-32) / 1.8$ & degrees Celsius $\left({ }^{\circ} \mathrm{C}\right)$ \\
\hline day $(\mathrm{d})$ & 86400 & second $(\mathrm{s})$ \\
\hline liter $(\mathrm{L})$ & 0.001 & cubic meters $\left(\mathrm{m}^{3}\right)$ \\
\hline gram $(\mathrm{g})$ & 106 & micrograms $(\mu \mathrm{g})$ \\
\hline gram (g) & 109 & nanograms $(\mathrm{ng})$ \\
\hline calorie (Cal) & 4.184 & joule $(\mathrm{J})$ \\
\hline
\end{tabular}




\section{Acronyms and Abbreviations}

$\begin{array}{ll}\text { AdH } & \text { Adaptive Hydraulics } \\ \text { AE } & \text { Arrhenius Equation } \\ \text { CSM } & \text { Contaminant Simulation Module } \\ \text { DLL } & \text { Dynamic Linked Library } \\ \text { D-MCM } & \text { Dynamic Mercury Cycling Model } \\ \text { DOC } & \text { Dissolved Organic Carbon } \\ \text { EL } & \text { Environmental Laboratory } \\ \text { EPA } & \text { Environmental Protection Agency } \\ \text { EPRI } & \text { Electric Power Research Institute } \\ \text { ERDC } & \text { U.S. Army Engineer Research and Development Center } \\ \text { EQT } & \text { Environmental Quality Technology } \\ \text { GC } & \text { General Constituent Simulation Module } \\ \text { H\&H } & \text { Hydrologic and Hydraulic } \\ \text { HEC-RAS } & \text { Hydrologic Engineering Center-River Analysis Systems } \\ \text { Hg } & \text { Mercury } \\ \text { Hgo } & \text { Elemental Mercury } \\ \text { HgII } & \text { Inorganic Mercury } \\ \text { HgSM } & \text { Mercury Simulation Module } \\ \text { MAE } & \text { Modified Arrhenius Equation } \\ \text { MeHg } & \text { Methylmercury } \\ \text { MW } & \text { Molecular Weight } \\ \text { NSM } & \text { Nutrient Simulation Module } \\ \text { NSMI } & \text { Nutrient Simulation Model I } \\ \text { POM } & \text { Particulate Organic Matter } \\ \text { SRH-2D } & \text { Sedimentation and River Hydrualics - 2 Dimension } \\ \text { USACE } & \text { U.S. Army Corps of Engineers } \\ & \end{array}$


WARMF Watershed Analysis Risk Management Framework

WASP Water Quality Analysis Simulation Program 


\section{Introduction}

\subsection{Background}

Contaminants are introduced into aquatic systems as a result of the weathering of soils and rocks, and from a variety of human activities involving the mining, processing, or use of substances that contain toxics. There are different types of sources of contaminants. The first type are point sources, where contaminants come from a single identifiable source. The second type of contaminant sources are non-point sources, where contaminants come from distributed sources. Once dissolved in water, contaminant concentrations may exceed water quality standards and impair the designated water uses. Exposure of aquatic organisms to contaminants can cause toxicity, or result in bioconcentration through the food chain. Human health may also be affected by ingesting contaminated water or fish. As a result, the criteria for protecting human health and indigenous aquatic communities have been promulgated by the U.S. Environmental Protection Agency (EPA) for toxic chemicals (Ambrose et al. 1993). Of these toxics, some organic chemicals and metals are of particular concern within the aquatic environment due to their high toxicity and having several known adverse effects on the natural ecosystem and human health (Wool et al. 2006; Ullrich et al. 2001; Brigham et al. 2009).

As the scientific and regulatory communities realize the significant environmental impacts of contaminants, it is increasingly imperative to apply modeling tools to evaluate and predict the fate and transport of these contaminants in the environment. Hydrologic and hydraulic (H\&H) models coupled with water qaulity become indispensable tools used by environmental analysts. Over the last three decades, a variety of H\&H models have been developed for predictive estimates of contaminant concentration and transport pattern (Bahadur et al. 2013). However, the Hydrologic Engineering Center-River Analysis System (HEC-RAS) (HEC 2010), twodimensional hydrodynamics and water quality (CE-QUAL-W2) model (Cole and Wells 2011), and Adaptive Hydraulics (AdH) (Berger et al. 2012), continuously developed and maintained by the U.S. Army Corps of Engineers (USACE), are still lacking the capability of modeling contaminants in aquatic systems. Recognizing this need, the research and development of contaminant and mercury simulation modules for a variety of H\&H models were sponsored under the USACE Environmental Quality 
Technology (EQT) research program. These modules were developed to add additional water quality capabilities for existing H\&H models.

\section{2 "Plug In" water quality modules}

A set of "plug in" nutrient simulation modules (NSMs) for existing H\&H models have been developed at the ERDC Environmental Laboratory (Zhang and Johnson 2016). Following the same principles and protocols, the contaminant simulation module (CSM), mercury simulation module ( $\mathrm{HgSM})$ and general constituent simulation module (GC) were also developed as "plug in" water quality modules for existing H\&H models. The GC, CSM, and HgSM modules were all written as dynamic link libraries (DLLs) and they must be integrated into H\&H models to predict concentrations of water quality constituents in an aquatic system. The $\mathrm{H} \& \mathrm{H}$ models simulate the physical processes of advection, dispersion, and boundary inflow, and are responsible for computing the transport of constituents across the model domain. The GC, CSM and HgSM modules simulate the speciation, reactions, and transformations of state variables and are responsible for computing internal source and sink terms in each water quality cell.

As with the NSM modules, newly developed GC, CSM, and HgSM modules were designed to be independent of the dimensionality of the spatial domain. The water quality computation domain only represents a wellmixed cell, including the water column and active sediment layer. The sediment layer represents the shallow, biologically active layer of surficial sediments. The depth of the sediment layer should be chosen based on the problem. The GC, CSM, and HgSM modules compute kinetics of water quality constituents occurring in the water column and sediment layer.

The CSM was designed for simulating general contaminants such as pesticides, polychlorinated biphenyls, halogenated aliphatic hydrocarbons, halogenated ethers, monocyclic aromatics, phthalate esters, polycyclic aromatic hydrocarbons, and nitrosamines. These chemicals can cause toxicity to aquatic organisms, or bioconcentrate through the food chain, affecting human health. The HgSM was designed specifically for simulating mercury cycling and kinetics in aquatic systems. Many of the concepts and kinetic algorithms employed in CSM and HgSM modules are adopted from the U.S. EPA developed Water Quality Analysis Simulation Program (WASP) (Wool et al. 2006) and the Electric Power Research Institute (EPRI) developed Dynamic Mercury Cycling Model (D-MCM) 
(EPRI 2013). Besides modeling solids and user-defined constituents, the GC module was developed for computing time varying parameters for CSM and HgSM.

\subsection{Report outline}

This report describes the theory and mathematical equations that are implemented in the GC, CSM, and HgSM modules and consists of five chapters:

- Chapter 1 introduces the background and concept of "plug in" water quality modules

- Chapter 2 describes the processes and mathematical equations included in the GC module

- Chapter 3 describes the processes and mathematical equations included in the CSM module

- Chapter 4 describes the processes and mathematical equations included in the HgSM module

- Chapter 5 provides the summary.

The appendices provide the user with the information necessary to understand the symbols used in each module:

- Appendix A summarizes mathematical symbols used in the GC module

- Appendix B summarizes mathematical symbols used in the CSM module

- Appendix C summarizes mathematical symbols used in the HgSM module. 


\section{General Constituent Simulation Module (GC)}

Many waterborne organic and inorganic chemicals exist both in dissolved form and as forms adsorbed to solids and other sorbents. Solids are important as an adsorbing surface for contaminants and play an important role in the transport of contaminants within aquatic systems. Contaminants in the water column may be lost or gained due to the settling and re-suspension of sediment solids onto which contaminants are adsorbed. Simulation of solids mass balance is critical step for predicting contaminant transport and ultimate fate in aquatic systems. The mechanisms and modeling the transport of sediment solids are well described in the literature (e.g., Winterwerp and ver Kerstern 2004; Khan and Wu 2013). The solids simulation included in GC was specifically designed for use with describing the transport of bound contaminants in the CSM and HgSM modules.

The GC module computes internal sources and sinks of multiple size solids in the water column and sediment layer. This module can compute the time varying input parameters such as solids settling, re-suspension, and solids concentrations for CSM and HgSM modules. Any number of solids can be modeled in GC. Solids may be modeled as a single variable or alternatively modeled as multiple independent solids classes. The number of the solids classes is a user defined parameter. Each of the solid classes is treated as an independent variable with no interactions, such as blocking or flocculation. Depending on the aquatic system being modeled, these solids can be assigned to mineral abiotic solids, detritus, or various classes or size categories of solids. A simple kinetics for user-defined constituents is also included in the GC module.

\subsection{Solids characterization and conceptual model}

Solid particles consist of an inorganic fraction (e.g., silts, clays) and an organic fraction (e.g., algae, zooplankton, bacteria, and detritus). The inorganic portion is usually considerably higher than the organic portion in the water column. Both are important in creating turbidity and limiting light within the water column. Natural waters can contain a mixture of solid particles ranging from gravel ( $2 \mathrm{~mm}$ to $20 \mathrm{~mm}$ ) or sand ( $0.07 \mathrm{~mm}$ to $2 \mathrm{~mm}$ ) down to very small particles classified as silt or clay (smaller than $0.07 \mathrm{~mm}$ ). 
The fine fraction of solids is characterized as cohesive sediment. Cohesive sediment can include silt and clay particles as well as particulate organic matter such as detritus and other forms of organic carbon, diatoms and other algae. From a water quality perspective, cohesive sediments are usually of greater importance in water quality modeling. In addition to the considerations of flow transport and solids settling deposition, the bed processes of consolidation, bioturbation and re-suspension are also important in water quality modeling. The behavior of fine-grained suspended solids affects water quality in several different ways. First, turbidity and its effect on underwater light is an important environmental condition for algae growth. The presence of suspended solids increases the attenuation of light in the water column, which leads to an inhibition of photosynthetic activity; and therefore, a reduction in primary production. Second, the fate of contaminants in waters is closely related to the amount of suspended solids, due to their large adsorbing capacities.

An overview of the major processes of solids modeled in GC is shown in Figure 1. The model domain is conceptualized as a well-mixed water column underlain by an active sediment layer. The sediment is modeled as a well-mixed surface layer. The specification of a mixed surface layer is included because this layer is often observed at the surface of sediments and interacts with the overlying water.

Figure 1. Conceptual model representation of water column and bed sediment interactions for solids.

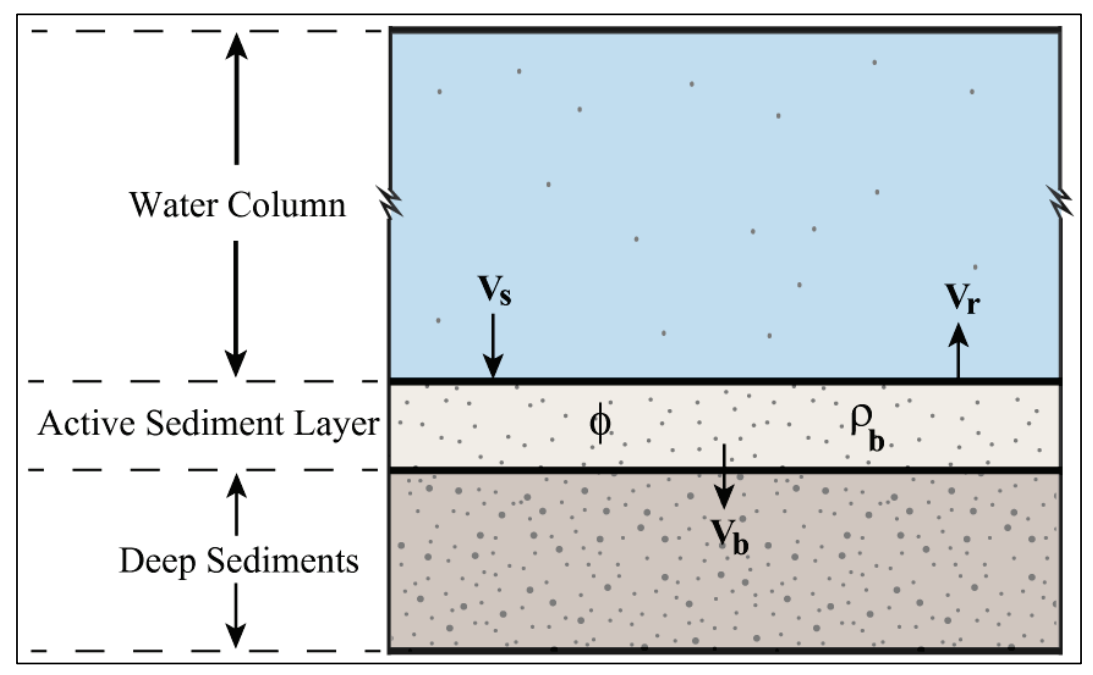

As shown in Figure 1, solids and attached contaminants in the water column can be transferred to the sediment layer by settling. An opposite reaction, contaminants can be released by sediment re-suspension, mixing by benthic 
organisms and diffusion from the sediment pore water. A single sediment layer with a constant thickness is simulated because of its interactions with the overlying water. The depth of the benthic sediment layer should be chosen based on the problem. The three most important sediment processes associated with contaminant modeling are settling, re-suspension or "erosion," and "burial" of sediment. In addition to these processes, the fate of solids in an aquatic system is also affected by physical transport.

The foundation of contaminant simulation models is a mass balance, which accounts for the production, loss, and accumulation of the contaminant within a specified control volume. The rate of accumulation of mass must balance the rates of production within the control volume, input from outside, loss across the boundaries, and loss by reaction. As stated in the introduction, $\mathrm{H} \& \mathrm{H}$ models are responsible for computing the physical transport of materials in aquatic systems. The "plug in" water quality modules only compute the internal source and sink terms associated with each state variable. These rates contained in each water quality module in this report are written as derivatives of concentration with respect to time.

\subsection{Suspended solids}

\subsubsection{Internal sources and sinks}

In the water column, suspended solids may settle and deposit on the sediment bed. The settling process moves solids downward through the water column and deposition results in their removal from the water column to the bed. Sediment re-suspension adds solids into the water column. For a completely mixed water column cell with an underlying sediment layer, the internal source (+) and sink (-) equation of suspended solids for each class is written as

$$
\frac{d m_{n}}{d t}=-\frac{v_{d p n}}{h} m_{n}+\frac{v_{r p n}}{h} m_{n 2}
$$

where

$$
\begin{aligned}
m_{n} & =\text { concentration of solid " } n \text { " in water }\left(\mathrm{mg} \mathrm{L}^{-1}\right) \\
m_{n 2} & =\text { concentration of solid " } n \text { " in sediment }\left(\mathrm{mg} \mathrm{L}^{-1}\right) \\
v_{d p n} & =\text { deposition velocity of solid " } n \text { " }\left(\mathrm{m} \mathrm{d}^{-1}\right) \\
v_{r p n} & =\text { re-suspension velocity of solid " } n \text { " }\left(\mathrm{m} \mathrm{d}^{-1}\right) \\
h & =\text { water depth }(\mathrm{m})(h>o) .
\end{aligned}
$$


Where the subscript $n$ denotes the index number of solids class which is unitless. Multiple solids classes can be modeled in GC. Equation 2.1 represents the time rate of change of the solids concentration in the water column. In the sediment layer, $m_{n 2}$ is the sediment bulk density. The user input parameters include the settling velocities of solids in the water column and the sediment solid re-suspension velocities. The settling and re-suspension parameters depend on the characteristics of the solids and the flow regime and can be varied over time and space.

\subsubsection{Settling and deposition}

Settling velocities must be specified for each of the solids classes. These parameters can be determined from field and laboratory experiments, or estimated using solids properties. Values of settling velocities calculated for a range of solids classes and densities are provided in Table 1.

Table 1. Settling velocities $\left(\mathrm{m} \mathrm{d}^{-1}\right)$ for a range of solid sizes and densities.

\begin{tabular}{|c|c|c|c|c|c|}
\hline \multirow{3}{*}{ Solid } & \multirow{3}{*}{ Diameter $(\mathrm{mm})$} & \multicolumn{4}{|c|}{ Solid Density $\left(\mathrm{g} \mathrm{cm}^{-3}\right)$} \\
\cline { 2 - 6 } & 0.3 & 1.80 & 2.0 & 2.5 & 2.7 \\
\hline \multirow{3}{*}{ Fine sand } & 0.05 & 900 & 400 & 710 & 800 \\
\cline { 2 - 6 } & 0.02 & 15 & 120 & 180 & 200 \\
\hline \multirow{3}{*}{ Silt } & 0.01 & 3.8 & 4.7 & 7.1 & 8.0 \\
\cline { 2 - 6 } & 0.005 & 0.94 & 1.2 & 1.8 & 2.0 \\
\cline { 2 - 6 } & 0.002 & 0.15 & 0.19 & 0.28 & 0.32 \\
\hline \multirow{2}{*}{ Clay } & 0.001 & 0.04 & 0.05 & 0.07 & 0.08 \\
\hline
\end{tabular}

As an alternative, solids settling velocities can also be calculated in the GC module. No universal model of computing settling velocities is available. Instead, a variety of simple equations have been used to estimate the solids settling velocity in the water column. Two types of formulations are implemented in GC: (1) Van Rijn's formula (Van Rijn 1989) and (2) Cheng's formula (Cheng 1997). If the solids settling velocity is internally calculated in GC, then the solid parameters listed in Table 2 must be specified in the model simulation. 
Option 1: Van Rijn's formula:

$$
v_{s p n}= \begin{cases}\frac{0.0864}{18} \frac{\Delta g d_{p n}^{2}}{v} & 0.065 \mathrm{~mm}<d_{p n}<0.1 \mathrm{~mm} \\ 8.64 \times 10^{8} \frac{v}{d_{p n}}\left(\sqrt{1.0+0.01 d_{*}^{3}}-1.0\right) & 0.1 \mathrm{~mm} \leq d_{p n} \leq 1 \mathrm{~mm} \\ 1.1 \sqrt{\frac{\Delta g d_{p n}}{1000}} \times 86400 & d_{p n}>1 \mathrm{~mm}\end{cases}
$$

and

$$
\begin{gathered}
\Delta=\frac{\rho_{p n}-\rho_{w}}{\rho_{w}} \\
d_{*}=\frac{d_{p n}}{1000}\left(\frac{\Delta g}{v^{2}}\right)^{1 / 3}
\end{gathered}
$$

where

$$
\begin{aligned}
v_{s p n} & =\text { settling velocity of solid “ } n \text { " }\left(\mathrm{m} \mathrm{d}^{-1}\right) \\
g & =\text { gravity acceleration }\left(9.81 \mathrm{~m} \mathrm{~s}^{-2}\right) \\
v & =\text { kinematic viscosity of water }\left(\mathrm{m}^{2} \mathrm{~s}^{-1}\right) \\
\rho_{p n} & =\text { density of solid " } n \text { " in water }\left(\mathrm{g} \mathrm{cm}^{-3}\right) \\
\rho_{w} & =\text { density of water }(1.0 \mathrm{~g} \mathrm{~cm}-3) \\
d_{p n} & =\text { diameter of solid " } n \text { " (mm) } \\
d^{*} & =\text { dimensionless solids parameter(unitless). }
\end{aligned}
$$

The second equation is Cheng (1979). On the basis of experimental data for natural particles, Cheng (1997) developed the following equation that approximates solids settling velocities

$$
v_{s p n}=8.64 \times 10^{7} \frac{v}{d_{p n}}\left[\sqrt{25+1.2 d_{*}^{2}}-5.0\right]^{1.5}
$$

Kinematic viscosity versus water temperature can be estimated from a regression relationship

$$
v=\frac{1.79 \cdot 10^{-6}}{1.0+0.03368 T_{w}+0.000221 T_{w}^{2}}
$$


where

$$
T_{w}=\text { water temperature }\left({ }^{\circ} \mathrm{C}\right) .
$$

In the GC module, the settling velocities are set to zero, when the shear stress exceeds a certain critical value, or when the water depth is smaller than a certain critical depth (Krone 1962).

For cohesive sediments, the settling behavior may not be non-interactive. For example, it has been found in both the laboratory and field that settlement of cohesive solids is often influenced by suspended sediment concentrations and flocculation (both coagulation and the break-up of particles). Additionally, suspended solids in natural systems exhibit variations in drag characteristics and settling behavior due to their nonuniform shapes. The above equations may not adequately capture these variations. Therefore, model calibration may be needed when these formulae are applied to different sites or conditions.

For solids settling onto the sediment bed, a distinction may be made between settling and deposition. A portion of the solids which settle through the water column may remain in suspension instead of depositing onto the surface of the sediment bed. Whether a solid will settle to the bed sediment layer depends on its physical and chemical properties as well as the hydraulic conditions over the depth of the water column. Deposition onto, and attachment to the sediment bed, are usually described as probabilistic processes (Krone 1962). Ariathuri and Krone (1976) used this concept to develop a linear probability of deposition function to determine what fraction of a particulate class of solids is truly depositional

$$
P_{d p n}= \begin{cases}1.0 & \tau<\tau_{c d l} \\ 1.0-\frac{\tau-\tau_{c d l}}{\tau_{c d u}-\tau_{c d l},}, & \tau_{c d l} \leq \tau \leq \tau_{c d u} \\ 0 & \tau>\tau_{c d u}\end{cases}
$$

where

$$
\begin{aligned}
\tau & =\text { bottom shear stress }\left(\mathrm{N} \mathrm{m}^{-2}\right) \\
\tau_{c d l} & =\text { lower critical shear stress for deposition }\left(\mathrm{N} \mathrm{m}^{-2}\right) \\
\tau_{c d u} & =\text { upper critical shear stress for deposition }\left(\mathrm{N} \mathrm{m}^{-2}\right) .
\end{aligned}
$$


Lower critical shear stress for deposition $\left(\tau_{c d l}\right)$ is below which all solids have a full probability to deposit on the bed. Upper critical shear stress for deposition $\left(\tau_{c d u}\right)$ is above which all solids remain in suspension yielding a zero deposition rate. Once the settling velocity is determined, the deposition velocity can be calculated as the product of the settling velocity and the probability of deposition

$$
v_{d p n}=P_{d p n} v_{s p n}
$$

where

$$
P_{d p n}=\text { deposition probability of solid " } n \text { " }(\mathrm{o}-1.0) \text {. }
$$

\subsection{Sediment layer}

When suspended solids settle to the bed of a water body, they become sediments. Sediment is composed of many materials, including individual primary particles, aggregates, organic materials, and associated chemicals. Particles can be mineral or organic in origin. The role of sediment in water quality modeling is tied both to the particle size of sediment, and to the amount of particulate organic carbon associated with the sediment.

The mass balance of solids must be tracked for the sediment layer in the underlying the water column. The GC uses a mass balance equation to calculate solids mass and concentrations for underlying sediment layer. The sediment layer is assumed in GC as homogeneous (well mixed) and the model does not change the thickness of sediment layer during the simulation. As the sediment layer accepts a new sediment increment on the top, an equal amount is removed from this layer for burial. When sediment re-suspension occurs, it is assumed that deeper sediments below this layer are entrained into the upper layer and then mixed with the remaining sediments. The density of the sediment layer can vary, depending on the variable sediment composition. The porosity within the sediment layer is assumed constant and user defined. The solids simulation module also requires a set of initial conditions of the sediment solids.

\subsubsection{Solids mass balance}

The mass balance of solids in the sediment layer is a flux balance between the incoming solids due to deposition from the water column, and loss due to sediment re-suspension and burial. Deposition from the water column 
adds the source of solids to the sediment layer. Re-suspension and deep burial result in a loss of solids in the sediment layer. Exchange of solids between the water column and the sediments are simulated via the deposition and re-suspension processes. The mass balance of sediment solids for each class is written as

$$
\frac{d m_{n 2}}{d t}=\frac{v_{d p n}}{h_{2}} m_{n}-\frac{v_{r p n}}{h_{2}} m_{n 2}-\frac{v_{b}}{h_{2}} m_{n 2}
$$

where

$$
\begin{aligned}
v_{b} & =\text { sediment burial velocity }\left(\mathrm{m} \mathrm{d}^{-1}\right) \\
h_{2} & =\text { sediment layer thickness }(\mathrm{m})\left(h_{2}>o\right) .
\end{aligned}
$$

Once concentrations of the sediment layer solids for each class are solved from equation 2.7. The interaction between solids in the water column and active sediment layer can be appropriately quantified in GC.

\subsubsection{Sediment re-suspension}

Suspended solids settle through the water column to the surficial sediment layer and can be re-introduced back to overlying water through resuspension. The re-suspension and erosion of sediments refers to the process by which solids, and their attached contaminants, are transported from bed sediments into the water column. As with settling and deposition, sediment re-suspension may be influenced by a variety of physical and chemical properties within the bed and the overlying water column. Resuspension of bottom sediments can be induced by an increase of hydrodynamic stress or a weakening of sediment resistance, depending on both hydrodynamics and the physicochemical characteristics of the sediment. There are two distinct erodibility attributes for a given solid. These attributes are critical shear stress (i.e., the critical level of flow shear stress that is sufficient to dislodge the sediment solids), and the erosion rate (i.e., the erosion velocity of bed sediment into the water column). Both attributes are a function of shear stress. The rate of erosion varies with the energy available for erosion, shear stress, and the characteristics of the sediments.

The sediment re-suspension velocity is a user-defined input parameter. Alternatively, given bottom shear stresses, the GC can compute the resuspension velocity using one of three equations: 1) Lick et al. (1995), 2) 
Parchure and Mehta (1985), and 3) Lick (2009). The first two equations are applied for cohesive sediments.

The first equation is based on the equation given by Lick et al. (1995) in which the critical shear stress is the major parameter controlling the resuspension mechanism.

$$
E=P\left(\frac{\tau}{\tau_{c e}}-1.0\right)^{m}
$$

where

$$
\begin{aligned}
E & =\text { sediment erosion rate }\left(\mathrm{g} \mathrm{cm}^{-2} \mathrm{~s}^{-1}\right) \\
P & =\text { surface erosion rate }\left(\mathrm{g} \mathrm{cm}^{-2} \mathrm{~s}^{-1}\right) \\
\tau_{c e} & =\text { critical shear stress for erosion }\left(\mathrm{N} \mathrm{m}^{-2}\right) \\
m & =\text { empirically determined constant (unitless). }
\end{aligned}
$$

The second equation is based on the equation given by Parchure and Mehta (1985)

$$
E=E_{0} e^{\alpha_{0}\left(\tau-\tau_{c e}\right)^{0.5}}
$$

where

$$
\begin{aligned}
& E_{o}=\text { surface erosion rate }\left(\mathrm{g} \mathrm{cm}^{-2} \mathrm{~s}^{-1}\right) \\
& \alpha_{o}=\text { empirical constant (unitless). }
\end{aligned}
$$

The empirical constants in the above two equations used for computing the re-suspension rate are site specific. The erodibility coefficients $P$ or $E_{o}$, can be a function of the degree of consolidation of sediments, their size distribution and factors affecting their stability (such as armoring due to the existence of mixtures of large and fine particles). Because these properties are poorly known, this entry can simply be considered as a calibration parameter.

The critical shear stress defines the point at which the erosion of bed sediments is initiated. Erosion or re-suspension of bed sediments is predicted to occur when the computed shear stress is greater than the critical sheer stress $\left(\tau>\tau_{c e}\right)$. No erosion will occur for a shear stress less than the critical shear stress $\left(\tau<\tau_{c e}\right)$. The critical shear stress for erosion is 
a function of the degree of compaction of the sediments. The critical shear stress must either be measured or estimated by model calibration. Typical values of critical shear stresses are on the order of $0.1-0.4 \mathrm{~N} \mathrm{~m}^{-2}$.

Once the sediment re-suspension rate is known, re-suspension velocity for each solids class is calculated by

$$
v_{r p n}=8.64 \cdot 10^{8} \frac{E}{m_{n 2}}
$$

The third equation used in the GC module is based on a general equation given by Lick (2009) and can be applied for both cohesive and non-cohesive sediment solids. This equation directly computes the re-suspension velocity

$$
v_{r}=10^{-4}\left(\frac{\tau-\tau_{c n}}{\tau_{c e}-\tau_{c n}}\right)^{m}
$$

where

$$
\begin{aligned}
v_{r}= & \text { sediment re-suspension velocity of solid " } n \text { " }\left(\mathrm{cm} \mathrm{d}^{-1}\right) \\
\tau_{c n}= & \text { critical shear stress for the initiation of movement of } \\
& \text { noncohensive solids }\left(\mathrm{N} \mathrm{m}^{-2}\right) .
\end{aligned}
$$

The critical shear stress $\left(\tau_{c n}\right)$ for the initiation of movement of noncohensive solids is specified as an input parameter. This parameter has been determined from experiments and more refined theoretical analyses.

\subsubsection{Bottom shear stress}

The resuspension formulations described above all relate the resuspension rate constant for cohesive sediments to the difference between the bottom shear stress $(\tau)$ and a critical shear stress $\left(\tau_{c e}\right)$. The bottom stress might be induced by flow velocities, tidal and wind-induced advective flows, and surface waves. The bottom shear stress may be estimated from wind speeds and direction and/or current velocities using a bottom boundary layer model, such as Kajiura's (1968). Otherwise, this parameter can be obtained from the H\&H models. 


\subsubsection{Sediment burial}

Sediment burial velocity is a user defined term used to convey that bed sediment is no longer available for re-suspension because it has been covered by much newer sediment (i.e., it has been buried.). In GC, sediment burial velocity can also be calculated according to the following mass balance for the sediment layer solids

$$
v_{b}(1-\varphi) \rho_{s} 10^{6}=\sum_{n} v_{d p n} m_{n}-\sum_{n}\left(v_{r p n} m_{n 2}\right)
$$

where

$$
\begin{aligned}
& \varphi=\text { sediment layer porosity (unitless) } \\
& \rho_{s}=\text { sediment dry density }\left(\mathrm{g} \mathrm{cm}^{-3}\right)
\end{aligned}
$$

Equation 2.12 can be used to calculate the burial velocity $\left(v_{b}\right)$ in GC. Within this equation suspended and sediment solids concentrations are determined respectively from equations 2.1 and 2.7 .

\subsection{Solids and sediment layer parameters}

The "plug in" water quality module operates based on the schematization already set up for the H\&H model and the flows computed by the H\&H model. This means that the user only has to specify a limited amount of water quality data:

- definition of the water quality cells

- initial concentrations of the state variables

- concentrations of all state variables on the inflow boundaries

- forcing functions

- water quality parameters.

Table 2 summarizes the solids and sediment layer input parameters that must be specified in the GC module when all options are turned on. Typical values are taken from a limited literature review. All of these parameters are spatially-variable parameters and do not vary with time. They are treated as constant values throughout the model simulation. 
Table 2. List of solids and user-defined constituent parameters.

\begin{tabular}{|c|c|c|c|}
\hline Symbola & Definition & Typical values & Units \\
\hline$k_{0 i}(T)$ & Zero-order decay rate of constituent i & $n / a^{b}$ & $m g L^{-1} d^{-1}$ \\
\hline$k_{1 i}(T)$ & First-order decay rate of constituent i & $n / a$ & $d^{-1}$ \\
\hline$v_{s i}$ & Settling velocity of constituent i & $\mathrm{n} / \mathrm{a}$ & $\mathrm{m} \mathrm{d}^{-1}$ \\
\hline$n$ & Solids classes & $1-5$ & - \\
\hline$v_{\text {spn }}$ & Solids settling velocity & $\mathrm{n} / \mathrm{a}$ & $\mathrm{m} \mathrm{d}^{-1}$ \\
\hline$d_{p n}$ & Solids diameter & $\mathrm{n} / \mathrm{a}$ & $\mathrm{mm}$ \\
\hline$T_{c d u}$ & Upper critical shear stress for deposition & $0.06-1.1$ & $\mathrm{~N} \mathrm{~m}^{-2}$ \\
\hline$T_{c d l}$ & Lower critical shear stress for deposition & $0.2^{d}$ & $\mathrm{~N} \mathrm{~m}^{-2}$ \\
\hline$h_{2}$ & Sediment layer thickness & 0.1 & $\mathrm{~m}$ \\
\hline$\phi$ & Sediment layer porosity & $0.3-0.9$ & - \\
\hline$\rho_{\mathrm{s}}$ & Sediment dry density & 1.6 & $\mathrm{~g} \mathrm{~cm}^{-3}$ \\
\hline$V_{r p n}$ & Re-suspension velocity & $n / a$ & $\mathrm{~m} \mathrm{~d}^{-1}$ \\
\hline$T_{c e}$ & Critical shear stress for erosion & $0.4^{c}$ & $\mathrm{~N} \mathrm{~m}^{-2}$ \\
\hline$T_{c n}$ & $\begin{array}{l}\text { Critical shear stress for the initiation of } \\
\text { movement of noncohensive solids }\end{array}$ & $0.414 \cdot 10^{3 d}$ & $\mathrm{~N} \mathrm{~m}^{-3}$ \\
\hline$\alpha_{0}$ & Empirical constant & 0.5 & - \\
\hline$P$ & Surface erosion rate & $\begin{array}{l}1.3-4.7 \cdot 10^{-5} \\
5 \cdot 10^{-6} c\end{array}$ & $\mathrm{~g} \mathrm{~cm}^{-2} \mathrm{~s}^{-1}$ \\
\hline$m$ & Empirically determined constant & 1 & - \\
\hline E0 & Surface erosion rate & $\mathrm{n} / \mathrm{a}$ & $\mathrm{g} \mathrm{cm}^{-2} \mathrm{~s}^{-1}$ \\
\hline$v_{b}$ & Sediment burial velocity & $n / a$ & $\mathrm{~m} \mathrm{yr} r^{-1}$ \\
\hline
\end{tabular}

a. Subscript i denotes the index number of user-defined constituents, subscript $\mathrm{n}$ denotes the index number of solid classes.

b. $n / a$ represents not available.

c. Mulder and Udink (1991).

d. Winterwerp et al. (1993).

Suspended solids parameters consist of a number of solids classes and the settling velocities for each class. Inclusion of the sediment layer introduces several additional sediment parameters. In addition to a layer thickness, the other sediment parameters include sediment re-suspension velocity, sediment burial rate, sediment bulk density $\left(\rho_{b}\right)$, sediment layer porosity $(\phi)$, and the percent by weight of each solid class. Sediment bulk density $\left(\rho_{b}\right)$ is also the layer total solids concentration (i.e., layer total solids mass divided by layer volume); the total, or mixed solids density (i.e., density of solids), is the layer total solids mass divided by layer total solids volume; and sediment layer porosity $(\phi)$ is the ratio of voids volume (i.e., water volume for saturated conditions in sediments) to total volume (i.e., water 
plus solids volume). Solids density averages about $2.65 \mathrm{~g} \mathrm{~m}^{-3}$ for most sediments (sands, silts, and clays). However, solids density for carbonoccluded minerals ranges from 1.5 to $2.2 \mathrm{~g} \mathrm{~m}^{-3}$ (Di Toro 2001). The porosity of the upper few centimeters of the sediment layer typically ranges from 0.7 to 0.9 or higher. Sediment porosity is known to decrease with solid particle diameter, where values range from approximately 0.7 to 0.9 for $0.001 \mathrm{~mm}$ to 0.3 for $1.0 \mathrm{~mm}$ (Di Toro 2001).

\subsection{Simple kinetics for user-defined constituents}

In addition to solids, the GC can model any number of user-defined constituents. These constituents are modeled with simple kinetics and only for the water column. Three processes are included in the GC module for any user-defined constituent: zero-order decay, first-order decay, and net settling loss. The user defines a temperature dependent zero - or firstorder decay rate, or a net settling loss rate for modeled constituents. The net settling rate of constituents can be negative, depending on the degree of sediment re-suspension.

For any user defined constituent in the water column, the internal source $(+)$ and sink (-) equation is

$$
\frac{d C_{i}}{d t}=-k_{0 i}(T)-k_{1 i}(T) C_{i}-\frac{v_{s i}}{h} C_{i}
$$

where

$$
\begin{aligned}
C_{i} & =\text { concentration of constituent } i\left(\mathrm{mg} \mathrm{L}^{-1}\right) \\
k_{o i}(T) & =\text { zero-order decay rate of constituent } i\left(\mathrm{mg} \mathrm{L}^{-1} \mathrm{~d}^{-1}\right) \\
k_{1 i}(T) & =\text { first-order decay rate of constituent } i\left(\mathrm{~d}^{-1}\right) \\
v_{s i} & =\text { net settling loss rate of constituent } i\left(\mathrm{~m} \mathrm{~d}^{-1}\right) .
\end{aligned}
$$

Where the subscript $i$ denotes the index number of user-defined constituents. The GC allows the user to specify simple reaction rates for each of the contaminants modeled. More complex reactions and transformations are simulated in CSM. User defined constituent parameters are listed in Table 2. Table 2. These are spatially-variable parameters, do not vary with time, and they are treated as constant values during the model simulation. 


\subsection{Water temperature correction equations}

The reaction coefficients used in GC, CSM, and HgSM modules are usually specified by the user at $20^{\circ} \mathrm{C}$. These coefficients must be corrected based on the temperature difference between the actual temperature and a reference temperature (usually $20^{\circ} \mathrm{C}$ ). Three temperature correction formulations are used in the GC, CSM, and HgSM modules to correct the temperature dependent coefficients. The first one is the Arrhenius Equation (AE). The second one is Q10 equation. The third one is the modified Arrhenius Equation (MAE).

\subsubsection{Arrhenius Equation (AE)}

The general form of Arrhenius Equation (Fogler 2005) can be written as

$$
k(T)=k\left(T_{w r}\right) e^{E_{a} \frac{T_{w k}-T_{w r}}{R \cdot T_{w k} \cdot T_{w r}}}
$$

where

$$
\begin{aligned}
k(T) & =\text { value of the rate at local temperature }\left(\mathrm{d}^{-1}\right) \\
k\left(T_{w r}\right) & =\text { value of the rate at reference temperature }\left(\mathrm{d}^{-1}\right) \\
E_{a} & =\text { activation energy }\left(\mathrm{J} \mathrm{mol}^{-1}\right) \\
R & =\text { universal gas constant }\left(8.314 \mathrm{~J} \mathrm{~mol}^{-1} \mathrm{~K}^{-1}\right) \\
T_{w r} & =\text { reference water temperature }(\mathrm{o}) .
\end{aligned}
$$

For some chemicals, the $\mathrm{Q}_{10}$ equation is also used to correct temperature dependent reaction coefficients (Behradek 1930)

$$
k(T)=k\left(T_{w r}\right) \theta_{10}^{T_{w}-\frac{T_{w r}}{10}}
$$

In this equation, $\theta_{10}$ gives the change of reaction coefficient for every $10^{\circ} \mathrm{C}$ temperature change.

The $\mathrm{Q}_{10}$ equation is based on an approximation of the $A E, Q_{10}$ is defined by (Jonsson and Agerberg 2015)

$$
\theta_{10}=e^{\frac{10 E_{a}}{R \cdot 273.15^{2}}}
$$




\subsubsection{Modified Arrhenius Equation (MAE)}

The MAE makes explicit the temperature dependence of the exponential factor. The MAE is usually of the form

$$
k(T)=k\left(T_{w r}\right) \theta^{T_{w}-T_{w r}}
$$

where

$$
\theta=\text { temperature correction coefficient. }
$$

In contrast to the $\mathrm{AE}$, the temperature coefficient $\theta$ is needed in the MAE, which usually ranges between 1.01 and 1.10. The relationship of the rate coefficient and water temperature defined in this function is illustrated in Figure 2.

Figure 2. Relationship of the rate coefficient and temperature as defined in modified Arrhenius Equation.

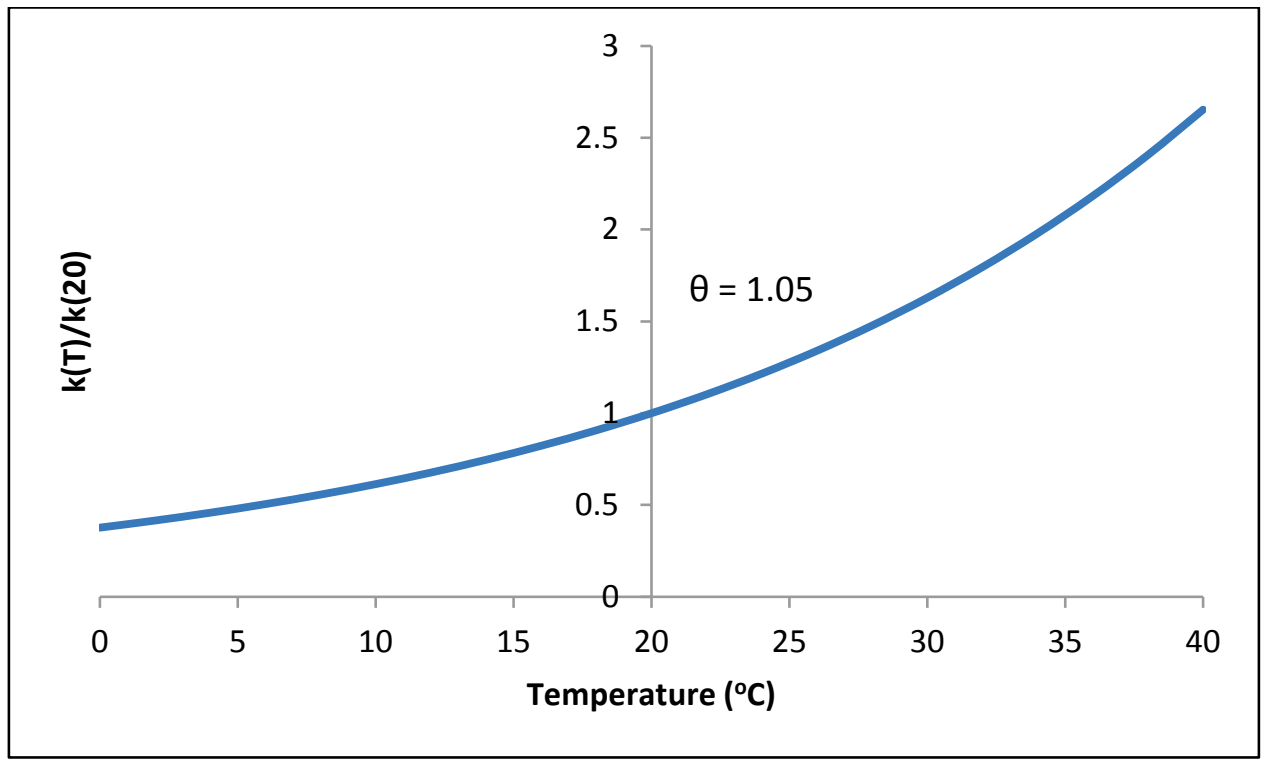




\section{Contaminant Simulation Module (CSM)}

This chapter describes the theory and mathematical formulations implemented in CSM. The CSM is capable of modeling contaminants in an aquatic system as influenced by the following processes; ionization, multiphase partitioning, degradation, photolysis, hydrolysis, volatilization, generalized second-order reaction, and transformations where one chemical undergoes a reaction and is transformed to a daughter product. Any process in CSM can be ignored by use of switches where such processes are not applicable. Two types of contaminant partitioning options are included for algae and solid particulates; equilibrium and non-equilibrium in which adsorption/desorption can be affected by rate limiting processes. The CSM models the water column exchange with underlying sediments and exchange with the atmosphere through a volatilization process. The CSM can model multiple contaminants in one simulation. The contaminants themselves are arbitrary, in that the specific contaminant to be simulated is defined through the specification of processes and kinetic rates. All concentrations of contaminants in CSM are expressed in terms of micrograms per volumetric units of liter $\left(\mu \mathrm{L} \mathrm{L}^{-1}\right)$.

\subsection{Overview}

The transport and fate of contaminants in aquatic systems involve four media; atmosphere, water, sediment, and biota. The importance of each of these media depends on the chemical properties of the contaminant and the form in which the contaminant enters the environment. The atmosphere can be an important source of contaminants to the water through both dry and wet deposition, and can act as a sink for more volatile contaminants. The bottom sediment is often a repository for contaminants discharged or released into the aquatic environment. Sediment re-suspension, burial and bioturbation, reactions, and partitioning between the water and sediment all affect the fate of contaminants in aquatic systems. The biological and chemical processes can alter the form and the rate of the contaminant.

As discussed in Chapter 1, the CSM computes kinetics of contaminants in aquatic systems. At a minimum, the CSM needs to simulate the water column and a bed layer, and include both chemical reactions and sorption to solids. The conceptual representation of a water column and sediment contaminant interactions and processes modeled in CSM is depicted in 
Figure 3. It is important to note that Figure 3 does not show all processes and fluxes of the contaminant cycle, but only the most relevant for the water column and benthic sediment layer. Each contaminant in the water column is subject to adsorption and desorption with dissolved organic carbon (DOC) and solids. The dissolved phase in the bulk water (aqueous phase), the adsorbed phase to DOC in the bulk water, and the adsorbed phases to organic and inorganic solids are modeled in CSM. The chemical species in the active sediment layer is also partitioned into corresponding forms: the truly dissolved phase in the pore water, the adsorbed phase to DOC in the pore water, and the adsorbed phase to the sediments. Two types of partitioning (equilibrium and non-equilibrium) are included for algae; particulate organic matter (POM), and solids. Contaminants can enter the water column via surface runoff, atmospheric deposition, and/or direct discharge. Once contaminants are in aquatic systems, they may be degraded or transformed by various processes.

Figure 3. Conceptual representation of contaminant processes modeled in CSM.

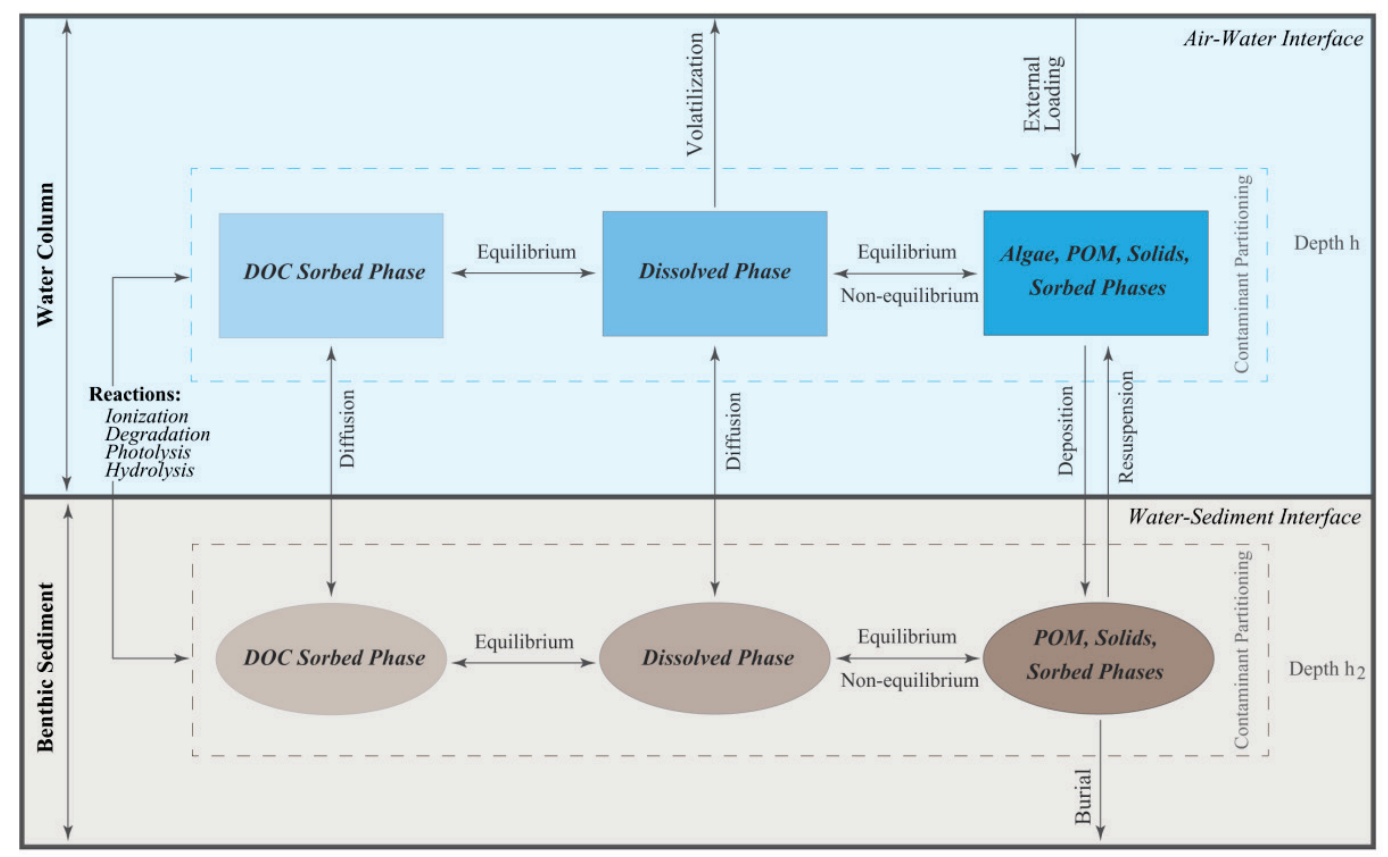

The contaminant in the water column is exchanged with benthic sediments by dispersive mixing. Sorbed contaminant settles through water column and deposits to or erodes from benthic sediments. Within the bed, dissolved contaminant migrates downward or upward through percolation and pore water diffusion. Sorbed chemical migrates downward or upward through net sedimentation or erosion. All of these processes are simulated in CSM and are combined with contaminant reactions and 
transformations into internal source and sink terms. In CSM, the sediment layer represents the upper mixed layer and may be on the order of several centimeters thick due to bioturbation and mixing. The conceptualization is based on the observation that bioturbation forms a well-mixed sediment layer in a variety of locations and environments (Boudreau 1998). The single, well-mixed layer forms the basis for some of the earliest toxic models (O'Connor et al. 1983). For example, the RECOVERY model (Boyer et al. 1994; Ruiz et al. 2000) places a well-mixed layer at the sedimentwater interface, above a succession of deeper sediment layers.

A variety of toxic contaminant transport and fate models are available. Over the last few decades, considerable effort has been made to describe and model contaminant transport, reactions, transformations, and bioavailability in aquatic ecosystems (Wool et al. 2006). Model representations of organic contaminants in the water column are usually similar with regard to kinetic processes and formulations; however, representations of the bottom sediment vary widely. The biogeochemical reactions and transformations implemented in CSM build upon previous contaminant modeling efforts. The following processes are implemented in CSM: ionization, multi-phase partitioning, degradation, photolysis, hydrolysis, volatilization, generalized second-order reaction, and transformations. Each process is controlled by a on/off switch. The relative importance of each of the processes included in the model is directly governed by the contaminant species and their associated properties. Each of these processes is discussed in detail below.

\subsection{Contaminant ionization}

Ionization is the dissociation of a contaminant into multiple charged chemical species. In an aquatic environment some contaminants may occur only in their neutral forms while others may react with water molecules to form positively (cationic) or negatively (anionic) charged ions. Ionization can be important because of the different toxicological and chemical properties of the neutral and ionized species. For example, in some cases only the neutral form of the chemical may react or be transported through biotic membranes resulting in toxicity. As a result, it is often necessary to compute the distribution of the contaminant among the ionic forms to allow them to react or transform at different rates.

In CSM, the ionization process simulates the contaminant for as many as five species: 1) the neutral molecule, 2) singly charged cations, 3) doubly 
charged cations, 4) singly charged anions, and 5) doubly charged anions. Each of the neutral or ionic species may also occur in the dissolved phase or adsorbed to DOC, algae, POM, or the multiple solids. Each chemical species may have different reactivity as reflected by different transformation rates. The formation of the contaminant is controlled by the user specified inputs. Ionization reactions are rapid and are generally assumed to be at (local) equilibrium. At equilibrium, the distribution of the contaminant between the neutral and the ionized species is controlled by the $\mathrm{pH}$ and temperature of the water and the ionization constants. Given the total concentration, the $\mathrm{pH}$, and the equilibrium constants, the fractions of the contaminant occurring in each of the chemical species $\mathrm{k}$, respectively, are defined as (Wool et al. 2006)

$$
\begin{gathered}
f^{1}=\frac{1}{D} \\
f^{2}=\frac{K_{b 1} / 10^{p H-14}}{D} \\
f^{3}=\frac{K_{b 1} K_{b 2} /\left(10^{p H-14}\right)^{2}}{D} \\
f^{4}=\frac{K_{a 1} / 10^{-p H}}{D} \\
f^{5}=\frac{K_{a 1} K_{a 2} /\left(10^{-p H}\right)^{2}}{D}
\end{gathered}
$$

and

$$
\mathrm{D}=\left[\frac{\mathrm{K}_{\mathrm{b} 1}}{10^{\mathrm{pH}-14}}+\frac{\mathrm{K}_{\mathrm{b} 1} \mathrm{~K}_{\mathrm{b} 2}}{\left(10^{\mathrm{pH}-14}\right)^{2}}+\frac{\mathrm{K}_{\mathrm{a} 1}}{10^{-\mathrm{pH}}}+\frac{\mathrm{K}_{\mathrm{a} 1} \mathrm{~K}_{\mathrm{a} 2}}{\left(10^{-\mathrm{pH}}\right)^{2}}\right]+1
$$

where

$$
\begin{aligned}
f^{i}= & \text { fraction of the chemical occurring in each of the chemical } \\
& \text { species } i \text { (unitless) } \\
K_{i}= & \text { equilibrium constant for the formation of the acid ( } \left.K_{a i}\right), \text { or } \\
& \text { anionic species, or the base }\left(K_{b i}\right) \text { or cationic species (unitless). }
\end{aligned}
$$


Where superscript $i$ is the chemical species index ( $i=1$ to 5 ). When the ionization is simulated in CSM, the five chemical species are defined for each contaminant. Different partition coefficients and reaction rates (e.g., for degradation, hydrolysis, photolysis, volatilization, etc.) may be specified for each ionic species of the contaminant modeled in CSM.

\subsection{Contaminant partitioning and distribution}

The partitioning process is used to describe the distribution of a contaminant between pairs of media. Partitioning, also called sorption, is the bonding of dissolved chemicals onto solid phases, such as suspended solids, biological material, and sometimes dissolved or colloidal organic material. The distribution between dissolved and adsorbed forms impacts the transport and fate of the contaminants in aquatic systems. Partitioning of the contaminant is often associated with DOC and the organic carbon content of the solids (Karickhoff 1984; Di Toro et al. 1991). The sorption of xenobiotic organic compounds to DOC is a driving force in determining the bioavailability (Traina et al. 1996). Therefore, multiple phase partitioning (dissolved in water, adsorbed to DOC, and adsorbed to solids) is modeled in CSM. Organic solids are derived from plant materials, dead bacterial or algal cells, and decaying aquatic organisms. Depending on the aquatic system being modeled, solids can be assigned to mineral abiotic solids, detrital, or various classes or size categories of solids. Sorption or uptake of the contaminant associated with algae in the water column is also included in CSM. Inside the algae contaminant kinetics and transformations are not modeled in CSM.

Slow diffusion in solid matter has been acknowledged to take place after fast equilibrium adsorption or prior to fast equilibrium desorption (Runkel et al. 1999; Zheng and Bennett 2002). An alternative to equilibrium partitioning is to simulate sorption using kinetic rate equations. In CSM, partitioning can be simulated with two options: 1) equilibrium approaches, and 2) non-equilibrium adsorption/desorption kinetics. Eiither nonlinear sorption isotherms or non-equilibrium sorption and desorption can be simulated in CSM for contaminants. Some limitations should be kept in mind when applying the equilibrium partitioning. First, contaminant concentrations should be near trace levels, (i.e., below half the solubility). At higher concentrations, the assumptions of linear partitioning and transformation begin to break down. 


\subsubsection{Equilibrium partitioning}

\subsubsection{Partitioning isotherms}

When sorption reactions are fast relative to other environmental processes, then an equilibrium partitioning isotherm is often used in the modeling contaminant transport and fate in aquatic systems. Under equilibrium partitioning, adsorption and desorption can be simulated as either a linear or non-linear function of organic matter and solids. Therefore, three commonly reported sorption isotherms are implemented in CSM: 1) Linear, 2) Langmuir, and 3) Freundlich. Figure 4 shows the adsorbed concentration as a function of aqueous concentration defined by three isotherms. The input coefficients and requirements for the linear, Freundlich, and Langmuir isotherm equations are different.

Figure 4. Three equilibrium sorption isotherms.

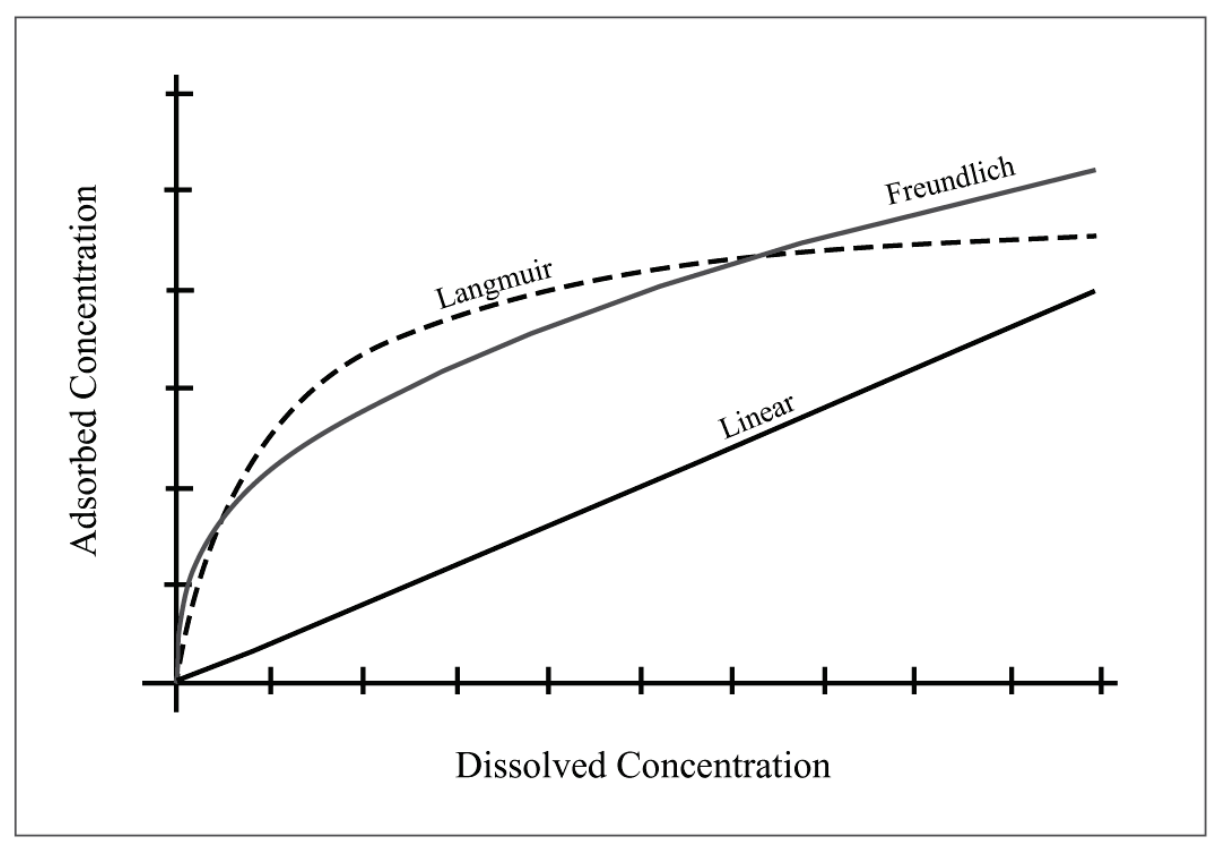

The sorption isotherm indicates how the contaminant distributes between the aqueous phase and the solid phase when the sorption process reaches an equilibrium state. Adsorption isotherms at very low solute concentrations are often linear.

- Linear isotherm: The linear partition coefficient is simply a ratio of the adsorbed phase concentration (expressed in mg per kg adsorbing material) to the dissolved phase concentration (expressed in $\mu \mathrm{g}$ per $\mathrm{L}$ of solution) at equilibrium. The linear isotherm is defined as 


$$
C_{p s}=K_{d} C_{d} \cdot 10^{-3}
$$

where

$$
\begin{aligned}
& C_{p s}=\text { mass of solids adsorbed phase in water }\left(\mu g \mathrm{~g}^{-1}\right) \\
& K_{d}=\text { sorption or partition coefficient }\left(\mathrm{L} \mathrm{kg}^{-1}\right) \\
& C_{d}=\text { concentration of dissolved phase in water }\left(\mu \mathrm{g} \mathrm{L}^{-1}\right) .
\end{aligned}
$$

The $K_{d}$ value is a direct measure of the partitioning of a contaminant between the solid and aqueous phases. The unit of $K_{d}$ is therefore $\mathrm{L} \mathrm{Kg}^{-1}$. Values for $K_{d}$ not only vary greatly between contaminants, but also vary as a function of aqueous and solid phase chemistry (Delegard and Barney 1983; Kaplan and Serne 1995). $K_{d}$ for partitioning between suspended solids and surface water, and $K_{d}$ for partitioning between sediment solids and its pore water can be defined as different values in CSM. Linear adsorption best describes the partitioning at low concentrations.

- Freundlich isotherm: Contaminant adsorption on solids can deviate from the above linear relationship. The Freundlich isotherm (Freundlich 1926) has been widely used to describe solute adsorption by solids. The Freundlich isotherm is defined as

$$
C_{p s}=K_{f}\left(C_{d}\right)^{b}
$$

where

$$
\begin{aligned}
K_{f} & =\text { Freundlich adsorption constant }\left(\left[\mu \mathrm{g} \mathrm{g}^{-1}\right]\left[\mu \mathrm{g} \mathrm{\textrm {L } ^ { - 1 }}\right]^{-\mathrm{b}}\right) \\
b & =\text { Freundlich exponent (unitless). }
\end{aligned}
$$

The Freundlich equation is sometimes written with the exponent in equation 3.4 being $1 / b$ instead of $b$. The linear isotherm is a special case of the Freundlich isotherm where the Freundlich exponent $b$ is equal to 1 . When $b>1$, the adsorption rate increases with increasing solution concentration. When $b<1$, the adsorption rate decreases with solution concentration, as the low energy sites are occupied. The Freundlich model does not account for finite adsorption capacity at high concentrations of solute. However, when considering trace constituent adsorption, ignoring such physical constraints is usually not critical. 
- Langmuir isotherm: The Langmuir model was originally proposed to describe the adsorption of gas molecules onto homogeneous solid surfaces (crystalline materials) that exhibit one type of adsorption site (Langmuir 1918). The Langmuir adsorption model has been extended to describe adsorption of solution species onto solid adsorbents including heterogeneous solids. The Langmuir isotherm assumes that a saturation point, adsorption capacity, is reached at which no further adsorption occurs. The lower portion of the Langmuir isotherm is also linear. The Langmuir isotherm is defined as

$$
C_{p s}=\frac{q_{c} K_{l} C_{d}}{1+K_{l} C_{d}}
$$

where

$$
\begin{aligned}
& K_{l}=\text { Langmuir adsorption constant }\left(\mathrm{L}_{\mu \mathrm{g}^{-1}}\right) \\
& q_{\mathrm{c}}=\text { maximum amount adsorbed by the solid }\left(\mu \mathrm{g} \mathrm{g}^{-1}\right) .
\end{aligned}
$$

The Langmuir isotherm was based on different assumptions, one of which is that a solid surface possesses a finite number of adsorption sites. Once filled, the surface will no longer adsorb solute from solution. As a result, a major advantage of the Langmuir isotherm over linear and Freundlich isotherms is that a maximum adsorption capacity is incorporated into the formulation of the model.

\subsubsection{Computation of linear equilibrium partition coefficients}

For a particular contaminant, the partition coefficient in water depends on the nature of suspended or bed sediment solids, and key geochemical parameters of the water and sediment layer. In CSM, partition coefficients are user specified parameters for each chemical species. Differences in the characteristics of water column and sediment layer may also result in different partition coefficients of the contaminant. Contaminant partitioning for POM can be simulated separately from inorganic solids, rather than as a fraction of the solids. Values for the partition coefficients can be obtained from laboratory experiments.

For organic chemicals, laboratory studies have shown that the partition coefficient is related to the hydrophobicity of the chemical and the organic matter content of the sediment. The adsorption of hydrophobic organic compounds in general, is considered to be primarily to the organic matter in 
solids. Studies related to a variety of organic contaminants have generally shown a linear log-log correlation between $K_{o w}$ and $K_{d}$. This has been demonstrated by several researchers (e.g., Karickhoff et al. 1979; Seth et al. 1999). As a alternative, the equilibrium partition coefficients for DOC, algae, POM, and solids can be computed in CSM from a user-defined $K_{o w}$

$$
\begin{gathered}
K_{d o c}=\alpha_{d o c} \cdot K_{o w} \\
K_{a p}=\alpha_{a p} \cdot K_{o w} \\
K_{p o m}=\alpha_{p o m} \cdot K_{o w} \\
K_{p n}=\alpha_{p n} \cdot K_{o w}
\end{gathered}
$$

where

$$
\begin{aligned}
K_{o w} & =\text { octanol-water partition coefficient (unitless) } \\
\alpha_{d o c}, \alpha_{a p}, \alpha_{p o m}, \alpha_{p n}= & \text { partition correlation coefficient with DOC, algae, POM, } \\
& \text { solids. }
\end{aligned}
$$

The user may input Kow rather than Kd. In general, $\log K_{o w}$ values can be found from the literature. The above equations indicate that partition coefficients and the rates of sorption are determined not only by the amount of organic matter but also by the amount of each type of organic matter. $\alpha_{d o c}, \alpha_{a p}, \alpha_{p o m}, \alpha_{p n}$ vary widely. LaGrega (1994) reports a value of $\left(\alpha_{\text {pom }}=0.63\right)$ as a commonly used value while Seth et al. (1999) calculate a value of $\left(\alpha_{p o m}=0.35\right)$ with a variation in $\alpha$ by a factor of 2.5 in either direction. To use this relationship, the contaminant must be nonionic, because sorption of ionic contaminants are affected by $\mathrm{pH}$.

\subsubsection{Linear equilibrium partitioning}

Under a linear equilibrium partitioning, the distribution among the phases is controlled by the partition coefficients $\mathrm{Kd}$. The total mass of contaminant in each phase is controlled by $\mathrm{Kd}$ and the concentration of sorbent present. For a contaminant partitioning to DOC, algae, POM and multiple solids phases, the fractions of each phase are functions of the partition coefficients and the concentrations of DOC, algae, POM and solids. Solids should be representative of fine-grained, cohesive solids (e.g., clay, silt, organic matter). Formulations of computing the linear equilibrium partitioning 
fractions of the contaminant on a total volume basis in the water column are written as

$$
\begin{gathered}
f_{d}=\frac{C_{d}}{C_{T}}=\frac{10^{6}}{R} \\
f_{d o c}=\frac{C_{d o c}}{C_{T}}=\frac{K_{d o c} D O C}{R} \\
f_{a p}=\frac{C_{a p}}{C_{T}}=\frac{K_{a p} A_{p d}}{R} \\
f_{p o m}=\frac{C_{p o m}}{C_{T}}=\frac{K_{p o m} P O M}{R} \\
f_{p n}=\frac{C_{p n}}{C_{T}}=\frac{K_{p n} m}{R}
\end{gathered}
$$

and

$$
R=10^{6}+K_{d o c} \mathrm{DOC}+K_{a p} A_{p d}+K_{p o m} P O M+\sum_{n=1}^{N} K_{p n} m_{n}
$$

In CSM, equilibrium partitioning of contaminants is handled in the same manner in the sediment layer as in the water column. The description of water column partitioning provided above applies for partitioning in the sediment layer. The fractions associated with dissolved phase in pore water, DOC, and sediment solids adsorbed phases, are calculated by considering the water content and porosity. Formulations of computing the linear equilibrium partitioning fractions of the contaminant in the sediment layer are written as

$$
\begin{gathered}
f_{d 2}=\frac{C_{d 2}}{C_{T 2}}=\frac{10^{6} \varphi}{R_{2}} \\
f_{d o c 2}=\frac{C_{d o c 2}}{C_{T 2}}=\frac{K_{d o c 2} \varphi \cdot D O C_{2}}{R_{2}} \\
f_{p o m 2}=\frac{C_{p o m 2}}{C_{T 2}}=\frac{K_{p o m 2} \cdot P O M_{2}}{R_{2}} \\
f_{p n 2}=\frac{C_{p n 2}}{C_{T 2}}=\frac{K_{p n 2} m_{n 2}}{R_{2}}
\end{gathered}
$$


and

$$
R_{2}=10^{6} \varphi+K_{d o c 2} \varphi \cdot D O C_{2}+K_{p o m 2} \cdot P O M_{2}+\sum_{n=1}^{N} K_{p n 2} m_{n 2}
$$

The symbols and definitions used in equations $3.7 \mathrm{a}-3.8 \mathrm{e}$ are given in Table 3 .

Table 3. Symbols and definitions used in equations 3.7a - 3.8e.

\begin{tabular}{|c|c|c|}
\hline Symbol & Definition & Units \\
\hline \multicolumn{3}{|c|}{ Water column } \\
\hline$f_{d}$ & Fraction of dissolved phase in water & - \\
\hline$f_{d o c}$ & Fraction of DOC adsorbed phase in water & - \\
\hline$f_{a p}$ & Fraction of algae adsorbed phase in water & - \\
\hline$f_{\text {pom }}$ & Fraction of POM adsorbed phase in water & - \\
\hline$f_{p n}$ & Fraction of solid " $n$ " adsorbed phase in water & - \\
\hline$K_{d o c}$ & Equilibrium partition coefficient for DOC in water & $\mathrm{L} \mathrm{kg}^{-1}$ \\
\hline$K_{a p}$ & Equilibrium partition coefficient for algae in water & $\mathrm{L} \mathrm{kg}^{-1}$ \\
\hline$K_{\text {pom }}$ & Equilibrium partition coefficient for POM in water & $\mathrm{L} \mathrm{kg}^{-1}$ \\
\hline$K_{p n}$ & Equilibrium partition coefficient for solid " $n$ " in water & $\mathrm{L} \mathrm{kg}^{-1}$ \\
\hline$D O C$ & Dissolved organic carbon in water & $\mathrm{mg} \mathrm{L}^{-1}$ \\
\hline$A_{p d}$ & Algal biomass (dry weight) in water & $\mathrm{mg} \mathrm{L}^{-1}$ \\
\hline POM & Particulate organic matter in water & $m g L^{-1}$ \\
\hline$m_{n}$ & Concentration of solid " $n$ ” in water & $\mathrm{mg} \mathrm{L}^{-1}$ \\
\hline$C_{T}$ & Total concentration in water & $\mu g L^{-1}$ \\
\hline \multicolumn{3}{|c|}{ Sediment layer } \\
\hline$f_{d 2}$ & Fraction of dissolved phase in sediment & - \\
\hline$f_{\text {doc2 }}$ & Fraction of DOC adsorbed phase in sediment & - \\
\hline$f_{\text {pom2 }}$ & Fraction of POM adsorbed phase in sediment & - \\
\hline$f_{p n 2}$ & Fraction of solid " $n$ " adsorbed phase in sediment & - \\
\hline$K_{d o c 2}$ & Equilibrium partition coefficient for sediment DOC & $\mathrm{L} \mathrm{kg}^{-1}$ \\
\hline$K_{\text {pom2 }}$ & Equilibrium partition coefficient for sediment POM & $\mathrm{L} \mathrm{kg}^{-1}$ \\
\hline$K_{p n 2}$ & Equilibrium partition coefficient for sediment solid “ $n$ ” & $\mathrm{L} \mathrm{kg}^{-1}$ \\
\hline$D O C_{2}$ & Sediment dissolved organic carbon in pore water & $m g L^{-1}$ \\
\hline $\mathrm{POM}_{2}$ & Sediment particulate organic matter & $\mathrm{mg} \mathrm{L}^{-1}$ \\
\hline$m_{n 2}$ & Concentration of sediment solid " $n$ " & $\mathrm{mg} \mathrm{L}^{-1}$ \\
\hline$C_{\text {T2 }}$ & Total concentration in sediment & $\mu g L^{-1}$ \\
\hline
\end{tabular}


DOC, POM, POM2, Apd used in partitioning equations are user specified parameters and can be computed from the NSM modules (Zhang and Johnson 2016). In CSM, equilibrium partitioning is simulated based on the total concentration of the contaminant. At equilibrium, the concentration of chemical in any phase can be calculated from the total concentration. Therefore, only a single state variable representing total concentration is used for each contaminant. Contaminant concentrations for each phase can be calculated by

$$
\begin{gathered}
C_{d}=\sum_{i} C_{d}^{i}=\sum_{i} f_{d}^{i} C_{T}^{i} \\
C_{d o c}=\sum_{i} C_{d o c}^{i}=\sum_{i} f_{d o c}^{i} C_{T}^{i} \\
C_{a p}=\sum_{i} C_{a p}^{i}=\sum_{i} f_{a p}^{i} C_{T}^{i} \\
C_{p o m}=\sum_{i} C_{p o m}^{i}=\sum_{i} f_{p o m}^{i} C_{T}^{i} \\
C_{p t}=\sum_{i} C_{p n}^{i}=\sum_{i} \sum_{n=1}^{N} f_{p n}^{i} C_{T}^{i} \\
C_{p t s}=10^{3} \frac{\sum_{i} \sum_{n=1}^{N} f_{p n}^{i} C_{T}^{i}}{\sum_{i} \sum_{n=1}^{N} m_{n}}
\end{gathered}
$$

Where the subscript $i$ denotes the $i$ th chemical species if the ionization is modeled in CSM ( $i=1$ to 5 ), the subscript $\mathrm{n}$ denotes the nth solids class ( $n=$ 1 to $\mathrm{N})$.

In the sediment layer, concentrations of dissolved, DOC and adsorbed phases can also be calculated from the total concentration with respect to a unit volume of total sediments by

$$
C_{d 2}=\sum_{i} C_{d 2}^{i}=\sum_{i} f_{d 2}^{i} C_{T 2}^{i}
$$




$$
\begin{gathered}
C_{d o c 2}=\sum_{i} C_{d o c 2}^{i}=\sum_{i} f_{d o c 2}^{i} C_{T 2}^{i} \\
C_{p o m 2}=\sum_{i} C_{p o m 2}^{i}=\sum_{i} f_{p o m 2}^{i} C_{T 2}^{i} \\
C_{p t 2}=\sum_{i} C_{p n 2}^{i}=\sum_{i} \sum_{n=1}^{N} f_{p n 2}^{i} C_{T 2}^{i} \\
C_{p t s 2}=10^{3} \frac{\sum_{i} \sum_{n=1}^{N} f_{p n 2}^{i} C_{T 2}^{i}}{\sum_{i} \sum_{n=1}^{N} m_{n 2}}
\end{gathered}
$$

The above $C_{d 2}$ and $C_{d o c 2}$ are computed based on the mass of dissolved phase and adsorbed on DOC on the sediment total volume. Their pore water concentrations of the contaminant are expressed as

$$
\begin{gathered}
C_{d p 2}=C_{d 2} / \varphi \\
C_{d o c p 2}=C_{d o c 2} / \varphi
\end{gathered}
$$

\begin{tabular}{|c|c|c|}
\hline Symbol & Definition & Units \\
\hline \multicolumn{3}{|c|}{ Water column } \\
\hline$C_{d}$ & Concentration of dissolved phase in water & $\mu g L^{-1}$ \\
\hline$C_{d o c}$ & Concentration of DOC adsorbed phase in water & $\mu g L^{-1}$ \\
\hline Cap & Concentration of algae adsorbed phase in water & $\mu g L^{-1}$ \\
\hline$C_{p o m}$ & Concentration of POM adsorbed phase in water & $\mu g L^{-1}$ \\
\hline$C_{p n}$ & Concentration of solid " $n$ " adsorbed phase in water & $\mu g L^{-1}$ \\
\hline$C_{p t}$ & Total concentration of solids adsorbed phase in water & $\mu g L^{-1}$ \\
\hline Cpts & Total concentration of solids adsorbed on solids in water & $\mu g g^{-1}$ \\
\hline \multicolumn{3}{|c|}{ Sediment layer } \\
\hline$C_{d 2}$ & Concentration of dissolved phase in sediment & $\mu g L^{-1}$ \\
\hline$C_{d o c 2}$ & Concentration of DOC adsorbed phase in sediment & $\mu g L^{-1}$ \\
\hline$C_{\text {pom2 }}$ & Concentration of POM adsorbed phase in sediment & $\mu g L^{-1}$ \\
\hline
\end{tabular}

The symbols of the contaminant concentrations used in equations $3 \cdot 9 \mathrm{a}-$ 3.11b are defined in Table 4 .

Table 4. Symbols and definitions of the contaminant concentrations in equations $3.9 \mathrm{a}-3.11 \mathrm{~b}$. 


\begin{tabular}{|l|l|l|}
\hline Symbol & Definition & Units \\
\hline$C_{p n 2}$ & Concentration of solid “ $n$ ” adsorbed phase in sediment & $\mu g \mathrm{~L}^{-1}$ \\
\hline$C_{p t 2}$ & Total concentration of solids adsorbed phase in sediment & $\mu g \mathrm{~L}^{-1}$ \\
\hline$C_{p t s 2}$ & Total concentration of solids adsorbed on sediment solids & $\mu g \mathrm{~g}^{-1}$ \\
\hline$C_{d p 2}$ & Concentration of dissolved phase in pore water & $\mu g \mathrm{~L}^{-1}$ \\
\hline$C_{d o c p 2}$ & Concentration of DOC adsorbed phase in pore water & $\mu g \mathrm{~L}^{-1}$ \\
\hline
\end{tabular}

\subsubsection{Non-linear equilibrium partitioning}

When the concentration of the contaminant increases beyond a certain level, not enough sites might be available for adsorption. Therefore, competition effects will lead to an increase in non-linear partitioning on the concentration of the contaminant. However, there is no evidence that competition effects the adsorption of the substance onto the DOC in the range of environmentally relevant DOC concentrations in water (Krop et al. 2001). It is assumed that the partitioning distribution between DOC and water always follows a linear isotherm and this is true in HgSM as well. In subsequent sections, $K_{d o c}$ is defined with the assumption of linearity of contaminant partitioning isotherms. Following the Freundlich equilibrium sorption isotherm, total concentrations of the contaminant in the water column and sediment layer can be determined by the following mass balances.

Water column:

$$
\begin{aligned}
C_{d}+ & 10^{-6} K_{d o c} C_{d} D O C \\
& +10^{-3} K_{f a p} C_{d}^{b a p} A_{p d}+10^{-3} K_{f p o m} C_{d}^{b p o m} P O M+10^{-3} \sum_{n=1}^{N} K_{f p n} C_{d}^{b p n} m_{n}=C_{T}
\end{aligned}
$$

Sediment layer:

$$
\begin{aligned}
C_{d 2}+ & 10^{-6} K_{d o c 2} C_{d 2} D O C_{2} \\
& +10^{-3} K_{f p o m 2}\left(C_{d 2} / \varphi\right)^{b p o m 2} P^{\prime} M_{2}+10^{-3} \sum_{n=1}^{N} K_{f p n 2}\left(C_{d 2} / \varphi\right)^{b p n 2} m_{n 2}=C_{T 2}
\end{aligned}
$$

With the Langmuir equilibrium partitioning, similar mass balance equations of total concentrations are developed.

Water column: 


$$
\begin{aligned}
& C_{d}+10^{-6} K_{\text {doc }} C_{d} D O C \\
& \quad+\frac{10^{-3} K_{l a p} C_{d} q_{c a p} A_{p d}}{10^{3}+K_{l a p} C_{d}}+\frac{10^{-3} K_{l p o m} C_{d} q_{\text {cpom }} P O M}{10^{3}+K_{l p o m} C_{d}}+\sum_{n=1}^{N} \frac{10^{-3} K_{l p n} C_{d} q_{c n} m_{n}}{10^{3}+K_{l p n} C_{d}}=C_{T}
\end{aligned}
$$

Sediment layer:

$$
\begin{aligned}
C_{d 2}+ & 10^{-6} K_{d o c 2} C_{d 2} D O C_{2} \\
& +\frac{10^{-3} K_{l p o m 2}\left(C_{d 2} / \varphi\right) q_{\text {cpom } 2} P O M_{2}}{10^{3}+K_{l p o m 2}\left(C_{d 2} / \varphi\right)}+\sum_{n=1}^{N} \frac{10^{-3} K_{l p n 2}\left(C_{d 2} / \varphi\right) q_{c n 2} m_{n 2}}{10^{3}+K_{l p n 2}\left(C_{d 2} / \varphi\right)}=C_{T 2}
\end{aligned}
$$

where

$$
\begin{aligned}
& K_{\text {fpom }}=\text { Freundlich adsorption constant for POM in water }\left(\mu \mathrm{g} \mathrm{g}^{-1}\right)\left(\mu \mathrm{g} \mathrm{L}^{-1}\right)^{-\mathrm{b}} \\
& K_{\text {fpom } 2}=\text { Freundlich adsorption constant for sediment POM }\left(\mu g g^{-1}\right)\left(\mu g \mathrm{~L}^{-1}\right)^{-\mathrm{b}} \\
& K_{f a p}=\text { Freundlich adsorption constant for algae in water }\left(\mu \mathrm{g} \mathrm{g}^{-1}\right)\left(\mu \mathrm{g} \mathrm{L}^{-1}\right)^{-\mathrm{b}} \\
& K_{f p n}=\text { Freundlich adsorption constant for solid " } n \text { " in water }\left(\mu \mathrm{g} \mathrm{g}^{-1}\right) \\
& \left(\mu \mathrm{g} \mathrm{L} \mathrm{L}^{-1}\right)^{-\mathrm{b}} \\
& \left.K_{f p n 2}=\text { Freundlich adsorption constant for sediment solid " } n \text { ” ( } \mu \mathrm{g} \mathrm{g}^{-1}\right) \\
& \left(\mu \mathrm{g} \mathrm{L^{-1 }}\right)^{-b} \\
& b_{\text {pom }}=\text { Freundlich exponent for POM in water (uniteless) } \\
& b_{\text {pom } 2}=\text { Freundlich exponent for sediment POM (uniteless) } \\
& b_{a p}=\text { Freundlich exponent for algae in water (uniteless) } \\
& b_{p n}=\text { Freundlich exponent for solid " } n \text { " in water (uniteless) } \\
& b_{p n 2}=\text { Freundlich exponent for sediment solid " } n \text { " (uniteless) } \\
& K_{l a p}=\text { Langmuir adsorption constant for algae in water }\left({\left.\mathrm{L} \mu g^{-1}\right)}^{-}\right. \\
& K_{\text {lpom }}=\text { Langmuir adsorption constant for POM in water }\left({\left.\mathrm{L} \mu g^{-1}\right)}^{-1}\right.
\end{aligned}
$$

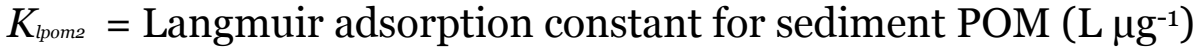

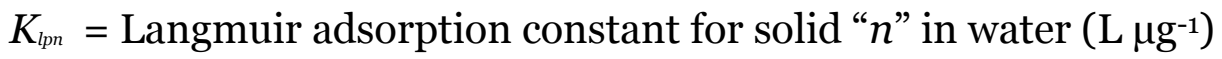

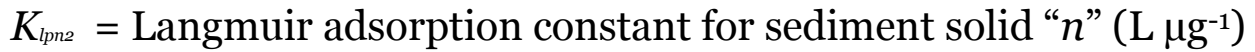

$$
\begin{aligned}
& q_{\text {cap }}=\text { maximum amount adsorbed by algae in water }\left(\mu \mathrm{g} \mathrm{g}^{-1}\right) \\
& q_{\text {cpom }}=\text { maximum amount adsorbed by POM in water }\left(\mu \mathrm{g} \mathrm{g}^{-1}\right) \\
& q_{\text {срот } 2}=\text { maximum amount adsorbed by sediment POM }\left(\mu \mathrm{g} \mathrm{g}^{-1}\right) \\
& q_{c n}=\text { maximum amount adsorbed by solid " } n \text { " in water }\left(\mu \mathrm{g} \mathrm{g} \mathrm{g}^{-1}\right) \\
& q_{c n 2}=\text { maximum amount adsorbed by sediment solid " } n \text { " }\left(\mu \mathrm{g} \mathrm{g}^{-1}\right) \text {. }
\end{aligned}
$$

The above non-linear equations 3.12 to 3.15 contain unknown concentrations ( $C_{d}$ and $C_{d 2}$ ) and are solved numerically. Two numerical methods are implemented in CSM: 1) Newton-Raphson, and 2) Bisection. Both methods are described in Chapra and Canale (2006). 


\subsubsection{Non-equilibrium partitioning}

The equilibrium partitioning methods discussed above assumes that all sorption sites have equal energy, an infinite number of adsorption sites, and exposure time. The problem with equilibrium adsorption is that these assumptions are generally false. Often, there is an absence of equilibrium due to insufficient exposure time, metabolic biotransformation, and nonlinear relationships for very large and/or super hydrophobic compounds (Bertelsen et al. 1998). For example, polychlorinated biphenyls in Lake Ontario exhibit a 25-fold non-equilibrium (Cook and Burkhard 1998). If the adsorption process is slow or irreversible, dissolved and adsorbed concentrations cannot be directly calculated from the total concentration of the contaminant. The state variables for a contaminant include the concentrations of potential phases.

Under non-equilibrium partitioning, the effects of the adsorption and desorption of the contaminant between water and solids must be computed separately in the transport equations. The rate of adsorption is a function of the adsorptive capacity of the solid and the dissolved concentration, while desorption rate depends only on the adsorbed concentration. Net adsorption and desorption rates of the contaminant associated with algae, POM, and solids can be written as

$$
\begin{gathered}
\frac{\partial C_{a p}}{\partial t}=k_{a d a p}\left(10^{-3} q_{c a p} A_{p d}-C_{a p}\right) C_{d}-k_{d a a p} C_{a p} \\
\frac{\partial C_{p o m}}{\partial t}=k_{a d p o m}\left(10^{-3} q_{c p o m} P O M-C_{p o m}\right) C_{d}-k_{d a p o m} C_{p o m} \\
\frac{\partial C_{p n}}{\partial t}=k_{a d n}\left(10^{-3} q_{c n} m_{n}-C_{p n}\right) C_{d}-k_{d a n} C_{p n}
\end{gathered}
$$

where

$$
\begin{aligned}
k_{a d n} & =\text { adsorption coefficient for solid " } n \text { " in water }\left(\mathrm{L}^{-1} \mathrm{~g}^{-1} \mathrm{~d}^{-1}\right) \\
k_{\text {adap }} & =\text { adsorption coefficient for algae in water }\left(\mathrm{L}^{-1} \mathrm{~d}^{-1}\right) \\
k_{\text {adpom }} & =\text { adsorption coefficient for POM in water }\left(\mathrm{L}^{-1} \mathrm{~d}^{-1}\right) \\
k_{\text {dan }} & =\text { desorption rate for solid " } n \text { " in water }\left(\mathrm{d}^{-1}\right) \\
k_{\text {daap }} & =\text { desorption rate for algae in water }\left(\mathrm{d}^{-1}\right) \\
k_{\text {dapom }} & =\text { desorption rate for POM in water }\left(\mathrm{d}^{-1}\right) .
\end{aligned}
$$


As a result, two parameters, $k_{a d n}$, and $k_{d a n}$ are required to account for nonequilibrium partitioning. The kinetic rate coefficients are related to the equilibrium constants.

The net adsorption and desorption rates of the contaminant associated with sediment POM and solids can be written as

$$
\begin{gathered}
\frac{\partial C_{\text {pom } 2}}{\partial t}=k_{\text {adpom } 2}\left(10^{-3} q_{c p o m 2} P O M_{2}-C_{p o m 2}\right) \frac{C_{d 2}}{\varphi}-k_{d a p o m 2} C_{p o m 2} \\
\frac{\partial C_{p n 2}}{\partial t}=k_{a d n 2}\left(10^{-3} q_{c n 2} m_{n 2}-C_{p n 2}\right) \frac{C_{d 2}}{\varphi}-k_{d a n 2} C_{p n 2}
\end{gathered}
$$

where

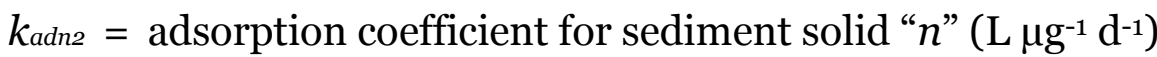

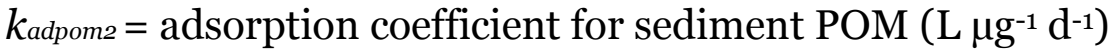

$$
\begin{aligned}
& k_{\text {dan } 2}=\text { desorption rate for sediment solid " } n \text { " }\left(\mathrm{d}^{-1}\right) \\
& k_{\text {dapom } 2}=\text { desorption rate for sediment POM }\left(\mathrm{d}^{-1}\right) \text {. }
\end{aligned}
$$

In the above non-equilibrium equations, the concentrations of dissolved and adsorbed phases are dependent upon each other, and each is a function of time. In this case the contaminant is simulated with more than one state variable, which may include dissolved, POM, algae, and solids adsorbed phases. Kinetic source and sink terms will be computed separately for each phase and their transport equations must be solved simultaneously. For simplicity, non-equilibrium partitioning only applies for non-ionic chemical species. In other words, the ionization and non-equilibrium partitioning processes cannot be activated at the same time in CSM.

The adsorption coefficients are related to the equilibrium constants (equation 3.3). The desorption rates are additional parameters for the non-equilibrium option and are water temperature dependent. The desorption rates are corrected using the MAE. Activation energy values $\left(E_{a}\right)$ are defined for each solid class.

\subsection{Contaminant reactions and transformations}

In addition to species and phase partitioning, contaminants participate in chemical or biological reactions in the aquatic environment. These processes can influence the ultimate fate of contaminants. Contaminant 
degradation, photolysis, hydrolysis, volatilization, generalized second-order reaction, and transformations are implemented within CSM. The importance of each of these processes is highly dependent on both the contaminant and its environment. Some contaminants undergo a complex set of reactions, while others behave in a more simplified manner. The CSM can be used as a simpler model to conduct simulations of dye tracers, or first order degradation. More complex simulations of the contaminant may employ all processes included in CSM.

\subsubsection{Degradation}

Contaminants may degrade, either chemically or biochemically. The rate of contaminant degradation in the environment is a complex function dependent on the numerous local conditions. Often the individual degradation processes are not well known or cannot be quantified exactly for a given contaminant. The degradation kinetics of contaminants is then described as the $n$ order kinetics without coupling with the limiting substrate (Schnoor 1996).

The degradation process is simulated for the water column and underlying sediment layer. Different degradation rate coefficients $\left(k_{1 d}, k_{1 p}\right)$ can be specified for the water column and sediment layer. This degradation process of contaminants, whether they are dissolved or adsorbed to solids, is simulated using the same equations. In CSM, the overall degradation rate of the contaminant is calculated from each partitioning phase and each chemical species

$$
S_{d e c}=\sum_{i}\left[k_{1 d}^{i}(T) f_{d}^{i}+k_{1 d o c}^{i}(T) f_{d o c}^{i}+k_{1 a p}^{i}(T) f_{a p}^{i}+k_{1 p o m}^{i}(T) f_{p o m}^{i}+\sum_{n=1}^{N} k_{1 p n}^{i}(T) f_{p n}^{i}\right] C_{T}^{i}
$$

where

$$
S_{d e c}=\text { contaminant degradation }\left(\mu \mathrm{L} \mathrm{L}^{-1} \mathrm{~d}^{-1}\right)
$$

$k_{1 d}^{i}(T)=$ degradation rate for dissolved species in water $\left(\mathrm{d}^{-1}\right)$

$k_{1 d o c}^{i}(T)=$ degradation rate for DOC adsorbed species in water $\left(\mathrm{d}^{-1}\right)$

$k_{1 a p}^{i}(T)=$ degradation rate for algae adsorbed species in water $\left(\mathrm{d}^{-1}\right)$

$k_{1 p o m}^{i}(T)=$ degradation rate for POM adsorbed species in water $\left(\mathrm{d}^{-1}\right)$

$k_{1 p n}^{i}(T)=$ degradation rate for solid " $n$ " adsorbed species in water $\left(\mathrm{d}^{-1}\right)$. 
First-order degradation rates appear more practical and can be obtained from experiments under field conditions. Since the chemical natures of aqueous solutions and solid environments differ greatly, contaminant degradation for each form may occur at very different rates. The CSM allows for specifying different degradation rates for each form. The degradation rates are temperature dependent parameters and are corrected using a MAE.

\subsubsection{Hydrolysis}

Hydrolysis is a reaction in which cleavage of a molecular bond of the contaminant and formation of a new bond with either the hydrogen or the hydroxyl component of a water molecule occurs. Contaminants in water may react with positively charged hydronium ions $\left[\mathrm{H}^{+}\right]$, negatively charged hydroxide ions $\left[\mathrm{OH}^{-}\right]$, or neutral water molecules. Therefore $\mathrm{pH}$ can affect water ionization and hydrolysis reactions.

Hydrolysis may affect both the dissolved and particulate phases. The WASP model allows for specifying hydrolysis for any partitioning phases. However, in many model applications, hydrolysis and photolysis reactions are considered to affect only the dissolved phase (Schnoor 1996). Therefore, the hydrolysis process is simulated in CSM for only the dissolved phase in the water column and underlying sediment layer. Different hydrolysis rate coefficients $\left(k_{h a}, k_{h n}, k_{h b}\right)$ can be specified for the water column and sediment layer. In CSM, the hydrolysis rate of the contaminant is calculated based on the first order reaction for the neutral, and second order reaction for the acidic or basic ions.

$$
S_{\text {hyd }}=\sum_{i}\left\{\begin{array}{l}
\left(\begin{array}{l}
\left.k_{h a}^{i}(T)\left[H^{+}\right]+k_{h n}^{i}(T)+k_{h b}^{i}(T)\left[O H^{-}\right]\right) f_{d}^{i}+ \\
\left(k_{\text {hadoc }}^{i}(T)\left[H^{+}\right]+k_{\text {hndoc }}^{i}(T)+k_{h b d o c}^{i}(T)\left[O H^{-}\right]\right) f_{\text {doc }}^{i}
\end{array}\right.
\end{array} C_{T}^{i}\right.
$$

where

Shyd $=$ contaminant hydrolysis $\left(\mu \mathrm{g} \mathrm{L}^{-1} \mathrm{~d}^{-1}\right)$

$k_{h a}^{i}(T)=$ acid hydrolysis rate constant for dissolved species in water $\left(\mathrm{L} \mathrm{mol}^{-1} \mathrm{~d}^{-1}\right)$

$k_{h b}^{i}(T)=$ base hydrolysis rate constant for dissolved species in water ( $\left.\mathrm{L} \mathrm{mol}^{-1} \mathrm{~d}^{-1}\right)$

$k_{h n}^{i}(T)=$ neutral hydrolysis rate for dissolved species in water $\left(\mathrm{d}^{-1}\right)$ 
$k_{\text {hadoc }}^{i}(T)=$ acid hydrolysis rate constant for DOC adsorbed species in water $\left(\mathrm{L} \mathrm{mol}^{-1} \mathrm{~d}^{-1}\right)$

$k_{h b d o c}^{i}(T)=$ base hydrolysis rate constant for DOC adsorbed species in water ( $\left.\mathrm{L} \mathrm{mol}^{-1} \mathrm{~d}^{-1}\right)$

$k_{\text {hndoc }}^{i}(T)=$ neutral hydrolysis rate for DOC adsorbed chemical species in water $\left(\mathrm{d}^{-1}\right)$

$\left[\mathrm{H}^{+}\right],\left[\mathrm{OH}^{-}\right]=$molar concentrations of hydrogen and hydroxide ions $\left(\mathrm{mol} \mathrm{L}^{-1}\right)$, respectively.

The $\mathrm{pH}$ is a water quality parameter. $\mathrm{H}^{+}$and $\mathrm{OH}^{-}$can be determined from the $\mathrm{pH}$ value

$$
\begin{gathered}
{\left[\mathrm{H}^{+}\right]=10^{-p H}} \\
{\left[\mathrm{OH}^{-}\right]=10^{-p O H}=10^{(14-p H)}}
\end{gathered}
$$

Hydrolysis is one of the most important mechanisms in the environment for the breakdown of a parent chemical and these rates are affected by water temperature. In CSM, the hydrolysis rates are corrected using the AE. An activation energy value $\left(E_{a}\right)$ of $75 \mathrm{KJ} \mathrm{mol}^{-1}$ (a mid-range value for organic chemicals) is used as the default value.

\subsubsection{Photolysis}

Contaminant photolysis is assumed to occur due to the water surface being exposed to sun light. However, the relative significance of photolysis in relation to other processes may vary. Aquatic photolysis is the transformation or degradation of a contaminant that results directly from the adsorption of light energy. The amount of contaminant loss due to photolysis is a function of the quantity and wavelength distribution of incident light, the light absorption characteristics of the contaminant, and the efficiency at which absorbed light yields a chemical reaction. Only certain chemical species of the contaminant can be photolytically altered and CSM allows for specifying photolyzed species. The photolysis process is simulated in CSM for only the dissolved phase of the contaminant in the water column.

A first-order rate equation has been used to estimate aquatic photolysis rate (Thomann and Mueller 1987; Chapra 1997). This equation relates the 
observed surface photolysis rate under laboratory conditions, and such values are then corrected to the field conditions by using a light attenuation coefficient

$$
S_{p h t}=1.33 \frac{I_{0}}{I_{\mathrm{opht}}} \frac{1-e^{-\lambda_{\max } \cdot h}}{\lambda_{\max } \cdot h}\left(1-0.56 C_{L}\right) \sum_{i}\left(k_{p h t}^{i} f_{d}^{i}+k_{p h t d o c}^{i} f_{d o c}^{i}\right) C_{T}^{i}
$$

where

$$
\begin{aligned}
S_{p h t} & =\text { contaminant photolysis }\left(\mu \mathrm{g} \mathrm{L}^{-1} \mathrm{~d}^{-1}\right) \\
h & =\text { water depth }(h>0)(\mathrm{m}) \\
k_{p h t}^{i} & =\text { surface photolysis rate for dissolved species }\left(\mathrm{d}^{-1}\right) \\
k_{\text {phtoc }}^{i} & =\text { surface photolysis rate for DOC adsorbed species }\left(\mathrm{d}^{-1}\right) \\
I_{o} & =\text { solar radiation at the water surface }\left(\mathrm{W} \mathrm{m}^{-2}\right) \\
I_{\text {opht }} & =\text { light intensity when } k_{p h t} \text { is measured }\left(\mathrm{W} \mathrm{m}^{-2}\right) \\
\lambda_{\max } & =\text { maximium light extinction coefficient }\left(\mathrm{m}^{-1}\right)
\end{aligned}
$$

and

$$
\lambda_{\max }=\alpha_{l} \cdot \lambda
$$

where

$$
\begin{aligned}
\alpha_{l} & =\text { correction factor for light attenuation (1.1 to 1.6) } \\
\lambda & =\text { light extinction coefficient }\left(\mathrm{m}^{-1}\right) .
\end{aligned}
$$

The light extinction coefficient $(\lambda)$ is computed in NSM modules (Zhang and Johnson 2016). In NSMs, it is assumed that suspended solids, algae, and organic matter affect the light extinction. The surface photolysis rate of a contaminant is not a temperature dependent.

\subsubsection{Volatilization}

Volatilization is the movement of a contaminant from the bulk water phase of a water body across the water-air interface and into the air. This process depends on the contaminant and the physical properties of the water body and the atmosphere. The CSM assumes that only dissolved contaminants can be transferred across the water-air interface, and adsorption to solids or organic carbon reduces volatilization. The overall volatilization rate is determined by the well-known two-film theory (Whitman 1923). The two- 
film method assumes that two "stagnant films" are bounded on either side by well mixed compartments. The transfer coefficients $K_{L}$ and $K_{G}$ are used to quantify the exchange of contaminants between water and atmosphere. The volatilization transfer velocity is then derived as the reciprocal of the total resistance

$$
v_{v}(T)=\left(\frac{1}{K_{L}}+\frac{1}{K_{G} K_{H} /\left(R \cdot T_{w k}\right)}\right)^{-1}
$$

where

$$
\begin{aligned}
v_{v}(T) & =\text { volatilization velocity across the air-water interface }\left(\mathrm{m} \mathrm{d}^{-1}\right) \\
K_{L} & =\text { mass transfer velocity from the liquid film }\left(\mathrm{m} \mathrm{d}^{-1}\right) \\
K_{G} & =\text { mass transfer velocity from the gaseous film }\left(\mathrm{m} \mathrm{d}^{-1}\right) \\
R & =\text { universal gas constant }\left(8.314 \mathrm{~Pa} \mathrm{~m}^{3} \mathrm{~mol}^{-1}{ }^{\circ} \mathrm{K}^{-1}\right) \\
T_{w k} & =\text { water temperature }\left({ }^{\circ} \mathrm{K}\right) \\
K_{H} & =\text { Henry's Law constant }\left(\mathrm{Pa} \mathrm{m}^{3} \mathrm{~mol}^{-1}\right) .
\end{aligned}
$$

The value of $v_{v}(T)$, depends on the intensity of turbulence in a water body and in the overlying atmosphere. Mackay and Leinonen (1975) have discussed conditions under which the value of $v_{v}(T)$ is primarily determined by the intensity of turbulence in the water. The $K_{H}$ relates the concentration of a contaminant in the air phase to its concentration in the water phase, strongly affecting the air-phase resistance. Depending on the $K_{H}$ value, the water phase, the air phase, or both may control the volatilization rate. A common way to define Henry's Law constant is by dividing the partial pressure by the aqueous-phase concentration as in equation 3.23. The Henry volatility can also be expressed as the dimensionless ratio between the gas-phase concentration of a species and its aqueous-phase concentration.

As the Henry's Law coefficient increases, the transfer tends to be increasingly influenced by the intensity of turbulence in water. As the $K_{H}$ decreases, the air-water transfer coefficient tends to be increasingly influenced by the intensity of atmospheric turbulence. For small values of $K_{H}$, transfer velocity through the air side of the interface will control the overall volatilization rate of the contaminant. At very low values of $K_{H}$ $\left(<10^{-7}\right)$, the volatilization velocity is so slow and therefore can be considered unimportant as an inter-media transfer mechanism. The 
volatilization velocity is usually of relatively less magnitude in lakes and reservoirs than in rivers and streams.

Two transfer coefficients need to be determined, $K_{L}$ for the liquid film and $K_{G}$ for the gas film bordering the interface between water and atmosphere. These coefficients are in fact mass transfer velocities. Numerous empirical relations exist that describe the transfer coefficients as functions of the wind speed and/or the water flow velocity (Lyman et al. 1990). The following formulations are implemented in CSM for computing the transfer coefficients of $K_{L}$ and $K_{G}$ (Mill et al. 1982).

$$
\begin{gathered}
K_{L}=k_{a}\left(\frac{32}{M W}\right)^{0.25} \\
K_{G}=168 u_{w}\left(\frac{18}{M W}\right)^{0.25}
\end{gathered}
$$

where

$$
\begin{aligned}
k_{a} & =\text { oxygen reaeration rate }\left(\mathrm{m} \mathrm{d}^{-1}\right) \\
M W & =\text { molecular weight }\left(\mathrm{g} \mathrm{mol}^{-1}\right) \\
u_{w} & =\text { wind speed }\left(\mathrm{m} \mathrm{s}^{-1}\right) .
\end{aligned}
$$

Oxygen reaeration rate $k_{a}$ in riverine systems can be calculated using the formulations implemented in NSM modules (Zhang and Johnson 2016). Concentration differences serve as the driving force for the water layer diffusion. In CSM, the volatilization rate of the contaminant is calculated as

$$
S_{v l t}=\frac{1}{h} v_{v}(T)\left(f_{d} C_{T}-\frac{C_{0}}{K_{H} /\left(R \cdot T_{w k}\right)}\right)
$$

where

$$
\begin{aligned}
S_{v l t} & =\text { contaminant volatilization }\left(\mu \mathrm{g} \mathrm{L}^{-1} \mathrm{~d}^{-1}\right) \\
C_{o} & =\text { air concentration (gaseous) of contaminant }\left(\mu \mathrm{g} \mathrm{L}^{-1}\right) .
\end{aligned}
$$

Note that only the un-ionized form (neutral molecule) of the dissolved contaminant is subject to volatilization if the ionization process is simulated in CSM. The volatilization velocity, which is specified by the 
user or calculated from equation 3.23, is corrected with the local water temperature through the MAE.

\subsubsection{Generalized second-order reaction}

A generalized second-order reaction is included to allow the user to simulate the effect of processes that are not considered in the above mechanisms. The reaction depends upon a rate constant and an environmental factor which may be taken to represent, for example, some reducing or oxidizing agent. In CSM, the generalized second-order reaction is linear with respect to the concentration of a contaminant and environmental property

$$
S_{\text {exa }}=\sum_{i}\left[k_{\text {ed }}^{i}(T) f_{d}^{i}+k_{\text {edoc }}^{i}(T) f_{\text {doc }}^{i}+k_{\text {eap }}^{i}(T) f_{a p}^{i}+k_{\text {epom }}^{i}(T) f_{p o m}^{i}+\sum_{n=1}^{N} k_{e p n}^{i}(T) f_{p n}^{i}\right] C_{T}^{i}[E]
$$

where

$S_{\text {exa }}=$ contaminant generalized second-order reaction $\left(\mu \mathrm{g} \mathrm{L}^{-1} \mathrm{~d}^{-1}\right)$

$[E]=$ concentration of environmental property driving generalized second-order reaction in water $\left(\mathrm{mg} \mathrm{L}^{-1}\right)$

$k_{e d}(T)=$ second order rate for dissolved species in water $\left(\left[\mathrm{mg} \mathrm{L}^{-1}\right]^{-1} \mathrm{~d}^{-1}\right)$

$k_{e d o c}(T)=$ second order rate for DOC adsorbed species in water $\left(\left[\mathrm{mg} \mathrm{L}^{-1}\right]^{-1} \mathrm{~d}^{-1}\right)$

$k_{\text {eap }}(T)=$ second order rate for algae adsorbed species in water $\left(\left[\mathrm{mg} \mathrm{L}^{-1}\right]^{-1} \mathrm{~d}^{-1}\right)$

$k_{\text {epom }}(T)=$ second order rate for POM adsorbed species in water $\left(\left[\mathrm{mg} \mathrm{L}^{-1}\right]^{-1} \mathrm{~d}^{-1}\right)$

$k_{e p n}(T)=$ second order rate for solids adsorbed species in water $\left(\left[\mathrm{mg} \mathrm{L}^{-1}\right]^{-1} \mathrm{~d}^{-1}\right)$.

In CSM, the second-order rates are temperature dependent and are corrected using the AE. Activation energy values $\left(E_{a}\right)$ are needed for each chemical species.

\subsubsection{Transformations}

In an aquatic environment, chemical reactions can result in the removal of primary contaminants, while sometimes also creating secondary contaminants, (e.g., a parent chemical-daughter product sequence). In CSM the contaminants may be independent or they are allowed to transform into other species. This process is useful to estimate the persistence of contaminants, including their degradation products. Due to a lack of detailed process information, all transformation processes are grouped together in one model formulation. This is represented as a lumped 
transformation yield operating on the pool of the reactants with rate constants that can vary spatially. When two or more contaminants are modeled, linked transformations that convert one state variable into another can be calculated by specifying a pathway and transformation efficiency coefficient for each reaction process.

$$
S_{t r m}=\sum_{j} k_{j \rightarrow i}(T) Y_{j \rightarrow i} C_{T}^{j}
$$

where

$$
\begin{aligned}
S_{t r m}= & \text { total contaminant transformation }\left(\mu \mathrm{L} \mathrm{L}^{-1} \mathrm{~d}^{-1}\right) \\
j= & \text { species index that can be transformed into daughter products } \\
& \quad \text { (unitless) } \\
k_{j->i}(T)= & \text { transformation reaction rate }\left(\mathrm{d}^{-1}\right) \\
Y_{j->i}= & \text { transformation yield coefficient from species } j \text { to } i(\mathrm{~g}-\mathrm{i} / \mathrm{g}-\mathrm{j}) .
\end{aligned}
$$

In a simulation, the contaminant can undergo several chemical transformations. Any combinations of contaminant transformations between two state variables can be modeled in CSM for the water column and sediment layer. Transformation processes include degradation, hydrolysis, photolysis and generalized second-order reaction. Yield rate coefficients can be applied at varying strengths.

\subsection{Contaminant air deposition, settling and sedimentation}

\subsubsection{Air deposition}

Contaminants may be added to a water body by both wet and dry atmospheric deposition. A user defined load is used to describe the atmospheric deposition in CSM.

$$
S_{a t m}=10^{3} A_{s} L_{0}
$$

where

$$
\begin{aligned}
S_{a t m} & =\text { contaminant air deposition }\left(\mu \mathrm{g} \mathrm{L}^{-1} \mathrm{~d}^{-1}\right) \\
A_{s} & =\text { surface water area }\left(\mathrm{m}^{-2}\right) \\
L_{o} & =\text { areal deposition of contaminant }\left(\mathrm{g} \mathrm{m}^{-2} \mathrm{~d}^{-1}\right) .
\end{aligned}
$$

Contaminant concentrations in air and rain can be obtained from monitoring and then converted into loads. The wet deposition load is 
calculated by multiplying the precipitation amount by the contaminant concentration in the rain. The dry deposition load is the product of the deposition velocity and the air concentration of the contaminant.

\subsubsection{Settling}

The settling and erosion of sediments and associated contaminants are two important processes in water quality modeling. When adsorbed on suspended solids, contaminants can be carried to the sediments by solids settling from the water column, possibly becoming a part of the bed sediment. The settling of contaminants is coupled to the settling of suspended solids. In CSM, the settling rate of the contaminant $\left(\mathrm{g} \mathrm{m}^{-3} \mathrm{~d}^{-1}\right)$ is calculated as the production of the settling velocity and the adsorbed phase concentration in the water column

$$
S_{\text {set }}=\frac{1}{h} \sum_{i}\left(\sum_{n=1}^{N} v_{s p n} f_{p n}^{i}+v_{\text {sap }} f_{a p}^{i}+v_{\text {som }} f_{\text {pom }}^{i}\right) C_{T}^{i}
$$

where

$$
\begin{aligned}
S_{\text {set }} & =\text { contaminant settling }\left(\mu \mathrm{L} \mathrm{L}^{-1} \mathrm{~d}^{-1}\right) \\
v_{\text {spn }} & =\text { solids settling velocity }\left(\mathrm{m} \mathrm{d}^{-1}\right) \\
v_{\text {sap }} & =\text { algae settling velocity }\left(\mathrm{m} \mathrm{d}^{-1}\right) \\
v_{\text {som }} & =\text { POM settling velocity }\left(\mathrm{m} \mathrm{d}^{-1}\right)
\end{aligned}
$$

Settling of suspended solids results in adsorbed contaminants being subtracted from the water column. Although a constant sediment layer is assumed in CSM, its position relative to the sediment-water interface changes as additional material is deposited on the bed. Thus, deposition of solids from the water column results in older sediments moving further from the sediment-water interface.

\subsubsection{Re-suspension}

The sediment erosion and re-suspension processes bring solids and attached contaminants from the bed sediment to the water column. The resuspension results in older sediments moving toward the sediment-water interface. Because erosion and re-suspension rates are highly variable in space and time, contaminant fluxes due to the erosion and re-suspension of solids with their attached contaminants are also highly variable in space and time. In CSM, the chemical composition of the re-suspending sediment is 
assumed to be the same as that of the bed sediment. The re-suspension rate of the contaminant $\left(\mathrm{g} \mathrm{m}^{-3} \mathrm{~d}^{-1}\right)$ is calculated based on the rate at which sediment particles are eroded (resuspended)

$$
S_{\text {res }}=\frac{1}{h_{2}} \sum_{i}\left(\sum_{n=1}^{N} v_{r p n} f_{p n 2}^{i}\right) C_{T 2}^{i}
$$

where

$$
\begin{aligned}
S_{r e s} & =\text { contaminant re-suspension }\left(\mu \mathrm{g} \mathrm{L}^{-1} \mathrm{~d}^{-1}\right) \\
h_{2} & =\text { thickness of active sediment layer }(\mathrm{m}) \\
v_{r p n} & =\text { re-suspension velocity }\left(\mathrm{m} \mathrm{d}^{-1}\right) .
\end{aligned}
$$

The settling and re-suspension processes of contaminants are assumed to operate on all particulate fractions of contaminants. Solids adsorbed contaminant mass migrates according to the migration of the solids classes. The amount of chemical mass associated with each solids class is computed from partitioning relationships, and the mass of each adsorbed chemical. This is distributed in the same manner as the solids, (e.g., deposition, re-suspension, and sediment layer redistribution).

\subsubsection{Sediment burial}

Since a constant sediment layer is simulated in CSM, the burial of contaminants adsorbed on sediment solids results from net settling at the sediment-water interface. The burial rate of sediment contaminants is calculated as the production of the burial velocity and the adsorbed phase concentration in the sediment layer

$$
S_{b}=\frac{1}{h_{2}} \sum_{i} v_{b}\left(\sum_{n=1}^{N} f_{p n 2}^{i}+f_{\text {pom } 2}^{i}\right) C_{T 2}^{i}
$$

where

$$
\begin{aligned}
& S_{b}=\text { contaminant sediment burial }\left(\mu \mathrm{g} \mathrm{L}^{-1} \mathrm{~d}^{-1}\right) \\
& v_{b}=\text { sediment burial velocity }\left(\mathrm{m} \mathrm{d}^{-1}\right) .
\end{aligned}
$$

\subsubsection{Sediment-water transfer}

Dissolved contaminants may be exchanged between sediment and overlying water by means of several processes. The sediment-water 
transfer of contaminants is primarily due to sediment erosion, deposition, diffusion and bioturbation. In general, they occur more or less simultaneously and there are several interactions among them. In CSM, the sediment-water interaction and transfer of contaminants are modeled using with a simplified approach. The overall mass transfer coefficient is applied to calculate a diffusion flux proportional to a concentration gradient across the sediment-water interface.

$$
S_{s w}=\frac{v_{m}}{h_{2}} \sum_{i}\left(C_{d 2}^{i} / \varphi-C_{d}^{i}\right)
$$

where

$$
\begin{aligned}
S_{s w} & =\text { contaminant sediment-water transfer }\left(\mu \mathrm{g} \mathrm{L}^{-1} \mathrm{~d}^{-1}\right) \\
v_{m} & =\text { sediment-water transfer velocity }\left(\mathrm{m} \mathrm{d}^{-1}\right) .
\end{aligned}
$$

The sediment-water transfer velocity is either specified as a constant input parameter or computed using empirical formulations. A theoretical model based on the well-known resistance in-series concepts for chemical transport between phases was proposed by several researchers (e.g., Thibodeaux et al. 2001; Erickson et al. 2005). The in-bed process on the sediment side is predominantly particle bio diffusion. Whereas, that on the water side is based on the well-known benthic boundary layer masstransport coefficient concept. Desorption occurs from a particle-bound state into solution at the interface. Individually, these processes have a sound theoretical basis, with numerous observational data sets both in laboratory studies and in the field. Figure 5. illustrates the chemical release pathway from the sediment.

Four equations are implemented in CSM for computing the sedimentwater transfer of the contaminant: 1) Thibodeaux et al. (2001), 2) Di Toro et al. (1981), 3) Boyer et al. (1994), and 4) Schink and Guinasso (1977).

The first equation is Thibodeaux et al. (2001) who gives the following equation to calculate the mass transfer velocity from bed sediment

$$
v_{m}=\frac{1}{\frac{z_{2}}{D_{b} \rho_{b} K_{d 2}}+\frac{1}{v_{m s}}}
$$

where 
$D_{b}=$ biodiffusion coefficient representing particle diffusivity $\left(\mathrm{m}^{2} \mathrm{~d}^{-1}\right)$

$\rho b=$ sediment bulk density $\left(\mathrm{g} \mathrm{cm}^{-3}\right)$

$v_{m s}=$ user-defined sediment-water transfer velocity $\left(\mathrm{m} \mathrm{d}^{-1}\right)$

$z_{2}=$ sediment bioturbation layer thickness $(\mathrm{m})$.

Figure 5. Schematic representation for soluble chemical release from bed sediment.

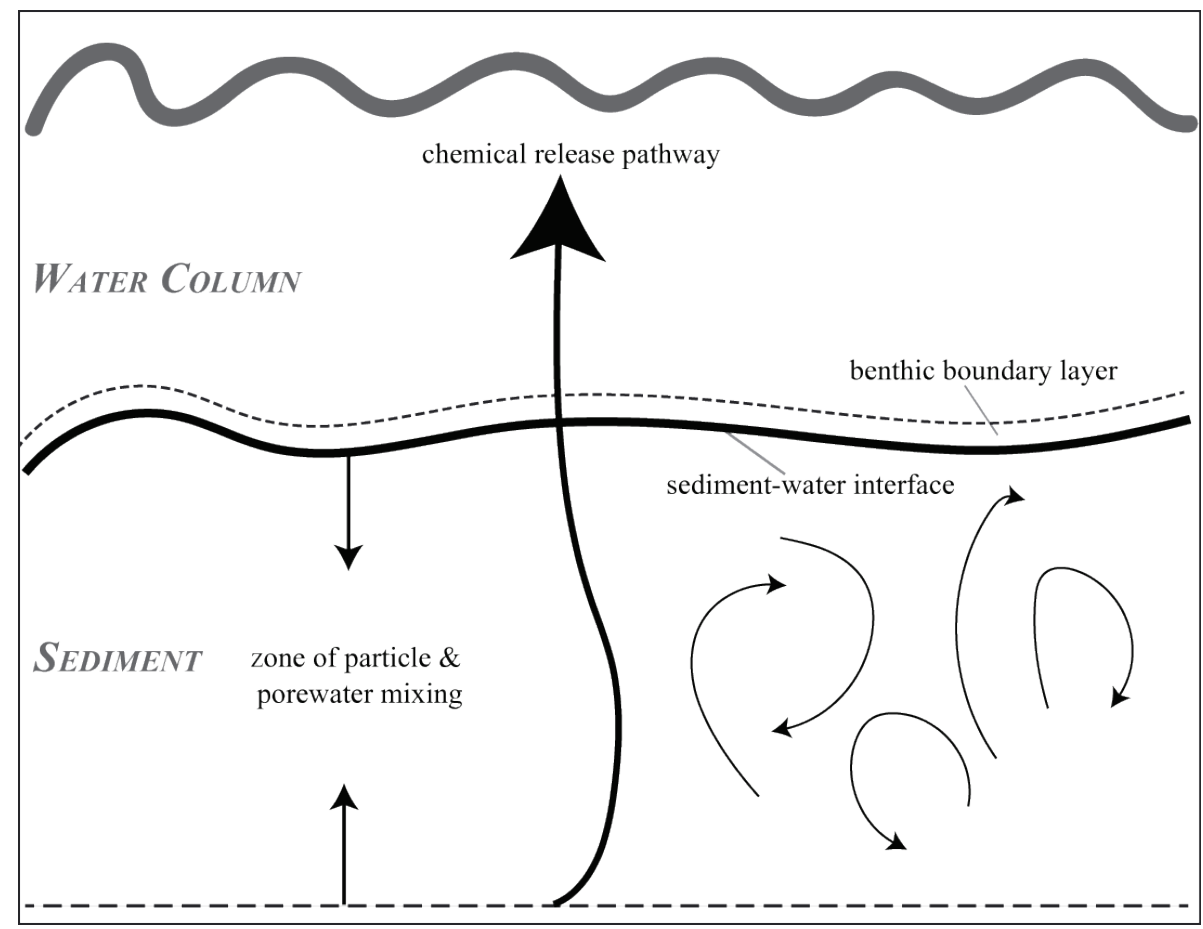

In this equation, the concentration gradient across the sediment-water interface is affected by the sediment adsorption. The second equation is based on the one given by Di Toro et al. (1981). The sediment-water masstransfer velocity is defined as a function of the molecular weight of the constituent and the sediment porosity.

$$
v_{m}=0.19 \varphi(M W)^{2 / 3}
$$

The third equation is determined from a sediment diffusion coefficient where $z_{1}$ is the thickness of the pore water diffusion layer (Boyer et al. 1994)

$$
v_{m}=\frac{\varphi^{3} D_{m}}{z_{1}}
$$

where 


$$
\begin{aligned}
D_{m} & =\text { molecular diffusion coefficient }\left(\mathrm{m}^{2} \mathrm{~d}^{-1}\right) \\
Z_{1} & =\text { pore water diffusion layer thickness }(=0.01 \mathrm{~m})
\end{aligned}
$$

The fourth equation is given by Schink and Guinasso (1977)

$$
v_{m}=8.64 \times 10^{4} \frac{u_{*}\left(D_{m} / v\right)^{2 / 3}}{24}
$$

where

$$
\begin{aligned}
u^{*}= & \text { flow shear velocity along the bed, which is approximately } 10 \\
& \text { percent of the mean velocity of flow }\left(\mathrm{m} \mathrm{s}^{-1}\right) \\
v= & \text { kinematic viscosity of water }\left(\mathrm{m}^{2} \mathrm{~d}^{-1}\right) .
\end{aligned}
$$

\subsection{Environmental factors}

It is known that environmental properties such as $\mathrm{pH}$, water temperature, microbial population, light attenuation, and organic and inorganic solids influence the the reactions and transformations of the contaminants modeled in the aquatic environment. For example, water temperature affects most reaction coefficients and kinetic rates. Also, $\mathrm{pH}$ values are important to ionization and hydrolysis reactions, their chemical speciation is directly affected by $\mathrm{pH}$. Adorption is associated with organic and inorganic solids. These environmental properties are important forcing functions for computing the transport and fate of contaminants. These properties often vary significantly with space and time. Table 5 provides a list of environmental variables and affected contaminant processes in CSM.

Table 5. List of environmental dependent variables and affected processes in CSM.

\begin{tabular}{|l|l|l|l|}
\hline Symbol & Definition & Units & Affected Process \\
\hline$T_{\mathrm{w}}$ & Water temperature & ${ }^{\circ} \mathrm{C}$ & All in water column \\
\hline $\mathrm{T}_{\text {sed }}$ & Sediment temperature & ${ }^{\circ} \mathrm{C}$ & All in sediment \\
\hline $\mathrm{l}_{0}$ & Solar radiation at the water surface & $\mathrm{W} \mathrm{m}-2$ & Photolysis \\
\hline$\lambda$ & Light extinction coefficient & $\mathrm{m}^{-1}$ & Photolysis \\
\hline $\mathrm{pH}$ & $\mathrm{pH}$ & - & lonization, Hydrolysis \\
\hline $\mathrm{DOC}$ & Dissolved organic carbon & $\mathrm{mg}-\mathrm{C} \mathrm{L}^{-1}$ & Partitioing \\
\hline $\mathrm{DOC} 2$ & Sediment dissolved organic carbon & $\mathrm{mg}-\mathrm{C} \mathrm{L}^{-1}$ & Partitioing \\
\hline$A_{\mathrm{pd}}$ & Algal biomass & $\mathrm{mg}-\mathrm{D} \mathrm{L}^{-1}$ & Partitioing \\
\hline $\mathrm{POM}^{-1}$ & Particulate organic matter & $\mathrm{mg}-\mathrm{D} \mathrm{L}^{-1}$ & Partitioing \\
\hline $\mathrm{POM}_{2}$ & Sediment particulate organic matter & $\mathrm{mg}-\mathrm{D} \mathrm{L}^{-1}$ & Partitioing \\
\hline
\end{tabular}




\begin{tabular}{|l|l|l|l|}
\hline Symbol & Definition & Units & Affected Process \\
\hline $\mathrm{L}_{0}$ & Deposition load & $\mathrm{g} \mathrm{m}^{-2} \mathrm{yr}^{-1}$ & - \\
\hline $\mathrm{V}_{\mathrm{spn}}$ & Solids settling velocity & $\mathrm{m} \mathrm{d}^{-1}$ & Settling \\
\hline $\mathrm{V}_{\mathrm{rpn}}$ & Solids re-suspension velocity & $\mathrm{m} \mathrm{d}^{-1}$ & Re-suspension \\
\hline $\mathrm{V}_{\mathrm{b}}$ & Sediment burial velocity & $\mathrm{m} \mathrm{d}^{-1}$ & Burial \\
\hline
\end{tabular}

The dependent variables listed above must be specified either from observed data or generated from other modules before the CSM can be employed. Most of them can be computed from the GC module as described in this report and NSM modules as described in Zhang and Johnson (2016). For example, NSMI (nutrient simulation module I) can be used to compute Apd, POM, POM2, DOC, $\lambda$, and pH listed above. The NSMI module does not explicitly compute pore water concentrations of DOC in the sediment layer, which must be defined.

The three most important sediment processes associated with water quality modeling are settling, re-suspension or "erosion," and "burial" of sediment. Adsorbed contaminants can settle to the bottom with suspended solids and algae. Contaminated sediments may be re-suspended into the water column. Their fates are controlled by hydraulic factors (e.g., flow, sediment transport), and depend strongly on the sediment size fractionation (e.g., clay, silt, sand and gravel). Relatively simple sediment algorithms for calculating settling, re-suspension, and burial of sediment particles have been incorporated directly into the GC module discussed in the previous chapter. The GC module computes water column and sediment bed concentrations of cohesive and non-cohesive solids, water column settling rates, deposition and re-suspension of solids between the water column and sediment bed.

\subsection{Water column contaminant source/sink equations}

The pathways modeled for each contaminant are depicted in Figure 2. Major physical processes simulated in CSM are particulate settling, resuspension, and sediment-water diffusion of contaminants. In addition, CSM has options for simulating the following kinetic processes: multi-phase partitioning, ionization, sorption, degradation, hydrolysis, photolysis, volatilization, and transformations. They can all be included into the source and sink term in the transport and mass balance equation. For each simulation time step, the CSM computes the rate changes of contaminant concentrations due to internal sources and sinks. 
A well-mixed water column with an underlying sediment layer is assumed for the source and sink equations. Concentrations in these equations, including those for sediment contaminants, are expressed in terms of mass per unit volume of water plus solids $\left(\mu \mathrm{g} \mathrm{L}^{-1}\right)$. The method employed here is numerically equivalent and simpler because all the state variables are in the same units, and no correction term is needed in the transport equations. Furthermore, this method is more amenable to integration with $\mathrm{H} \& \mathrm{H}$ transport models, for which the common concentration units are mass per unit volume.

\subsubsection{Equilibrium partitioning}

In CSM, the source (+) and sink (-) terms of water column contaminant under equilibrium partitioning implementation are computed for the total concentration and are listed in Table 6.

\subsubsection{Non-equilibrium partitioning}

Under non-equilibrium partitioning implementation, the concentrations of dissolved and adsorbed phases of the contaminant are dependent of each other. The state variables for a contaminant must include concentrations of potential phases. The source (+) and sink (-) terms of the contaminant are computed in CSM for each contaminant dissolved in water, adsorbed to DOC, algae, POM and solids and are listed in Table 7. The first step in modeling a contaminant with non-equilibrium partitioning is to determine the concentration of the contaminant in each phase. The transport equation describing the mass balance of a contaminant with non-equilibrium partioning must also be developed for each individual phase and solved simultaneously.

Table 6. Water column total contaminant source/sink terms and pathways under equilibrium partitioning.

\begin{tabular}{|l|l|}
\hline Source/Sink term* & Pathway \\
\hline$S S_{T}=$ & \\
\hline$+10^{3} A_{s} L_{0}$ & Air deposition \\
\hline$-\frac{1}{h} \sum_{i}\left(v_{s a p} f_{a p}^{i}+v_{s o m} f_{p o m}^{i}+\sum_{n=1}^{N} v_{s p n} f_{p n}^{i}\right) C_{T}^{i}$ & Settling \\
\hline$+\frac{1}{h} \sum_{i}\left(\sum_{n=1}^{N} v_{r n} f_{p n 2}^{i}\right) C_{T 2}^{i}$ & Re-suspension \\
\hline$+\frac{v_{m}}{h} \sum_{i}\left(\left(f_{d 2}^{i}+f_{d o c 2}^{i}\right) C_{T 2}^{i} / \phi-\left(f_{d}^{i}+f_{d o c}^{i}\right) C_{T}^{i}\right)$ & Water-sediment transfer \\
\hline
\end{tabular}




\begin{tabular}{|c|c|}
\hline Source/Sink term* & Pathway \\
\hline$-\sum_{i}\left[k_{1 d}^{i}(T) f_{d}^{i}+k_{1 d o c}^{i}(T) f_{d o c}^{i}+k_{1 a p}^{i}(T) f_{a p}^{i}+k_{1 p o m}^{i}(T) f_{p o m}^{i}+\sum_{n=1}^{N} k_{1 p n}^{i}(T) f_{p n}^{i}\right] C_{T}^{i}$ & Degradation \\
\hline$-\sum_{i}\left\{\left(k_{h a}^{i}(T)\left[H^{+}\right]+k_{h n}^{i}(T)+k_{h b}^{i}(T)\left[O H^{-}\right]\right) f_{d}^{i}+\left(\begin{array}{l}k_{\text {hadoc }}^{i}(T)\left[H^{+}\right]+k_{h n d o c}^{i}(T) \\
+k_{h b d o c}^{i}(T)\left[O H^{-}\right]\end{array}\right) f_{d o c}^{i}\right\} C_{T}^{i}$ & Hydrolysis \\
\hline$-1.33 \frac{I_{0}}{I_{0 \mathrm{pht}}} \frac{1-e^{-\lambda_{\max } \cdot h}}{\lambda_{\max } \cdot h}\left(1-0.56 C_{L}\right) \sum_{i}\left(k_{p h t}^{i}(T) f_{d}^{i}+k_{p h t d o c}^{i}(T) f_{d o c}^{i}\right) C_{T}^{i}$ & Photolysis \\
\hline$-\frac{1}{h} v_{v}(T)\left(f_{d} C_{T}-\frac{C_{0}}{K_{H} / R T_{k}}\right)$ & Volatilization \\
\hline$-\sum_{i}\left[k_{e d}^{i}(T) f_{d}^{i}+k_{e d o c}^{i}(T) f_{d o c}^{i}+k_{\text {eap }}^{i}(T) f_{a p}^{i}+k_{\text {epom }}^{i}(T) f_{p o m}^{i}+\sum_{n=1}^{N} k_{e p n}^{i}(T) f_{p n}^{i}\right] C_{T}^{i}[E]$ & $\begin{array}{l}\text { Generalized second-order } \\
\text { reaction }\end{array}$ \\
\hline$+\sum_{j} k_{j \rightarrow t}(T) Y_{j \rightarrow i} C_{T}^{j}$ & Total transformations \\
\hline
\end{tabular}

* $S S_{T}$ is the sum of internal source and sink terms of total contaminant in water $\left(\mu g \mathrm{~L}^{-1} \mathrm{~d}^{-1}\right)$.

Table 7. Water column contaminant partitioning phase source/sink terms and pathways under non-equilibrium partitioning.

\begin{tabular}{|c|c|}
\hline Source/Sink term* & Pathway \\
\hline \multicolumn{2}{|c|}{ Dissolved phase } \\
\hline$S S_{d}=$ & \\
\hline$+10^{3} A_{s} L_{0}$ & Air deposition \\
\hline$+\frac{1}{h} v_{m}\left(C_{d 2} / \phi-C_{d}\right)$ & Water-sediment transfer \\
\hline$-k_{1 d}(T) C_{d}$ & Degradation \\
\hline$-\left(k_{h a}(T)\left[H^{+}\right]+k_{h n}(T)+k_{h b}(T)\left[O H^{-}\right]\right) C_{d}$ & Hydrolysis \\
\hline$-1.33 \frac{I_{0}}{I_{0 \mathrm{pht}}} \frac{1-e^{-\lambda_{\max } \cdot h}}{\lambda_{\max } \cdot h}\left(1-0.56 C_{L}\right) k_{p h t}(T) C_{d}$ & Photolysis \\
\hline$-\frac{1}{h} v_{v}(T)\left(C_{d}-\frac{C_{0}}{K_{H} / R T_{k}}\right)$ & Volatilization \\
\hline$-k_{e d}(T) C_{d}[E]$ & Generalized second-order reaction \\
\hline$+\sum_{j} k_{j \rightarrow i}(T) Y_{j \rightarrow i} C_{d}^{j}$ & Total transformations \\
\hline
\end{tabular}




\begin{tabular}{|c|c|}
\hline Source/Sink term* & Pathway \\
\hline $\begin{array}{l}-k_{\text {adap }}(T) C_{d}\left(10^{-3} q_{\text {cap }} A_{p d}-C_{a p}\right)+k_{\text {daap }}(T) C_{a p} \\
-k_{\text {adpom }}(T) C_{d}\left(10^{-3} q_{c p o m} P O M-C_{p o m}\right)+k_{d a p o m}(T) C_{p o m} \\
-\sum_{n=1}^{N}\left[k_{a d n}(T) C_{d}\left(10^{-3} q_{c n} m_{n}-C_{p n}\right)-k_{d a n}(T) C_{p n}\right]\end{array}$ & Adsorption-desorption \\
\hline \multicolumn{2}{|c|}{ DOC adsorbed phase } \\
\hline \multicolumn{2}{|l|}{$S S_{d o c}=$} \\
\hline$+\frac{1}{h} v_{m}\left(C_{d o c 2} / \phi-C_{d o c}\right)$ & Water-sediment transfer \\
\hline$-k_{1 d o c}(T) C_{d o c}$ & Degradation \\
\hline$-\left(k_{\text {hadoc }}(T)\left[H^{+}\right]+k_{\text {hndoc }}(T)+k_{\text {hbdoc }}(T)\left[O H^{-}\right]\right) C_{d o c}$ & Hydrolysis \\
\hline$-1.33 \frac{I_{0}}{I_{0 \mathrm{pht}}} \frac{1-e^{-\lambda_{\max } \cdot h}}{\lambda_{\max } \cdot h}\left(1-0.56 C_{L}\right) k_{p h t d o c}(T) C_{d o c}$ & Photolysis \\
\hline$-k_{\text {edoc }}(T) C_{d o c}[E]$ & Generalized second-order reaction \\
\hline \multicolumn{2}{|c|}{ Algae adsorbed phase } \\
\hline \multicolumn{2}{|l|}{$S S_{a p}=$} \\
\hline$-\frac{1}{h} v_{s a p} C_{a p}$ & Settling \\
\hline$-k_{1 a p}(T) C_{a p}$ & Degradation \\
\hline$-k_{\text {eap }}(T) C_{a p}[E]$ & Generalized second-order reaction \\
\hline$+k_{\text {adap }}(T) C_{d}\left(10^{-3} q_{c a p} A_{p d}-C_{a p}\right)-k_{\text {daap }}(T) C_{a p}$ & Adsorption-desorption \\
\hline \multicolumn{2}{|c|}{ POM adsorbed phase } \\
\hline \multicolumn{2}{|l|}{$S S_{p o m}=$} \\
\hline$-\frac{1}{h} v_{\text {som }} C_{p o m}$ & Settling \\
\hline$-k_{1 p o m}(T) C_{p o m}$ & Degradation \\
\hline$-k_{\text {epom }}(T) C_{\text {pom }}[E]$ & Generalized second-order reaction \\
\hline$+k_{\text {adpom }}(T) C_{d}\left(10^{-3} q_{\text {cpom }} P O M-C_{p o m}\right)-k_{\text {dapom }}(T) C_{\text {pom }}$ & Adsorption-desorption \\
\hline \multicolumn{2}{|c|}{ Solids adsorbed phase } \\
\hline$S S_{p n}=$ & \\
\hline$-\frac{1}{h} v_{s p n} C_{p n}$ & Settling \\
\hline$+\frac{1}{h} v_{r n} C_{p n 2}$ & Re-suspension \\
\hline
\end{tabular}




\begin{tabular}{|l|l|}
\hline Source/Sink term* & Pathway \\
\hline$-k_{1 p n}(T) C_{p n}$ & Degradation \\
\hline$-k_{e p n}(T) C_{p n}[E]$ & Generalized second-order reaction \\
\hline$+k_{a d n}(T) C_{d}\left(10^{-3} q_{c n} m_{n}-C_{p n}\right)-k_{d a n}(T) C_{p n}$ & Adsorption-desorption \\
\hline
\end{tabular}

${ }^{*} S_{d}$ is the sum of internal source and sink terms of dissolved phase in water $\left(\mu \mathrm{g}^{-1} \mathrm{~d}^{-1}\right)$.

$\mathrm{SS}_{d o c}$ is the sum of internal source and sink terms of DOC adsorbed phase in water $\left(\mu \mathrm{g} \mathrm{L}^{-1} \mathrm{~d}^{-1}\right)$.

$\mathrm{SS}_{a p}$ is the sum of internal source and sink terms of algae adsorbed phase in water $\left(\mu \mathrm{L}^{-1} \mathrm{~d}^{-1}\right)$.

$\mathrm{SS}_{\text {pom }}$ is the sum of internal source and sink terms of POM adsorbed phase in water $\left(\mu \mathrm{g} \mathrm{L}^{-1} \mathrm{~d}^{-1}\right)$.

$S S_{p n}$ is the sum of internal source and sink terms of solids adsorbed phase in water $\left(\mu \mathrm{g} \mathrm{L}^{-1} \mathrm{~d}^{-1}\right)$.

\subsection{Sediment contaminant mass balance equations}

The sediment layer is envisioned as a single, well-mixed layer (Figure 1). The sediment layer is assumed to have constant thickness, volume, and porosity. The sediment layer gains mass through deposition, but loses it through re-suspension as well as sediment burial. As the active sediment layer accepts a new sediment increment on the top, an equal amount is removed from the bottom for burial. When sediment re-suspension occurs, it is assumed that deeper sediments below the active layer are entrained into the active layer and mixed with the remaining sediments.

Similar to the water column, contaminant kinetics in the sediment layer include partitioning, chemical reactions, and transformations.

Contaminants in the sediment layer are partitioned into those that are freely dissolved in pore waters and those that are adsorbed to DOC, organic and inorganic solids. The one exception is the assumption that algae do not exist. The chemical reactions and transformations in the sediment layer are largely based on the same processes applied in the water column. However, contaminant volatilization and aquatic photolysis are ignored for the sediment layer. The description of most water column algorithms provided above applies for the sediment layer as well. The differences come into play via the parameters used for the reactions.

In CSM, the transport of contaminants in the sediment layer is simulated basically as two separate procedures. One procedure accounts for changes in the mass of contaminants within the bed as affected by deposition, resuspension, and deep burial. This procedure involves mostly particulate chemicals, which are added through settling, and lost through resuspension and burial. The other procedure solves for pore water transport of the dissolved contaminants (water and DOC adsorbed phases). The effects of both procedures are combined with the biochemical reactions to 
determine the changes of total concentration in the sediment layer. The coupling between the water column and sediment layer is performed explicitly using internal source and sink terms. The equation presented here assumes a well-mixed sediment layer with an overlying water column.

\subsubsection{Equilibrium partitioning}

Under equilibrium partitioning implementation, the source (+) and sink $(-)$ terms of the sediment contaminant are computed in CSM for the total concentration (per unit volume of sediment) and are listed in Table 8.

Table 8. Sediment total contaminant source/sink terms and pathways under equilibrium partitioning.

\begin{tabular}{|c|c|}
\hline Source/Sink terms* & Pathway \\
\hline \multicolumn{2}{|l|}{$S S_{T 2}=$} \\
\hline$+\frac{1}{h_{2}} \sum_{i}\left(v_{s a p} f_{a p}^{i}+v_{s o m} f_{p o m}^{i}+\sum_{n=1}^{N} v_{s p n} f_{p n}^{i}\right) C_{T}^{i}$ & Deposition \\
\hline$-\frac{1}{h_{2}} \sum_{i}\left(\sum_{n=1}^{N} v_{r p n} f_{p n 2}^{i}\right) C_{T 2}^{i}$ & Re-suspension \\
\hline$-\frac{1}{h_{2}} \sum_{i} v_{b}\left(f_{\text {pom } 2}^{i}+\sum_{n=1}^{N} f_{p n 2}^{i}\right) C_{T 2}^{i}$ & Deep burial \\
\hline$-\frac{v_{m}}{h_{2}} \sum_{i}\left(\left(f_{d 2}^{i}+f_{d o c 2}^{i}\right) C_{T 2}^{i} / \phi-\left(f_{d}^{i}+f_{d o c}^{i}\right) C_{T}^{i}\right)$ & Water-sediment transfer \\
\hline$-\sum_{i}\left[k_{1 d 2}^{i}(T) f_{d 2}^{i}+k_{1 d o c 2}^{i}(T) f_{d o c 2}^{i}+k_{1 p o m 2}^{i}(T) f_{p o m 2}^{i}+\sum_{n=1}^{N} k_{1 p n 2}^{i}(T) f_{p n 2}^{i}\right] C_{T 2}^{i}$ & Degradation \\
\hline$-\sum_{i}\left\{\begin{array}{l}\left(k_{h a 2}^{i}(T)\left[H^{+}\right]+k_{h n 2}^{i}(T)+k_{h b 2}^{i}(T)\left[O H^{-}\right]\right) f_{d 2}^{i}+ \\
\left(k_{h a d o c 2}^{i}(T)\left[H^{+}\right]+k_{h n d o c 2}^{i}(T)+k_{h b d o c 2}^{i}(T)\left[O H^{-}\right]\right) f_{d o c 2}^{i}\end{array}\right\} C_{T 2}^{i}$ & Hydrolysis \\
\hline$-\sum_{i}\left[k_{e d 2}^{i}(T) f_{d 2}^{i}+k_{e d o c 2}^{i}(T) f_{d o c 2}^{i}+k_{\text {epom } 2}^{i}(T) f_{\text {pom } 2}^{i}+\sum_{n=1}^{N} k_{e p n 2}^{i}(T) f_{p n 2}^{i}\right] C_{T 2}^{i}\left[E_{2}\right]$ & $\begin{array}{l}\text { Generalized second-order } \\
\text { reaction }\end{array}$ \\
\hline$+\sum_{j} k_{2 j \rightarrow i}(T) Y_{2 j \rightarrow i} C_{T 2}^{j}$ & Total transformations \\
\hline
\end{tabular}

* SST2 is the sum of source and sink terms of total contaminant concentration in sediment $\left(\mu g \mathrm{~L}^{-1} \mathrm{~d}^{-1}\right)$.

\subsubsection{Non-equilibrium partitioning}

With non-equilibrium partitioning implementation, the source (+) and sink (-) terms of the sediment contaminant are computed in CSM for each contaminant dissolved in pore water, adsorbed to DOC, POM and solids (again per unit volume of sediment) and are listed in Table 9. 
Table 9. Sediment contaminant partitioning phase source/sink terms and pathways under nonequilibrium partitioning.

\begin{tabular}{|c|c|}
\hline Source/Sink term* & Pathway \\
\hline \multicolumn{2}{|l|}{ Dissolved phase } \\
\hline \multicolumn{2}{|l|}{$S S_{d 2}=$} \\
\hline$-\frac{v_{m}}{h_{2}}\left(\frac{C_{d 2}}{\phi}-C_{d}\right)$ & Water-sediment transfer \\
\hline$-k_{1 d 2}(T) C_{d 2}$ & Degradation \\
\hline$-\left(k_{h a 2}(T)\left[H^{+}\right]+k_{h n 2}(T)+k_{h b 2}(T)\left[O H^{-}\right]\right) C_{d 2}$ & Hydrolysis \\
\hline$-k_{e d 2}(T) C_{d 2}\left[E_{2}\right]$ & $\begin{array}{l}\text { Generalized second-order } \\
\text { reaction }\end{array}$ \\
\hline$+\sum_{j} k_{2 j \rightarrow i}(T) Y_{2 j \rightarrow i} C_{d 2}^{j}$ & Total transformations \\
\hline $\begin{array}{l}-k_{\text {adpom } 2}(T) \frac{C_{d 2}}{\phi}\left(10^{-3} q_{\text {cpom } 2} P O M_{2}-C_{p o m 2}\right)+k_{\text {dapom } 2}(T) C_{p o m 2} \\
-\sum_{n=1}^{N}\left[k_{a d n 2}(T) \frac{C_{d 2}}{\phi}\left(10^{-3} q_{c p n 2} m_{n 2}-C_{p n 2}\right)-k_{d a n 2}(T) C_{p n 2}\right]\end{array}$ & Adsorption-desorption \\
\hline \multicolumn{2}{|l|}{ DOC adsorbed phase } \\
\hline \multicolumn{2}{|l|}{$S S_{d o c 2}=$} \\
\hline$-\frac{v_{m}}{h_{2}}\left(C_{d o c 2} / \phi-C_{d o c}\right)$ & Water-sediment transfer \\
\hline$-k_{1 d o c 2}(T) C_{d o c 2}$ & Degradation \\
\hline$-\left(k_{\text {hadoc } 2}(T)\left[H^{+}\right]+k_{\text {hndoc } 2}(T)+k_{h b d o c 2}(T)\left[O H^{-}\right]\right) C_{d o c 2}$ & Hydrolysis \\
\hline$-k_{e d o c 2}(T) C_{d o c 2}\left[E_{2}\right]$ & $\begin{array}{l}\text { Generalized second-order } \\
\text { reaction }\end{array}$ \\
\hline \multicolumn{2}{|l|}{ POM adsorbed phase } \\
\hline \multicolumn{2}{|l|}{$S S_{\text {pom } 2}=$} \\
\hline$+\frac{1}{h_{2}}\left(v_{s a p} C_{a p}+v_{s o m} C_{p o m}\right)$ & Deposition \\
\hline$-\frac{1}{h_{2}} v_{b} C_{p o m 2}^{i}$ & Deep burial \\
\hline$-k_{1 p o m 2}(T) C_{p o m 2}$ & Degradation \\
\hline$-k_{\text {epom } 2}(T) C_{\text {pom } 2}\left[E_{2}\right]$ & $\begin{array}{l}\text { Generalized second-order } \\
\text { reaction }\end{array}$ \\
\hline$+k_{\text {adpom } 2}(T) \frac{C_{d 2}}{\phi}\left(10^{-3} q_{\text {cpom } 2} P O M_{2}-C_{\text {pom } 2}\right)-k_{\text {dapom } 2}(T) C_{p o m 2}$ & Adsorption-desorption \\
\hline
\end{tabular}




\begin{tabular}{|c|c|}
\hline Source/Sink term* & Pathway \\
\hline \multicolumn{2}{|c|}{ Solids adsorbed phase } \\
\hline$S S_{p n 2}=$ & \\
\hline$+\frac{1}{h_{2}} v_{s p n} C_{p n}$ & Deposition \\
\hline$-\frac{1}{h_{2}} v_{r p n} C_{p n 2}$ & Re-suspension \\
\hline$-\frac{1}{h_{2}} v_{b} C_{p n 2}$ & Deep burial \\
\hline$-k_{1 p n 2}(T) C_{p n 2}$ & Degradation \\
\hline$-k_{e p n 2}(T) C_{p n 2}\left[E_{2}\right]$ & $\begin{array}{l}\text { Generalized second-order } \\
\text { reaction }\end{array}$ \\
\hline$+k_{a d n 2}(T) \frac{C_{d 2}}{\phi}\left(10^{-3} q_{c n 2} m_{n 2}-C_{p n 2}\right)-k_{d a n 2}(T) C_{p n 2}$ & Adsorption-desorption \\
\hline
\end{tabular}

$* S S_{d 2}$ is the sum of source and sink terms of dissolved phase in sediment $\left(\mu \mathrm{g} \mathrm{L}^{-1} \mathrm{~d}^{-1}\right)$. $\mathrm{SS}_{d o c 2}$ is the sum of source and sink terms of DOC adsorbed phase in sediment $\left(\mu \mathrm{g} \mathrm{L}^{-1} \mathrm{~d}^{-1}\right)$. $S_{\text {pom2 } 2}$ is the sum of source and sink terms of POM adsorbed phase in sediment $\left(\mu \mathrm{g}^{-1} \mathrm{~d}^{-1}\right)$. $\mathrm{SS}_{p n 2}$ is the sum of source and sink terms of solids adsorbed phase in sediment $\left(\mu \mathrm{g} \mathrm{L}^{-1} \mathrm{~d}^{-1}\right)$.

\subsection{CSM parameters}

The CSM operates based on the schematization already set up for the $\mathrm{H} \& \mathrm{H}$ model and the flows computed by the H\&H model. Table 10 provides a list of the contaminant-specific input parameters needed to run the CSM model simulation when all options are turned on. Each contaminant may exist as a neutral compound and up to four ionic species. The neutral and ionic species can exist in multiple phases. CSM input parameters can be determined from field and laboratory experiments, or estimated using chemical properties and from the literature. Knowledge of a contaminant's chemical form and of the chemical's ability to be adsorbed, to be degraded, or reacted is necessary if the fate of the chemical is to be modeled accurately. Literature values were taken from a compilation of several studies. It gives a range of values for each of the parameters (if available). It should be noted that these values are based on a limited literature review. Most of them are model calibration parameters in real world applications.

This table will be repeated for each contaminant and each water quality region, allowing the user to define the different values for input parameters. In CSM, several simulation options are available and the required input parameters depend upon their selections. The complete 
mass balance approach involves adding a sediment layer to the computational grid. For the same contaminants and processes, different parameter values are allowed for the water column and sediment layer. All contaminant parameters can be specified as either a uniform constant, a single value for all water quality cells, or a spatially-varying value by userdefined water quality regions.

Table 10. List of CSM input parameters.

\begin{tabular}{|c|c|c|c|c|c|c|}
\hline \multicolumn{2}{|c|}{ Symbol } & Definition & $\begin{array}{l}\text { Typical } \\
\text { values }^{a}\end{array}$ & Units & \multicolumn{2}{|c|}{$\begin{array}{l}\text { Temperature } \\
\text { Correction }^{\mathrm{b}}\end{array}$} \\
\hline \multicolumn{7}{|c|}{ Global } \\
\hline \multicolumn{2}{|c|}{$M W$} & Molecular weight & $10-10^{3}$ & $\mathrm{~g} \mathrm{~mol}^{-1}$ & & \\
\hline \multicolumn{2}{|c|}{$C_{s d}$} & Solubility & $n / a$ & $\mu g \mathrm{~L}^{-1}$ & & \\
\hline \multicolumn{2}{|c|}{$D_{m}$} & Molecular diffusivity & $\mathrm{n} / \mathrm{a}$ & $m^{2} d^{-1}$ & & \\
\hline \multicolumn{2}{|c|}{$V m$} & Sediment-water mass transfer velocity & $\mathrm{n} / \mathrm{a}$ & $\mathrm{m} \mathrm{d}^{-1}$ & & \\
\hline \multicolumn{2}{|c|}{$h_{2}$} & Sediment layer thickness & $0.1-0.15$ & $\mathrm{~m}$ & & \\
\hline \multicolumn{2}{|c|}{$Z_{2}$} & Sediment bioturbation layer thickness & $0.05-0.1$ & $\mathrm{~m}$ & & \\
\hline \multicolumn{2}{|c|}{$V_{s s}$} & Solids settling velocity & - & $n / a$ & $\mathrm{~m} \mathrm{~d}^{-1}$ & \\
\hline \multicolumn{2}{|c|}{$V_{\text {som }}$} & Organic matter settling velocity & - & $n / a$ & $\mathrm{~m} \mathrm{~d}^{-1}$ & \\
\hline $\begin{array}{l}\text { Water } \\
\text { column }\end{array}$ & $\begin{array}{l}\text { Sediment } \\
\text { layer }\end{array}$ & & & & & \\
\hline \multicolumn{7}{|c|}{ Ionization } \\
\hline$K_{a 1}$ & $K_{a 12}$ & Ionization constant for anionic species & $n / a$ & unitless & $E_{a}$ & $n / a$ \\
\hline$K_{a 2}$ & $K_{a 22}$ & Ionization constant for anionic species & $n / a$ & unitless & $E_{a}$ & $n / a$ \\
\hline$K_{b 1}$ & $K_{b 12}$ & Ionization constant for cationic species & $n / a$ & unitless & $E_{a}$ & $\mathrm{n} / \mathrm{a}$ \\
\hline$K_{b 2}$ & $K_{b 22}$ & Ionization constant for cationic species & $\mathrm{n} / \mathrm{a}$ & unitless & $E_{a}$ & $n / a$ \\
\hline \multicolumn{7}{|c|}{ Equilibrium partitioning } \\
\hline$K_{d o c}$ & $K_{\text {doc2 }}$ & $\begin{array}{l}\text { Equilibrium partition coefficient for } \\
\text { DOC }\end{array}$ & $n / a$ & $\mathrm{~L} \mathrm{~kg}^{-1}$ & & \\
\hline$K_{p n}$ & $K_{p n 2}$ & $\begin{array}{l}\text { Equilibrium partition coefficient for } \\
\text { solid " } n \text { " }\end{array}$ & $10^{-1}-10^{5}$ & L kg-1 & & \\
\hline$f_{o c}$ & $f_{\text {oc2 }}$ & Fraction of organic carbon in solids & $\begin{array}{l}0.005- \\
0.5\end{array}$ & unitless & & \\
\hline$b$ & $b_{2}$ & Freundlich exponent & $\mathrm{n} / \mathrm{a}$ & unitless & & \\
\hline$K_{f}$ & $K_{f 2}$ & Freundlich adsorption constant & $n / a$ & $\begin{array}{l}\left(\mu g g^{-1}\right)(\mu g \\
\left.L^{-1}\right)^{-b}\end{array}$ & & \\
\hline$K_{l}$ & $K_{12}$ & Langmuir adsorption constant & $n / a$ & $\mathrm{~L} \mathrm{mg}^{-1}$ & & \\
\hline$q_{c n}$ & $q_{\mathrm{cn} 2}$ & Adsorption capacity for solid " $n$ " & $\mathrm{n} / \mathrm{a}$ & $\mu g g^{-1}$ & & \\
\hline Kow & - & Octanol-water partitioning coefficient & $n / a$ & unitless & & \\
\hline$\alpha_{d o c}$ & - & Partition correlation coefficient for DOC & 0.4 & unitless & & \\
\hline
\end{tabular}




\begin{tabular}{|c|c|c|c|c|c|c|}
\hline \multicolumn{2}{|c|}{ Symbol } & \multirow{2}{*}{$\begin{array}{l}\text { Definition } \\
\text { Partition correlation coefficient for } \\
\text { algae }\end{array}$} & \multirow{2}{*}{\begin{tabular}{|l|}
$\begin{array}{l}\text { Typical } \\
\text { values }\end{array}$ \\
n/a
\end{tabular}} & \multirow{2}{*}{$\begin{array}{l}\text { Units } \\
\text { unitless }\end{array}$} & \multicolumn{2}{|c|}{$\begin{array}{l}\text { Temperature } \\
\text { Correction }{ }^{\mathrm{b}}\end{array}$} \\
\hline$\alpha_{a p}$ & - & & & & & \\
\hline$\alpha_{p o m}$ & - & $\begin{array}{l}\text { Partition correlation coefficient for } \\
\text { POM }\end{array}$ & $n / a$ & unitless & & \\
\hline$\alpha_{p n}$ & - & $\begin{array}{l}\text { Partition correlation coefficient for } \\
\text { solids }\end{array}$ & $n / a$ & unitless & & \\
\hline \multicolumn{7}{|c|}{ Non-equilibrium partitioning } \\
\hline kadn & kadn2 & Adsorption coefficient & $n / a$ & $L \mu g^{-1} d^{-1}$ & & \\
\hline$k_{d a n}$ & $k_{\text {dan2 }}$ & Desorption rate & $n / a$ & $d^{-1}$ & & \\
\hline$q_{\mathrm{cn}}$ & $q_{\mathrm{cn} 2}$ & Adsorption capacity for solid "n" & $n / a$ & $\mu g g^{-1}$ & & \\
\hline \multicolumn{7}{|c|}{ Volatilization } \\
\hline$v_{v}(T)$ & - & Volatilization velocity & $0.6-25$ & $\mathrm{~m} \mathrm{~d}^{-1}$ & $\theta$ & $n / a$ \\
\hline$K_{H}$ & - & Henry's constant & $1-10^{7}$ & $\mathrm{~Pa} \mathrm{~m}^{3} \mathrm{~mol}^{-1}$ & & \\
\hline Cog & - & Air (gaseous) concentration & $0-1.0$ & $\mu g L^{-1}$ & & \\
\hline \multicolumn{7}{|c|}{ Photolysis } \\
\hline$k_{p h t}$ & - & $\begin{array}{l}\text { Aquatic photolysis rate for dissolved } \\
\text { phase }\end{array}$ & $0-10$ & $d^{-1}$ & & \\
\hline$k_{\text {phtdoc }}$ & - & $\begin{array}{l}\text { Aquatic photolysis rate for DOC } \\
\text { adsorbed phase }\end{array}$ & $0-10$ & $d^{-1}$ & & \\
\hline lopht & - & Light intensity when kpht is measured & $\mathrm{n} / \mathrm{a}$ & $W \mathrm{~m}^{-2}$ & & \\
\hline$\alpha_{l}$ & - & & $1.2-1.6$ & unitless & & \\
\hline \multicolumn{7}{|c|}{ Degradation } \\
\hline$n$ & & Degradation order & 1.0 & unitless & & \\
\hline$k_{1 d}(T)$ & $k_{1 d 2}(T)$ & Degradation rate for dissolved phase & $0-0.5$ & $d^{-1}$ & $\theta$ & $n / a$ \\
\hline$k_{1} \operatorname{doc}(T)$ & $k_{1 \operatorname{doc} 2}(T)$ & $\begin{array}{l}\text { Degradation rate for DOC adsorbed } \\
\text { phase }\end{array}$ & $0-0.5$ & $d^{-1}$ & $\theta$ & $n / a$ \\
\hline$k_{1 a p}(T)$ & & $\begin{array}{l}\text { Degradation rate for algae adsorbed } \\
\text { phase }\end{array}$ & $0-0.5$ & $d^{-1}$ & $\theta$ & $n / a$ \\
\hline$k_{1 p o m}(T)$ & $k_{1 p o m 2}(T)$ & $\begin{array}{l}\text { Degradation rate for POM adsorbed } \\
\text { phase }\end{array}$ & $0-0.5$ & $d^{-1}$ & $\theta$ & $n / a$ \\
\hline$k_{1 p}(T)$ & $k_{1 p 2}(T)$ & $\begin{array}{l}\text { Degradation rate for solids adsorbed } \\
\text { phase }\end{array}$ & $n / a$ & $d^{-1}$ & $\theta$ & $n / a$ \\
\hline \multicolumn{7}{|c|}{ Hydrolysis } \\
\hline$k_{h b}(T)$ & $k_{h b 2}(T)$ & $\begin{array}{l}\text { Alkaline hydrolysis rate of dissolved } \\
\text { phase }\end{array}$ & $0-10^{7}$ & $\mathrm{~m}^{3} \mathrm{~mol}^{-1} \mathrm{~d}^{-1}$ & $E_{a}$ & 75 \\
\hline
\end{tabular}




\begin{tabular}{|c|c|c|c|c|c|c|}
\hline \multicolumn{2}{|c|}{ Symbol } & \multirow{2}{*}{$\begin{array}{l}\text { Definition } \\
\text { Neutral hydrolysis rate of dissolved } \\
\text { phase }\end{array}$} & \multirow{2}{*}{\begin{tabular}{|l}
$\begin{array}{l}\text { Typical } \\
\text { values }^{a}\end{array}$ \\
$0-10^{2}$
\end{tabular}} & \multirow{2}{*}{$\begin{array}{l}\text { Units } \\
d^{-1}\end{array}$} & \multicolumn{2}{|c|}{$\begin{array}{l}\text { Temperature } \\
\text { Correction }^{\mathrm{b}}\end{array}$} \\
\hline$k_{h n}(T)$ & $k_{h n 2}(T)$ & & & & $E_{a}$ & 75 \\
\hline$k_{h a}(T)$ & $k_{h a 2}(T)$ & Acid hydrolysis rate of dissolved phase & $0-10^{7}$ & $\mathrm{~m}^{3} \mathrm{~mol}^{-1} \mathrm{~d}^{-1}$ & $E_{a}$ & 75 \\
\hline$k_{h b d o c}(T)$ & $k_{h b d o c 2}(T)$ & $\begin{array}{l}\text { Alkaline hydrolysis rate of DOC } \\
\text { adsorbed phase }\end{array}$ & $0-10^{7}$ & $\mathrm{~m}^{3} \mathrm{~mol}^{-1} \mathrm{~d}^{-1}$ & $E_{a}$ & 75 \\
\hline$k_{h n d o c}(T)$ & Khndoc2 $(T)$ & $\begin{array}{l}\text { Neutral hydrolysis rate of DOC } \\
\text { adsorbed phase }\end{array}$ & $0-10^{2}$ & $d^{-1}$ & $E_{a}$ & 75 \\
\hline knadoc $(T)$ & khadoc2 $(T)$ & $\begin{array}{l}\text { Acid hydrolysis rate of DOC adsorbed } \\
\text { phase }\end{array}$ & $0-10^{7}$ & $\mathrm{~m}^{3} \mathrm{~mol}^{-1} \mathrm{~d}^{-1}$ & $E_{a}$ & 75 \\
\hline \multicolumn{7}{|c|}{ Generalized second-order reaction } \\
\hline$k_{e d}(T)$ & $k_{e d 2}(T)$ & Second-order rate for dissolved phase & $\mathrm{n} / \mathrm{a}$ & $\left(m g ~ L^{-1}\right)^{-1} d^{-1}$ & $E_{a}$ & $n / a$ \\
\hline $\operatorname{kedoc}(T)$ & $\operatorname{kedoc} 2(T)$ & $\begin{array}{l}\text { Second-order rate for DOC adsorbed } \\
\text { phase }\end{array}$ & $\mathrm{n} / \mathrm{a}$ & $\left(m g L^{-1}\right)^{-1} d^{-1}$ & $E_{a}$ & $\mathrm{n} / \mathrm{a}$ \\
\hline $\operatorname{keap}(T)$ & & $\begin{array}{l}\text { Second-order rate for algae adsorbed } \\
\text { phase }\end{array}$ & $\mathrm{n} / \mathrm{a}$ & $\left(m g L^{-1}\right)^{-1} d^{-1}$ & $E_{a}$ & $\mathrm{n} / \mathrm{a}$ \\
\hline $\operatorname{kepom}(T)$ & $k_{\text {epom } 2}(T)$ & $\begin{array}{l}\text { Second-order rate for POM adsorbed } \\
\text { phase }\end{array}$ & $\mathrm{n} / \mathrm{a}$ & $\left(m g L^{-1}\right)^{-1} d^{-1}$ & $E_{a}$ & $\mathrm{n} / \mathrm{a}$ \\
\hline$k_{e p}(T)$ & $k_{e p 2}(T)$ & $\begin{array}{l}\text { Second-order rate for solids adsorbed } \\
\text { phase }\end{array}$ & $n / a$ & $\left(m g L^{-1}\right)^{-1} d^{-1}$ & $E_{a}$ & $\mathrm{n} / \mathrm{a}$ \\
\hline \multicolumn{7}{|c|}{ Transformations } \\
\hline$Y_{j i}$ & & $\begin{array}{l}\text { Transformation yield coefficient from } \\
\text { chemical j to i }\end{array}$ & 1.0 & unitless & & \\
\hline
\end{tabular}

a. Wool et al. (2006).

b. Ea units is $\mathrm{KJ} \mathrm{mol}^{-1}$.

\subsection{CSM outputs}

This section summarizes the CSM outputs from a model simulation. The fundamental output produced by CSM consists of predicted concentrations and predicted mass fluxes at specified locations within the system. Concentrations of the contaminant computed for each physical compartment (water column and sediment layer) include total, dissolved, DOC adsorbed, algae, POM and solids adsorbed phases. Table 11 lists the symbols and definitions of concentrations of the contaminant computed in CSM.

In addition, contaminant pathway fluxes of the contaminant are internally computed in CSM and can be reported in the model outputs. Table 12 lists the symbols and definitions of the pathway fluxes computed in CSM. The CSM allows the user to selectively turn on and off each pathway flux in the model outputs. 
Table 11. List of contaminant concentrations computed in CSM.

\begin{tabular}{|c|c|c|}
\hline Symbol & Definition & Units \\
\hline \multicolumn{3}{|c|}{ Water column } \\
\hline$C_{T}$ & Total concentration in water & $\mu g L^{-1}$ \\
\hline Cion & Ionic concentration in water & $\mu g L^{-1}$ \\
\hline$C_{d}$ & Concentration of dissolved phase in water & $\mu g L^{-1}$ \\
\hline$C_{d o c}$ & Concentration of DOC adsorbed phase in water & $\mu g L^{-1}$ \\
\hline Cap & Concentration of algae adsorbed phase in water & $\mu g L^{-1}$ \\
\hline$C_{p o m}$ & Concentration of POM adsorbed phase in water & $\mu g L^{-1}$ \\
\hline$C_{p t}$ & Total concentration of solids adsorbed phase in water & $\mu g L^{-1}$ \\
\hline$C_{p t s}$ & Total concentration of solids adsorbed phase in water & $\mu g g^{-1}$ \\
\hline \multicolumn{3}{|c|}{ Sediment layer } \\
\hline $\mathrm{C}_{\mathrm{T} 2}$ & Total concentration in sediment & $\mu g L^{-1}$ \\
\hline Cion2 & Ionic concentration in water & $\mu g L^{-1}$ \\
\hline$C_{d 2}$ & Concentration of dissolved phase in pore water & $\mu g L^{-1}$ \\
\hline Cdoc2 & Concentration of DOC adsorbed phase in pore water & $\mu g L^{-1}$ \\
\hline$C_{p o m 2}$ & Concentration of POM adsorbed phase in sediment & $\mu g L^{-1}$ \\
\hline$C_{p t 2}$ & Total concentration of solids adsorbed phase in sediment & $\mu g L^{-1}$ \\
\hline$C_{p t s 2}$ & Total concentration of solids adsorbed phase in sediment & $\mu g g^{-1}$ \\
\hline
\end{tabular}


Table 12. List of contaminant pathway fluxes computed in CSM.

\begin{tabular}{|c|c|c|}
\hline Symbol & Definition & Units \\
\hline \multicolumn{3}{|c|}{ Water column } \\
\hline$S_{d e c}$ & Contaminant degradation in water & $\mu g \mathrm{~L}^{-1} \mathrm{~d}^{-1}$ \\
\hline Shyd & Contaminant hydrolysis in water & $\mu g L^{-1} d^{-1}$ \\
\hline$S_{\text {pht }}$ & Contaminant photolysis in water & $\mu g L^{-1} d^{-1}$ \\
\hline$S_{v / t}$ & Contaminant volatilization in water & $\mu g L^{-1} d^{-1}$ \\
\hline Sexa & Contaminant generalized second-order reaction in water & $\mu g L^{-1} d^{-1}$ \\
\hline$S_{t r m}$ & Total contaminant transformations in water & $\mu g \mathrm{~L}^{-1} \mathrm{~d}^{-1}$ \\
\hline Satm & Contaminant air deposition & $\mu g L^{-1} d^{-1}$ \\
\hline $\mathrm{S}_{\text {set }}$ & Contaminant settling & $\mu g \mathrm{~L}^{-1} \mathrm{~d}^{-1}$ \\
\hline Sres & Contaminant re-suspension & $\mu g L^{-1} d^{-1}$ \\
\hline$S_{s w}$ & Contaminant sediment-water transfer & $\mu g L^{-1} d^{-1}$ \\
\hline \multicolumn{3}{|c|}{ Sediment layer } \\
\hline Sdec & Sediment contaminant degradation & $\mu g L^{-1} d^{-1}$ \\
\hline Shyd & Sediment contaminant hydrolysis & $\mu g L^{-1} d^{-1}$ \\
\hline Sexa & Sediment contaminant generalized second-order reaction & $\mu g \mathrm{~L}^{-1} \mathrm{~d}^{-1}$ \\
\hline$S_{t r m}$ & Total sediment contaminant transformations & $\mu g \mathrm{~L}^{-1} \mathrm{~d}^{-1}$ \\
\hline$S_{\text {set }}$ & Contaminant deposition & $\mu g \mathrm{~L}^{-1} \mathrm{~d}^{-1}$ \\
\hline Sres & Sediment contaminant re-suspension & $\mu g L^{-1} d^{-1}$ \\
\hline$S_{s w}$ & Contaminant sediment-water transfer & $\mu g \mathrm{~L}^{-1} \mathrm{~d}^{-1}$ \\
\hline$S_{b}$ & Sediment contaminant burial & $\mu g L^{-1} d^{-1}$ \\
\hline
\end{tabular}




\section{Mercury Simulation Module (HgSM)}

This chapter describes the theory and mathematical formulations implemented in the Mercury Simulation Module (HgSM). The HgSM is capable of modeling three major mercury $(\mathrm{Hg})$ species in an aquatic system; elemental mercury (abbreviated as $\mathrm{Hgo}$ ), divalent mercury (abbreviated as $\mathrm{HgII}$ ), and methylmercury (referred to as $\mathrm{MeHg}$ ), and their interactions with DOC, algae, organic, and inorganic solids. The $\mathrm{HgSM}$ computes internal source and sink terms for $\mathrm{HgO}, \mathrm{HgII}$, and $\mathrm{MeHg}$ in the water column and $\mathrm{HgII}$ and $\mathrm{MeHg}$ in the sediment layer. Due to the small concentration of mercury species compared to the major water quality constituents, all concentrations of mercury species in $\mathrm{HgSM}$ are expressed in terms of nanograms per volumetric units of liter (ng L $\left.\mathrm{L}^{-1}\right)$.

\subsection{Overview}

Mercury is introduced into the environment by a variety of natural processes and anthropogenic activities. Mercury exists in several different chemical species with highly differing behaviors and toxicities. $\mathrm{HgO}$ is the most common form of mercury found in the atmosphere (USEPA 1997). Besides $\mathrm{HgO}$, most of the mercury encountered in water, soil, sediments, and biota (all environmental media except in the atmosphere) is in the form of inorganic mercury as $\mathrm{HgII}$ and organic mercury, particularly $\mathrm{MeHg}$ (Mason et al. 1993, 1994). HgII and $\mathrm{MeHg}$ can exist in the dissolved phase as well as in the colloidal and suspended phases within aquatic systems. These mercury species often undergo complex cycling (Krabbenhoft and Rickert 2003; Harris et al. 2007; EPRI 2006; EPRI 2013). One of the major concerns of mercury and its impact to the environment and human health is its transformation to $\mathrm{MeHg}$, a highly toxic form of mercury. A crucial determinant of the fate of $\mathrm{MeHg}$ in aquatic systems is the cycling of various species. Cycling consists of inputs to, and outputs from, a system, as well as transport and transformation of the mercury species within the system.

The HgSM was designed to simulate three species ( $\mathrm{Hgo}, \mathrm{HgII}$, and $\mathrm{MeHg}$ ) as model state variables. Among the mercury state variables, $H g I I$, and $\mathrm{MeHg}$ exist in both the water column and the sediment layer as dissolved phase and associated with the DOC, POM and inorganic solids. Hgo exists in the system only in the dissolved phase. $\mathrm{HgII}$ is used to represent 
inorganic mercury that can exist as $\mathrm{Hg}^{2+}$ complexed to chloride, hydroxide and sulfide ions (i.e., $\mathrm{HgCl}_{2}, \mathrm{Hg}(\mathrm{OH})_{2}, \mathrm{HgS}$, etc). Mercury species can be adsorbed by DOC, algae, POM and other inorganic solids. Physical and biochemical processes modeled in HgSM include: 1) adsorption and desorption of mercury, 2) volatilization, 3) atmospheric deposition, 4) diffusive exchange between the water column and sediment layer, 5) deposition and re-suspension, 6) sediment burial of adsorbed mercury, and 7) biogeochemical transformations among three species. Similar to the CSM, the HgSM only computes the kinetics of mercury state variables in aquatic systems. Figure 6. provides an overview of the model representation of the mercury species and cycling processes modeled in HgSM (with the exception of transport).

Figure 6. Conceptual representation of mercury speciation and processes modeled in HgSM.

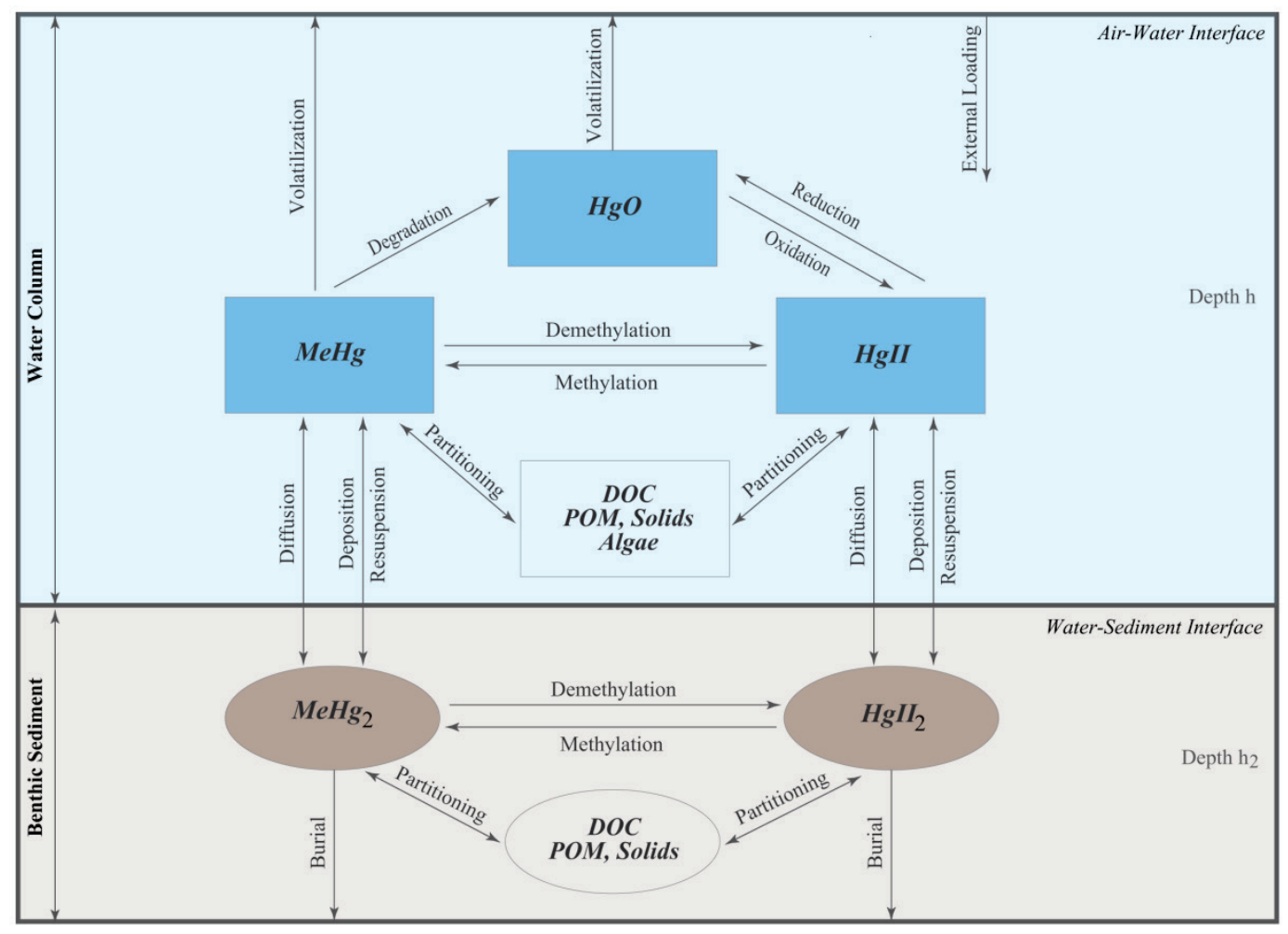

Mercury cycling in aquatic systems has been extensively studied, but it still represents the major uncertainty in modeling transport and fate of mercury species. In $\mathrm{HgSM}$, the transformation processes of $\mathrm{Hgo}, \mathrm{HgII}$, and $\mathrm{MeHg}$ and their reaction rates are described using simple kinetic equations adopted in part from the WASP mercury module (Wool et al. 2006) and D-MCM (EPRI 2013). The WASP mercury module was developed as a companion to the other two WASP water quality submodels: EUTRO and 
TOXI. The WASP model simulates the transport and fate of $H g o, H g I I$, and $\mathrm{MeHg}$ in surface water. The D-MCM is a time dependent, mechanistic mass balance model for simulating mercury cycling and bioaccumulation. The D-MCM simulates $\mathrm{Hgo}, \mathrm{HgII}$, and $\mathrm{MeHg}$, and the simplified food web that includes phytoplankton, zooplankton, benthos, and three fish species.

\subsection{Mercury speciation and partitioning}

\subsubsection{Mercury speciation}

Mercury speciation plays a major role in determining the cycling and therefore, the effects of transport and fate of mercury in the environment (Turner 1987; Stein et al. 1996; Jackson 1997; Morel et al. 1998). The HgSM models three primary mercury species of environmental concern: Hgo, $\mathrm{HgII}$, and $\mathrm{MeHg}$. Gaseous $\mathrm{HgO}$ is the dominant form in the atmosphere (Nater and Grigal 1992). Hgo has an approximate atmospheric residence time of 6 months to 1 year (Fitzgerald 1989). The mercury species differ greatly in their solubility. Hgo is slightly water soluble and has a high Henry's Law constant (Schroeder and Munthe 1998). Hgo constitutes very little of the total mercury in the surface water but may provide a significant pathway for the volatilization of mercury from surface waters. In HgSM, $\mathrm{HgO}$ is assumed to exist in the dissolved phase and only in the water column.

The main dissolved mercury species in aquatic systems is $\mathrm{Hg}^{2+}$ complexes with various inorganic and organic ligands. $\mathrm{MeHg}$ is the methylated form of mercury that can be synthesized in aqueous systems. $\mathrm{Hg}^{2+}$ and $\mathrm{MeHg}$ in aquatic environments are generally not free ions, but complex to various inorganic or organic ligands, including hydroxide, chloride, sulfides, and dissolved organic matter (Morel et al. 1998). In oxidizing conditions, the dominant forms are $\mathrm{Hg}^{2+}$ and $\mathrm{Hg}_{2}{ }^{2+}$ as chloride and hydroxide complexes. While in reducing conditions, the dominant forms are sulphur-mercury compounds such as mono- and bi-sulphide complexes ( $\mathrm{HgS}(\mathrm{s}), \mathrm{HgS}_{2} \mathrm{H}_{2}$, $\mathrm{HgS}_{2} \mathrm{H}^{-}$and $\mathrm{HgS}_{2}{ }^{2}$ ) (Puk and Weber 1994; Morel et al. 1998). In intermediate conditions, the most common forms are alkyl mercury compounds (Rundgren et al. 1992). The HgSM combines all $\mathrm{Hg}^{2+}$ species of mercury into a state variable identified by $\mathrm{HgII}$. $\mathrm{HgII}$ is modeled for the water column and sediment layer.

$\mathrm{HgO}$ and $\mathrm{HgII}$ are the major chemical forms of mercury input into the environment from anthropogenic or natural sources (Stein 1996). During 
the biogeochemical cycling of mercury, organic mercury species can be produced. In freshwater systems the predominant form of organic mercury compound is methylmercury $\left(\mathrm{CH}_{3} \mathrm{Hg}^{+}\right)$, which is represented by $\mathrm{MeHg}$ Although $\mathrm{MeHg}$ only accounts for a small fraction of mercury in the environment, it is the species of most concern to humans due to its high toxicity, prevalent existence, and capability of being accumulated and amplified along the food chain. The bioaccumulation of $\mathrm{MeHg}$ in the food chain, in particular in aquatic ecosystems, has caused exposure of both humans and wildlife to $\mathrm{MeHg}$, posing severe health risks (Zillioux et al. 1993; Carroll et al. 2000; Wang et al. 2004; Evers 2005). Therefore, $\mathrm{MeHg}$ is modeled for the water column and sediment layer.

\subsubsection{Mercury partitioning}

Mercury species may be present under different phases in aquatic systems: 1) elemental Hgo as a non-aqueous liquid phase, 2) dissolved in the aqueous phase as a free ion $\left(\mathrm{Hg}^{2+}\right)$ or complexed with inorganic and/or organic ligands, 3) sorbed on inorganic solids and organic matter, and 4) in solid (precipitated) phase. The importance of adsorption/desorption on mercury bioavailability has been confirmed by both laboratory and field studies. It has been well documented that DOC and solids are two principal carriers of $\mathrm{MeHg}$ and $\mathrm{HgII}$ (Lyon et al. 1997). DOC is an effective complex for ligand for many trace metals, including mercury. $\mathrm{HgII}$ and $\mathrm{MeHg}$ may exist in various dissolved and particulate forms in aquatic systems. In $\mathrm{HgSM}$, all $\mathrm{HgO}$ is assumed in the dissolved phase, $\mathrm{HgII}$ and $\mathrm{MeHg}$ are allowed to be partitioned among the dissolved phase and DOC, algae, and solids adsorbed phases. Similar to the CSM, solids can be assigned to mineral abiotic solids, detrital, or various classes or size categories of solids. Adsorption or uptake of $\mathrm{HgII}$ and $\mathrm{MeHg}$ with algae in the water column is simulated in a similar manner as is done for contaminants in CSM. Inside the algae mercury kinetics and transformations are not considered in HgSM. Sediment $\mathrm{HgII}$ and $\mathrm{MeHg}$ are allowed to be partitioned between dissolved, DOC, algae, POM and solids adsorbed phases. Under an equilibrium partitioning, all $\mathrm{HgII}$ and $\mathrm{MeHg}$ are assumed to be instantly exchangeable between the dissolved and adsorbed phases.

It is recognized that adsorbed $H g I I$ may be not at true "equilibrium" with the dissolved phase. Alternatively, sorption of $\mathrm{HgII}$ on algae, organic and inorganic solids can be simulated according to non-equilibrium partitioning kinetics described in chapter 3 . 


\subsubsection{Linear equilibrium partitioning}

In HgSM, partitioning factions of $\mathrm{HgII}$ and $\mathrm{MeHg}$ in the water column and sediment layer are identically calculated based on the formulations developed for contaminants (Chapter 3.3). Table 13 summarizes formulations for calculating the linear equilibrium partitioning fractions of $\mathrm{HgII}$ and $\mathrm{MeHg}$. The symbols in these equations are defined in Table 14.

Partition coefficients of $H g I I$ and $\mathrm{MeHg}$ have been calculated for sediment or soil over water. Values of the partition coefficient $K_{d}$ on the order of 10$10^{5} \mathrm{~L} \mathrm{~kg}^{-1}$ for soil, $10^{5} \mathrm{~L} \mathrm{~kg}^{-1}$ for sediment and $10^{5+} \mathrm{L} \mathrm{kg}^{-1}$ for suspended material are typically found for $\mathrm{HgII}$ and $\mathrm{MeHg}$ (USEPA 1997), indicating a strong preference for $\mathrm{HgII}$ and $\mathrm{MeHg}$ to remain bound to soil, bottom sediment, or suspended matter (increasing affinity in that order). Harris et al. (1996) reported that the partitioning of HgII to total suspended solids is 20-25\% higher than partitioning to abiotic solids, while the partitioning of $\mathrm{MeHg}$ to total suspended solids is 2.5 times higher than partitioning to abiotic solids.

For the benthic sediment, the values of the partition coefficient $K_{d}$ ranging from $1.6 \cdot 10^{4}$ to $9.9 \cdot 10^{5} \mathrm{~L} \mathrm{~kg}^{-1}$ with median values between $5 \cdot 4 \cdot 10^{4}$ and $7.9 \cdot 10^{4} \mathrm{~L} \mathrm{~kg}^{-1}$ for $\mathrm{HgII}$ and $6.5 \cdot 10^{2}$ to $1.1 \cdot 10^{5}$ between $6.1 \cdot 10^{3}$ and $9.0 \cdot 10^{3} \mathrm{~L}$ $\mathrm{kg}^{-1}$ for $\mathrm{MeHg}$ are reported by Lyon et al. (1997). Harris et al. (1996) reported that the values of the partition coefficient of HgII to benthic solids in four lakes range from $3.0 \cdot 10^{4}$ to $10^{5} \mathrm{~L} \mathrm{~kg}^{-1}$, while the values of the partition coefficient of $\mathrm{MeHg}$ range from $2.2 \cdot 10^{3}$ to $7 \cdot 8 \cdot 10^{3} \mathrm{~L} \mathrm{~kg}^{-1}$. Generally, the distribution coefficient for water column partitioning is higher than for sediment pore water. Similarly, the distribution coefficients of $\mathrm{MeHg}$ are typically several folds smaller than the corresponding values for $\mathrm{HgII}$.

Table 13. Formulations of calculating Hgll and MeHg partitioning fractions in HgSM.

\begin{tabular}{|l|l|}
\hline Inorganic Mercury (HgII) & Methylmercury (MeHg) \\
\hline \multicolumn{2}{|c|}{ Water column } \\
\hline$f_{d-H g I I}=\frac{10^{6}}{R_{H g I I}}$ & $f_{d-M e H g}=\frac{10^{6}}{R_{\text {MeHg }}}$ \\
\hline$f_{\text {doc-HgII }}=\frac{K_{d o c-H g l l} D O C}{R_{H g I I}}$ & $f_{\text {doc-MeHg }}=\frac{K_{\text {doc }- \text { MeHg }} D O C}{R_{\text {MeHg }}}$ \\
\hline
\end{tabular}




\begin{tabular}{|c|c|}
\hline Inorganic Mercury (HgII) & Methylmercury (MeHg) \\
\hline$f_{a p-H g I I}=\frac{K_{a p-H g I I} A_{p d}}{R_{H g I I}}$ & $f_{a p-\mathrm{MeHg}}=\frac{K_{a p-\mathrm{MeHg}} A_{p d}}{R_{\mathrm{MeHg}}}$ \\
\hline$f_{\text {pom-HgII }}=\frac{K_{p o m-H g I I} P O M}{R_{H g I I}}$ & $f_{\text {pom-MeHg }}=\frac{K_{\text {pom-MeHg}} P O M}{R_{\mathrm{MeHg}}}$ \\
\hline$f_{p n-H g I I}=\frac{K_{p n-H g I I} m_{n}}{R_{H g I I}}$ & $f_{p n-\mathrm{MeHg}}=\frac{K_{p n-\mathrm{MeHg}} m_{n}}{R_{\mathrm{MeHg}}}$ \\
\hline \multicolumn{2}{|c|}{$\begin{array}{l}R_{H g I I}=10^{6}+K_{d o c-H g I I} D O C+K_{a p-H g I t} A_{p d}+K_{p o m-H g I I} P O M+\sum_{n=1}^{N} K_{p n-H g I I} m_{n} \\
R_{M e H g}=10^{6}+K_{d o c-M e H g} D O C+K_{a p-M e H g} A_{p d}+K_{p o m-M e H g} P O M+\sum_{n=1}^{N} K_{p n-M e H g} m_{n}\end{array}$} \\
\hline \multicolumn{2}{|c|}{ Sediment layer } \\
\hline$f_{d-H g I I 2}=\frac{10^{6} \phi}{R_{H g I I 2}}$ & $f_{d-\mathrm{MeHg} 2}=\frac{10^{6} \phi}{R_{M e H g} 2}$ \\
\hline$f_{d o c-H g I I 2}=\frac{K_{d o c-H g I I 2} \phi D O C_{2}}{R_{H g I I 2}}$ & $f_{d o c-M e H g 2}=\frac{K_{d o c-M e H g} \phi D O C_{2}}{R_{M e H g} 2}$ \\
\hline$f_{\text {pom-HgII } 2}=\frac{K_{p o m-H g I I 2} \mathrm{POM}_{2}}{R_{H g I I 2}}$ & $f_{\text {pom-MeHg } 2}=\frac{K_{\text {pom-MeHg} 2} \mathrm{POM}_{2}}{R_{\mathrm{MeHg} 2}}$ \\
\hline$f_{p n-H g I I 2}=\frac{K_{p n-H g I I 2} m_{n 2}}{R_{H g I I 2}}$ & $f_{p n-\mathrm{MeHg} 2}=\frac{K_{p n-\mathrm{MeHg} 2} m_{n 2}}{R_{\mathrm{MeHg} 2}}$ \\
\hline \multicolumn{2}{|c|}{ 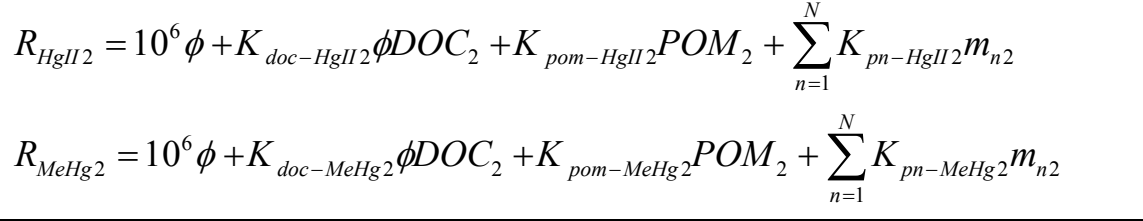 } \\
\hline
\end{tabular}

Table 14. Symbols and definitions used in Table 13.

\begin{tabular}{|c|c|c|}
\hline Name & Definition & Units \\
\hline \multicolumn{3}{|c|}{ Water column } \\
\hline$f_{d-H g \|}$ & Fraction of dissolved Hgll in water & - \\
\hline$f_{\text {doc-Hgll }}$ & Fraction of DOC adsorbed Hgll in water & - \\
\hline$f_{\text {ap-Hgll }}$ & Fraction of algae adsorbed $\mathrm{Hgll}$ in water & - \\
\hline$f_{\text {pom-Hgll }}$ & Fraction of POM adsorbed $\mathrm{Hgll}$ in water & - \\
\hline$f_{p n-H g l l}$ & Fraction of solids adsorbed $\mathrm{Hgll}$ in water & - \\
\hline Kdoc-HgII & Hgll equilibrium partition coefficient for DOC in water & $\mathrm{L} \mathrm{kg}^{-1}$ \\
\hline Kap-Hgll & Hgll equilibrium partition coefficient for algae in water & $\mathrm{L} \mathrm{kg}^{-1}$ \\
\hline
\end{tabular}




\begin{tabular}{|c|c|c|}
\hline Name & Definition & Units \\
\hline Kom-HgII & Hgll equilibrium partition coefficient for POM in water & $\mathrm{L} \mathrm{kg}^{-1}$ \\
\hline$K_{p n-H g l l}$ & Hgll equilibrium partition coefficient for solids in water & $\mathrm{L} \mathrm{kg}^{-1}$ \\
\hline$f_{d-M e H g}$ & Fraction of dissolved MeHg in water & - \\
\hline$f_{\text {doc-MeHg }}$ & Fraction of DOC adsorbed MeHg in water & - \\
\hline fap-MeHg & Fraction of algae adsorbed MeHg in water & - \\
\hline$f_{\text {pom-MeHg }}$ & Fraction of POM adsorbed $\mathrm{MeHg}$ in water & - \\
\hline$f_{p n-M e H g}$ & Fraction of solids adsorbed MeHg in water & - \\
\hline$K_{\text {doc-MeHg }}$ & MeHg equilibrium partition coefficient for DOC in water & $\mathrm{L} \mathrm{kg}^{-1}$ \\
\hline Kap-MeHg & MeHg equilibrium partition coefficient for algae in water & $\mathrm{L} \mathrm{kg}^{-1}$ \\
\hline Kom-MeHg & MeHg equilibrium partition coefficient for POM in water & $\mathrm{L} \mathrm{kg}^{-1}$ \\
\hline$K_{p n-M e H g}$ & MeHg equilibrium partition coefficient for solids in water & $\mathrm{L} \mathrm{kg}^{-1}$ \\
\hline \multicolumn{3}{|c|}{ Sediment layer } \\
\hline$f_{d-H g / / 2}$ & Fraction of dissolved Hgll in sediment & - \\
\hline$f_{\text {doc-HgII2 }}$ & Fraction of DOC adsorbed Hgll in sediment & - \\
\hline$f_{\text {pom-Hg } / 12}$ & Fraction of POM adsorbed Hgll in sediment & - \\
\hline$f_{p n-H g l / 2}$ & Fraction of solids adsorbed Hgll in sediment & - \\
\hline$K_{\text {doc-Hgll2 }}$ & Hgll equilibrium partition coefficient for sediment DOC & $\mathrm{L} \mathrm{kg}^{-1}$ \\
\hline$K_{\text {pom-Hgll2 }}$ & Hgll equilibrium partition coefficient for sediment POM & $\mathrm{L} \mathrm{kg}^{-1}$ \\
\hline Kpn-HgII2 & Hgll equilibrium partition coefficient for sediment solids & $\mathrm{L} \mathrm{kg}^{-1}$ \\
\hline$f_{d-M e H g 2}$ & Fraction of dissolved MeHg in sediment & - \\
\hline$f_{\text {doc-MeHg2 }}$ & Fraction of DOC adsorbed MeHg in sediment & - \\
\hline$f_{\text {pom-MeHg2 }}$ & Fraction of POM adsorbed MeHg in sediment & - \\
\hline$f_{p n-M e H g 2}$ & Fraction of solids adsorbed MeHg in sediment & - \\
\hline$K_{\text {doc-MeHg2 }}$ & MeHg equilibrium partition coefficient for sediment DOC & $\mathrm{L} \mathrm{kg}^{-1}$ \\
\hline Kom-MeHg2 & MeHg equilibrium partition coefficient for sediment POM & $\mathrm{L} \mathrm{kg}^{-1}$ \\
\hline Kpn-MeHg2 & MeHg equilibrium partition coefficient for sediment solids & $\mathrm{L} \mathrm{kg}^{-1}$ \\
\hline
\end{tabular}

Concentrations of $\mathrm{HgII}$ and $\mathrm{MeHg}$ in each phase in the water column and sediment layer can be calculated from the partitioning factions and are listed in Table 15. Dissolved concentrations of $\mathrm{HgII}$ and $\mathrm{MeHg}$ in the sediment layer are the mass of dissolved and DOC adsorbed phases relative to the total volume of solids and water. The porosity corrected concentrations in pore water are also listed in Table 15. The symbols in Table 15 are defined in Table 16. 
Table 15. Formulations of calculating Hgll and MeHg partitioning concentrations in HgSM.

\begin{tabular}{|c|c|}
\hline Inorganic Mercury (HgII) & Methylmercury (MeHg) \\
\hline \multicolumn{2}{|c|}{ Water column } \\
\hline$H g I I_{d}=f_{d-H g I I} H g I I$ & $\mathrm{MeHg}_{d}=f_{d-\mathrm{MeHg}} \mathrm{MeHg}$ \\
\hline$H g I I_{d o c}=f_{d o c-H g I I} H g I I$ & $\mathrm{MeHg}_{d o c}=f_{d o c-\mathrm{MeHg}} \mathrm{MeHg}$ \\
\hline$H g I I_{p t}=\sum_{n=1}^{N} f_{p n-H g I I} H g I I$ & $M e H g_{p t}=\sum_{n=1}^{N} f_{p n-M e H g} M e H g$ \\
\hline$H g I I_{p t s}=10^{3} \frac{\sum_{n=1}^{N} f_{p n-H g I I} H g I I}{\sum_{n=1}^{N} m_{n}}$ & $\mathrm{MeHg}_{p t s}=10^{3} \frac{\sum_{n=1}^{N} f_{p n-\mathrm{MeHg}} \mathrm{MeHg}}{\sum_{n=1}^{N} m_{n}}$ \\
\hline \multicolumn{2}{|c|}{ Sediment layer } \\
\hline$H g I I_{d 2}=f_{d-H g I I 2} H g I I_{2}$ & $\mathrm{MeHg}_{d 2}=f_{d-\mathrm{MeHg} 2} \mathrm{MeHg}_{2}$ \\
\hline$H g I I_{d o c 2}=f_{d o c-H g I I} H g I I_{2}$ & $\mathrm{MeHg}_{d o c 2}=f_{d o c-M e H g} \mathrm{MeHg}_{2}$ \\
\hline$H g I I_{p t 2}=\sum_{n=1}^{N} f_{p n-H g I I 2} \mathrm{HgII}_{2}$ & $\mathrm{MeHg}_{p t 2}=\sum_{n=1}^{N} f_{p n-\mathrm{MeHg} 2} \mathrm{MeHg}_{2}$ \\
\hline$H g I I_{p t s 2}=10^{3} \frac{\sum_{n=1}^{N} f_{p n-H g I I} \mathrm{HgII}_{2}}{\sum_{n=1}^{N} m_{n 2}}$ & $\mathrm{MeHg}_{p t s 2}=10^{3} \frac{\sum_{n=1}^{N} f_{p n-\mathrm{MeHg} 2} \mathrm{MeHg}_{2}}{\sum_{n=1}^{N} m_{n 2}}$ \\
\hline \multicolumn{2}{|c|}{ Pore water } \\
\hline$H g I I_{d p 2}=H g I I_{d 2} / \phi$ & $M e H g_{d p 2}=M e H g_{d 2} / \phi$ \\
\hline$H g I I_{d o c p 2}=H g I I_{d o c 2} / \phi$ & $M e H g_{d o c p 2}=M e H g_{d o c 2} / \phi$ \\
\hline
\end{tabular}

Table 16. Symbols and definitions of Hgll and MeHg concentrations used in Table 16.

\begin{tabular}{|c|c|c|}
\hline Symbol & Definition & Units \\
\hline \multicolumn{3}{|c|}{ Water column } \\
\hline Hgll & Concentration of total Hgll in water & $n g L^{-1}$ \\
\hline$H g l_{d}$ & Concentration of dissolved Hgll in water & $n g L^{-1}$ \\
\hline$H g l_{d o c}$ & Concentration of DOC adsorbed $\mathrm{Hgll}$ in water & $n g \mathrm{~L}^{-1}$ \\
\hline$H g \|_{p t}$ & Total concentration of solids adsorbed Hgll in water & $n g L^{-1}$ \\
\hline Hgll pts & Total concentration of solids adsorbed Hgll in water & $n g g^{-1}$ \\
\hline $\mathrm{MeHg}$ & Concentration of total MeHg in water & $n g L^{-1}$ \\
\hline $\mathrm{MeHg} d$ & Concentration of dissolved $\mathrm{MeHg}$ in water & $n g L^{-1}$ \\
\hline $\mathrm{MeHg} d o c$ & Concentration of DOC adsorbed $\mathrm{MeHg}$ in water & $n g \mathrm{~L}^{-1}$ \\
\hline $\mathrm{MeHg}$ & Total concentration of solids adsorbed MeHg in water & ng $L^{-1}$ \\
\hline
\end{tabular}




\begin{tabular}{|c|c|c|}
\hline Symbol & Definition & Units \\
\hline MeHgpts & Total concentration of solids adsorbed $\mathrm{MeHg}$ in water & ng g-1 \\
\hline \multicolumn{3}{|c|}{ Sediment layer } \\
\hline $\mathrm{Hg} \|_{2}$ & Concentration of total Hgll in sediment & $n g L^{-1}$ \\
\hline$H g I_{d p 2}$ & Concentration of dissolved Hgll in pore water & ng L-1 \\
\hline Hglldocp2 & Concentration of DOC adsorbed Hgll in pore water & ng L-1 \\
\hline Hgllpt2 & Total concentration of solids adsorbed Hgll in sediment & ng L $L^{-1}$ \\
\hline$H g \|_{p t s 2}$ & Total concentration of solids adsorbed Hgll in sediment & ng g-1 \\
\hline $\mathrm{MeHg} 2$ & Concentration of total MeHg on in sediment & ng L-1 \\
\hline MeHgdp2 & Concentration of dissolved MeHg in pore water & ng L-1 \\
\hline $\mathrm{MeHg}$ docp2 & Concentration of DOC adsorbed MeHg in pore water & ng L-1 \\
\hline MeHgpt2 & Total concentration of solids adsorbed MeHg in sediment & ng L-1 \\
\hline MeHgpts2 & Total concentration of solids adsorbed MeHg in sediment & ng $g^{-1}$ \\
\hline
\end{tabular}

\subsubsection{Non-linear equilibrium partitioning}

In HgSM, two of the most popular adsorption isotherms including the Langmuir and Freundlich isotherms are used for $\mathrm{HgII}$ and $\mathrm{MeHg}$. As with non-linear equilibrium partitioning implemented in CSM, concentrations of $\mathrm{HgII}$ and $\mathrm{MeHg}$ for each phase must be solved numerically from the total concentration of $\mathrm{HgII}$ and $\mathrm{MeHg}$. With the Freundlich equilibrium partitioning implemented, concentrations of total $\mathrm{HgII}$ and $\mathrm{MeHg}$ in the water column and sediment layer are determined with the following mass balances.

Water column:

$$
\begin{aligned}
& H g I I_{d}+10^{-6} K_{d o c-H g I I} H g I I_{d} D O C+10^{-3 b p o m} K_{f p o m-H g I I} H_{g I I}{ }_{d}^{b p o m} P O M \\
& +10^{-3 b a p} K_{f a p-H g I I} H g I I_{d}{ }^{f a p} A_{p d}+10^{-3 b p n} \sum_{n=1}^{N} K_{f p n-H g I I} H g I I_{d}^{b p n} m_{n}=H g I I \\
& \mathrm{MeHg}_{d}+10^{-6} \mathrm{~K}_{\text {doc-MeHg}} \mathrm{MeHg}_{d} \mathrm{DOC}+10^{-3 \mathrm{bpom}} \mathrm{K}_{\text {fрom-MeHg}} \mathrm{MeHg}_{d}^{\text {bpom }} \mathrm{POM} \\
& +10^{-3 b a p} K_{\text {fap-MeHg }} \mathrm{MeHg}_{d}^{\text {bap }} A_{p d}+10^{-3 b p n} \sum_{n=1}^{N} K_{f p n-\mathrm{MeHg}} \mathrm{MeHg} g_{d}^{b p n} m_{n}=\mathrm{MeHg}
\end{aligned}
$$

Sediment layer:

$$
\begin{aligned}
H g I I_{d 2} & +10^{-6} K_{d o c-H g I I 2} H_{g I I_{d 2}} \mathrm{DOC}_{2}+10^{-3 b p o m 2} K_{f p o m-H g I I 2}\left(H g I I_{d 2} / \varphi\right)^{b p o m 2} \mathrm{POM}_{2} \\
& +10^{-3 b p n} \sum_{n=1}^{N} K_{f p n-H g I I 2}\left(H g I I_{d 2} / \varphi\right)^{b p n 2} m_{n 2}=H_{g I I_{2}}
\end{aligned}
$$




$$
\begin{aligned}
\mathrm{MeHg}_{d 2} & +10^{-6} K_{d o c-M e H g 2} \mathrm{MeHg}_{d 2} \mathrm{DOC}_{2}+10^{-3 b p o m 2} K_{f p o m-M e H g 2}\left(\mathrm{MeHg}_{d 2} / \varphi\right)^{b p o m 2} \mathrm{POM}_{2} \\
& +10^{-3 b p n 2} \sum_{n=1}^{N} K_{f p n-\mathrm{MeHg} 2}\left(\mathrm{MeHg}_{d 2} / \varphi\right)^{b p n 2} m_{n 2}=\mathrm{MeHg}_{2}
\end{aligned}
$$

where

$$
\begin{aligned}
& K_{\text {fpom-HgII }}=H g I I \text { Freundlich adsorption constant for POM in water }\left(\mu g^{-1}\right) \\
& \left(\mu \mathrm{g} \mathrm{L} \mathrm{L}^{-1}\right)^{-\mathrm{b}} \\
& K_{\text {fpom-HgII }}=H g I I \text { Freundlich adsorption constant for sediment POM ( } \mu \mathrm{g} \mathrm{g}^{-} \\
& \text {1) }\left(\mu \mathrm{g} \mathrm{L^{-1 }}\right)^{-b} \\
& K_{\text {fap-HgII }}=H g I I \text { Freundlich adsorption constant for algae in water }\left(\mu \mathrm{g} \mathrm{g}^{-1}\right) \\
& \left(\mu \mathrm{g} \mathrm{L^{-1 }}\right)^{-\mathrm{b}} \\
& K_{f p n-H g I I}=H g I I \text { Freundlich adsorption constant for solid " } n \text { " in water ( } \mu g \\
& \left.\mathrm{~g}^{-1}\right)\left(\mu \mathrm{g} \mathrm{L} \mathrm{L}^{-1}\right)^{-\mathrm{b}} \\
& K_{f p n-H g I I 2}=H g I I \text { Freundlich adsorption constant for sediment solid " } n \text { " } \\
& \left(\mu \mathrm{g} \mathrm{g}^{-1}\right)\left(\mu \mathrm{g} \mathrm{L}^{-1}\right)^{-\mathrm{b}} \\
& K_{\text {fpom-Менg }}=\mathrm{MeHg} \text { Freundlich adsorption constant for POM in water ( } \mu \mathrm{g} \mathrm{g}^{-} \\
& \text {1) }\left(\mu g \mathrm{~L}^{-1}\right)^{-b} \\
& K_{\text {fpom-MeHg2 }}=M e H g \text { Freundlich adsorption constant for sediment POM ( } \mu \mathrm{g} \\
& \left.\left.\mathrm{g}^{-1}\right)(\mu \mathrm{g} \mathrm{L})^{-1}\right)^{-b} \\
& K_{\text {fap-Менg }}=\mathrm{MeHg} \text { Freundlich adsorption constant for algae in water ( } \mu \mathrm{g} \mathrm{g}^{-} \\
& \text {1) }\left(\mu \mathrm{g} \mathrm{L} \mathrm{L}^{-1}\right)^{-\mathrm{b}} \\
& K_{\text {fpn-Менg }}=\mathrm{MeHg} \text { Freundlich adsorption constant for solid " } n \text { " in water } \\
& \left(\mu \mathrm{g} \mathrm{g}^{-1}\right)\left(\mu \mathrm{g} \mathrm{L}^{-1}\right)^{-b} \\
& K_{f p n-\mathrm{MeHg}}=\mathrm{MeHg} \text { Freundlich adsorption constant for sediment solid " } n \text { " } \\
& \left.\left(\mu \mathrm{g} \mathrm{g}^{-1}\right)(\mu \mathrm{g} \mathrm{L})^{-1}\right)^{-b} \\
& b_{\text {pom }}=\text { Freundlich exponent for POM in water (uniteless) } \\
& b_{\text {pom } 2}=\text { Freundlich exponent for sediment POM (uniteless) } \\
& b_{a p}=\text { Freundlich exponent for algae in water (uniteless) } \\
& b_{p n}=\text { Freundlich exponent for solid " } n \text { " in water (uniteless) } \\
& b_{p n 2}=\text { Freundlich exponent for sediment solid " } n \text { " (uniteless). }
\end{aligned}
$$

With the Langmuir equilibrium partitioning implemented, concentrations of total $\mathrm{HgII}$ and $\mathrm{MeHg}$ in the water column and sediment layer are determined with the following mass balance equations 
Water column:

$$
\begin{aligned}
& H g I I_{d}+10^{-6} K_{d o c-H g I I} D O C \cdot H g I I_{d}+\frac{K_{\text {lap-HgII }} q_{c a p-H g I I} A_{p d} H g I I_{d}}{10^{3}+K_{\text {lap-HgII }} H g I I_{d}} \\
& +\frac{K_{\text {lpom-HgII }} q_{\text {cpom-HgII }} P O M \cdot H g I I_{d}}{10^{3}+K_{l p o m-H g I I} H g I I_{d}}+\sum_{n=1}^{N} \frac{K_{l p n-H g I I} q_{c n-H g I I} m_{n} H g I I_{d}}{10^{3}+K_{l p n-H g I I} H g I I_{d}}=H g I I \\
& \mathrm{MeHg}_{d}+10^{-6} K_{\text {doc-MeHg}} \mathrm{DOC} \cdot \mathrm{MeHg}_{d}+\frac{K_{\text {lap-MeHg}} q_{\text {cap-MeHg}} A_{p d} \mathrm{MeHg}_{d}}{10^{3}+K_{\text {lap-MeHg }} M e H g_{d}} \\
& +\frac{K_{l p o m-\mathrm{MeHg}} q_{\text {cpom-MeHg}} P O M \cdot \mathrm{MeHg}_{d}}{10^{3}+K_{\text {lpom-MeHg }} M e H g_{d}}+\sum_{n=1}^{N} \frac{K_{l p n-\mathrm{MeHg}} q_{\text {cn-MeHg }} m_{n} \mathrm{MeHg}_{d}}{10^{3}+K_{l p n-\mathrm{MeHg}} M e H g_{d}}=\mathrm{MeHg}
\end{aligned}
$$

Sediment layer:

$$
\begin{aligned}
& H g I I_{d 2}+10^{-6} K_{d o c-H g I I 2} D_{2} C_{2} H g I I_{d 2}+\frac{K_{l p o m-H g I I 2} q_{\text {cpom-HgIL }} P M_{2}\left(H g I I_{d 2} / \varphi\right)}{10^{3}+K_{l p o m-H g I I 2}\left(H g I I_{d 2} / \varphi\right)} \\
& +\sum_{n=1}^{N} \frac{K_{l p n-H g I I 2} q_{c n-H g I I 2} m_{n 2}\left(H g I I_{d 2} / \varphi\right)}{10^{3}+K_{l p n-H g I I 2}\left(H g I I_{d 2} / \varphi\right)}=H g I I_{2} \\
& \mathrm{MeHg}_{d 2}+10^{-6} K_{\text {doc-MeHg2 }} \mathrm{DOC}_{2} \cdot \mathrm{MeHg}_{d 2}+\frac{K_{\text {lpom-MeHg2 }} q_{\text {cpom-MeHg2 }} \mathrm{POM}_{2}\left(\mathrm{MeHg}_{d 2} / \varphi\right)}{10^{3}+K_{\text {lpom-MeHg2 }}\left(\mathrm{MeHg}_{d 2} / \varphi\right)} \\
& +\sum_{n=1}^{N} \frac{K_{l p n-M e H g 2} q_{c n-M e H g 2} m_{n 2}\left(\mathrm{MeHg}_{d 2} / \varphi\right)}{10^{3}+K_{l p n-\mathrm{MeHg} 2}\left(\mathrm{MeHg}_{d 2} / \varphi\right)}=\mathrm{MeHg}_{2}
\end{aligned}
$$

where

$K_{\text {lap-HgII }}=H g I I$ Langmuir adsorption constant for algae in water $\left({\left.\mathrm{L} \mu g^{-1}\right)}^{-1}\right.$

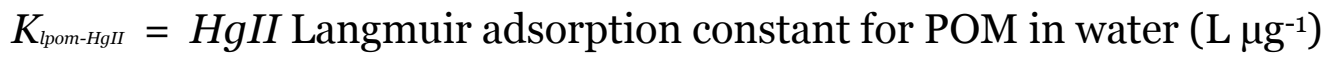

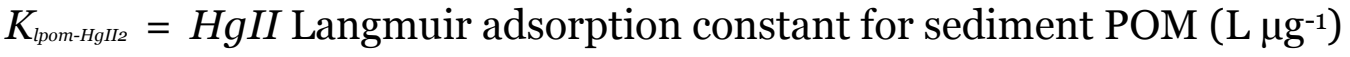

$K_{\text {lpn-HgII }}=H g I I$ Langmuir adsorption constant for solid " $n$ " in water $\left(\mathrm{L} \mathrm{\mu g}^{-1}\right)$

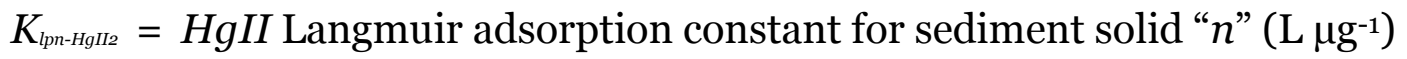

$q_{\text {cap-HgII }}=$ maximum amount of $H g I I$ adsorbed by algae in water $\left(\mu g^{-1}\right)$

$q_{\text {cpom-HgII }}=$ maximum amount of $H g I I$ adsorbed by POM in water $\left(\mu \mathrm{g} \mathrm{g}^{-1}\right)$

$q_{\text {cpom-HgII }}=$ maximum amount of $H g I I$ adsorbed by sediment POM $\left(\mu g^{-1}\right)$

$q_{c n-H g I I}=$ maximum amount of $H g I I$ adsorbed by solid " $n$ " in water $\left(\mu g^{-1}\right)$

$q_{\text {cn-HgIl }}=$ maximum amount of $H g I I$ adsorbed by sediment solid " $n$ " $\left(\mu g^{-1}\right)$

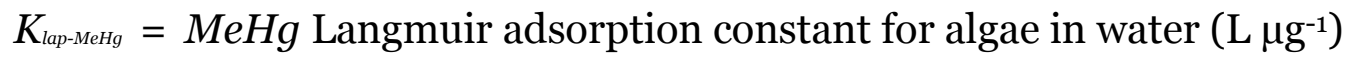

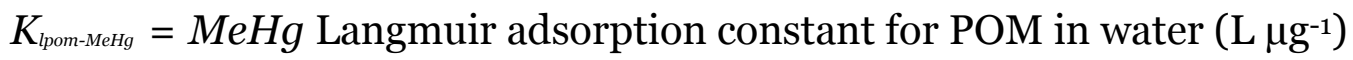

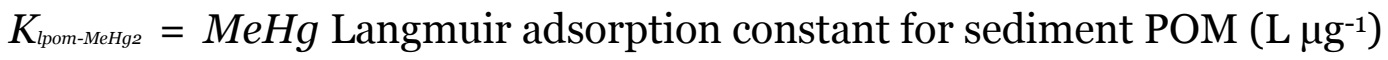




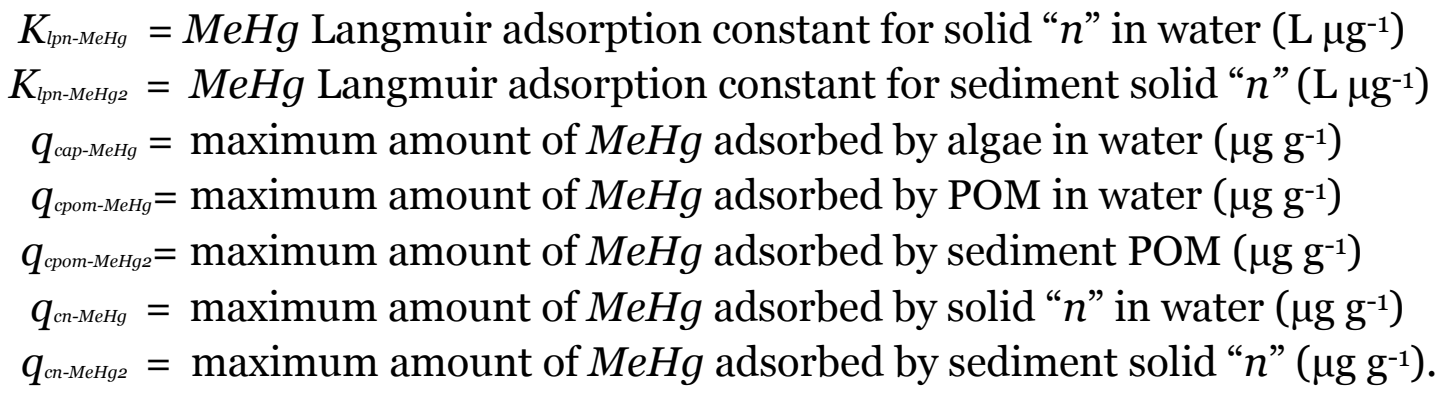

\subsubsection{Non-equilibrium partitioning}

As discussed by several researchers (e.g. Hudson et al. 1994; Yin et al. 1997), HgII sorption onto algae and solids is partially instantaneous and partially rate limited (slow). HgII species are strongly adsorbed by soils and sediments and are desorbed slowly. Clay minerals adsorb mercury maximally at $\mathrm{pH}$ 6. In acid soils, most mercury is adsorbed by organic matter. When organic matter is not present, mercury becomes relatively more mobile in acid soils. Therfore a non-equilibrium sorption of $H g I I$ onto algae, POM and inorganic solids is included in HgSM. Rate limited adsorption and desorption equations of $\mathrm{HgII}$ with algae, POM and suspended solids can be written as

$$
\begin{gathered}
\frac{\partial H g I I_{a p}}{\partial t}=10^{-3} k_{\text {adap }}\left(q_{c a p-H g I I} A_{p d}-H g I I_{a p}\right) H g I I_{d}-k_{\text {daap }} H g I I_{a p} \\
\frac{\partial H g I I_{p o m}}{\partial t}=10^{-3} k_{\text {adpom }}\left(q_{\text {cpom- }-H g I I} P O M-H g I I_{\text {pom }}\right) H g I I_{d}-k_{\text {dapom }} H g I I_{p o m} \\
\frac{\partial H g I I_{p n}}{\partial t}=10^{-3} k_{a d n}\left(q_{c n-H g I I} m_{n}-H g I I_{p n}\right) H g I I_{d}-k_{d a n} H g I I_{p n}
\end{gathered}
$$

where

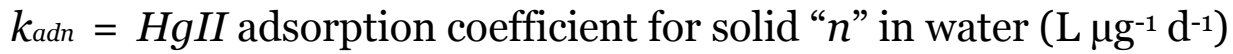

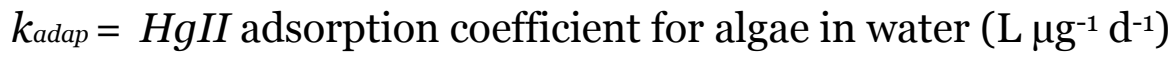

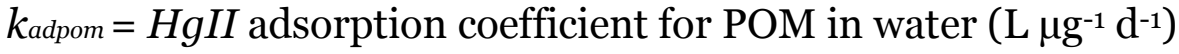

$$
\begin{aligned}
& k_{d a n}=H g I I \text { desorption rate for solid " } n \text { " in water }\left(\mathrm{d}^{-1}\right) \\
& k_{\text {daap }}=H g I I \text { desorption rate for algae in water }\left(\mathrm{d}^{-1}\right) \\
& k_{\text {dapom }}=H g I I \text { desorption rate for POM in water }\left(\mathrm{d}^{-1}\right) \text {. }
\end{aligned}
$$

Rate limited adsorption and desorption equations of $\mathrm{HgII}$ with POM and solids in the sediment layer can be written as 


$$
\begin{gathered}
\frac{\partial H g I I_{\text {pom } 2}}{\partial t}=10^{-3} k_{\text {adpom } 2}\left(q_{\text {cpom-HgII }} P O M_{2}-H g I I_{\text {pom } 2}\right) \frac{H g I I_{d 2}}{\varphi}-k_{\text {dapom } 2} H g I I_{\text {pom } 2} \\
\frac{\partial H g I I_{p n 2}}{\partial t}=10^{-3} k_{a d n 2}\left(q_{c n-H g I I 2} m_{n 2}-H g I I_{p n 2}\right) \frac{H g I I_{d 2}}{\varphi}-k_{d a n 2} H g I I_{p n 2}
\end{gathered}
$$

where

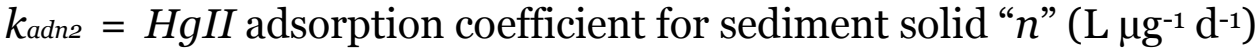

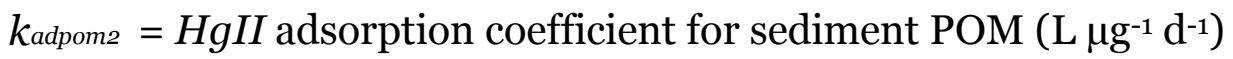

$$
\begin{aligned}
& k_{\text {dan } 2}=H g I I \text { desorption rate for sediment solid " } n \text { " }\left(\mathrm{d}^{-1}\right) \\
& k_{\text {dapom } 2}=H g I I \text { desorption rate for sediment } \operatorname{POM}\left(\mathrm{d}^{-1}\right) \text {. }
\end{aligned}
$$

\subsection{Mercury transformations}

The oxidation, reduction, methylation and demethylation reactions of mercury species are assumed to be widespread in the environment. Some of the reaction processes have not been well understood and defined. Therefore simplified transformation processes among the mercury state

\begin{tabular}{|c|c|c|c|c|c|}
\hline \multirow[b]{2}{*}{ Species } & \multicolumn{3}{|c|}{ Water column } & \multicolumn{2}{|c|}{ Sediment layer } \\
\hline & HgO & Hgll & $\mathrm{MeHg}$ & Hgll & $\mathrm{MeHg}$ \\
\hline $\mathrm{HgO}$ & & $\begin{array}{l}\text { Oxidation (HgO-- } \\
>\text { Hgll) }\end{array}$ & & & \\
\hline Hgll & $\begin{array}{l}\text { Photoreduction } \\
\text { (Hgll-->HgO) }\end{array}$ & & $\begin{array}{l}\text { Methylation } \\
\text { (Hgll-->MeHg) }\end{array}$ & & \begin{tabular}{|l} 
Methylation \\
$(\mathrm{Hg} \mid \mathrm{I}->\mathrm{MeHg})$
\end{tabular} \\
\hline $\mathrm{MeHg}$ & $\begin{array}{l}\text { Photoreduction } \\
\text { (MeHg-->Hg0) }\end{array}$ & $\begin{array}{l}\text { Demethylation } \\
\text { (MeHg-->HgII) }\end{array}$ & & $\begin{array}{l}\text { Demethylation } \\
\text { (MeHg-->Hgll) }\end{array}$ & \\
\hline
\end{tabular}
variables are modeled in $\mathrm{HgSM}$. Table 17 summarizes the key reaction and transformation processes modeled in $\mathrm{HgSM}$.

Table 17. Mercury species and their transformations modeled in HgSM.

In natural waters, the transformations of dissolved $\mathrm{HgII}$ and $\mathrm{MeHg}$ include mercury complexes with DOC (Nriagu 1979; Bloom et al. 1991). Therefore, the user can assign the DOC adsorbed phase that is available for the transformation in $\mathrm{HgSM}$.

\subsubsection{Elemental mercury oxidation}

Hgo can be relatively quickly oxidized by different reagents, mainly oxygen but also nitrates, nitrites, iron hydroxides, iron phosphates, sulphates, sulphur, and carbon dioxide (Stein et al. 1996). In HgSM, oxidation from 
$\mathrm{Hgo}$ to $\mathrm{HgII}$ is modeled as a first-order process. The first-order oxidation rate is calculated as a function of $\mathrm{HgO}$ concentration in the water column

$$
H g o \rightarrow H g I I=k_{12}(T) \cdot H g O
$$

where

$H g o-->H g I I=H g o$ oxidation yield into $H g I I$ in water $\left(\mathrm{ng} \mathrm{L}^{-1} \mathrm{~d}^{-1}\right)$

$k_{12}(T)=H g o$ oxidation rate in water $\left(\mathrm{d}^{-1}\right)$.

The $H g o$ oxidation rate $\left(k_{12}\right)$ are temperature dependent and corrected using the AE. The oxidation yield, $\mathrm{HgO}-->H g I I$, is subtracted from the $H g o$ as a sink (-) and added to the $H g I I$ as a source (+) with a specified yield coefficient $\left(Y_{12}\right)$ of 1.0.

\subsubsection{Inorganic mercury reduction}

Hgo may be formed through the reduction of $\mathrm{HgII}$ or the demethylation of $\mathrm{MeHg}$ (Allard and Arsenie 1991). On the basis of experimental data some authors indicate the biological processes as the most important, while others suggest that photoreduction reactions play the dominant role (Costa and Liss 2000). Photoreduction of $\mathrm{HgII}$ to $\mathrm{HgO}$ is light dependent; thus, reduction of $H g I I$ is expected to peak at midday. In HgSM, HgII reduction is assumed to be driven by sunlight, and the surface reduction rate is attenuated through the water column using a specified light extinction coefficient. Photoreduction from $\mathrm{HgII}$ to $\mathrm{Hgo}$ in the water column is modeled as a photolysis process as with the photoreduction kinetics used in WASP

$$
H g I I \rightarrow H g O=1.33 \frac{I_{0}}{I_{\text {opht }}} \frac{1-e^{-\lambda_{\text {max }} \cdot h}}{\lambda_{\text {max }} \cdot h}\left(1-0.56 C_{L}\right)\left(k_{d 21} f_{d-H g I I}+k_{d o c 21} f_{d o c-H g I I}\right) H g I I
$$

where

$$
\begin{gathered}
H g I I-->H g o=H g I I \text { photoreduction yield into } H g o \text { in water }\left(\mathrm{ng} \mathrm{L}^{-1} \mathrm{~d}^{-1}\right) \\
k_{d 21}=\text { dissolved } H g I I \text { photoreduction rate in water }\left(\mathrm{d}^{-1}\right) \\
k_{d o c 21}=\text { DOC adsorbed } H g I I \text { photoreduction rate in water }\left(\mathrm{d}^{-1}\right) .
\end{gathered}
$$

The surface photoreduction rates $\left(k_{d_{21}}, k_{d o c 21}\right)$ are not temperature dependent. The photoreduction yield, $H g I I-->H g o$, is subtracted from the 
$\mathrm{HgII}$ as a sink (-) and added to the $\mathrm{HgO}$ as a source (+) with a specified yield coefficient $\left(Y_{21}\right)$ of 1.0.

\subsubsection{Mercury methylation}

Several studies indicated that $H g I I$ methylation is the dominant source of $\mathrm{MeHg}$ in aquatic systems (USEPA 1997; EPRI 2013). HgII can be methylated to $\mathrm{MeHg}$ in water phase through biotic (microbially mediated) pathways or abiotic pathways (photo-mediated or non photo-mediated chemical methylation) (Stein 1996; Ullrich 2001). Methylation takes place mainly in surface layers of sediments and in soils, but it can also take place in water column although more weakly (Regnell et al. 1996). The mechanisms of $\mathrm{HgII}$ methylation in water column have not been fully recognized yet, but it is assumed that they involve microorganisms, similarly as in bed sediments (Morel et al. 1998).

HgII must be in solution or easily transferrable form for methylation (Benoit et al. 2003; Marvin-DiPasquale et al. 2009). Distribution of mercury species between the solid and aqueous phase significantly affects the bioavailability of the $\mathrm{Hg}$ species. DOC interacts strongly with dissolved $\mathrm{HgII}$ and likely affects methylation rate and $\mathrm{MeHg}$ production. Gilmour and Henry (1991) reported that increased DOC in the water column may increase ligand formation between DOC and dissolved $\mathrm{HgII}$, making it unavailable for microbial methylation. In $\mathrm{HgSM}$, methylation from $\mathrm{HgII}$ to $\mathrm{MeHg}$ in the water column is modeled as a first-order kinetic process based on the algorithm used in WASP

$$
H g I I \rightarrow M e H g=\left(k_{d 23}(T) f_{d-H g I I}+k_{d o c 23}(T) f_{d o c-H g I I}\right) H g I I
$$

where

$H g I I-->M e H g=H g I I$ methylation yield in water $\left(\mathrm{ng} \mathrm{L}^{-1} \mathrm{~d}^{-1}\right)$

$k_{d 23}(T)=$ dissolved $H g I I$ methylation rate in water $\left(\mathrm{d}^{-1}\right)$

$k_{\text {doc23 }}(T)=$ DOC sorbed $H g I I$ methylation rate in water $\left(\mathrm{d}^{-1}\right)$.

The water column $\mathrm{HgII}$ methylation rates $\left(k_{d_{23}}, k_{d o c 23}\right)$ are temperature dependent and corrected using the AE.

In the sediment layer sulfate reducing bacteria (SRB) are the most important for the biological methylation of $H g I I$. Sulfur, organic carbon, 
sediment structure, and composition in the sediment layer all affect $\mathrm{MeHg}$ production by changing the amount of bioavailable $\mathrm{HgII}$ and by stimulating SRB activity (Langer et al. 2001; Mason et al. 2005; Lin et al. 2012).

The $H g I I$ methylation rate is linked to sulfate reduction. Strong relationships were observed between sulfate reducing rates and $\mathrm{HgII}$ methylation rates in sediments (Benoit et al. 1999; King et al. 1999; King et al. 2001). Langer et al. (2001) shows the relationship between $H g I I$ methylation and sulfate in sediments (Figure 7. ).

As shown in Figure 7, the $H g I I$ methylation rate in high-sulfate estuarine sediments is far lower than the rate in low-sulfate freshwater sediments. In fresh water sediments, methylation has been observed to be optimal when sulfate concentrations range between 2 and $100 \mu \mathrm{M}$. Above this favorable range of sulfate concentrations, the production of sulfide through sulfate reduction would inhibit mercury methylation. Below this sulfate concentration range, sulfate availability would limit sulfate reduction and mercury methylation. The amount of $\mathrm{MeHg}$ increased in proportion to the concentration of sulfate, then the $\mathrm{MeHg}$ decreased. Sulfate reduction removes the sulfate and ultimately produces sulfide. The overall reaction equation is $\mathrm{SO}_{4}^{-2}+2 \mathrm{CH}_{2} \mathrm{O} \rightarrow \mathrm{S}^{-2}+2 \mathrm{CO}_{2}+2 \mathrm{H}_{2} \mathrm{O}$.

Figure 7. Relationship between Hgll methylation and sulfate in sediments (Langer et al. 2001).

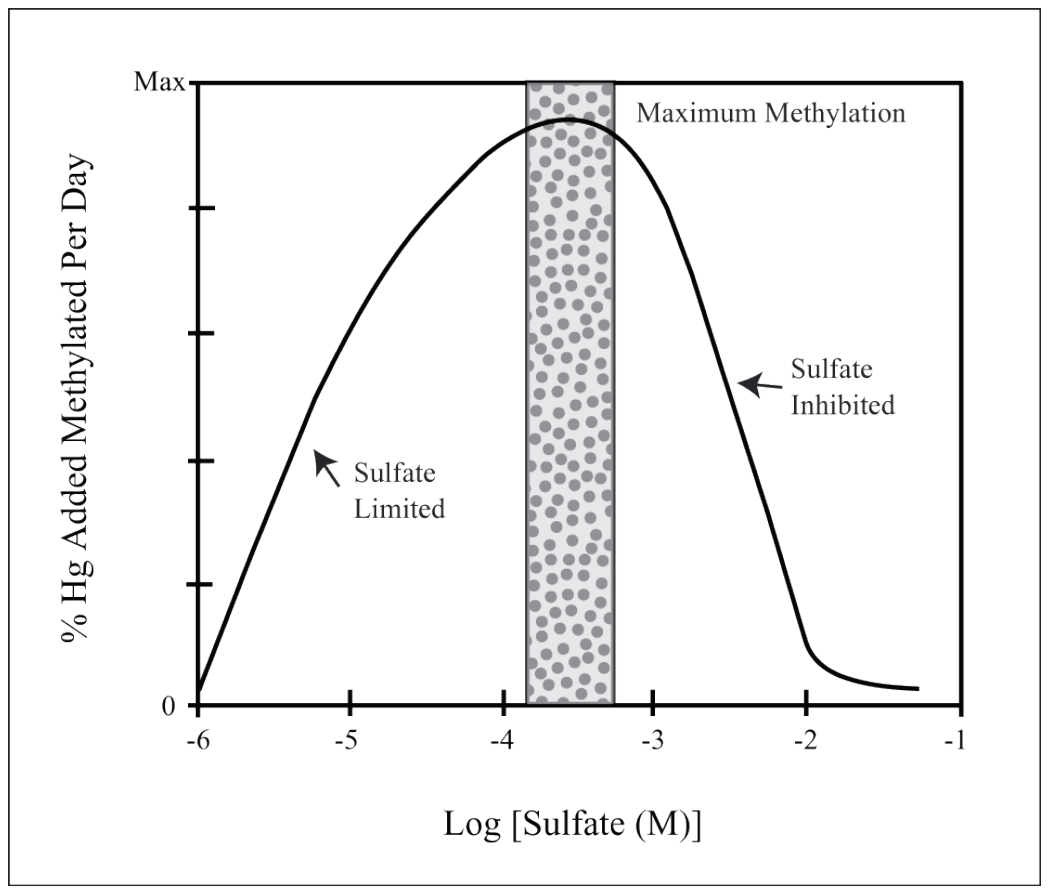


The reaction of $\mathrm{HgII}$ with sulfide to produce insoluble $\mathrm{HgS}$ decreases the availability of $H g I I$ for methylation (Gilmour et al. 1998). In HgSM, the sediment $H g I I$ methylation rate is simply calculated as a function of sulfate and dissolved $\mathrm{HgII}$ concentration based on the algorithm used in WARMF (EPRI 2006)

$$
(\mathrm{HgII} \rightarrow \mathrm{MeHg})_{2}=k_{\mathrm{SO} 42}(\mathrm{~T})\left(\frac{\mathrm{SO}_{2}}{\mathrm{~K}_{\mathrm{SO} 4}+\mathrm{SO}_{2}}\right) \mathrm{SO}_{2} r_{m s 04} f_{d-\mathrm{HgII}_{2}} \mathrm{HgII}_{2}
$$

where

$$
\begin{aligned}
& (H g I I-->M e H g)_{2}=H g I I \text { methylation yield in sediment }\left(\mathrm{ng} \mathrm{L}^{-1} \mathrm{~d}^{-1}\right) \\
& k_{\text {SO42 }}(T)=\text { sediment sulfate reduction rate }\left(\mathrm{d}^{-1}\right) \\
& r_{m s 04}=\text { ratio of sediment methylation rate and sulfate reduction rate }(\mathrm{L} \\
& \mathrm{mg}^{-1} \text { ) } \\
& \mathrm{KSO}_{4}=\text { half-saturation constant for the effect of sulfate on methylation } \\
& \left(\mathrm{mg}-\mathrm{O}_{2} \mathrm{~L}^{-1}\right) \\
& \mathrm{SO}_{42}=\text { sediment pore water sulfate concentration }\left(m g-\mathrm{O}_{2} \mathrm{~L}^{-1}\right) \text {. }
\end{aligned}
$$

The above equation relates methylation to the sediment sulfate reduction rate but requires that the sulfate must be modeled in the system. A halfsaturation constant is used to adjust the sulfate effect on the methylation rate. This relationship results in methylation rate dependencies which are nearly linear when sulfate concentrations are much less than $K_{\text {sou. }}$. Conversely, the methylation rate does not vary with sulfate if the sulfate is much greater than $K_{\text {so4. }}$. However, the above algorithm does not adequately capture the complex interactions between $\mathrm{MeHg}$ production and the sulfur cycle. The inhibitory influence of $\mathrm{H}_{2} \mathrm{~S}$ on $\mathrm{HgII}$ methylation is not otherwise captured in the above equation 4.10.

The sediment sulfate reduction rate is temperature dependent. A Q10 equation is used to correct sulfate reduction rate according to local temperature (Wool et al. 2006; EPRI 2013). The methylation yield, $H g I I--$ $>\mathrm{MeHg}$, is subtracted from the $\mathrm{HgII}$ as a sink (-) and added to the $\mathrm{MeHg}$ as a source $(+)$ with a specified yield coefficient $\left(Y_{23}\right)$ of 1.07 .

\subsubsection{Methylmercury reduction}

Photolysis of $\mathrm{MeHg}$ has been shown to occur in water (Callahan et al. 1979). Photoreduction from $\mathrm{MeHg}$ to $\mathrm{Hgo}$ is simulated as a light dependent process in HgSM. This process occurs primarily in the water 
surface due to light attenuation. Photoreduction of $\mathrm{MeHg}$ can also be affected by the speciation of $\mathrm{MeHg}$ in the water column. A previous study reported that sunlight induced $\mathrm{MeHg}$ photoreduction could not occur when the $\mathrm{MeHgCl}, \mathrm{MeHgOH}$ or $\mathrm{MeHg}$ ion was the dominant species of $\mathrm{MeHg}$ in water, and while phenyl and sulfur bonded $\mathrm{MeHg}$ species could be decomposed (Baughman et al. 1973).

In $\mathrm{HgSM}$, the $\mathrm{MeHg}$ reduction rate is calculated based on the light attenuation and available $\mathrm{MeHg}$ in the water column

$$
M e H g \rightarrow H g O=1.33 \frac{I_{0}}{I_{\text {opht }}} \frac{1-e^{-\lambda_{\text {max }} h}}{\lambda_{\text {max }} \cdot h}\left(1-0.56 C_{L}\right)\left(k_{d 11} f_{d-M e H g}+k_{\text {doc31 }} f_{\text {doc-MeHg }}\right) M e H g(4.12)
$$

where

$M e H g-->H g o=M e H g$ photoreduction yield into $H g o$ in water $\left(\mathrm{ng} \mathrm{L}^{-1} \mathrm{~d}^{-1}\right)$

$k_{d_{31}}=$ dissolved $\mathrm{MeHg}$ photoreduction rate in water $\left(\mathrm{d}^{-1}\right)$

$k_{d o c 31}=$ DOC adsorbed $\mathrm{MeHg}$ photoreduction rate in water $\left(\mathrm{d}^{-1}\right)$.

The surface photoreduction rates $\left(k_{d_{31}}, k_{d_{0}{ }_{31}}\right)$ are not temperature dependent. The photoreduction yield is subtracted from the $\mathrm{MeHg}$ as a sink (-) and added to the $\mathrm{HgO}$ as a source (+) with a specified yield coefficient $\left(Y_{31}\right)$ of 0.93 .

\subsubsection{Mercury demethylation}

Methylation and demethylation are concurrent reactions. Demethylation is a reverse process of $\mathrm{HgII}$ methylation. As not all of mercury complexes are available for methylation and demethylation, speciation of $H g I I$ and $\mathrm{MeHg}$ in water and pore water is an important factor determining bioavailability of mercury species. Demethylation of $\mathrm{MeHg}$ is also influenced by biotic and abiotic factors (photodemethylation or non photo-mediated demethylation (Hobman et al. 2000). Demethylation by photolysis is assumed to occur in the water column. In $\mathrm{HgSM}$, the water column demethylation from $\mathrm{MeHg}$ to $\mathrm{HgII}$ is modeled as a hydrolysis process

$$
\mathrm{MeHg} \rightarrow \mathrm{HgII}=1.33 \frac{I_{0}}{I_{\mathrm{opht}}} \frac{1-e^{-\lambda_{\max } \cdot h}}{\lambda_{\max } \cdot h}\left(1-0.56 C_{L}\right)\left(k_{d 32} f_{d-\mathrm{MeHg}}+k_{\text {doc } 32} f_{\text {doc }-\mathrm{MeHg}}\right) \mathrm{MeHg}(4.13
$$

where 
$M e H g-->H g I I=M e H g$ demethylation yield into $H g I I$ in water $\left(\mathrm{ng} \mathrm{L}^{-1} \mathrm{~d}^{-1}\right)$ $k_{d_{32}}=$ dissolved $\mathrm{MeHg}$ demethylation rate in water $\left(\mathrm{d}^{-1}\right)$ $k_{d o c 32}=$ DOC adsorbed $M e H g$ demethylation rate in water $\left(\mathrm{d}^{-1}\right)$.

There are several possible pathways for $\mathrm{MeHg}$ demethylation that are discussed in the literature (Marvin-DiPasquale et al. 2000). The biotic process was suggested to be the dominant pathway of $\mathrm{MeHg}$ demethylation in the sediment layer. The biological demethylation of $\mathrm{MeHg}$ is a slow process in contrast to methylation and is most effective in aerobic conditions (Gilmour and Henry 1991). The turnover time of $\mathrm{MeHg}$ demethylation in sediments is on the order of days to weeks. In HgSM, the sediment demethylation from $\mathrm{MeHg}$ to $\mathrm{HgII}$ is modeled as a first-order process acting on the dissolved $\mathrm{MeHg}$ based on based on the algorithm used in WASP

$$
(\mathrm{MeHg} \rightarrow \mathrm{HgII})_{2}=k_{d 32-2}(T) f_{d-\mathrm{MeHg} 2} \mathrm{MeHg}_{2}
$$

where

$(\mathrm{MeHg}-->\mathrm{HgII})_{2}=\mathrm{MeHg}$ demethylation yield in sediment $\left(\mathrm{ng} \mathrm{L}^{-1} \mathrm{~d}^{-1}\right)$

$k_{d_{32-2}(T)}=$ dissolved $\mathrm{MeHg}$ demethylation rate in sediment $\left(\mathrm{d}^{-1}\right)$.

The water column demethylation rates $\left(k_{d_{32}}, k_{d_{0} c_{2}}\right)$ are not temperature dependent. The sediment demethylation rate is temperature dependent and corrected using the AE. An activation energy value $\left(E_{a}\right)$ of $10 \mathrm{Kcal}$ $\mathrm{mol}^{-1}\left(41.84 \mathrm{KJ} \mathrm{mol}^{-1}\right)$ is used as the default value. The demethylation yield, $\mathrm{MeHg}-->H g I I$, is subtracted from the $\mathrm{MeHg}$ as a sink (-) and added to the $H g I I$ as a source $(+)$ with a specified yield coefficient $\left(Y_{32}\right)$ of 0.93 .

\subsection{Mercury volatilization}

Volatilization of both $\mathrm{HgO}$ and $\mathrm{MeHg}$ are modeled in $\mathrm{HgSM}$ at the surface of the water column. Volatilization of $H g I I$ is ignored in the model since HgII has much lower Henry's Law Constants (USEPA 1997). The volatilization rate is calculated using a two-phase film resistance theory as discussed in CSM. In HgSM, volatilization rates can also be defined by the user, which is referenced to $20^{\circ} \mathrm{C}$. 


\subsubsection{Elemental mercury}

$\mathrm{HgO}$ is a liquid in water at ambient temperatures and can emit to the air via volatilization. The volatilization of $H g o$ represents the most important part of the exchange between water and the air. In HgSM, the $\mathrm{Hgo}$ volatilization across the air-water interface is calculated as

$$
A t m \rightarrow H g 0=v_{v-H g 0}(T) \frac{1}{h}\left(\mathrm{HgO}-\frac{\mathrm{HgO}_{0}}{K_{H} /\left(R \cdot T_{w k}\right)}\right)
$$

where

$$
\begin{aligned}
A t m-->H g o & =H g o \text { volatilization rate }\left(\mathrm{ng} \mathrm{L}^{-1} \mathrm{~d}^{-1}\right) \\
v_{v-H g o}(T) & =\text { volatilization velocity of } H g o\left(\mathrm{~m} \mathrm{~d}^{-1}\right) \\
H g O_{o} & =\text { air concentration of } H g o(\text { gaseous })\left(\mathrm{ng} \mathrm{L}^{-1}\right) \\
K_{H-H g o} & =\text { Henry's Law constant of } H g o\left(\mathrm{~Pa} \mathrm{~m}^{3} \mathrm{~mol}^{-1}\right) .
\end{aligned}
$$

Air-surface exchange of $\mathrm{HgO}$ can occur bi-directionally, allowing transfer of mercury from the atmosphere. Ambient air concentrations of $\mathrm{HgO}$ are reported to range from about 2 to $10 \mathrm{ngm}-3$, with the higher end of this range reflecting contributions from specific local sources (ATSDR 2005).

\subsubsection{Methylmercury}

Similar to Hgo, the $\mathrm{MeHg}$ volatilization across the air-water interface is calculated as

$$
A t m \rightarrow M e H g=v_{v-\text { MeHg }} \frac{1}{h}\left(\mathrm{f}_{\mathrm{d}-\mathrm{MeHg}} \mathrm{MeHg}-\frac{\mathrm{MeHg}_{0}}{K_{H} /\left(R \cdot T_{w k}\right)}\right)
$$

where

$$
\begin{aligned}
A t m-->M e H g & =M e H g \text { volatilization rate }\left(\mathrm{ng} \mathrm{L}^{-1} \mathrm{~d}^{-1}\right) \\
v_{v-M e H g}(\mathrm{~T}) & =\text { volatilization velocity of } \mathrm{MeHg}\left(\mathrm{m} \mathrm{d}^{-1}\right) \\
M e H g_{o} & =\text { air concentration of } M e H g(\text { gaseous })\left(\mathrm{ng} \mathrm{L}^{-1}\right) \\
K_{H-M e H g} & =\text { Henry's Law constant of } M e H g\left(\mathrm{~Pa} \mathrm{~m}^{3} \mathrm{~mol}^{-1}\right) .
\end{aligned}
$$

\subsection{Mercury air deposition, settling and sedimentation}

Mercury may be added to a water body through both wet and dry atmospheric deposition. Atmospheric deposition of $\mathrm{HgII}$ and $\mathrm{MeHg}$ is 
included in HgSM. In addition, mercury attached to suspended solids can settle onto the sediments where it can diffuse into the water column, be resuspended, or be buried to deep sediments. Mercury settling, sediment resuspension and the burial processes are assumed to operate on all particulate fractions of $\mathrm{HgII}$ and $\mathrm{MeHg}$ in $\mathrm{HgSM}$.

\subsubsection{Air deposition}

Atmospheric deposition of $\mathrm{HgII}$ and $\mathrm{MeHg}$ represent the sum of wet and dry mercury deposition. In $\mathrm{HgSM}$, deposition rates of $\mathrm{HgII}$ and $\mathrm{MeHg}$ are calculated by

$$
\begin{gathered}
A t m \rightarrow H g I I=A_{s} L_{\mathrm{HgII}} \\
A t m \rightarrow M e H g=A_{s} L_{\mathrm{MeHg}}
\end{gathered}
$$

where

$$
\begin{aligned}
A t m-->H g I I & =\text { HgII air deposition }\left(\mathrm{ng} \mathrm{L}^{-1} \mathrm{~d}^{-1}\right) \\
A t m-->M e H g & =\text { MeHg air deposition }\left(\mathrm{ng} \mathrm{L}^{-1} \mathrm{~d}^{-1}\right) \\
A_{s} & =\text { surface water area }\left(\mathrm{m}^{-2}\right) \\
L_{H g I I} & =\text { HgII areal air deposition rate }\left(\mu \mathrm{g} \mathrm{m}^{-2} \mathrm{~d}^{-1}\right) \\
L_{M e H g} & =\text { MeHg areal air deposition rate }\left(\mu \mathrm{g} \mathrm{m}^{-2} \mathrm{~d}^{-1}\right) .
\end{aligned}
$$

\subsubsection{Settling}

Mercury may enter the aquatic system in the insoluble form adsorbed onto suspended solids. Suspended solids can then settle either to the sediment layer or to an underlying water compartment. Settling of suspended solids will remove adsorbed mercury species in proportion to their bulk concentration. In HgSM, settling rates of solids adsorbed $\mathrm{HgII}$ and $\mathrm{MeHg}$ from the water column are calculated by

$$
\begin{array}{r}
H g I I \rightarrow B e d=-\frac{1}{h}\left(\sum_{n=1}^{N} v_{s p n} f_{p n-H g I I}+v_{s a p} f_{a p-H g I I}+v_{s o m} f_{p o m-H g I I}\right) H g I I \\
M e H g \rightarrow \text { Bed }=-\frac{1}{h}\left(\sum_{n=1}^{N} v_{s p n} f_{p n-M e H g}+v_{s a p} f_{a p-M e H g}+v_{s o m} f_{\text {pom-MeHg }}\right) M e H g
\end{array}
$$

where

$H g I I-->B e d=H g I I$ settling rate in water $\left(\mathrm{ng} \mathrm{L}^{-1} \mathrm{~d}^{-1}\right)$ 
$M e H g-->B e d=M e H g$ settling rate in water $\left(\mathrm{ng} \mathrm{L}^{-1} \mathrm{~d}^{-1}\right)$.

\subsubsection{Re-suspension}

The re-suspension/erosion of sediments refers to the process by which solids, and their adsorbed contaminants, are transported from the sediment layer into the water column. In HgSM, the re-suspension rates of $\mathrm{HgII}$ and $\mathrm{MeHg}$ are calculated respectively as the product of sediment adsorbed concentration and the re-suspension velocity

$$
\begin{gathered}
\text { Bed } \rightarrow H g I I=\frac{1}{h_{2}}\left(\sum_{n=1}^{N} v_{r p n} f_{p n-H g I I 2}\right) H g I_{2} \\
B e d \rightarrow M e H g=\frac{1}{h_{2}}\left(\sum_{n=1}^{N} v_{r p n} f_{p n-M e H g 2}\right) M e H g_{2}
\end{gathered}
$$

where

Bed-->HgII = sediment $H g I I$ re-suspension rate $\left(\mathrm{ng} \mathrm{L}^{-1} \mathrm{~d}^{-1}\right)$

Bed-->MeHg = sediment $M e H g$ re-suspension rate $\left(n g \mathrm{~L}^{-1} \mathrm{~d}^{-1}\right)$.

\subsubsection{Sediment burial}

As new sediments are deposited, an equal mass of sediment is lost to burial due to the constant sediment layer assumption. In $\mathrm{HgSM}$, the fluxes of $\mathrm{HgII}$ and $\mathrm{MeHg}$ out of the active sediment layer and into underlying sediments are calculated respectively as the product of active sediment adsorbed mercury concentration and burial velocity

$$
\begin{gathered}
\mathrm{HgII}_{2} \text { burial }=\frac{1}{h_{2}} v_{b}\left(\sum_{n=1}^{N} f_{\text {pn-HgII } 2}+f_{\text {pom-HgII } 2}\right) \mathrm{HgII}_{2} \\
\mathrm{MeHg} \text { burial }=\frac{1}{h_{2}} v_{b}\left(\sum_{n=1}^{N} f_{\text {pn-MeHg2 }}+f_{\text {pom-MeHg2 }}\right) \mathrm{MeHg}_{2}
\end{gathered}
$$

where

$\mathrm{HgII}_{2}$ burial $=$ sediment $\mathrm{HgII}$ burial rate $\left(\mathrm{ng} \mathrm{L}^{-1} \mathrm{~d}^{-1}\right)$

$\mathrm{MeHg}_{2}$ burial $=$ sediment $\mathrm{MeHg}$ burial rate $\left(\mathrm{ng} \mathrm{L}^{-1} \mathrm{~d}^{-1}\right)$. 


\subsubsection{Sediment-water transfer}

Dissolved mercury species in the sediment layer can transfer across the sediment-water interface, or vice versa. Pore water mass transfer is assumed to operate on all dissolved fractions of $\mathrm{HgII}$ and $\mathrm{MeHg}$. In $\mathrm{HgSM}$, sediment-water transfer fluxes of $\mathrm{HgII}$ and $\mathrm{MeHg}$ are calculated by

$$
\begin{aligned}
& H g I I \leftrightarrow H g I I_{2}=\frac{v_{m}}{h}\left[\left(f_{d-H g I I 2}+f_{\text {doc-HgII }}\right) H g I I_{2} / \varphi-\left(f_{d-H g I I}+f_{\text {doc-HgII }}\right) H g I I\right] \\
& M e H g \leftrightarrow M^{\prime} H g_{2}=\frac{v_{m}}{h}\left[\left(f_{d-M e H g 2}+f_{\text {doc-MeHg2 }}\right) M e H g_{2} / \varphi-\left(f_{d-M e H g}+f_{\text {doc-MeHg}}\right) M e H g\right]
\end{aligned}
$$

where

$H g I I<-->H g I I_{2}=H g I I$ sediment-water transfer $\left(\mathrm{ng} \mathrm{L}^{-1} \mathrm{~d}^{-1}\right)$ $\mathrm{MeHg}<-->\mathrm{MeHg}_{2}=\mathrm{MeHg}$ sediment-water transfer $\left(\mathrm{ng} \mathrm{L}^{-1} \mathrm{~d}^{-1}\right)$.

A positive flux results in the transport of mercury from the sediment to the overlying water, a negative flux means the transport of mercury from the overlying water to the sediment. A high concentration of $\mathrm{MeHg}$ at the interface between the oxic and anoxic layers could be a result of either production or accumulation of settling particulate matter (Cossa et al. 1994). The sediment-water mass-transfer velocity of $\mathrm{HgII}$ and $\mathrm{MeHg}$ is a user specified parameter or internally computed in the model. Four alternative sediment-water transfer equations implemented in $\mathrm{HgSM}$ are based on thoses included in CSM: 1) Thibodeaux et al. (2001), 2) Di Toro et al. (1981), 3) Boyer et al. (1994), and 4) Schink and Guinasso (1977).

\subsection{Water column mercury source/sink equations}

The pathways for three mercury species are depicted in Figure 6. Major processes modeled in HgSM include partitioning of $\mathrm{HgII}$ and $\mathrm{MeHg}$, particulate settling, re-suspension and burial, sediment-water diffusion, volatilization, and transformations. Meanwhile, mercury species can be transported together with water, DOC, and suspended solids. All concentrations in source and sink term equations of mercury state variables are expressed in terms of mass per unit volume of water plus solids (ng $\left.\mathrm{L}^{-1}\right)$. 


\subsubsection{Elemental mercury}

$\mathrm{Hgo}$ is the predominant mercury cycling product in the water column. Major processes involved in $\mathrm{HgO}$ cycling in the water column include $\mathrm{HgII}$ reduction to Hgo, demethylation, and volatilization. The internal source (+) and sink (-) terms of Hgo computed in HgSM are listed in Table 18.

Table 18. HgO source/sink terms and pathways.

\begin{tabular}{|c|c|}
\hline Source/Sink term* & Pathway \\
\hline \multicolumn{2}{|l|}{$S S_{H g 0}=$} \\
\hline$-v_{v-H g} \frac{1}{h}\left(\mathrm{Hg} 0-\frac{\mathrm{Hg}_{0}}{K_{H} / R T_{K}}\right)$ & $\mathrm{HgO}$ volatilization \\
\hline$-k_{12}(T) \cdot H g 0$ & HgO oxidation \\
\hline$+1.33 \frac{I_{0}}{I_{0 \mathrm{pht}}} \frac{1-e^{-\lambda_{\max } \cdot h}}{\lambda_{\max } \cdot h}\left(1-0.56 C_{L}\right)\left(k_{d 21} f_{d-H g I I}+k_{d o c 21} f_{d o c-H g I I}\right) H g I I \cdot Y_{21}$ & Hgll photoreduction \\
\hline$+1.33 \frac{I_{0}}{I_{0 \mathrm{pht}}} \frac{1-e^{-\lambda_{\max } \cdot h}}{\lambda_{\max } \cdot h}\left(1-0.56 C_{L}\right)\left(k_{d 31} f_{d-\mathrm{MeHg}}+k_{d o c 31} f_{d o c-\mathrm{MeHg}}\right) \mathrm{MeHg} \cdot Y_{31}$ & MeHg photoreduction \\
\hline
\end{tabular}

* $\mathrm{SS}_{\mathrm{HgO}}$ is the sum of internal source and sink terms of $\mathrm{HgO}$ in water $\left(\mathrm{ng} \mathrm{L}^{-1} \mathrm{~d}^{-1}\right)$.

$Y_{21}$ is the $\mathrm{Hgll}$ photoreduction yield coefficient in water.

$Y_{31}$ is the $\mathrm{MeHg}$ photoreduction yield coefficient in water.

\subsubsection{Inorganic mercury}

Major processes involved in $H g I I$ cycling in the water column include $H g I I$ reduction, methylation, settling of adsorbed particulates into the underlying sediment layer, $H g I I$ diffusion across the sediment-water interface, and sediment re-suspension. HgII may be adsorbed by DOC, algae, POM, and suspended solids. Both equilibrium and non-equilibrium partitioning of $\mathrm{HgII}$ are allowed in HgSM. Under the non-equilibrium partitioning option, the internal source and sink terms are computed separately for potential partitioning phases in a similar manner as is done for contaminants.

\subsubsection{Equilibrium partitioning}

Under equilibrium partitioning implementation, the internal source (+) and sink (-) terms of water column $\mathrm{HgII}$ are computed in HgSM for the total concentration and are listed in Table 19. 
Table 19. Water column total Hgll source/sink terms and pathways under equilibrium partitioning.

\begin{tabular}{|c|c|}
\hline Source/Sink term* & Pathway \\
\hline \multicolumn{2}{|l|}{$S S_{H g I I}=$} \\
\hline$+A_{s} L_{H g I I}$ & $\begin{array}{l}\text { Atmospheric Hgll } \\
\text { deposition }\end{array}$ \\
\hline$-\frac{1}{h}\left(\sum_{n=1}^{N} v_{s p n} f_{p n-H g I I}+v_{s a p} f_{a p-H g I I}+v_{s o m} f_{p o m-H g I I}\right) H g I I$ & Hgll settling \\
\hline$+\frac{1}{h}\left(\sum_{n=1}^{N} v_{r p n} f_{p n-H g I I 2}\right) H g I I_{2}$ & Hgll re-suspension \\
\hline$+\frac{v_{m}}{h}\left[\left(f_{d-H g I I 2}+f_{d o c-H g I I 2}\right) H g I I_{2} / \phi-\left(f_{d-H g I I}+f_{d o c-H g I I}\right) H g I I\right]$ & $\begin{array}{l}\text { Hgll sediment-water } \\
\text { transfer }\end{array}$ \\
\hline$+k_{12}(T) \cdot H g O \cdot Y_{12}$ & Hg0 oxidation \\
\hline$-1.33 \frac{I_{0}}{I_{0 \mathrm{pht}}} \frac{1-e^{-\lambda_{\max } \cdot h}}{\lambda_{\max } \cdot h}\left(1-0.56 C_{L}\right)\left(k_{d 21} f_{d-H g I I}+k_{d o c 21} f_{d o c-H g I I}\right) H g I I$ & Hgll photoreduction \\
\hline$-\left(k_{d 23}(T) f_{d-H g I I}+k_{d o c 23}(T) f_{d-H g I I}\right) H g I I$ & Hgll methylation \\
\hline$+1.33 \frac{I_{0}}{I_{0 \mathrm{pht}}} \frac{1-e^{-\lambda_{\max } \cdot h}}{\lambda_{\max } \cdot h}\left(1-0.56 C_{L}\right)\left(k_{d 32} f_{d-\mathrm{MeHg}}+k_{d o c 32} f_{d o c-M e H g}\right) \mathrm{MeHg} \cdot Y_{32}$ & MeHg demethylation \\
\hline
\end{tabular}

* $\mathrm{SS}_{\mathrm{Hg} / l}$ is the sum of internal source and sink terms of total $\mathrm{Hgll}$ in water ( $\left.\mathrm{ng} \mathrm{L}^{-1} \mathrm{~d}^{-1}\right)$.

$\mathrm{Y}_{12}$ is the $\mathrm{HgO}$ oxidation yield coefficient in water.

$Y_{32}$ is the $\mathrm{MeHg}$ demethylation yield coefficient in water.

\subsubsection{Non-equilibrium partitioning}

Under non-equilibrium partitioning implementation, the state variables for $\mathrm{HgII}$ include concentrations of potential phases. The internal source and sink equations of $H g I I$ are developed in a similar manner as for nonequilibrium partitioning of contaminants implemented in CSM. The internal source (+) and sink (-) terms of water column HgII are computed in $\mathrm{HgSM}$ for dissolved, DOC adsorbed, algae adsorbed, POM adsorbed, and solids adsorbed $H g I I$ and are listed in Table 20.

Table 20. Water column Hgll partitioning phase source/sink terms and pathways under nonequilibrium partitioning.

\begin{tabular}{|l|l|}
\hline Source/Sink term* & Pathway \\
\hline \multicolumn{2}{|c|}{ Dissolved Hgll } \\
\hline$S S_{\text {HgIld }}=$ & $\begin{array}{l}\text { Atmospheric Hgll } \\
\text { deposition }\end{array}$ \\
\hline$+A_{s} L_{H g I I}$ & \\
\hline
\end{tabular}




\begin{tabular}{|c|c|}
\hline Source/Sink term* & Pathway \\
\hline$+\frac{v_{m}}{h}\left[H g I I_{d 2} / \phi-H g I I_{d}\right]$ & $\begin{array}{l}\text { Hgll sediment-water } \\
\text { transfer }\end{array}$ \\
\hline$+k_{12}(T) \cdot H g O \cdot Y_{12}$ & HgO oxidation \\
\hline$-1.33 \frac{I_{0}}{I_{0 \mathrm{pht}}} \frac{1-e^{-\lambda_{\max } \cdot h}}{\lambda_{\max } \cdot h}\left(1-0.56 C_{L}\right) k_{d 21} H g I I_{d}$ & Hgll photoreduction \\
\hline$-k_{d 23}(T) H g I I_{d}$ & Hgll methylation \\
\hline$+1.33 \frac{I_{0}}{I_{0 \mathrm{pht}}} \frac{1-e^{-\lambda_{\max } \cdot h}}{\lambda_{\max } \cdot h}\left(1-0.56 C_{L}\right)\left[\left(k_{d 32}(T) M e H g_{d}\right)+\left(k_{d o c 32}(T) M e H g_{d o c}\right)\right] Y_{32}$ & MeHg demethylation \\
\hline $\begin{array}{l}-\left(10^{-3} k_{\text {adap }}(T) H g I I_{d}\left(q_{c a p} A_{p d}-H g I I_{a p}\right)-k_{\text {daap }}(T) H g I I_{a p}\right) \\
-\left(10^{-3} k_{\text {adpom }}(T) H g I I_{d}\left(q_{c p o m} P O M-H g I I_{p o m}\right)-k_{\text {dapom }}(T) H g I I_{p o m}\right) \\
-\sum_{n=1}^{N}\left[10^{-3} k_{\text {adn }}(T) H g I I_{d}\left(q_{c n} m_{n}-H g I I_{p n}\right)-k_{d a n}(T) H g I I_{p n}\right]\end{array}$ & Adsorption-desorption \\
\hline \multicolumn{2}{|l|}{ DOC adsorbed Hgll } \\
\hline \multicolumn{2}{|l|}{$S S_{\text {HgIIdoc }}=$} \\
\hline$+\frac{v_{m}}{h}\left[H g I I_{d o c 2} / \phi-H g I I_{d o c}\right]$ & $\begin{array}{l}\text { Hgll sediment-water } \\
\text { transfer }\end{array}$ \\
\hline$-1.33 \frac{I_{0}}{I_{0 \mathrm{pht}}} \frac{1-e^{-\lambda_{\max } \cdot h}}{\lambda_{\max } \cdot h}\left(1-0.56 C_{L}\right) k_{d o c 21} H g I I_{d o c}$ & Hgll photoreduction \\
\hline$-k_{d o c 23}(T) H g I I_{d o c}$ & Hgll methylation \\
\hline \multicolumn{2}{|l|}{ Algae adsorbed Hgll } \\
\hline \multicolumn{2}{|l|}{$S S_{\text {HgIIap }}=$} \\
\hline$-\frac{1}{h} v_{\text {sap }} H g I I_{a p}$ & Hgll settling \\
\hline$+10^{-3} k_{\text {adap }}(T) H g I I_{d}\left(q_{c a p} A_{p d}-H g I I_{a p}\right)-k_{\text {daap }}(T) H g I I_{a p}$ & Adsorption-desorption \\
\hline \multicolumn{2}{|l|}{ POM adsorbed Hgll } \\
\hline \multicolumn{2}{|l|}{$S S_{\text {HgIIpom }}=$} \\
\hline$-\frac{1}{h} v_{s o m} H g I I_{p o m}$ & Hgll settling \\
\hline$+10^{-3} k_{\text {adpom }}(T) H g I I_{d}\left(q_{\text {cpom }} P O M-H g I I_{\text {pom }}\right)-k_{\text {dapom }}(T) H g I I_{\text {pom }}$ & Adsorption-desorption \\
\hline \multicolumn{2}{|l|}{ Solids adsorbed Hgll } \\
\hline$S S_{H g I I p n}=$ & \\
\hline
\end{tabular}




\begin{tabular}{|l|l|}
\hline Source/Sink term* & Pathway \\
\hline$-\frac{1}{h} v_{s p n} H g I I_{p n}$ & Hgll settling \\
\hline$+\frac{1}{h} v_{r p n} H g I I_{p n 2}$ & Hgll re-suspension \\
\hline$+10^{-3} k_{a d n}(T) H g I I_{d}\left(q_{c n} m_{n}-H g I I_{p n}\right)-k_{d a n}(T) H g I I_{p n}$ & Adsorption-desorption \\
\hline
\end{tabular}

* SS Hglld is the sum of internal source and sink terms of dissolved $H g l l$ in water $\left(\mathrm{ng} \mathrm{L}^{-1} \mathrm{~d}^{-1}\right)$.

$\mathrm{SS}_{H g l l d o c}$ is the sum of internal source and sink terms of DOC adsorbed $\mathrm{Hg} / \mathrm{l}$ in water $\left(\mathrm{ng} \mathrm{L}^{-1} \mathrm{~d}^{-1}\right)$.

$\mathrm{SS}_{\text {Hgllap }}$ is the sum of internal source and sink terms of algae adsorbed $H g l l$ in water $\left(n g \mathrm{~L}^{-1} \mathrm{~d}^{-1}\right)$.

$\mathrm{SS}_{\text {Hgllpom }}$ is the sum of internal source and sink terms of POM adsorbed $\mathrm{Hg} / \mathrm{l}$ in water $\left(\mathrm{ng} \mathrm{L}^{-1} \mathrm{~d}^{-1}\right)$.

$\mathrm{SS}_{H g \| l}$ is the sum of internal source and sink terms of solids adsorbed $\mathrm{Hgll}$ in water $\left(\mathrm{ng} \mathrm{L}^{-1} \mathrm{~d}^{-1}\right)$.

\subsubsection{Methylmercury}

Major processes involved in $\mathrm{MeHg}$ cycling in the water column include volatilization, methylation, photodegradation, settling of adsorbed particulates into the sediment layer, $\mathrm{MeHg}$ diffusion across the sedimentwater interface, and sediment re-suspension and burial. $\mathrm{MeHg}$ may be adsorbed by DOC, algae, POM, and suspended solids. Only equilibrium partitioning of $\mathrm{MeHg}$ is modeled in HgSM. The internal source (+) and sink (-) terms of water column $\mathrm{MeHg}$ are computed in HgSM for the total concentration and are listed in Table 21.

Table 21. Water column total MeHg source/sink terms and pathways under equilibrium partitioning.

\begin{tabular}{|c|c|}
\hline Source/Sink term* & Pathway \\
\hline \multicolumn{2}{|l|}{$S S_{M e H g}=$} \\
\hline$+A_{s} L_{\mathrm{MeHg}}$ & $\begin{array}{l}\text { Atmospheric MeHg } \\
\text { deposition }\end{array}$ \\
\hline$-\frac{1}{h}\left(\sum_{n=1}^{N} v_{s p n} f_{p n-M e H g}+v_{s a p} f_{a p-M e H g}+v_{s o m} f_{p o m-M e H g}\right) M e H g$ & MeHg settling \\
\hline$+\frac{1}{h}\left(\sum_{n=1}^{N} v_{r p n} f_{p n-M e H g 2}\right) M e H g_{2}$ & MeHg re-suspension \\
\hline$+\frac{v_{m}}{h}\left[\left(f_{d-M e H g}+f_{d o c-M e H g}\right) M_{e H g} / \phi-\left(f_{d-M e H g}+f_{d o c-M e H g}\right) M e H g\right]$ & $\begin{array}{l}\text { MeHg sediment-water } \\
\text { transfer }\end{array}$ \\
\hline$-v_{v-M e H g} \frac{1}{h}\left(\mathrm{f}_{\mathrm{d}-\mathrm{MeHg}} \mathrm{MeHg}-\frac{\mathrm{MeHg}_{0}}{K_{H} / R T_{K}}\right)$ & MeHg volatilization \\
\hline$-1.33 \frac{I_{0}}{I_{0 \mathrm{pht}}} \frac{1-e^{-\lambda_{\max } \cdot h}}{\lambda_{\max } \cdot h}\left(1-0.56 C_{L}\right)\left(k_{d 31} f_{d-M e H g}+k_{d o c 31} f_{d o c-M e H g}\right) M e H g$ & MeHg photoreduction \\
\hline
\end{tabular}




\begin{tabular}{|l|l|}
\hline$+\left(k_{d 23}(T) f_{d-H g I I}+k_{d o c 23}(T) f_{d o c-H g I I}\right) H g I I \cdot Y_{23}$ & Hgll methylation \\
\hline$-1.33 \frac{I_{0}}{I_{0 \mathrm{pht}}} \frac{1-e^{-\lambda_{\max } \cdot h}}{\lambda_{\max } \cdot h}\left(1-0.56 C_{L}\right)\left(k_{d 32} f_{d-\mathrm{MeHg}}+k_{d o c 32} f_{d o c-M e H g}\right) \mathrm{MeHg}$ & MeHg demethylation \\
\hline
\end{tabular}

* $\mathrm{SS}_{\mathrm{MeHg}}$ is the sum of internal source and sink terms of total $\mathrm{MeHg}$ in water (ng L-1 $\left.\mathrm{d}^{-1}\right)$.

$Y_{23}$ is the $\mathrm{Hgll}$ methylation yield coefficient in water.

\subsection{Sediment mercury mass balance equations}

The major species considered for sediment cycling are $\mathrm{HgII}$ and $\mathrm{MeHg}$, $\mathrm{HgO}$ is not included for the sediment layer (Figure 6). Major processes modeled in HgSM include partitioning of $\mathrm{HgII}$ and $\mathrm{MeHg}$, sediment resuspension and burial, sediment-water diffusion, and transformations. Because of varying environmental conditions, the rate of the reactions and transformations can vary dramatically from those in the water column. Similar to the CSM, the sediment layer is assumed to have constant properties including the thickness, volume, porosity, and bulk density. In the sediment layer, concentrations of mercury state variables are expressed in terms of mass per unit volume of total sediments (ng $\left.\mathrm{L}^{-1}\right)$.

\subsubsection{Inorganic mercury}

Major processes involved in $\mathrm{HgII}$ cycling in the sediment layer include methylation, demethylation, water column settling, pore water diffusion across the sediment-water interface, and sediment re-suspension and burial. HgII may be adsorbed by DOC, sediment POM and solids.

\subsubsection{Equilibrium partitioning}

Under equilibrium partitioning implementation, the source $(+)$ and sink

(-) terms of sediment $\mathrm{HgII}$ are computed in HgSM for the total concentration are listed in Table 22.

Table 22. Sediment layer total Hgll source/sink terms and pathways under equilibrium partitioning.

\begin{tabular}{|l|l|}
\hline Source/Sink term* & Pathway \\
\hline$S S_{H g I I 2}=$ & \\
\hline$+\frac{1}{h_{2}}\left(\sum_{n=1}^{N} v_{s p n} f_{p n-H g I I}+v_{s a p} f_{a p-H g I I}+v_{\text {som }} f_{p o m-H g I I}\right) H g I I$ & Hgll deposition \\
\hline$-\frac{1}{h_{2}}\left(\sum_{n=1}^{N} v_{r p n} f_{p n-H g I I 2}\right) H g I I_{2}$ & Hgll erosion \\
\hline
\end{tabular}




\begin{tabular}{|l|l|}
\hline$-\frac{v_{b}}{h_{2}}\left(\sum_{n=1}^{N} f_{p n-H g I I 2}+f_{\text {pom-HgII } 2}\right) \mathrm{HgII}_{2}$ & Hgll deep burial \\
\hline$-\frac{v_{m}}{h_{2}}\left[\left(f_{d-H g I I 2}+f_{d o c-H g I I 2}\right) H g I I_{2} / \phi-\left(f_{d-H g I I}+f_{d o c-H g I I}\right) H g I I\right]$ & Hgll sediment-water transfer \\
\hline$-k_{s o 42}(T)\left(\frac{\mathrm{SO}_{2}}{\mathrm{~K}_{\mathrm{SO} 4}+\mathrm{SO}_{2}}\right) \mathrm{SO}_{2} r_{m s o 4} f_{d-H g I L} \mathrm{HgII}_{2}$ & Hgll methylation \\
\hline$+k_{d 32-2} f_{d-\mathrm{MeHg}_{2} \mathrm{MeHg}_{2} \mathrm{Y}_{32}}$ & MeHg demethylation \\
\hline
\end{tabular}

* $\mathrm{SS}_{\mathrm{Hg} \text { III }}$ is the sum of source and sink terms of total $\mathrm{Hg} / l$ in sediment $\left(\mathrm{ng} \mathrm{L}^{-1} \mathrm{~d}^{-1}\right)$.

\subsubsection{Non-equilibrium partitioning}

Non-equilibrium kinetics of $H g I I$ onto sediment solids is modeled identically to the partitioning of $H g I I$ onto suspended solids in the water column. However, the values for the number of binding sites for sediments can be different, thus providing the ability to reflect the difference in adsorption characteristics between sediment solids and solids suspended in the water column. Under a non-equilibrium partitioning implementation, the mass balances of $\mathrm{HgII}$ in each phase must be solved simultaneously. The source (+) and sink (-) terms of sediment $\mathrm{HgII}$ are computed in HgSM for dissolved, DOC adsorbed, POM and solids adsorbed $H g I I$ and are listed in Table 23.

Table 23. Sediment layer Hgll partitioning phase source/sink terms and pathways under non-equilibrium partitioning.

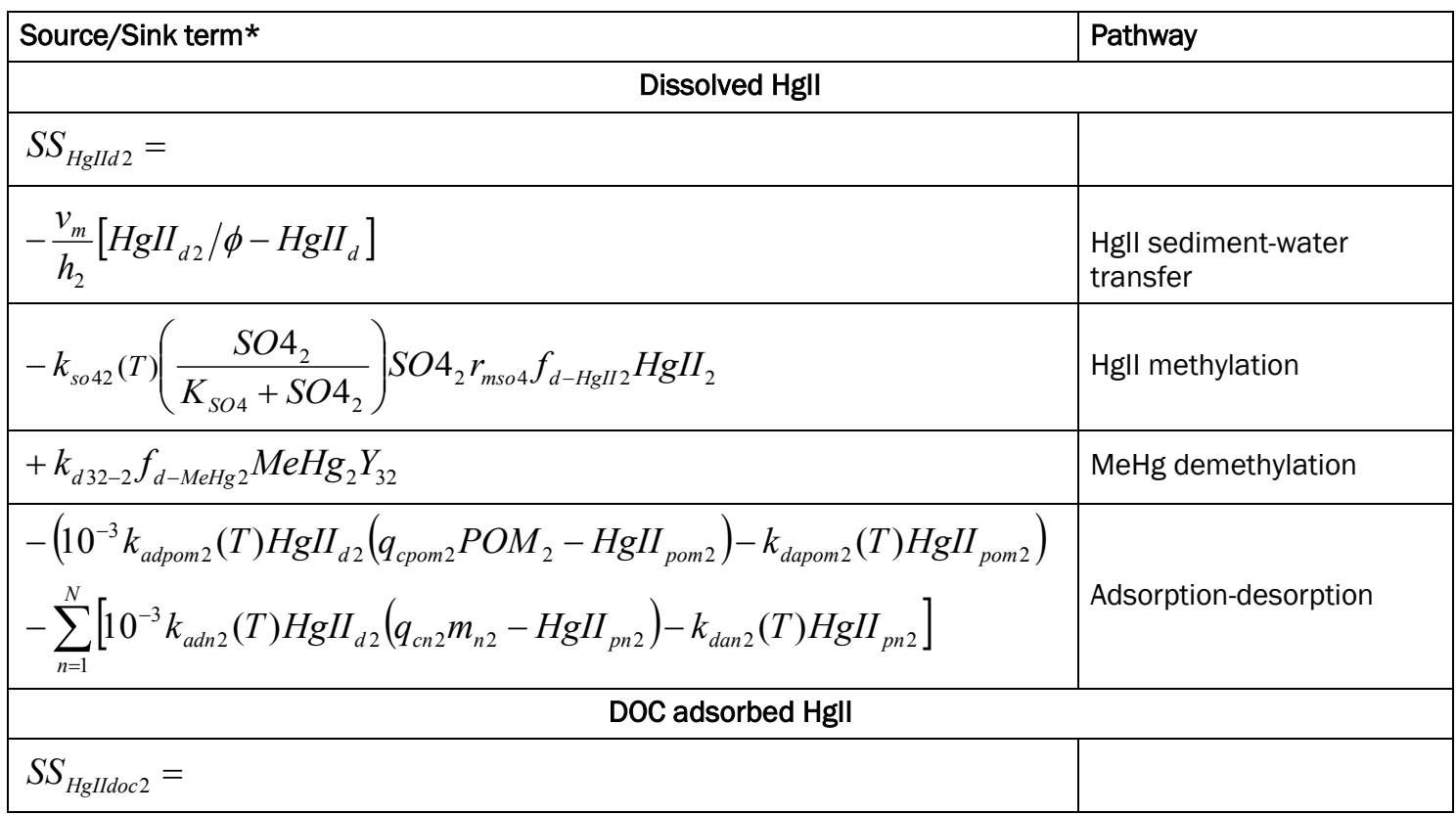




\begin{tabular}{|c|c|}
\hline$-\frac{v_{m}}{h_{2}}\left[H g I I_{d o c 2} / \phi-H g I I_{d o c}\right]$ & $\begin{array}{l}\text { Hgll sediment-water } \\
\text { transfer }\end{array}$ \\
\hline \multicolumn{2}{|l|}{ POM adsorbed HgII } \\
\hline \multicolumn{2}{|l|}{$S S_{\text {HgIlpom } 2}=$} \\
\hline$+\frac{1}{h_{2}}\left(v_{s a p} H g I I_{a p}+v_{s o m} H g I I_{p o m}\right)$ & Hgll deposition \\
\hline$-\frac{v_{b}}{h_{2}} H g I I_{p o m 2}$ & Hgll deep burial \\
\hline$+10^{-3} k_{\text {adpom } 2}(T) H g I I_{d 2}\left(q_{\text {cpom } 2} P O M_{2}-H g I I_{\text {pom } 2}\right)-k_{\text {dapom } 2}(T) H g I I_{\text {pom } 2}$ & Adsorption-desorption \\
\hline \multicolumn{2}{|l|}{ Solids adsorbed Hgll } \\
\hline \multicolumn{2}{|l|}{$S S_{H g I l p n 2}=$} \\
\hline$S S_{H g I I p n 2}=\frac{1}{h_{2}} v_{s p n} H g I I_{p n}$ & Hgll deposition \\
\hline$-\frac{1}{h_{2}} v_{r p n} H g I I_{p n 2}$ & Hgll re-suspension \\
\hline$-\frac{v_{b}}{h_{2}} H g I I_{p n 2}$ & Hgll deep burial \\
\hline$+10^{-3} k_{a d n 2}(T) H g I I_{d 2}\left(q_{c n 2} m_{n 2}-H g I I_{p n 2}\right)-k_{d a n 2}(T) H g I I_{p n 2}$ & Adsorption-desorption \\
\hline
\end{tabular}

* SS Hglld2 is the sum of source and sink terms of dissolved $\mathrm{Hgll}$ in sediment $\left(\mathrm{ng} \mathrm{L}^{-1} \mathrm{~d}^{-1}\right)$.

$\mathrm{SS}_{\text {Hglldoc2 } 2}$ is the sum of source and sink terms of DOC adsorbed Hgll in sediment (ng $\left.\mathrm{L}^{-1} \mathrm{~d}^{-1}\right)$.

$\mathrm{SS}_{\mathrm{Hgllpom} 2}$ is the sum of source and sink terms of POM adsorbed $\mathrm{Hgll}$ in sediment (ng $\left.\mathrm{L}^{-1} \mathrm{~d}^{-1}\right)$.

$\mathrm{SS}_{\mathrm{Hgllp} 2}$ is the sum of source and sink terms of solids adsorbed $\mathrm{Hgll}$ in sediment $\left(n \mathrm{~L} \mathrm{~L}^{-1} \mathrm{~d}^{-1}\right)$.

\subsubsection{Methylmercury}

Major processes involved in $\mathrm{MeHg}$ cycling in the sediment layer include methylation, biological demethylation, pore water diffusion across the sediment-water interface, water column settling, sediment re-suspension, and burial. $\mathrm{MeHg}$ may be adsorbed by DOC, sediment POM and solids. The source (+) and sink (-) terms of sediment $\mathrm{MeHg}$ are computed in HgSM for the total concentration and are listed in Table 24. 
Table 24. Sediment layer total MeHg source/sink terms and pathways under equilibrium partitioning.

\begin{tabular}{|c|c|}
\hline Source/Sink term* & Pathway \\
\hline \multicolumn{2}{|l|}{$S S_{\mathrm{MeHg} 2}=$} \\
\hline$+\frac{1}{h_{2}}\left(\sum_{n=1}^{N} v_{s p n} f_{p n-\mathrm{MeHg}}+v_{\text {sap }} f_{a p-\mathrm{MeHg}}+v_{\text {som }} f_{\text {pom-MeHg}}\right) \mathrm{MeHg}$ & MeHg deposition \\
\hline$-\frac{1}{h_{2}}\left(\sum_{n=1}^{N} v_{r p n} f_{p n-M e H g 2}\right) \mathrm{MeHg}_{2}$ & MeHg erosion \\
\hline$-\frac{v_{m}}{h_{2}}\left[\left(f_{d-M e H g 2}+f_{d o c-M e H g}\right) M_{e H g} / \phi-\left(f_{d-M e H g}+f_{d o c-M e H g}\right) M e H g\right]$ & $\begin{array}{l}\text { MeHg sediment-water } \\
\text { transfer }\end{array}$ \\
\hline$-\frac{v_{b}}{h_{2}}\left(\sum_{n=1}^{N} f_{p n-\mathrm{MeHg} 2}+f_{\text {pom-MeHg2 }}\right) \mathrm{MeHg}_{2}$ & MeHg deep burial \\
\hline$+k_{s o 42}(T)\left(\frac{\mathrm{SO}_{2}}{K_{\mathrm{SO} 4}+\mathrm{SO}_{2}}\right) \mathrm{SO}_{2} r_{m s o 4} f_{d-\mathrm{HgII} 2} \mathrm{HgII}_{2} \mathrm{Y}_{23}$ & Hgll methylation \\
\hline$-k_{d 32-2} f_{d-M e H g} \mathrm{MeHg}_{2}$ & MeHg demethylation \\
\hline
\end{tabular}

* $\mathrm{SS}_{\mathrm{MeHg} 2}$ is the sum of source and sink terms of total MeHg in sediment (ng $\left.\mathrm{L}^{-1} \mathrm{~d}^{-1}\right)$.

\subsection{HgSM parameters}

The HgSM operates based on the schematization already set up for the $\mathrm{H} \& \mathrm{H}$ model and the flows computed by the $\mathrm{H} \& \mathrm{H}$ model. Table 25 provides a summary of mercury input parameters that must be specified when all options are turned on in the HgSM module. Literature values were taken from a compilation of several studies if they are available. Most of them are model calibration parameters in real world applications. Similar to CSM, HgSM's parameters for the water column and sediment layer can be specified as either a uniform constant, a single for all water quality cells, or spatially-varying values by user defined water quality regions. There are three groups of parameters: global, water column and sediment layer. This table will be repeated for each water quality region, allow the user to define the different values for input parameters.

Table 25. List of HgSM's input parameters.

\begin{tabular}{|l|l|l|l|l|l|}
\hline Symbol & Definition & $\begin{array}{l}\text { Default } \\
\text { values }\end{array}$ & $\begin{array}{l}\text { Approximate } \\
\text { range }\end{array}$ & Units & $\begin{array}{l}\text { Temp } \\
\text { correction }\end{array}$ \\
\hline \multicolumn{5}{|c|}{ Global } \\
\hline$D_{m}$ & Molecular diffusivity & - & $\mathrm{n} / \mathrm{a}$ & $\mathrm{m}^{2} \mathrm{~d}^{-1}$ & \\
\hline$v_{m}$ & $\begin{array}{l}\text { Sediment-water mass transfer } \\
\text { velocity }\end{array}$ & - & $\mathrm{n} / \mathrm{a}$ & $\mathrm{m} \mathrm{d}^{-1}$ & \\
\hline
\end{tabular}




\begin{tabular}{|c|c|c|c|c|c|c|}
\hline Symbol & Definition & $\begin{array}{l}\text { Default } \\
\text { values }\end{array}$ & $\begin{array}{l}\text { Approximate } \\
\text { range }\end{array}$ & Units & \multicolumn{2}{|c|}{$\begin{array}{l}\text { Temp } \\
\text { correction }\end{array}$} \\
\hline$h_{2}$ & Sediment layer thickness & $0.1-$ & $\mathrm{m}$ & & & \\
\hline$Z_{2}$ & $\begin{array}{l}\text { Sediment bioturbation layer } \\
\text { thickness }\end{array}$ & $\begin{array}{l}0.05- \\
0.1\end{array}$ & $\mathrm{~m}$ & & & \\
\hline$v_{s s}$ & Solids settling velocity & - & $n / a$ & $\mathrm{~m} \mathrm{~d}^{-1}$ & & \\
\hline$v_{\text {som }}$ & Organic matter settling velocity & - & $n / a$ & $\mathrm{~m} \mathrm{~d}^{-1}$ & & \\
\hline$k_{p h t}(T)$ & Aquatic photolysis rate & - & $n / a$ & $d^{-1}$ & $E_{a}$ & $n / a$ \\
\hline lopht & $\begin{array}{l}\text { Light intensity when kpht is } \\
\text { measured }\end{array}$ & - & $n / a$ & $W \mathrm{~m}^{-2}$ & & \\
\hline$\alpha_{l}$ & $\begin{array}{l}\text { Light attenuation adjusting } \\
\text { coefficient }\end{array}$ & 1.33 & $1.2-1.6$ & unitless & & \\
\hline \multicolumn{7}{|c|}{ Water column - elemental mercury } \\
\hline$M W$ & Hg0 molecular weighta & 200.6 & - & $\mathrm{g} \mathrm{mol}^{-1}$ & & \\
\hline $\mathrm{S}_{\mathrm{HgO}}$ & HgO solubility & 56 & - & $\mu g L^{-1}$ & & \\
\hline$V_{v-H g O}(T)$ & HgO volatilization velocity $f^{f}$ & 0.006 & $0.0059-0.45$ & $\mathrm{~m} \mathrm{hr} r^{-1}$ & $\theta$ & $n / a$ \\
\hline$K_{H}$ & HgO Henry's Law constant & 0.09 & - & $\mathrm{Pa} \mathrm{m}^{3} \mathrm{~mol}^{-1}$ & & \\
\hline $\mathrm{HgOO}$ & HgO air concentration & $2.10^{-3}$ & $n / a$ & $n g L^{-1}$ & & \\
\hline$k_{12}(T)$ & HgO oxidation rate ${ }^{b}$ & $10^{-3}$ & $10^{-3}-10^{-1}$ & $d^{-1}$ & $E_{a}$ & $\mathrm{n} / \mathrm{a}$ \\
\hline$Y_{12}$ & HgO oxidation yield coefficient & 1.0 & $0-2.0$ & unitless & & \\
\hline \multicolumn{7}{|c|}{ Water column - inorganic mercury } \\
\hline$M W$ & Hgll molecular weighta & 271.52 & $\begin{array}{l}232.68(\mathrm{HgS}) \\
271.52\left(\mathrm{HgCl}_{2}\right) \\
\end{array}$ & $\mathrm{g} \mathrm{mol}^{-1}$ & & \\
\hline$K_{p-H g l l}$ & $\begin{array}{l}\text { Hgll equilibrium partition coefficient } \\
\text { for algaec }^{c}\end{array}$ & - & $10^{5}-10^{6}$ & $\mathrm{~L} \mathrm{~kg}^{-1}$ & & \\
\hline$K_{p-H g l l}$ & $\begin{array}{l}\text { Hgll equilibrium partition coefficient } \\
\text { for siltb }\end{array}$ & $2.10^{5}$ & $10^{3}-10^{6}$ & $\mathrm{~L} \mathrm{~kg}^{-1}$ & & \\
\hline$K_{p-H g l l}$ & $\begin{array}{l}\text { Hgll equilibrium partition coefficient } \\
\text { for clayb }\end{array}$ & $2.10^{5}$ & $10^{3}-10^{6}$ & $\mathrm{~L} \mathrm{~kg}^{-1}$ & & \\
\hline$K_{p-H g l l}$ & $\begin{array}{l}\text { Hgll equilibrium partition coefficient } \\
\text { for solidse }\end{array}$ & $10^{5.3}$ & $10^{4.2}-10^{6.9}$ & $\mathrm{~L} \mathrm{~kg}^{-1}$ & & \\
\hline$b_{\text {HgII }}$ & Hgll Freundlich exponent ${ }^{\mathrm{h}}$ & - & $0.4-1.2$ & unitless & & \\
\hline$K_{f-H g \|}$ & Hgll Freundlich adsorption constant ${ }^{\mathrm{h}}$ & - & $\begin{array}{l}4.5 \cdot 10^{4}- \\
2.52 \cdot 10^{8}\end{array}$ & $\left(\mu g g^{-1}\right)\left(\mu g L^{-1}\right)^{-b}$ & & \\
\hline$K_{\text {I-HgIII }}$ & Hgll Langmuir adsorption constant ${ }^{\text {h }}$ & - & $10^{6}-7 \cdot 10^{6}$ & $L_{\mu g^{-1}}$ & & \\
\hline$q_{c n-H g l l}$ & $\begin{array}{l}\text { Hgll adsorption capacity for solid } \\
\text { “n”h }\end{array}$ & - & $\begin{array}{l}2.8 \cdot 10^{2}- \\
3.58 \cdot 10^{3}\end{array}$ & $\mu g g^{-1}$ & & \\
\hline$K_{\text {adn-Hgll }}$ & Hgll adsorption coefficient & - & $n / a$ & $L \mu g^{-1} d^{-1}$ & & \\
\hline
\end{tabular}




\begin{tabular}{|c|c|c|c|c|c|}
\hline Symbol & Definition & \begin{tabular}{|l|} 
Default \\
values
\end{tabular} & $\begin{array}{l}\text { Approximate } \\
\text { range }\end{array}$ & Units & $\begin{array}{l}\text { Temp } \\
\text { correction }\end{array}$ \\
\hline Kdan-HgII & Hgll desorption rate & 1.0 & $n / a$ & $d^{-1}$ & \\
\hline k doc-HgII & Hgll partition coefficient for DOCe & $10^{5.3}$ & $10^{5.3}-10^{5.6}$ & $\mathrm{~L} \mathrm{~kg}^{-1}$ & \\
\hline$k_{d 21}$ & Dissolved Hgll photoreduction rate ${ }^{b}$ & $5.10^{-2}$ & $10^{-3}-5 \cdot 10^{-1}$ & $d^{-1}$ & \\
\hline$k_{\text {doc } 21}$ & $\begin{array}{l}\text { DOC adsorbed Hgll photoreduction } \\
\text { rate }^{\mathrm{b}}\end{array}$ & 0.0 & $10^{-3}-5 \cdot 10^{-1}$ & $d^{-1}$ & \\
\hline$Y_{21}$ & Hgll photoreduction yield coefficient & 1.0 & $0-2.0$ & unitless & \\
\hline$k_{d 23}(T)$ & Dissolved Hgll methylation rate ${ }^{b}$ & $10^{-3}$ & $10^{-5}-5 \cdot 10^{-2}$ & $d^{-1}$ & 1.14 \\
\hline$k_{\text {doc } 23}(T)$ & $\begin{array}{l}\text { DOC adsorbed Hgll methylation } \\
\text { rate }^{b}\end{array}$ & $10^{-3}$ & $10^{-5}-5 \cdot 10^{-2}$ & $d^{-1}$ & 1.14 \\
\hline$Y_{23}$ & Hgll methylation yield coefficient & 1.07 & $0-2.0$ & unitless & \\
\hline \multicolumn{6}{|c|}{ Water column - methymercury } \\
\hline$M W$ & MeHg molecular weighta & \begin{tabular}{|l|}
230.66 \\
$\left(\mathrm{CH} 3{ }_{2} \mathrm{Hg}\right)$
\end{tabular} & $n / a$ & g mol-1 & \\
\hline Kp-MeHg & $\begin{array}{l}\text { MeHg equilibrium partition } \\
\text { coefficient for algaeg }\end{array}$ & $10^{5}$ & $10^{5}-10^{7}$ & $\mathrm{~L} \mathrm{~kg}^{-1}$ & \\
\hline Kp-Mенg & $\begin{array}{l}\text { MeHg equilibrium partition } \\
\text { coefficient for silt }{ }^{b}\end{array}$ & $2 \cdot 10^{5}$ & $10^{3}-10^{6}$ & $\mathrm{~L} \mathrm{~kg}^{-1}$ & \\
\hline$K_{p-M e H g}$ & $\begin{array}{l}\text { MeHg equilibrium partition } \\
\text { coefficient for caly }{ }^{b}\end{array}$ & $2 \cdot 10^{5}$ & $10^{3}-10^{6}$ & $\mathrm{~L} \mathrm{~kg}^{-1}$ & \\
\hline Kp-MеHg & $\begin{array}{l}\text { MeHg equilibrium partition } \\
\text { coefficient for solidse }\end{array}$ & $10^{5.4}$ & $10^{4.2}-10^{6.2}$ & $\mathrm{~L} \mathrm{~kg}^{-1}$ & \\
\hline Kdoc-MeHg & $\begin{array}{l}\text { MeHg equilibrium partition } \\
\text { coefficients for } \mathrm{DOC}^{\mathrm{b}}\end{array}$ & $2 \cdot 10^{5}$ & $10^{5}-10^{6}$ & $\mathrm{~L} \mathrm{~kg}^{-1}$ & \\
\hline$b_{\mathrm{MeHg}}$ & MeHg Freundlich exponent & - & $n / a$ & unitless & \\
\hline$K_{f-M e H g}$ & $\begin{array}{l}\text { MeHg Freundlich adsorption } \\
\text { constant }\end{array}$ & - & $\mathrm{n} / \mathrm{a}$ & $\left(\mu g g^{-1}\right)\left(\mu g L^{-1}\right)^{-b}$ & \\
\hline $\mathrm{K}_{\mathrm{I}-\mathrm{MeHg}}$ & $\begin{array}{l}\text { MeHg Langmuir adsorption } \\
\text { constant }^{\mathrm{h}}\end{array}$ & - & $n / a$ & $L \mu g^{-1}$ & \\
\hline$q_{\mathrm{cn}-\mathrm{MeHg}}$ & $\begin{array}{l}\text { MeHg adsorption capacity for solid } \\
\text { "n” }\end{array}$ & - & $n / a$ & $\mu g g^{-1}$ & \\
\hline$k_{d 31}$ & $\begin{array}{l}\text { Dissolved MeHg photoreduction rate } \\
\text { into } \mathrm{HgO}^{\mathrm{b}}\end{array}$ & - & $10^{-3}-5 \cdot 10^{-1}$ & $d^{-1}$ & \\
\hline Kdoc31 & $\begin{array}{l}\mathrm{DOC} \text { adsorbed } \mathrm{MeHg} \\
\text { photoreduction rate into } \mathrm{HgO}^{\mathrm{b}}\end{array}$ & 0.0 & $10^{-3}-5 \cdot 10^{-1}$ & $d^{-1}$ & \\
\hline$Y_{31}$ & $\begin{array}{l}\text { MeHg photoreduction yield } \\
\text { coefficient }\end{array}$ & 0.93 & $0-2.0$ & unitless & \\
\hline$k_{d 32}$ & $\begin{array}{l}\text { Dissolved MeHg demethylation rate } \\
\text { into Hgl|b }\end{array}$ & $5 \cdot 10^{-2}$ & $10^{-3}-5 \cdot 10^{-1}$ & $d^{-1}$ & \\
\hline$k_{\text {doc32 }}$ & $\begin{array}{l}\text { DOC adsorbed MeHg demethylation } \\
\text { rate into Hgl| }\end{array}$ & 0.0 & $10^{-3}-5 \cdot 10^{-1}$ & $d^{-1}$ & \\
\hline
\end{tabular}




\begin{tabular}{|c|c|c|c|c|c|}
\hline Symbol & Definition & \begin{tabular}{|l|} 
Default \\
values
\end{tabular} & $\begin{array}{l}\text { Approximate } \\
\text { range }\end{array}$ & Units & $\begin{array}{l}\text { Temp } \\
\text { correction }\end{array}$ \\
\hline$Y_{32}$ & $\begin{array}{l}\text { MeHg demethylation yield } \\
\text { coefficient }\end{array}$ & 0.93 & $0-2.0$ & unitless & \\
\hline$V_{V-M e H g}(T)$ & MeHg volatilization velocity & $1.9 \cdot 10^{-5}$ & $n / a$ & $\mathrm{~m} \mathrm{~d}^{-1}$ & $\mathrm{n} / \mathrm{a}$ \\
\hline$K_{H}$ & MeHg Henry's constant & $4.5 \cdot 10^{-6}$ & $n / a$ & $\mathrm{~Pa} \mathrm{~m}^{3} \mathrm{~mol}^{-1}$ & \\
\hline $\mathrm{MeHg}$ & MeHg air concentration & 0.0 & $n / a$ & $n g L^{-1}$ & \\
\hline \multicolumn{6}{|c|}{ Sediment layer - inorganic mercury } \\
\hline$K_{p-H g \| 2}$ & $\begin{array}{l}\text { Hgll equilibrium partition coefficient } \\
\text { for silt }{ }^{\mathrm{b}}\end{array}$ & - & $10^{3}-10^{6}$ & $\mathrm{~L} \mathrm{~kg}^{-1}$ & \\
\hline$K_{p-H g / 12}$ & $\begin{array}{l}\text { Hgll equilibrium partition coefficient } \\
\text { for clay }\end{array}$ & - & $10^{3}-10^{6}$ & $\mathrm{~L} \mathrm{~kg}^{-1}$ & \\
\hline$K_{p-H g / 12}$ & $\begin{array}{l}\text { Hgll equilibrium partition coefficient } \\
\text { for solidse }\end{array}$ & $10^{4.9}$ & $10^{3.8}-10^{6}$ & $\mathrm{~L} \mathrm{~kg}^{-1}$ & \\
\hline$b_{\text {HgIII2 }}$ & Hgll Freundlich exponent & - & $n / a$ & unitless & \\
\hline$K_{f-H g I I 2}$ & Hgll Freundlich adsorption constant & - & $n / a$ & $\left(\mu g g^{-1}\right)\left(\mu g L^{-1}\right)^{-b}$ & \\
\hline$K_{1-H g l \mid 2}$ & HgII Langmuir adsorption constant ${ }^{d}$ & - & $51-390$ & $L \mu g^{-1}$ & \\
\hline$q_{c n-H g l l 2}$ & Hgll adsorption capacity for solid " $n$ " & - & $n / a$ & $\mu g g^{-1}$ & \\
\hline$k_{a d n-H g l l 2}$ & Hgll adsorption coefficient & - & $n / a$ & $L \mu g^{-1} d^{-1}$ & \\
\hline Kdan-Hgll2 & Hgll desorption rate & 0.1 & $n / a$ & $d^{-1}$ & \\
\hline Kdoc-Hgll2 & Hgll partition coefficient for $\mathrm{DOC}^{b}$ & - & $10^{4}-10^{5}$ & $\mathrm{~L} \mathrm{~kg}^{-1}$ & \\
\hline$k_{s 042}(T)$ & Sediment SO4 reduction rate & - & - & $d^{-1}$ & $n / a$ \\
\hline KsO4 & $\begin{array}{l}\text { Half-saturation constant for the } \\
\text { effect of SO4 on methylation }\end{array}$ & - & - & $m g-O_{2} L^{-1}$ & \\
\hline$r_{m s 04}$ & $\begin{array}{l}\text { Ratio of sediment methylation rate } \\
\text { and sulfate reduction rate }\end{array}$ & - & - & $\mathrm{L} \mathrm{mg}^{-1}$ & \\
\hline \multicolumn{6}{|c|}{ Sediment layer - methymercury } \\
\hline$K_{p-M e H g 2}$ & $\begin{array}{l}\text { MeHg equilibrium partition } \\
\text { coefficient for silt } \mathrm{b}\end{array}$ & - & $10^{3}-10^{6}$ & $\mathrm{~L} \mathrm{~kg}^{-1}$ & \\
\hline$K_{p-M e H g} 2$ & $\begin{array}{l}\text { MeHg equilibrium partition } \\
\text { coefficient for clayb }\end{array}$ & - & $10^{3}-10^{6}$ & $\mathrm{~L} \mathrm{~kg}^{-1}$ & \\
\hline$K_{p-M e H g} 2$ & $\begin{array}{l}\text { MeHg equilibrium partition } \\
\text { coefficient for solidse }\end{array}$ & $10^{3.6}$ & $10^{2.8}-10^{5}$ & $\mathrm{~L} \mathrm{~kg}^{-1}$ & \\
\hline$K_{\text {doc-MeHg2 }}$ & $\begin{array}{l}\text { MeHg equilibrium partition } \\
\text { coefficients for } \text { DOC }^{\mathrm{b}}\end{array}$ & - & $10^{5}-10^{6}$ & $\mathrm{~L} \mathrm{~kg}^{-1}$ & \\
\hline$b_{\text {MeHg2 }}$ & MeHg Freundlich exponent & - & $n / a$ & Unitless & \\
\hline$K_{f-\mathrm{MeHg} 2}$ & $\begin{array}{l}\text { MeHg Freundlich adsorption } \\
\text { constant }\end{array}$ & - & $n / a$ & $\left(\mu g g^{-1}\right)\left(\mu g L^{-1}\right)^{-b}$ & \\
\hline$K_{1-M e H g 2}$ & $\begin{array}{l}\text { MeHg Langmuir adsorption } \\
\text { constant }{ }^{d}\end{array}$ & - & $n / a$ & $L \mu g^{-1}$ & \\
\hline
\end{tabular}




\begin{tabular}{|l|l|l|l|l|l|l|}
\hline Symbol & Definition & $\begin{array}{l}\text { Default } \\
\text { values }\end{array}$ & $\begin{array}{l}\text { Approximate } \\
\text { range }\end{array}$ & Units & \multicolumn{2}{l|}{$\begin{array}{l}\text { Temp } \\
\text { correction }\end{array}$} \\
\hline$q_{\mathrm{cn}-\mathrm{MeHg} 2}$ & $\begin{array}{l}\text { MeHg adsorption capacity for solid } \\
\text { "n" }\end{array}$ & - & $\mathrm{n} / \mathrm{a}$ & $\mathrm{\mu g} \mathrm{g-1}$ & \multicolumn{2}{|l|}{} \\
\hline$k_{d 32-2}(T)$ & Sediment MeHg demethylation rate & $0.2^{\mathrm{j}}$ & - & $\mathrm{d}^{-1}$ & $\mathrm{E}$ & $\mathrm{n} / \mathrm{a}$ \\
\hline
\end{tabular}

a. ATSDR (2005).

b. Wool (et al. 2006).

c. Hudson et al. (1994).

d. Tsiros and Ambrose (1999).

e. Allison and Allison (2005).

f. Loux (2004).

g. Miles et al. (2001).

h. Chen et al. (2009).

I. Lin et al. (2012).

j. Gilmour et al. (2007).

As discussed in the CSM module, the sediment layer has a constant volume and thickness during a simulation. Sediment particle density and porosity are fixed. Settling velocities of particles and sediment resuspension rate parameters can be computed from the GC module. Benthic sediment layer parameters have been discussed in the GC module and are listed in Table 2.

\subsection{HgSM outputs}

This section summarizes the HgSM outputs from a model simulation. The fundamental output produced by HgSM consists of predicted concentrations and predicted mass fluxes of mercury species at specified locations within the system. Concentrations of the $\mathrm{HgII}$ and $\mathrm{MeHg}$ computed for each physical compartment (water column and sediment layer) include dissolved, DOC adsorbed, algae, POM, and solids adsorbed phases. Table 26 lists the symbols and definitions of concentrations of mercury species computed in HgSM. 
Table 26. List of concentrations of mercury species computed in HgSM.

\begin{tabular}{|c|c|c|}
\hline Symbol & Definition & Units \\
\hline \multicolumn{3}{|c|}{ Elemental mercury } \\
\hline $\mathrm{HgO}$ & HgO concentration in water & $n g L^{-1}$ \\
\hline \multicolumn{3}{|c|}{ Inorganic mercury } \\
\hline Hgll & Concentration of total Hgll in water & $n g L^{-1}$ \\
\hline$H g \|_{d}$ & Concentration of dissolved Hgll in water & $n g L^{-1}$ \\
\hline$H g l_{d o c}$ & Concentration of DOC adsorbed Hgll in water & $n g L^{-1}$ \\
\hline$H g \|_{a p}$ & Concentration of algae adsorbed Hgll in water & $n g L^{-1}$ \\
\hline$H g \|_{\text {pom }}$ & Concentration of POM adsorbed Hgll in water & $n g L^{-1}$ \\
\hline$H g \|_{p t}$ & Total concentration of solids adsorbed $\mathrm{Hgll}$ in water & $n g L^{-1}$ \\
\hline$H g l l_{p t s}$ & Total concentration of solids adsorbed Hgll in water & $n g g^{-1}$ \\
\hline $\mathrm{Hg} \|_{2}$ & Concentration of total Hgll in sediment & $n g L^{-1}$ \\
\hline$H g I_{d p 2}$ & Concentration of dissolved Hgll in pore water & $n g L^{-1}$ \\
\hline Hglldocp2 & Concentration of DOC adsorbed Hgll in pore water & $n g L^{-1}$ \\
\hline Hgllpom2 & Concentration of POM adsorbed Hgll in sediment & $n g L^{-1}$ \\
\hline$H g l l_{p t 2}$ & Total concentration of solids adsorbed Hgll in sediment & $n g L^{-1}$ \\
\hline$H g \|_{p t s 2}$ & Total concentration of solids adsorbed Hgll in sediment & $n g g^{-1}$ \\
\hline \multicolumn{3}{|c|}{ Methymercury } \\
\hline $\mathrm{MeHg}$ & Concentration of total MeHg in water & $n g L^{-1}$ \\
\hline MeHgd & Concentration of dissolved MeHg in water & $n g L^{-1}$ \\
\hline MeHgdoc & Concentration of DOC adsorbed MeHg in water & $n g L^{-1}$ \\
\hline MeHgap & Concentration of algae adsorbed MeHg in water & $n g L^{-1}$ \\
\hline MeHgpom & Concentration of POM adsorbed MeHg in water & $n g L^{-1}$ \\
\hline $\mathrm{MeHg}$ & Total concentration of MeHg adsorbed on solids in water & ng L-1 \\
\hline MeHgpts & Total concentration of MeHg adsorbed on solids in water & $n g g^{-1}$ \\
\hline $\mathrm{MeHg}_{2}$ & Concentration of total MeHg in sediment & $n g L^{-1}$ \\
\hline MeHgdp2 & Concentration of dissolved MeHg in pore water & $n g L^{-1}$ \\
\hline $\mathrm{MeHg} g_{d o c p 2}$ & Concentration of DOC adsorbed MeHg in pore water & $n g L^{-1}$ \\
\hline MeHgpom2 & Concentration of POM adsorbed MeHg in sediment & $n g L^{-1}$ \\
\hline MeHgpt2 & Total concentration of solids adsorbed $\mathrm{MeHg}$ in sediment & $n g L^{-1}$ \\
\hline MeHgpts2 & Total concentration of solids adsorbed $\mathrm{MeHg}$ in sediment & $n g g^{-1}$ \\
\hline
\end{tabular}

Mercury pathway fluxes are internally computed in HgSM and can be reported in the model outputs. Table 27 lists the symbols and definitions of pathway fluxes of mercury species computed in $\mathrm{HgSM}$. The $\mathrm{HgSM}$ allows the user to selectively turn on and off each variable in the model outputs. 
Table 27. List of pathway fluxes of mercury species computed in HgSM.

\begin{tabular}{|c|c|c|}
\hline Symbol & Definition & Units \\
\hline \multicolumn{3}{|c|}{ Elemental mercury } \\
\hline Atm<-->HgO & HgO volatilization in water & $n g L^{-1} d^{-1}$ \\
\hline HgO-->Hgll & HgO oxidation into $\mathrm{Hgll}$ in water & $n g L^{-1} d^{-1}$ \\
\hline \multicolumn{3}{|c|}{ Inorganic mercury } \\
\hline $\mathrm{Hg} / \mathrm{l}-\mathrm{-} \mathrm{HgO}$ & Hgll photoreduction into $\mathrm{HgO}$ in water & $n g \mathrm{~L}^{-1} \mathrm{~d}^{-1}$ \\
\hline $\mathrm{Hg} / \mathrm{l}->\mathrm{MeHg}$ & Hgll methylation into $\mathrm{MeHg}$ in water & $n g L^{-1} d^{-1}$ \\
\hline Hgll-->Bed & Hgll settling & $n g L^{-1} d^{-1}$ \\
\hline Bed-->Hgll & Hgll re-suspension & $n g \mathrm{~L}^{-1} \mathrm{~d}^{-1}$ \\
\hline$H g\|l<-->H g\|_{2}$ & Hgll sediment-water transfer & $n g L^{-1} d^{-1}$ \\
\hline $\mathrm{Hg} \mathrm{I}_{2--}>\mathrm{MeHg}_{2}$ & sediment $\mathrm{Hgll}$ methylation into $\mathrm{MeHg}$ & $n g L^{-1} d^{-1}$ \\
\hline Hgll-->Bed & Hgll deposition & $n g \mathrm{~L}^{-1} \mathrm{~d}^{-1}$ \\
\hline Bed-->Hgll & sediment Hgll erosion & $n g L^{-1} d^{-1}$ \\
\hline$H g\|l<-->H g\|_{2}$ & Hgll sediment-water transfer & $n g L^{-1} d^{-1}$ \\
\hline $\mathrm{Hg} / l_{2}$ burial & sediment Hgll burial & $n g \mathrm{~L}^{-1} \mathrm{~d}^{-1}$ \\
\hline \multicolumn{3}{|c|}{ Methymercury } \\
\hline Atm<-->MeHg & MeHg volatilization in water & $n g \mathrm{~L}^{-1} \mathrm{~d}^{-1}$ \\
\hline $\mathrm{MeHg}->\mathrm{HgO}$ & MeHg photoreduction into $\mathrm{HgO}$ in water & $n g L^{-1} d^{-1}$ \\
\hline MeHg-->Hgll & MeHg demethylation into Hgll in water & $n g L^{-1} d^{-1}$ \\
\hline MeHg->Bed & MeHg settling & $n g \mathrm{~L}^{-1} \mathrm{~d}^{-1}$ \\
\hline Bed-->MeHg & MeHg re- suspension & $n g L^{-1} d^{-1}$ \\
\hline $\mathrm{MeHg}<-->\mathrm{MeHg}_{2}$ & MeHg sediment-water transfer & $n g \mathrm{~L}^{-1} \mathrm{~d}^{-1}$ \\
\hline $\mathrm{MeHg}_{2}-\mathrm{-} \mathrm{Hgll}_{2}$ & sediment MeHg bacterial demethylation into Hgll & $n g L^{-1} d^{-1}$ \\
\hline $\mathrm{MeHg}->\mathrm{Bed}$ & MeHg deposition & $n g L^{-1} d^{-1}$ \\
\hline $\mathrm{Bed}->\mathrm{MeHg}$ & sediment MeHg erosion & $n g L^{-1} d^{-1}$ \\
\hline $\mathrm{MeHg}<-->\mathrm{MeHg}_{2}$ & MeHg sediment-water transfer & $n g L^{-1} d^{-1}$ \\
\hline $\mathrm{MeHg}_{2}$ burial & sediment MeHg burial & $n g L^{-1} d^{-1}$ \\
\hline
\end{tabular}




\section{Summary}

The preceding chapters describe three newly developed GC, CSM, and HgSM water quality modules. These modules are written as DLLs and compiled as GC.dll, CSM.dll, and HgSM.dll, respectively. Zhang and Johnson (2016) present general principles and protocols to integrate "plug in" water quality modules into the 1 D HEC-RAS model. Following the same integration approach implemented in HEC-RAS for NSM modules, GC, CSM, and HgSM modules have been integrated into the HEC-RAS model. Wherein the HEC-RAS is used to describe physical processes of advection and dispersion, the GC, CSM, and HgSM modules are used to compute speciation, reactions and transformations in the water column and sediment layer. HEC-RAS obtains kinetics source and sink terms from each water quality module and performs the transport and mass balance computation for each water quality cell and each state variable. HEC-RAS has the control over the initial and boundary conditions. The water quality module returns the rate change of state variables, derived variables, and pathways back to HEC-RAS. The HEC-RAS graphic user interface with preand post-processer can be utilized to setup the model, perform the runs, and present and analyze the results. This report is primarily intended for use as a technical reference for applying these water quality modules. These three water quality modules will also be integrated into other H\&H models (e.g. AdH and SRH-2D).

This report provides theory and mathematical formulations implemented in GC, CSM, and HgSM modules. The report describes the scientific basis for three water quality modules and how they are formulated. The GC is a supporting water quality module that can be used to model simple kinetics for solids and user-defined constituents in the water column and bed sediments. The scientific basis of the CSM and HgSM modules reflects empirical and theoretical support precedence in the literature, and in widely used toxic chemical models. The GC, CSM, and HgSM modules have been tested and verified with a variety of examples, and compared against existing water quality models. The results from the comparison showed that the computer codes are correctly implemented in these water quality modules. Additional validation of these modules against observed data collected in aquatic systems is underway. Future model validation 
will evaluate how well the water quality module's theoretical foundation and computer implementation describe actual system behavior in terms of the degree of correlation between computed and independently observed responses of the aquatic system.

The computer codes in all of the water quality modules have been checked for consistency with the formulations described in the report. The variable names in the report correspond to those used in the codes so that the mathematical formulations and codes can be compared. Through a series of model verification tests, the model formulations appear correct. The modularity forms the basis for the flexibility of these "plug in" water quality modules (e.g. GC, CSM, HgSM), including the ability to add and modify processes for future development and enhancement. Despite the CSM and HgSM modules can be used to quantify the major processes of contaminants and mercury species in aquatic systems, many of the mechanisms that govern contaminant partitioning and reactions are still poorly understood. Determing contaminant fate in the environment and understanding their potential effects on human and environmental health is a complex topic requiring further research. These water quality modules can be continuously enhanced and further developed through revision of water quality formulations and computer codes presented above in this report. 


\section{References}

Ailard, B., and I. Arsenie. 1991. Abiotic reduction of mercury by humic substances in aquatic system - an important process for mercury cycle. Water, Air, Soil Pollution 56:457-464.

Allison, J. D., and T. L. Allison. 2005. Partition coefficients for metals in surface water, soil, and waste. EPA/600/R-05/074. Athens, GA: U.S. Environmental Protection Agency.

Ambrose, R. B., T. A. Wool, J. L. Martin, J. P. Connolly, and R. W. Schanz. 1993. The water quality analysis simulation program, WASP5, Part A: model documentation. Environmental Research Laboratory, Athens, GA: U.S. Environmental Protection Agency.

Ariathuri, R., and R. B. Krone. 1976. Finite element model for cohesive sediment transport. Journal of the Hydraulic Division 102(3):323-388.

ATSDR (Agency for Toxic Substances and Disease Registry). 2005. Toxicological profile for mercury. Atlanta, GA: U.S. Department of Health and Human Services, Public Health Service.

Bahadur, R., D. E. Amstutz, and W. B. Samuels. 2013. Water contaminant modeling - a review of the state of the science. Journal of Water Resource and Protection $5: 142-155$.

Baughman, G. L., A. Gordon, N. L. Wolfe, and R. G. Zepp. 1973. Chemistry of organomercurials in aquatic systems. EPA-66o/3-73-012. Corvallis, OR: U.S. Environmental Protection Agency.

Behradek, J. 1930. Temperature coefficients in biology. Biological Reviews 5(1):30-58.

Benoit, J. M., C. C. Gilmour, A. Heyes, R. P. Mason, and C. L. Miller. 2003. Geochemical and biological controls over methylmercury production and degradation in aquatic systems. In: Biogeochemistry of Environmentally Important Trace Elements. ed. Y. Cai and O. C. Braids. American Chemical Society Symposium Series \# 835:262-297.

Berger, R. C., J. N. Tate, G. L. Brown, and G. Savant. 2012. Adaptive hydraulics user's manual: Guidelines for solving two-dimensional shallow water problems with the adaptive hydraulics modeling system. Vicksburg, MS: U.S. Army Engineer Research and Development Center. http://chl.erdc.usace.army.mil/Media/1/2/7/8/AdH_Manual-4.201.pdf.

Bertelsen, S. L., A. D. Hoffman, C. A. Gallinat, C. M. Elonen, and J. W. Nichols. 1998. Evaluation of $\log$ Kow and tissue lipid content as predictors of chemical partitioning to fish tissues. Environmental Toxicology and Chemistry 17:14471455 . 
Bloom, N. S., C. J. Watras, and J. P. Hurley. 1991. Impact of acidification on the methylmercury cycle of remote seepage lakes. Water, Air, and Soil Pollution 56:477-491.

Boudreau, B. P. 1998. Mean mixed depth of sediments: The wherefore and the why. Limnology and Oceanography 43:524-526.

Boyer, J. M., Chapra, S. C., Ruiz, C. E., and M. S. Dortch. 1994. RECOVERY, a mathematical model to predict the temporal response of surface water to contaminated sediments. Technical Report W-94-4. Vicksburg, MS: U.S. Army Engineer Waterways Experiment Station.

Brigham, M. E., D. A. Wentz, G. R. Aiken, and D. P. Krabbenhoft. 2009, Mercury cycling in stream ecosystems. 1. Water column chemistry and transport. Environmental Science and Technology 43(8):2720-2725. doi: 10.1021/es802694n.

Chapra, S. C. 1997. Surface water quality modeling. New York, NY: McGraw-Hill.

Carroll, R. W. H., J. J. Warwick, K. J. Heim, J. C. Bonzongo, J. R. Miller, and W. B. Lyons. 2000. Simulation of mercury transport and fate in the Carson River, Nevada. Ecological Modelling 125(2-3):55-278. doi:10.1016/So304-3800(99)oo186-6.

Callahan, M. A., M. W. Slimak, N. W. Gabel, I. P. May, C. F. Fowler, J. R. Freed, P. Jennings, R. L. Durfee, F. C. Whitmore, B. Maestri, W. R. Mabey, B. R. Holt, and C. Gould. 1979. Water related environmental fate of 129 priority pollutants. Volume 1: Introduction and technical background, metals and inorganics, pesticides and PCBs. EPA 440/4-79-029a. Washington, DC: U.S. Environmental Protection Agency, Office of Water Waste and Management, 14-1-14-15.

Chapra, S. C., and R. P. Canale. 2006. Numerical methods for engineers. $5^{\text {th }}$ Ed. New York, NY: McGraw-Hill.

Cheng, N. S. 1997. Simplified settling velocity formula for sediment particle. Journal of Hydraulic Engineering 123(2):149-152.

Chen, Wei-Chin, L. Hsun-Yu, Y. Chung-Shin, and H. Chung-Hsuang. 2009. Kinetic modeling on the adsorption of vapor-phase mercury chloride on activated carbon by thermogravimetric analysis. Journal of the Air and Waste Management Association 59(2):227-235. doi:10.3155/1047-3289.59.2.227.

Cole, T. M., and S. A. Wells. 2011. CE-QUAL-W2: A two-dimensional, laterally averaged, hydrodynamic and water quality model. Department of Civil and Environmental Engineering, Portland State University, Portland, OR.

Cook, P. M., and L. P. Burkhard. 1998. Development of bioaccumulation factors for protection of fish and wildlife in the Great Lakes. National Sediment Bioaccumulation Conference Proceedings, EPA 823-R-98-002. U.S. Environmental Protection Agency Office of Water.

Costa, M., and P. Liss. 2000. Photoreduction and evolution of mercury from seawater. Science of the Total Environment 261(1-3):125-135. doi:10.1016/Soo489697(00)00631-8. 
Cossa, D., J. M. Martin, and J. Sanjuan. 1994. Dimethylmercury in the Alboran Sea. Marine Pollution Bulletin 28:381-384.

Craig, P. J., and P. A. Moreton. 1986. Total mercury, methyl mercury and sulphide levels in British estuarine sediments-III. Water Research 20(9):1111-1118. doi:10.1016/0043-1354(86)90057-6.

Delegard, C. H., and G. S. Barney. 1983. Effects of Hanford high-level waste components on sorption of cobalt, strontium, neptunium, plutonium, and americium of Hanford sediments. RHO-RE-ST-1 P, Rockwell Hanford Operations, Richland, Washington.

Di Toro, D. M., C. S. Zarba, D. J. Hansen, W. J. Berry, R. C. Swartz, C. E. Cowan, S. P. Pavlou, H. E. Allen, N. A. Thomas, and P. R. Paquin. 1991. Technical basis for establishing sediment quality criteria for nonionic organic chemicals using equilibrium partitioning. Environmental Toxicology and Chemistry 10:15411583 .

Di Toro, D. M. 2001. Sediment flux modeling. New York, NY: J. Wiley and Sons.

Di Toro, D. M., D. J. O'Connor, R. V. Thomann, and J. P. John. 1981. Analysis of fate of chemicals in receiving waters. Phase 1 . Washington, DC: Chemical Manufacturers Association.

Erickson, M. J., C. L. Turner, and L. J. Thibodeaux. 2005. Field observation and modeling of dissolved fraction sediment-water exchange coefficients for PCBs in the Hudson River. Environmental Science and Technology 39(2):549-556.

EPRI (Electric Power Research Institute). 2006. Enhancement of watershed analysis risk management framework (WARMF) for mercury watershed management and total maximum daily loads (TMDLs). http://www.epri.com/abstracts/Pages/ProductAbstract.aspx?Productld $=00000000000100547$ 0. (Accessed 2 February, 2016).

EPRI (Electric Power Research Institute). 2013. Dynamic mercury cycling model for Windows 7/Vista/XP. D-MCM v4.o user's guide and technical support. http://www.epri.com/abstracts/Pages/ProductAbstract.aspx?Productld $=00000000300200251$ 8. (Accessed 2 February, 2016).

Evers, D. C. 2005. Mercury connections: The extent and effects of mercury pollution in northeastern North America. Gorham, ME. BioDiversity Research Institute.

Freundlich, H. 1926. Colloid and capillary chemistry. Methuen, London.

Fitzgerald, W. F. 1989. Atmospheric and oceanic cycling of mercury. In: Chemical Oceanography, Vol. 10, ed. Riley, J. P. and R. Chester. Academic Press, London.

Fogler, H. S. 2005. Elements of chemical reaction engineering. 4th ed. Upper Saddle River, NJ: Prentice Hall.

Gilmour, C., E. Roden, and R. Harris. 2007. Appendix 3B-3: Approaches to modeling sulfate reduction and methylmercury production in the Everglades. South Florida Water Management District and the Florida Department of Environmental Protection. 
Gilmour, C. C., and E. A. Henry. 1991. Mercury methylation in aquatic systems affected by acid deposition. Environmental Pollution 71(2-4):131-169. doi:10.1016/02697491(91)90031-Q.

Harris, R., S. A. Gherini and R. J. M. Hudson. 1996. Regional Mercury Cycling Model (RMCM): A model for mercury cycling in lakes. User's guide and technical reference. Electric Power Research Institute, Palo Alto, CA.

Harris, R., D. Krabbenhoft, R. Mason, M. Murray, R. Reash, and T. Saltman. 2007. Chapter 1 Introduction In Ecosystem Responses to Mercury Contamination: Indicators of Change. Boca Raton, FL: CRC Press.

Hobman, J. L., J. R. Wilson, and N. L. Brown. 2000. Microbial mercury reduction. In: Environmental Microbe-Metal Interaction. ed. D. R. Lovley. American Society for Microbiology Press, Washington, DC.

Hudson, R. J. M., S. A. Gherini, C. J. Watras, and D. B. Porcella. 1994. Modeling the biogeochemical cycle of mercury in lakes: the mercury cycle model (MCM) and its application to the MTL study lakes. In Mercury Pollution: Integration and Synthesis, ed. C. J. Waltras and J. W. Huckabee, 473-523. Boca Raton, FL.: Lewis Publishers.

Hydrologic Engineering Center (HEC). 2010. HEC-RAS river analysis system user's manual version 4.1. U.S. Army Corps of Engineers, Institute for Water Resources, Hydrologic Engineering Center, Davis, CA.

Jackson, T. A. 1997. Long-range atmospheric transport of mercury to ecosystems, and the importance of anthropogenic emissions - a critical review and evaluation of the published evidence. Environmental Reviews 5(2):99-120.

Jonsson, A. and S. Agerberg. 2015. Modelling of E. coli transport in an oligotrophic river in northern Scandinavia. Ecological Modelling 145-151.

Kajiura, K. 1968. A model of the bottom boundary layer in water waves. Bulletin of the Earthquake Research Institute 46:75-123.

Kaplan, D. I., and R. J. Serne. 1995. Distribution coefficient values describing iodine, neptunium, selenium, technetium, and uranium sorption to Hanford sediments. PNL-10379. Richland, Washington: Pacific Northwest Laboratory.

Karickhoff, S. W., D. S. Brown, and T. A. Scott. 1979. Sorption of hydrophobic pollutants on natural sediments. Water Research 13:241-248.

Karickhoff, S. W. 1984. Organic pollutant sorption in aquatic systems. Journal of. Hydraulic Engineering 110(6):707-735. doi.org/10.1061/(ASCE)07339429(1984)110:6(707).

Khan, A. and W. Wu. 2013. Sediment Transport monitoring, modeling and management. Nova Science Publishers, NY.

King, J., F. Saunders, R. Lee, and R. Jahnke. 1999. Coupling mercury methylation rates to sulfate reduction rates in marine sediments. Environmental Toxicology and Chemistry 18(7):1362-1369. doi: 10.1002/etc.5620180704. 
King, J., J. Kostka, M. Frischer, F. Saunders, and R. Jahnke. 2001. A quantitative relationship that demonstrated mercury methylation rates in marine sediments are based on the community composition and activity of sulfate-reducing bacteria. Environmental Science and Technology 35(12):2491-2496. doi: 10.1021/esoo1813q.

Krabbenhoft, D. P., and D. A. Rickert. 2003. Mercury contamination of aquatic ecosystems. U.S. Geological Survey Fact Sheet 216-95. http://pubs.usgs.gov/fs/1995/fs216-95/. (accessed on 2 February, 2016.)

Krone, R. B. 1962. Flume studies of the transport of sediment in estuarial processes. Final Report, Hydraulic Engineering Laboratory and Sanitary Engineering Research Laboratory, University of California, Berkeley.

Krop, H. B., P. C. M. Van Noort, and H. A. J. Govers. 2001. Determination and theoretical aspects of the equilibrium between dissolved organic matter and hydrophobic organic micropollutants in water (Kdoc). Reviews of Environmental Contamination and Toxicology 169:1-122.

LaGrega, M. D., P. L. Buckingham, and J. C. Evans. 1994. Hazardous waste management. New York, NY: McGraw-Hill, Inc.

Langmuir, I. 1918. The adsorption of gases on plane surfaces of glass, mica and platinum. Journal of American Chemical Society 40:1361-1402.

Langer, C. S., W. F. Fitzgerald, P. T. Visscher, and G. M. Vandal. 2001. Biogeochemical cycling of methylmercury at Barn Island Salt Marsh, Stonington, CT, USA.

Wetlands Ecology and Management 9:295-310. doi:10.1023/A:1011816819369.

Lick, W., Y. J. Xu, and J. McNeil. 1995. Resuspension properties of sediments from the Fox, Saginaw, and Buffalo rivers. Journal of Great Lakes Research 21(2):257274.

Lick, W. 2009. Sediment and contaminant transport in surface waters. CRC Press, Boca Raton, FL.

Lin, C.-C., N. Yee, and T. Barkay. 2012. Microbial transformations in the mercury cycle. In Environmental Chemistry and Toxicology of Mercury 155-191. Hoboken, NJ: John Wiley \& Sons, Inc.

Loux, N. T. 2004. A critical assessment of elemental mercury air/water exchange parameters. Chemical Speciation \& Bioavailability 16(4):127-138. doi: 10.3184/095422904782775018.

Lyman, W. J., W. F. Reehl, and D. H. Rosenblatt. 1990. Handbook of chemical property estimation methods: environmental behavior of organic compounds. American Chemical Society, Washington, DC.

Lyon, B. F., R. Ambrose, G. Rice, and C. J. Maxwell. 1997. Calculation of soil-water and benthic sediment partition coefficients for mercury. Chemosphere 35:791-808. doi:10.1016/So045-6535(97)00200-2. 
Marvin-DiPasquale, M., M. A. Lutz, M. E. Brigham, D. P. Krabbenhoft, G. R. Aiken, W. H. Orem, and B. D. Hall. 2009. Mercury cycling in stream ecosystems. 2. Benthic methylmercury production and sediment-pore water partitioning. Environmental Science and Technology 43(8):2726-2732. doi: $10.1021 / \mathrm{es} 802698 \mathrm{v}$.

Mason, R. P., W. F. Fitzgerald, J. Hurley, A. K. Hanson, P. L. Donaghay, and J. Sieburth. 1993. Mercury biogeochemical cycling in a stratified estuary. Limnology and. Oceanography 38(6):1227-1241. doi: 10.4319/lo.1993.38.6.1227.

Mason, R. P., W. F. Fitzgerald, and F. M. M. Morel. 1994. The biogeochemical cycling of elemental mercury: Anthropogenic influences. Geochimica et Cosmochimica Acta 58(15):3191-3198. doi: 10.1016/0016-7037(94)90046-9.

Mason, R. R., M. L. Abbot, R. A. Bodaly, O. R. Bullock, C. T. Driscoll, D. Evers, S. E. Lindberg, M. Murray, and E. B. Swain. 2005. Monitoring the response to changing mercury deposition. Environmental Science and Technology 39 (1): $14 \mathrm{~A}-22 \mathrm{~A}$.

Mackay, D. M., and P. J. Leinonen. 1975. Rate of evaporation of low solubility contaminants from water bodies to atmosphere. Environmental Science and Technology 24(4):1178-1180.

Miles, C. J., H. A. Moye, E. J. Phlips, and B. Sargent. 2001. Partitioning of monomethylmercury between freshwater algae and water. Environmental Science and Technology 35(21):4277-4282. doi: 10.1021/es010792c.

Mill, T., W. R. Mabey, D. C. Bomberger, T. W. Chou, D. G. Hendrey, and J. H. Smith. 1982. Laboratory protocols for evaluating the fate of organic chemicals in air and water. EPA-600/3-82-022. Athens, GA.: U.S. Environmental Protection Agency, Environmental Research Laboratory.

Morel, F. M. M., A. M. L. Kraepiel, and M. Amyot. 1998. The chemical cycle and bioaccumulation of mercury. Annual Review of Ecology and Systematics 29:543-566. doi: 10.1146/annurev.ecolsys.29.1.543.

Mulder, H., and C. Udink. 1991. Modelling of cohesive sediment transport. A case study: the Western Scheldt estuary. Coastal Engineering 3012-3023. doi: 10.1061/9780872627765.230.

Nater, E. A., and D. F. Grigal. 1992. Regional trends in mercury distribution across the Great Lakes states, north central USA. Nature 358:139-141.

Nriagu, J. O. 1979. The biogeochemistry of mercury in the environment. Elsevier/North Holland New York: Biomedical Press.

O'Connor, D. J., R. V. Thomann, J. L. Schnoor, and J. L. Manciani. 1983. Modeling toxic substances in natural water systems. Manhattan College, Riverdale: NY.

Parchure, T. M., and A. J. Mehta. 1985. Erosion of soft cohesive sediment deposits. Journal of Hydraulic Engineering 111(10):1308-1326. 
Puk, R., and J. H. Weber. 1994. Determination of mercury (II), monomethylmercury cation, dimethylmercury and diethylmercury by hydride generation, cryogenic trapping and atomic absorption spectrometric detection. Analytica Chimica. Acta. 292(1-2):175-183. doi:10.1016/0003-2670(94)ooo66-2.

Regnell, O., A. Tunlid, G. Ewald, and O. Sangfors. 1996. Methyl mercury production in freshwater microcosms affected by dissolved oxygen levels: role of cobolamin and microbial community composition. Canadian Journal of Fisheries and Aquatic Sciences 53(7):1535-1545. doi: 10.1139/f96-086.

Ruiz, C. E., N. M. Aziz, and P. R. Schroeder. 2000. RECOVERY: A contaminated sediment-water interaction model. ERDC/EL SR-D-oo-1, U.S. Army Engineer Research and Development Center, Waterways Experiment Station, Vicksburg, MS.

Runkel, R. L., B. A. Kimball, D. M. McKnight, and K. E. Bencala. 1999. Reactive solute transport in streams: a surface complexation approach for trace metal sorption. Water Resources Research 35:3829-3840.

Rundgren, S., Å. Ruhling, K. Schlütter, and G. Tyler. 1992. Mercury in soil distribution, speciation and biological effects. Nordic Council of Ministers. Copenhagen: SW.

Schnoor, J. L. 1996. Environmental modeling: fate and transport of pollutants in water, air, and soil. Ed. J. L. Schnoor, and A. Z. Zehnder. New York, NY: Wiley Interscience.

Schink, D. R., and N. L. Guinasso. 1977. Modelling the influence of bioturbation and other processes on calcium carbonate dissolution at the sea floor. In The Fate of Fossil Fuel CO2 in the Oceans. ed. N. R. Andersen and A. Malahoff, 375-399. New York: Plenum Press.

Schroeder, W. H., and J. Munthe. 1998. Atmospheric mercury-an overview, Atmospheric Environment 32:809-822.

Seth, R., D. Mackay, and J. Muncke. 1999. Estimating the organic carbon partition coefficient and its variability for hydrophobic chemicals. Environmental Science and Technology 33(14):2390-2394.

Stein, E. D., Y. Cohen, and A. M. Winer. 1996. Environmental distribution and transformation of mercury compounds. Critical Reviews in Environmental Science and Technology 26(1):1-43. doi: 10.1080/10643389609388485.

Thibodeaux, L. J., K. T. Valsaraj, and D. D. Rieble. 2001. Bioturbation driven transport of hydrophobic organic contaminants from bed sediment. Environmental Engineering Science 18 (4):215-223.

Thibodeaux, L. J. 2005. Recent advances in our understanding of sediment-to-water contaminant fluxes: The soluble release fraction. Aquatic Ecosystem Health \& Management 8(1):1-9. doi: 10.1080/14634980590914917.

Thomann, R. V., and J. A. Mueller. 1987. Principles of surface water quality modeling and control. New York, NY: Harper and Row. 
Traina, S. J., D. C. McAvoy, and D. J. Versteeg. 1996. Association of linear alkylbenzenesulfonates with dissolved humic substances and its effect on boavilibility. Environmental Science and Technology 30(4):1300-1309.

Tsiros, I. X. and R. B. Ambrose. 1999. An environmental simulation model for transport and fate of mercury in small rural catchments. Chemosphere 39(3):477-492. doi:10.1016/So045-6535(98)oo601-8.

Turner, D. R. 1987. Speciation cycling of arsenic, cadmium, lead and mercury in natural waters. In: Lead, Mercury, Cadmium and Arsenic in the Environment. ed. T. W. Hutchinson, and K. M. Meema. Chichester, UK: John Wiley and Sons Ltd.

Ullrich, S. M., T. W. Tanton, and S. A. Abdrashitova. 2001. Mercury in the aquatic environment: A review of factors affecting methylation. Critical Reviews Environmental Science and Technology 31(3):241-293. doi: $10.1080 / 20016491089226$.

USEPA (United States Environmental Protection Agency). 1997. Mercury study report to congress, volumes I through VIII. EPA/452/R-97-001. Office of Air Quality Planning and Standards and Office of Rearch and Development. Washington DC

Van Rijn, L. C. 1989. Handbook: Sediment transport by currents and waves. Report H461. Delft Hydraulics, Delft, The Netherlands.

Wang, Q., D. Kim, D. D. Dionysiou, G. A. Sorial, and D. Timberlake. 2004. Sources and remediation for mercury contamination in aquatic systems-a literature review. Environmental Pollution 131(2):323-336.

Whitman, W. G. 1923. Preliminary experimental confirmation of the two-film theory. Chemical Metallurgical Engineering 29:146-148.

Winterwerp, J. C., J. M. Cornelisse, and C. Kuiper. 1993. A Laboratory study of the behavior of mud from the Western Scheldt under tidal conditions. ed. A. J. Mehta. American Geophysical Union, Washington, DC. doi: 10.1029/CE042po295.

Winterwerp, J. C., and W. G. M van Kersteren. 2004. Introduction to the physics of cohesive sediment in the marine environment. Developments in Sedimentology 56.

Wool, T. A., R. B. Ambrose, J. L. Martin, and E. A. Comer. 2006. Water quality analysis simulation program (WASP) version 6.o draft: user's manual. http://www.epa.gov/athens/wwatsc/html/wasp.html. (accessed on 2 February, 2016.)

Yin, Y., H. F. Allen, C. P. Huang, D. L. Sparks, and P. F. Sanders. 1997. Kinetics of mercury (ii) adsorption and desorption on soil. Environmental Science and Technology 31(2): 496-503.

Zhang, Z., and B. E. Johnson. 2016. Aquatic nutrient simulation modules (NSMs) developed for hydrologic and hydraulic models. ERDC/EL TR-16-1. Vicksburg, MS: U.S. Army Engineer Research and Development Center.

Zheng, C., and G. D. Bennett. 2002. Applied contaminant transport modeling 2nd edition. New York: John Wiley \& Sons. 
Zillioux, E. J., D. B. Porcella, and J. M. Benoit. 1993. Mercury cycling and effects in freshwater wetland ecosystems. Environmental Toxicology Toxicology and Chemistry 12(12):2245-2264. doi:10.1002/etc.5620121208. 


\section{Appendix A: Definition of Mathematical Symbols used in the GC Module}

\begin{tabular}{|c|c|c|}
\hline Symbol & Definition & Units \\
\hline$C_{i}$ & concentration of constituent i & $m g L^{-1}$ \\
\hline$d_{p n}$ & diameter of solid " $n$ " & $\mathrm{mm}$ \\
\hline$d *$ & dimensionless solids parameter & unitless \\
\hline$E$ & sediment erosion rate & $\mathrm{g} \mathrm{cm}^{-2} \mathrm{~s}^{-1}$ \\
\hline Eo & surface erosion rate & $\mathrm{g} \mathrm{cm}^{-2} \mathrm{~s}^{-1}$ \\
\hline g & gravity acceleration & $\mathrm{m} \mathrm{s}^{-2}$ \\
\hline$h$ & water depth & $\mathrm{m}$ \\
\hline$h_{2}$ & sediment layer thickness & $\mathrm{m}$ \\
\hline$i$ & index number of user-defined constituents & unitless \\
\hline$k_{0 i}(T)$ & zero-order decay rate of constituent i & $m g L^{-1} d^{-1}$ \\
\hline$k_{1 i}(T)$ & first-order decay rate of constituent i & $d^{-1}$ \\
\hline$k(20)$ & value of the reaction rate at $20^{\circ} \mathrm{C}$ & $d^{-1}$ \\
\hline$k(T)$ & value of the rate at local temperature & $d^{-1}$ \\
\hline$k\left(T_{w r}\right)$ & value of the rate at reference temperature & $d^{-1}$ \\
\hline$m$ & empirically determined constant & unitless \\
\hline$m_{n}$ & concentration of solid " $n$ " in water & $m g L^{-1}$ \\
\hline$m_{n 2}$ & concentration of solid " $n$ " in sediment & $m g L^{-1}$ \\
\hline$n$ & index number of solids classes & unitless \\
\hline$N$ & number of solids classes & unitless \\
\hline$P$ & surface erosion rate & $\mathrm{g} \mathrm{cm}^{-2} \mathrm{~s}^{-1}$ \\
\hline$P_{d p n}$ & deposition probability of solid " $n$ " & unitless \\
\hline$T_{w}$ & water temperature & ${ }^{\circ} \mathrm{C}$ \\
\hline$u$ & water velocity & $\mathrm{m} \mathrm{s}^{-1}$ \\
\hline$V_{b}$ & sediment burial velocity & $\mathrm{m} \mathrm{yr}-1$ \\
\hline$V_{d p n}$ & deposition velocity of solid " $n$ " & $\mathrm{m} \mathrm{d}^{-1}$ \\
\hline$V_{r p n}$ & re-suspension velocity & $\mathrm{m} \mathrm{d}^{-1}$ \\
\hline$v_{s i}$ & settling velocity of constituent i & $\mathrm{m} \mathrm{d}^{-1}$ \\
\hline$V_{s p n}$ & settling velocity of solid " $n$ " & $\mathrm{m} \mathrm{d}^{-1}$ \\
\hline \multicolumn{3}{|c|}{ Greek } \\
\hline$\phi$ & sediment layer porosity & unitless \\
\hline$T$ & bottom shear stress & $\mathrm{N} \mathrm{m}^{-2}$ \\
\hline
\end{tabular}




\begin{tabular}{|l|l|l|}
\hline Symbol & Definition & Units \\
\hline$T_{c e}$ & critical shear stress for erosion & $\mathrm{N} \mathrm{m}^{-2}$ \\
\hline$T_{c n}$ & $\begin{array}{l}\text { critical shear stress for the initiation of movement of } \\
\text { noncohensive solids }\end{array}$ & $\mathrm{N} \mathrm{m}-2$ \\
\hline$T_{c d l}$ & lower critical shear stress for deposition & $\mathrm{N} \mathrm{m}^{-2}$ \\
\hline$T_{c d u}$ & upper critical shear stress for deposition & $\mathrm{N} \mathrm{m}^{-2}$ \\
\hline$\rho_{p n}$ & density of solid “ $n$ " in water & $\mathrm{g} \mathrm{cm}^{-3}$ \\
\hline$\rho_{p n 2}$ & density of solid " $\mathrm{n}$ " in sediment & $\mathrm{g} \mathrm{cm}^{-3}$ \\
\hline$\rho_{w}$ & density of water & $\mathrm{g} \mathrm{cm}^{-3}$ \\
\hline$\rho_{s}$ & sediment dry density & $\mathrm{mg} \mathrm{L}^{-1}$ \\
\hline$\rho_{b}$ & sediment bulk density & $\mathrm{g} \mathrm{cm}^{-3}$ \\
\hline$V$ & kinematic viscosity of water & $\mathrm{m}^{2} \mathrm{~s}^{-1}$ \\
\hline$\alpha_{0}$ & empirical constant & unitless \\
\hline$\theta$ & temperature correction coefficient & unitless \\
\hline
\end{tabular}




\section{Appendix B: Definition of Mathematical Symbols used in the CSM Module}

\begin{tabular}{|c|c|c|}
\hline Symbol & Definition & Units \\
\hline$A_{p d}$ & algal biomass in water & $\mathrm{mg} \mathrm{L} \mathrm{L}^{-1}$ \\
\hline As & surface water area & $m^{-2}$ \\
\hline$b$ & Freundlich exponent & unitless \\
\hline$b_{\text {pom }}$ & Freundlich exponent for POM in water & unitless \\
\hline$b_{\text {pom2 }}$ & Freundlich exponent for sediment POM & unitless \\
\hline$b_{a p}$ & Freundlich exponent for algae in water & unitless \\
\hline$b_{p n}$ & Freundlich exponent for solid " $n$ " in water & unitless \\
\hline$b_{\text {pn2 }}$ & Freundlich exponent for sediment solid " $n$ " & unitless \\
\hline$C_{T}$ & total oncentration in water & $\mu g L^{-1}$ \\
\hline$C_{\text {ion }}$ & ionic concentration in water & $\mu g L^{-1}$ \\
\hline$C_{d}$ & concentration of dissolved phase in water & $\mu g L^{-1}$ \\
\hline$C_{a p}$ & concentration of algae adsorbed phase in water & $\mu g L^{-1}$ \\
\hline$C_{d o c}$ & concentration of DOC adsorbed phase in water & $\mu g L^{-1}$ \\
\hline$C_{p o m}$ & concentration of POM adsorbed phase in water & $\mu g L^{-1}$ \\
\hline$C_{p n}$ & concentration of solids "n” adsorbed phase in water & $\mu g L^{-1}$ \\
\hline$C_{p t s}$ & total mass of solids adsorbed phase in water & mg kg-1 \\
\hline$C_{p s}$ & mass of solids " $n$ " adsorbed phase in water & mg kg-1 \\
\hline$C_{p t}$ & total concentration of solids adsorbed phase in water & $\mu g L^{-1}$ \\
\hline$C_{\text {T2 }}$ & total concentration in sediment & $\mu g L^{-1}$ \\
\hline$C_{d 2}$ & concentration of dissolved phase in sediment & $\mu g L^{-1}$ \\
\hline Cdp2 & concentration of dissolved phase in pore water & $\mu g L^{-1}$ \\
\hline$C_{d o c 2}$ & concentration of DOC adsorbed phase in sediment & $\mu g L^{-1}$ \\
\hline$C_{d o c p 2}$ & concentration of DOC adsorbed phase in pore water & $\mu g L^{-1}$ \\
\hline$C_{\text {pom2 }}$ & concentration of POM adsorbed phase in sediment & $\mu g L^{-1}$ \\
\hline$C_{p n 2}$ & concentration of solid " $n$ " adsorbed phase in sediment & $\mu g L^{-1}$ \\
\hline$C_{p t s 2}$ & total mass of solids adsorbed phase in sediment & mg kg-1 \\
\hline$C_{p t 2}$ & total concentration of solids adsorbed phase in sediment & $\mu g L^{-1}$ \\
\hline$C_{0}$ & air concentration (gaseous) of contaminant & $\mu g L^{-1}$ \\
\hline$C_{\mathrm{s} d}$ & solubility & $\mathrm{mg} \mathrm{L} \mathrm{L}^{-1}$ \\
\hline$D O C$ & dissolved organic carbon in water & $m g-C L^{-1}$ \\
\hline
\end{tabular}




\begin{tabular}{|c|c|c|}
\hline Symbol & Definition & Units \\
\hline$D O C_{2}$ & sediment dissolved organic carbon in pore water & $m g-C L^{-1}$ \\
\hline$D_{b}$ & biodiffusion coefficient representing particle diffusivity & $m^{2} d^{-1}$ \\
\hline$D_{m}$ & molecular diffusion coefficient & $\mathrm{m}^{2} \mathrm{~s}^{-1}$ \\
\hline$E_{a}$ & activation energy & $\mathrm{J} \mathrm{mol}^{-1}$ \\
\hline [E] & $\begin{array}{l}\text { concentration of environmental property driving generalized } \\
\text { second-order reaction in water }\end{array}$ & $\mathrm{mg} \mathrm{L} \mathrm{L}^{-1}$ \\
\hline$\left[E_{2}\right]$ & $\begin{array}{l}\text { concentration of environmental property driving generalized } \\
\text { second-order reaction in sediment }\end{array}$ & $m g L^{-1}$ \\
\hline$f^{\prime}$ & $\begin{array}{l}\text { fraction of the chemical occurring in each of the chemical } \\
\text { species i }\end{array}$ & unitless \\
\hline$f_{a p}$ & Freundlich exponent for algae in water & unitless \\
\hline$f_{\text {pom }}$ & Freundlich exponent for POM in water & unitless \\
\hline$f_{\text {pom2 }}$ & Freundlich exponent for POM in sediment & unitless \\
\hline$f_{p n}$ & Freundlich exponent for solid " $\mathrm{n}$ " in water & unitless \\
\hline$f_{p n 2}$ & Freundlich exponent for solid " $\mathrm{n}$ " in sediment & unitless \\
\hline$f_{d}$ & fraction of dissolved phase in water & unitless \\
\hline$f_{a p}$ & fraction of algae adsorbed phase in water & unitless \\
\hline$f_{d o c}$ & fraction of DOC adsorbed phase in water & unitless \\
\hline$f_{\text {pom }}$ & fraction of POM adsorbed phase in water & unitless \\
\hline$f_{p n}$ & fraction of solid " $n$ " adsorbed phase in water & unitless \\
\hline$f_{d 2}$ & fraction of dissolved phase in sediment & unitless \\
\hline$f_{\text {doc2 }}$ & fraction of DOC adsorbed phase in sediment & unitless \\
\hline$f_{\text {pom2 }}$ & fraction of POM adsorbed phase in sediment & unitless \\
\hline$f_{o c}$ & fraction of organic carbon in solids & unitless \\
\hline$f_{p n 2}$ & fraction of solid " $n$ ” adsorbed phase in sediment & unitless \\
\hline$h$ & water depth & $\mathrm{m}$ \\
\hline$h_{2}$ & sediment layer thickness & $\mathrm{m}$ \\
\hline$\left[H^{+}\right]$ & hydronium ions & mol L-1 \\
\hline$\left[\mathrm{OH}^{-}\right]$ & hydroxide ions & mol L-1 \\
\hline 10 & solar radiation at the water surface & $\mathrm{W} \mathrm{m}^{-2}$ \\
\hline lopht & light intensity when $k_{p h t}(T)$ is measured & $\mathrm{W} \mathrm{m}^{-2}$ \\
\hline j & species that can be transformed into daughter products & unitless \\
\hline$K_{i}$ & $\begin{array}{l}\text { equilibrium constant for the formation of the acid }\left(\mathrm{K}_{\mathrm{ai}}\right) \text {, or } \\
\text { anionic species, or the base }\left(\mathrm{K}_{\mathrm{bi}}\right) \text { or cationic species }\end{array}$ & unitless \\
\hline$K_{d}$ & sorption or partition coefficient & $\mathrm{L} \mathrm{kg}^{-1}$ \\
\hline$K_{f}$ & Freundlich adsorption constant & $\left(\mu g g^{-1}\right)\left(\mu g L^{-1}\right)^{-b}$ \\
\hline$K_{\text {fap }}$ & Freundlich adsorption constant for algae in water & $\left(\mu g g^{-1}\right)\left(\mu g L^{-1}\right)^{-b}$ \\
\hline Kfpom & Freundlich adsorption constant for POM in water & $\left(\mu g g^{-1}\right)\left(\mu g L^{-1}\right)^{-b}$ \\
\hline
\end{tabular}




\begin{tabular}{|c|c|c|}
\hline Symbol & Definition & Units \\
\hline Kfpom2 & Freundlich adsorption constant for sediment POM & $\left(\mu g g^{-1}\right)\left(\mu g L^{-1}\right)^{-b}$ \\
\hline$K_{f p n}$ & Freundlich adsorption constant for solid " $n$ " in water & $\left(\mu g g^{-1}\right)\left(\mu g L^{-1}\right)^{-b}$ \\
\hline$K_{\text {fpn2 }}$ & Freundlich adsorption constant for sediment solid "n" & $\left(\mu g g^{-1}\right)\left(\mu g L^{-1}\right)^{-b}$ \\
\hline$K_{\prime}$ & Langmuir adsorption constant & $L \mu g^{-1}$ \\
\hline Klap & Langmuir adsorption constant for algae in water & $L \mu g^{-1}$ \\
\hline Klpom & Langmuir adsorption constant for POM in water & $L \mu g^{-1}$ \\
\hline KIpom2 & Langmuir adsorption constant for sediment POM & $L \mu g^{-1}$ \\
\hline$K_{l p n}$ & Langmuir adsorption constant for solid " $\mathrm{n}$ ” in water & $L \mu g^{-1}$ \\
\hline$K_{\text {lpn2 }}$ & Langmuir adsorption constant for sediment solid "n" & $L \mu g^{-1}$ \\
\hline$K_{\text {doc }}$ & equilibrium partition coefficient for DOC in water & $\operatorname{Lkg}^{-1}$ \\
\hline Kap & equilibrium partition coefficient for algae in water & $\mathrm{L} \mathrm{kg}^{-1}$ \\
\hline$K_{p}$ & equilibrium partition coefficient for solid " $n$ " in water & $\mathrm{L} \mathrm{kg}^{-1}$ \\
\hline$K_{\text {pom }}$ & equilibrium partition coefficient for POM in water & $\mathrm{L} \mathrm{kg}^{-1}$ \\
\hline$K_{p n}$ & equilibrium partition coefficient for solid " $n$ " in water & $\mathrm{L} \mathrm{kg}^{-1}$ \\
\hline Kdoc2 & equilibrium partition coefficient for sediment DOC & $\mathrm{L} \mathrm{kg}^{-1}$ \\
\hline$K_{\text {pom2 }}$ & equilibrium partition coefficient for sediment POM & $\mathrm{L} \mathrm{kg}^{-1}$ \\
\hline$K_{p n 2}$ & equilibrium partition coefficient for sediment solid " $n$ " & $\mathrm{L} \mathrm{kg}^{-1}$ \\
\hline Kow & octanol-water partition coefficient & unitless \\
\hline Kadn & adsorption coefficient for solid " $n$ " in water & $L \mu g^{-1} d^{-1}$ \\
\hline Kadn2 & adsorption coefficient for sediment solid " $n$ " & $L \mu g^{-1} d^{-1}$ \\
\hline Kadap & adsorption coefficient for algae in water & $L \mu g^{-1} d^{-1}$ \\
\hline Kdaap & desorption rate for algae in water & $d^{-1}$ \\
\hline Kadpom & adsorption coefficient for POM in water & $L \mu g^{-1} d^{-1}$ \\
\hline Kdapom & desorption rate for POM in water & $d^{-1}$ \\
\hline Kadpom2 & adsorption coefficient for sediment POM & $L \mu g^{-1} d^{-1}$ \\
\hline kdapom2 & desorption rate for sediment POM & $d^{-1}$ \\
\hline kdan & desorption rate for solid “n” in water & $d^{-1}$ \\
\hline Kdan2 & desorption rate for solid " $\mathrm{n}$ " in sediment & $d^{-1}$ \\
\hline$k_{1 d}^{i}(T)$ & degradation rate for dissolved species in water & $d^{-1}$ \\
\hline$k_{1 d 2}^{i}(T)$ & degradation rate for dissolved species in sediment & $d^{-1}$ \\
\hline$k_{1 a p}^{i}(T)$ & degradation rate for algae adsorbed species in water & $d^{-1}$ \\
\hline$k_{1 d o c}^{i}(T)$ & degradation rate for DOC adsorbed species in water & $d^{-1}$ \\
\hline$k_{1 d o c 2}^{i}(T)$ & degradation rate for DOC adsorbed species in sediment & $d^{-1}$ \\
\hline$k_{1 p o m}^{i}(T)$ & degradation rate for POM adsorbed species in water & $d^{-1}$ \\
\hline$k_{1 p o m 2}^{i}(T)$ & degradation rate for POM adsorbed species in sediment & $d^{-1}$ \\
\hline
\end{tabular}




\begin{tabular}{|c|c|c|}
\hline Symbol & Definition & Units \\
\hline$k_{1 p n}^{i}(T)$ & degradation rate for solid "n" adsorbed species in water & $d^{-1}$ \\
\hline$k_{1 p n 2}^{i}(T)$ & degradation rate for solid " $\mathrm{n}$ " adsorbed species in sediment & $d^{-1}$ \\
\hline$k_{h a}^{i}(T)$ & acid hydrolysis rate constant for dissolved species in water & $L \mathrm{~mol}^{-1} \mathrm{~d}^{-1}$ \\
\hline$k_{h a 2}^{i}(T)$ & $\begin{array}{l}\text { acid hydrolysis rate constant for dissolved species in } \\
\text { sediment }\end{array}$ & $L \mathrm{~mol}^{-1} \mathrm{~d}^{-1}$ \\
\hline$k_{h b}^{i}(T)$ & base hydrolysis rate constant for dissolved species in water & $\mathrm{L} \mathrm{mol}^{-1} \mathrm{~d}^{-1}$ \\
\hline$k_{h b 2}^{i}(T)$ & $\begin{array}{l}\text { base hydrolysis rate constant for dissolved species in } \\
\text { sediment }\end{array}$ & $L \mathrm{~mol}^{-1} \mathrm{~d}^{-1}$ \\
\hline$k_{h n}^{i}(T)$ & neutral hydrolysis rate for dissolved species in water & $d^{-1}$ \\
\hline$k_{h n 2}^{i}(T)$ & neutral hydrolysis rate for dissolved species in sediment & $d^{-1}$ \\
\hline$k_{\text {hadoc }}^{i}(T)$ & $\begin{array}{l}\text { acid hydrolysis rate constant for DOC adsorbed species in } \\
\text { water }\end{array}$ & $\mathrm{L} \mathrm{mol}^{-1} \mathrm{~d}^{-1}$ \\
\hline$k_{\text {hadoc } 2}^{i}(T)$ & $\begin{array}{l}\text { acid hydrolysis rate constant for DOC adsorbed species in } \\
\text { sediment }\end{array}$ & $L \mathrm{~mol}^{-1} \mathrm{~d}^{-1}$ \\
\hline$k_{h b d o c}^{i}(T)$ & $\begin{array}{l}\text { base hydrolysis rate constant for DOC adsorbed species in } \\
\text { water }\end{array}$ & $\mathrm{L} \mathrm{mol}^{-1} \mathrm{~d}^{-1}$ \\
\hline$k_{h b d o c 2}^{i}(T)$ & $\begin{array}{l}\text { base hydrolysis rate constant for DOC adsorbed species in } \\
\text { sediment }\end{array}$ & $\mathrm{L} \mathrm{mol}^{-1} \mathrm{~d}^{-1}$ \\
\hline$k_{\text {hndoc }}^{i}(T)$ & $\begin{array}{l}\text { neutral hydrolysis rate for DOC adsorbed chemical species in } \\
\text { water }\end{array}$ & $d^{-1}$ \\
\hline$k_{\text {hndoc } 2}^{i}(T)$ & $\begin{array}{l}\text { neutral hydrolysis rate for DOC adsorbed chemical species in } \\
\text { sediment }\end{array}$ & $d^{-1}$ \\
\hline$k_{p h t}^{i}$ & direct near-surface photolysis rate for dissolved species & $d^{-1}$ \\
\hline$k_{\text {phtdoc }}^{i}$ & direct near-surface photolysis rate for DOC adsorbed species & $d^{-1}$ \\
\hline$K_{L}$ & mass transfer velocity from the liquid film & $\mathrm{m} \mathrm{d}^{-1}$ \\
\hline$K_{G}$ & mass transfer velocity from the gaseous film & $\mathrm{m} \mathrm{d}^{-1}$ \\
\hline$K_{H}$ & Henry's Law constant & Pa m${ }^{3} \mathrm{~mol}^{-1}$ \\
\hline$k_{a}$ & oxygen reaeration rate & $\mathrm{m} \mathrm{d}^{-1}$ \\
\hline ked & second order rate for dissolved species in water & $\left(m g L^{-1}\right)^{-1} d^{-1}$ \\
\hline ked2 & second order rate for dissolved species in sediment & $\left(m g L^{-1}\right)^{-1} d^{-1}$ \\
\hline Kedoc & second order rate for DOC adsorbed species in water & $\left(m g L^{-1}\right)^{-1} d^{-1}$ \\
\hline Kedoc2 & second order rate for DOC adsorbed species in sediment & $\left(m g L^{-1}\right)^{-1} d^{-1}$ \\
\hline Keap & second order rate for algae adsorbed species & $\left(m g L^{-1}\right)^{-1} d^{-1}$ \\
\hline Kepom & second order rate for POM adsorbed species in water & $\left(m g L^{-1}\right)^{-1} d^{-1}$ \\
\hline Kepom2 & second order rate for POM adsorbed species in sediment & $\left(m g L^{-1}\right)^{-1} d^{-1}$ \\
\hline Kepn & second order rate for solids adsorbed species in water & $\left(m g L^{-1}\right)^{-1} d^{-1}$ \\
\hline Kepn2 & second order rate for solids adsorbed species in sediment & $\left(m g L^{-1}\right)^{-1} d^{-1}$ \\
\hline$k_{j \rightarrow i}(T)$ & transformation rate & $d^{-1}$ \\
\hline
\end{tabular}




\begin{tabular}{|c|c|c|}
\hline Symbol & Definition & Units \\
\hline Ka1 & ionization constant for anionic species in water & unitless \\
\hline$K_{a 12}$ & ionization constant for anionic species in sediment & unitless \\
\hline$K_{a 2}$ & ionization constant for anionic species in water & unitless \\
\hline$K_{a 22}$ & ionization constant for anionic species in sediment & unitless \\
\hline$K_{b 1}$ & ionization constant for cationic species in water & unitless \\
\hline$K_{b 12}$ & ionization constant for cationic species in sediment & unitless \\
\hline$K_{b 2}$ & ionization constant for cationic species in water & unitless \\
\hline$K_{b 22}$ & ionization constant for cationic species in sediment & unitless \\
\hline Lo & areal deposition of contaminant & $g \mathrm{~m}^{-2} \mathrm{~d}^{-1}$ \\
\hline$m_{n}$ & concentration of solid " $n$ " in water & $\mathrm{mg} \mathrm{L} \mathrm{L}^{-1}$ \\
\hline$m_{n 2}$ & concentration of solid " $n$ " in sediment & $\mathrm{mg} \mathrm{L-1}$ \\
\hline MW & molecular weight & $\mathrm{g} \mathrm{M}^{-1}$ \\
\hline$n$ & solids index & unitless \\
\hline$P O M$ & particulate organic matter in water & $\mathrm{mg} \mathrm{L-1}$ \\
\hline $\mathrm{POM}_{2}$ & sediment particulate organic matter & $\mathrm{mg} \mathrm{L} \mathrm{L}^{-1}$ \\
\hline $\mathrm{pH}$ & measure of the acidity or basicity & unitless \\
\hline$q_{c}$ & maximum amount adsorbed by the solid & $\mathrm{mg} \mathrm{kg}^{-1}$ \\
\hline qcap & maximum amount of contaminant adsorbed by algae in water & mg kg-1 \\
\hline$q_{c p o m}$ & maximum amount of contaminant adsorbed by POM in water & mg kg-1 \\
\hline qcpom2 & $\begin{array}{l}\text { maximum amount of contaminant adsorbed by sediment } \\
\text { POM }\end{array}$ & mg kg-1 \\
\hline$q_{c n}$ & $\begin{array}{l}\text { maximum amount of contaminant adsorbed by solid “ } n \text { ” in } \\
\text { water }\end{array}$ & mg kg-1 \\
\hline$q_{\mathrm{cn} 2}$ & $\begin{array}{l}\text { maximum amount of contaminant adsorbed by sediment } \\
\text { solid " } n \text { " }\end{array}$ & mg kg-1 \\
\hline$R$ & universal gas constant & $\mathrm{Pa} \mathrm{m}^{3} \mathrm{~mol}^{-1} \mathrm{oK}^{-1}$ \\
\hline$S_{d e c}$ & contaminant degradation & $\mu g L^{-1} d^{-1}$ \\
\hline Shyd & contaminant hydrolysis & $\mu g L^{-1} d^{-1}$ \\
\hline Spht & contaminant photolysis & $\mu g L^{-1} d^{-1}$ \\
\hline Sexa & contaminant generalized second-order reaction & $\mu g L^{-1} d^{-1}$ \\
\hline Strm & total contaminant transformation & $\mu g L^{-1} d^{-1}$ \\
\hline$S_{v / t}$ & contaminant volatilization & $\mu g L^{-1} d^{-1}$ \\
\hline Satm & contaminant air deposition & $\mu g L^{-1} d^{-1}$ \\
\hline $\mathrm{S}_{\text {set }}$ & contaminant settling & $\mu g L^{-1} d^{-1}$ \\
\hline Sres & contaminant re-suspension & $\mu g L^{-1} d^{-1}$ \\
\hline $\mathrm{SS}_{T}$ & $\begin{array}{l}\text { sum of internal source and sink terms of total contaminant in } \\
\text { water }\end{array}$ & $\mu g L^{-1} d^{-1}$ \\
\hline
\end{tabular}




\begin{tabular}{|c|c|c|}
\hline Symbol & Definition & Units \\
\hline $\mathrm{SS}_{d}$ & $\begin{array}{l}\text { sum of internal source and sink terms of dissolved phase in } \\
\text { water }\end{array}$ & $\mu g L^{-1} d^{-1}$ \\
\hline$S_{d o c}$ & $\begin{array}{l}\text { sum of internal source and sink terms of DOC adsorbed } \\
\text { phase in water }\end{array}$ & $\mu g L^{-1} d^{-1}$ \\
\hline$S_{a p}$ & $\begin{array}{l}\text { sum of internal source and sink terms of algae adsorbed } \\
\text { phase in water }\end{array}$ & $\mu g L^{-1} d^{-1}$ \\
\hline SS pom & $\begin{array}{l}\text { sum of internal source and sink terms of POM adsorbed } \\
\text { phase in water }\end{array}$ & $\mu g L^{-1} d^{-1}$ \\
\hline$S_{p n}$ & $\begin{array}{l}\text { sum of internal source and sink terms of solids adsorbed } \\
\text { phase in water }\end{array}$ & $\mu g L^{-1} d^{-1}$ \\
\hline $\mathrm{SS}_{T 2}$ & $\begin{array}{l}\text { sum of source and sink terms of total contaminant in } \\
\text { sediment }\end{array}$ & $\mu g L^{-1} d^{-1}$ \\
\hline $\mathrm{SS}_{d 2}$ & sum of source and sink terms of dissolved phase in sediment & $\mu g L^{-1} d^{-1}$ \\
\hline $\mathrm{SS}_{\text {doc2 }}$ & $\begin{array}{l}\text { sum of source and sink terms of DOC adsorbed phase in } \\
\text { sediment }\end{array}$ & $\mu g L^{-1} d^{-1}$ \\
\hline SSpom2 & $\begin{array}{l}\text { sum of source and sink terms of POM adsorbed phase in } \\
\text { sediment }\end{array}$ & $\mu g L^{-1} d^{-1}$ \\
\hline$S_{p n 2}$ & $\begin{array}{l}\text { sum of source and sink terms of solids adsorbed phase in } \\
\text { sediment }\end{array}$ & $\mu g L^{-1} d^{-1}$ \\
\hline$S_{b}$ & sediment contaminant burial & $\mu g L^{-1} d^{-1}$ \\
\hline$S_{s w}$ & contaminant sediment-water transfer & $\mu g L^{-1} d^{-1}$ \\
\hline$T_{w k}$ & water temperature & oK \\
\hline$T_{w}$ & water temperature & ${ }^{\circ} \mathrm{C}$ \\
\hline$T_{w r}$ & reference water temperature & oK \\
\hline$u_{w}$ & wind speed & $\mathrm{m} \mathrm{s}^{-1}$ \\
\hline$u_{*}$ & $\begin{array}{l}\text { flow shear velocity along the bed, which is approximately } 10 \\
\text { percent of the mean velocity of flow }\end{array}$ & $\mathrm{m} \mathrm{s}^{-1}$ \\
\hline$V_{b}$ & sediment burial velocity & $\mathrm{m} \mathrm{d}^{-1}$ \\
\hline$V_{m}$ & sediment-water transfer velocity & $\mathrm{m} \mathrm{d}^{-1}$ \\
\hline$V_{m s}$ & user-defined sediment-water transfer velocity & $m d^{-1}$ \\
\hline$V_{s p n}$ & solids settling velocity & $\mathrm{m} \mathrm{d}^{-1}$ \\
\hline$V_{r p n}$ & re-suspension velocity & $\mathrm{m} \mathrm{d}^{-1}$ \\
\hline$V_{\text {sap }}$ & algal settling velocity & $m d^{-1}$ \\
\hline$V_{\text {som }}$ & POM settling velocity & $m d^{-1}$ \\
\hline$v_{v}(T)$ & volatilization velocity across the air-water interface & $\mathrm{m} \mathrm{d}^{-1}$ \\
\hline$Y_{j \rightarrow i}$ & transformation yield coefficient from species $j$ to $i$ & g-i/g-j \\
\hline $\mathrm{Z}_{1}$ & pore water diffusion layer thickness & $\mathrm{mm}$ \\
\hline $\mathrm{Z}_{2}$ & sediment bioturbation layer thickness & $\mathrm{mm}$ \\
\hline \multicolumn{3}{|c|}{ Greek } \\
\hline$\alpha_{d o c}$ & partition correlation coefficient with DOC & unitless \\
\hline
\end{tabular}




\begin{tabular}{|c|c|c|}
\hline Symbol & Definition & Units \\
\hline$\alpha_{a p}$ & partition correlation coefficient with algae & unitless \\
\hline$\alpha_{\text {pom }}$ & partition correlation coefficient with POM & unitless \\
\hline$\alpha_{p n}$ & partition correlation coefficient with solids & unitless \\
\hline$\lambda_{\max }$ & maximium light extinction coefficient & $\mathrm{m}^{-1}$ \\
\hline$\alpha_{l}$ & correction factor for light attenuation & unitless \\
\hline$\lambda$ & light extinction coefficient & $m^{-1}$ \\
\hline$\rho_{b}$ & sediment bulk density & $\mathrm{g} \mathrm{cm}^{-3}$ \\
\hline$\theta$ & temperature correction coefficient & unitless \\
\hline$\phi$ & sediment layer porosity & unitless \\
\hline$v$ & kinematic viscosity of water & $m^{2} d^{-1}$ \\
\hline
\end{tabular}




\section{Appendix C: Definition of Mathematical Symbols used in the HgSM Module}

\begin{tabular}{|c|c|c|}
\hline Symbol & Definition & Units \\
\hline$A_{s}$ & surface water area & $m^{-2}$ \\
\hline Atm<-->HgO & HgO volatilization in water & $n g L^{-1} d^{-1}$ \\
\hline Atm-->HgO & HgO air deposition & $n g L^{-1} d^{-1}$ \\
\hline Atm<-->MeHg & MeHg volatilization in water & $n g L^{-1} d^{-1}$ \\
\hline Atm-->MeHg & MeHg air deposition & $n g L^{-1} d^{-1}$ \\
\hline$b_{\text {pom }}$ & Freundlich exponent for POM in water & unitless \\
\hline$b_{\text {pom2 }}$ & Freundlich exponent for sediment POM & unitless \\
\hline bap & Freundlich exponent for algae in water & unitless \\
\hline$b_{p n}$ & Freundlich exponent for solid " $\mathrm{n}$ ” in water & unitless \\
\hline$b_{p n 2}$ & Freundlich exponent for sediment solid "n" & unitless \\
\hline Bed-->HgII & sediment Hgll re-suspension rate & $n g L^{-1} d^{-1}$ \\
\hline $\mathrm{Bed-->MeHg}$ & sediment MeHg re-suspension rate & $n g L^{-1} d^{-1}$ \\
\hline DOC & dissolved organic carbon in water & mg-C L-1 \\
\hline $\mathrm{DOC}_{2}$ & dissolved organic carbon in sediment pore water & mg-C L-1 \\
\hline$f_{a p}$ & Freundlich exponent for algae in water & unitless \\
\hline$f_{d-H g l l}$ & fraction of dissolved Hgll in water & unitless \\
\hline$f_{\text {doc-HgII }}$ & fraction of DOC adsorbed Hgll in water & unitless \\
\hline$f_{a p-H g l l}$ & fraction of algae adsorbed Hgll in water & unitless \\
\hline$f_{\text {pom-Hgll }}$ & fraction of POM adsorbed Hgll in water & unitless \\
\hline$f_{p-H g l l}$ & fraction of solids adsorbed Hgll in water & unitless \\
\hline$f_{d-M e H g}$ & fraction of dissolved MeHg in water & unitless \\
\hline$f_{\text {doc-MeHg }}$ & fraction of DOC adsorbed MeHg in water & unitless \\
\hline$f_{a p-M e H g}$ & fraction of algae adsorbed MeHg in water & unitless \\
\hline$f_{\text {pom-MeHg }}$ & fraction of POM adsorbed MeHg in water & unitless \\
\hline$f_{p-M e H g}$ & fraction of solids adsorbed MeHg in water & unitless \\
\hline$f_{d-H g \| 2}$ & fraction of dissolved Hgll in sediment & unitless \\
\hline$f_{\text {doc-HgII2 }}$ & fraction of DOC adsorbed $\mathrm{Hgll}$ in sediment & unitless \\
\hline$f_{\text {pom-HgII2 }}$ & fraction of POM adsorbed Hgll in sediment & unitless \\
\hline$f_{p-H g \| / 2}$ & fraction of solids adsorbed $\mathrm{Hgll}$ in sediment & unitless \\
\hline$f_{d-M e H g 2}$ & fraction of dissolved MeHg in sediment & unitless \\
\hline
\end{tabular}




\begin{tabular}{|c|c|c|}
\hline Symbol & Definition & Units \\
\hline$f_{\text {doc-MeHg2 }}$ & fraction of DOC adsorbed MeHg in sediment & unitless \\
\hline$f_{\text {pom-MeHg2 }}$ & fraction of POM adsorbed MeHg in sediment & unitless \\
\hline$f_{p-M e H g}$ & fraction of solidsad sorbed MeHg in sediment & unitless \\
\hline$f_{\text {pom }}$ & Freundlich exponent for POM in water & unitless \\
\hline$f_{\text {pom2 }}$ & Freundlich exponent for sediment POM & unitless \\
\hline$f_{p n}$ & Freundlich exponent for solid " $\mathrm{n}$ ” in water & unitless \\
\hline$f_{p n 2}$ & Freundlich exponent for sediment solid “n” & unitless \\
\hline $\mathrm{HgO}$ & air concentration of $\mathrm{HgO}$ (gaseous) & $n g L^{-1}$ \\
\hline HgO-->Hgll & HgO oxidation yield into Hgll in water & $n g L^{-1} d^{-1}$ \\
\hline Hgll-->HgO & Hgll photoreduction yield into $\mathrm{HgO}$ in water & $n g L^{-1} d^{-1}$ \\
\hline $\mathrm{Hgll}-\mathrm{-} \mathrm{MeHg}$ & Hgll methylation yield in water & $n g L^{-1} d^{-1}$ \\
\hline $\mathrm{HgII}_{2--}>\mathrm{MeHg} 2$ & Hgll methylation yield in sediment & $n g L^{-1} d^{-1}$ \\
\hline $\mathrm{Hg} / \mathrm{l-}>\mathrm{MeHg}$ & Hgll methylation yield in water & $n g L^{-1} d^{-1}$ \\
\hline Hgll-->Bed & Hgll settling in water & $n g L^{-1} d^{-1}$ \\
\hline Hgll 2 burial & sediment Hgll burial in water & $n g L^{-1} d^{-1}$ \\
\hline $\mathrm{Hg}\|<-->\mathrm{Hg}\|_{2}$ & Hgll sediment-water transfer & $n g L^{-1} d^{-1}$ \\
\hline $\mathrm{HgO}$ & concentration of elemental mercury in water & $n g L^{-1}$ \\
\hline Hgll & concentration of total Hgll in water & $n g L^{-1}$ \\
\hline$H g l_{d}$ & concentration of dissolved Hgll in water & $n g L^{-1}$ \\
\hline$H g \|_{p n}$ & concentration of solids " $n$ " adsorbed Hgll in water & $n g L^{-1}$ \\
\hline$H g l_{p}$ & total concentration of solids adsorbed $\mathrm{Hgll}$ in water & $n g L^{-1}$ \\
\hline$H g l l_{p t s}$ & total concentration of solids adsorbed Hgll in water & ng kg-1 \\
\hline $\mathrm{Hg} \|_{2}$ & concentration of total Hgll in sediment & $n g L^{-1}$ \\
\hline$H g \|_{d 2}$ & concentration of dissolved Hgll in sediment & $n g L^{-1}$ \\
\hline$H g I_{d p 2}$ & concentration of dissolved Hgll in pore water & $n g L^{-1}$ \\
\hline$H g l_{d o c}$ & concentration of DOC adsorbed Hgll in water & $n g L^{-1}$ \\
\hline Hgll docp2 & concentration of DOC adsorbed Hgll in pore water & $n g L^{-1}$ \\
\hline $\mathrm{Hg} \|_{p 2}$ & total concentration of solids adsorbed Hgll in sediment & $n g L^{-1}$ \\
\hline HgIl pts2 & total concentration of solids adsorbed Hgll in sediment & ng kg-1 \\
\hline$h$ & water depth & $\mathrm{m}$ \\
\hline$h_{2}$ & sediment layer thickness & $\mathrm{m}$ \\
\hline 10 & solar radiation at the water surface & $\mathrm{W} \mathrm{m} \mathrm{m}^{-2}$ \\
\hline lopht & light intensity at which $k_{p h t}(T)$ is measured & $\mathrm{W} \mathrm{m}^{-2}$ \\
\hline Kdoc-MeHg & MeHg partitioning coefficient for DOC in water & $\mathrm{L} \mathrm{kg}^{-1}$ \\
\hline$K_{p-M e H g}$ & MeHg partitioning coefficient for solids in water & $\mathrm{L} \mathrm{kg}^{-1}$ \\
\hline Kap-MeHg & MeHg Partitioning coefficient for algae in water & $\mathrm{L} \mathrm{kg}^{-1}$ \\
\hline
\end{tabular}




\begin{tabular}{|c|c|c|}
\hline Symbol & Definition & Units \\
\hline$K_{\text {pom-MeHg }}$ & MeHg partitioning coefficient for POM in water & $\mathrm{L} \mathrm{kg}^{-1}$ \\
\hline$K_{d o c-H g l l}$ & Hgll equilibrium partitioning coefficient for DOC in water & $\mathrm{L} \mathrm{kg}^{-1}$ \\
\hline Kap-Hgll & Hgll equilibrium partitioning coefficient for algae in water & $\mathrm{L} \mathrm{kg}^{-1}$ \\
\hline$K_{\text {pom-HgIl }}$ & Hgll equilibrium partitioning coefficient for POM in water & $\mathrm{L} \mathrm{kg}^{-1}$ \\
\hline$K_{d o c-H g I I 2}$ & Hgll equilibrium partitioning coefficient for sediment DOC & $\mathrm{L} \mathrm{kg}^{-1}$ \\
\hline Kpom-Hgll2 & Hgll equilibrium partitioning coefficient for sediment POM & $\mathrm{L} \mathrm{kg}^{-1}$ \\
\hline$K_{p-H g I I 2}$ & Hgll equilibrium partitioning coefficient for sediment solids & $\mathrm{L} \mathrm{kg}^{-1}$ \\
\hline Koc-MeHg2 & MeHg partitioning coefficient for sediment DOC & $\mathrm{L} \mathrm{kg}^{-1}$ \\
\hline Kom-MeHg2 & MeHg Partitioning coefficient for sediment POM & $\mathrm{L} \mathrm{kg}^{-1}$ \\
\hline$K_{p-M e H g 2}$ & MeHg partitioning coefficient for sediment solids & $\mathrm{L} \mathrm{kg}^{-1}$ \\
\hline$K_{\text {fpom-Hgll }}$ & Hgll Freundlich adsorption constant for POM in water & $\left(\mu g g^{-1}\right)\left(\mu g L^{-1}\right)^{-b}$ \\
\hline Kfpom-Hgll2 & Hgll Freundlich adsorption constant for sediment POM & $\left(\mu g g^{-1}\right)\left(\mu g L^{-1}\right)^{-b}$ \\
\hline Kfap-Hgll & Hgll Freundlich adsorption constant for algae in water & $\left(\mu g g^{-1}\right)\left(\mu g L^{-1}\right)^{-b}$ \\
\hline$K_{f p-H g l l}$ & Hgll Freundlich adsorption constant for solid " $n$ ” in water & $\left(\mu g g^{-1}\right)\left(\mu g L^{-1}\right)^{-b}$ \\
\hline$K_{f p-H g l l 2}$ & Hgll Freundlich adsorption constant for sediment solid "n" & $\left(\mu g g^{-1}\right)\left(\mu g L^{-1}\right)^{-b}$ \\
\hline$K_{\text {fpom-MeHg }}$ & MeHg Freundlich adsorption constant for POM in water & $\left(\mu g g^{-1}\right)\left(\mu g L^{-1}\right)^{-b}$ \\
\hline$K_{\text {fpom-MeHg2 }}$ & MeHg Freundlich adsorption constant for sediment POM & $\left(\mu g g^{-1}\right)\left(\mu g L^{-1}\right)^{-b}$ \\
\hline$K_{\text {fap-MeHg }}$ & MeHg Freundlich adsorption constant for algae in water & $\left(\mu g g^{-1}\right)\left(\mu g L^{-1}\right)^{-b}$ \\
\hline$K_{f p-M e H g}$ & MeHg Freundlich adsorption constant for solid " $\mathrm{n}$ " in water & $\left(\mu g g^{-1}\right)\left(\mu g L^{-1}\right)^{-b}$ \\
\hline$K_{f p-M e H g 2}$ & MeHg Freundlich adsorption constant for sediment solid " $\mathrm{n}$ " & $\left(\mu g g^{-1}\right)\left(\mu g L^{-1}\right)^{-b}$ \\
\hline Klpom-HgII & Hgll Langmuir adsorption constant for POM in water & $L \mu g^{-1}$ \\
\hline Klpom-HgII2 & Hgll Langmuir adsorption constant for sediment POM & $L \mu g^{-1}$ \\
\hline$K_{\text {lap-Hgll }}$ & Hgll Langmuir adsorption constant for algae in water & $L \mu g^{-1}$ \\
\hline$K_{l p-H g l l}$ & Hgll Langmuir adsorption constant for solid " $\mathrm{n}$ ” in water & $L \mu g^{-1}$ \\
\hline$K_{I p-H g l / 2}$ & Hgll Langmuir adsorption constant for sediment solid "n” & $L \mu g^{-1}$ \\
\hline KIpom-MeHg & MeHg Langmuir adsorption constant for POM in water & $L \mu g^{-1}$ \\
\hline Klpom-MeHg2 & MeHg Langmuir adsorption constant for sediment POM & $L \mu g^{-1}$ \\
\hline Klap-MeHg & MeHg Langmuir adsorption constant for algae in water & $L \mu g^{-1}$ \\
\hline$K_{I p-M e H g}$ & MeHg Langmuir adsorption constant for solid “n” in water & $L \mu g-1$ \\
\hline$K_{\text {Ip-MeHg2 }}$ & MeHg Langmuir adsorption constant for sediment solid "n" & $L \mu g^{-1}$ \\
\hline $\mathrm{K}_{\mathrm{H}-\mathrm{HgO}}$ & Henry's Law constant of HgO & $\mathrm{Pa} \mathrm{m} \mathrm{mol}^{-1}$ \\
\hline $\mathrm{K}_{\mathrm{H}-\mathrm{MeHg}}$ & Henry's Law constant of MeHg & $\mathrm{Pa} \mathrm{m} \mathrm{m}^{3} \mathrm{~mol}^{-1}$ \\
\hline KsO4 & $\begin{array}{l}\text { half-saturation constant for the effect of sulfate on } \\
\text { methylation }\end{array}$ & $\mathrm{mg}-\mathrm{O}_{2} \mathrm{~L}^{-1}$ \\
\hline$k_{\mathrm{so} 42}(T)$ & sediment SO4 reduction rate & $d^{-1}$ \\
\hline Kdm32 & sediment MeHg demethylation rate & $d^{-1}$ \\
\hline kadn & Hgll adsorption coefficient for solid " $n$ " in water & $L_{\mu g} g^{-1} d^{-1}$ \\
\hline
\end{tabular}




\begin{tabular}{|c|c|c|}
\hline Symbol & Definition & Units \\
\hline Kdan & Hgll desorption rate for solid “n” in water & $d^{-1}$ \\
\hline Kadap & Hgll adsorption coefficient for algae in water & $L \mu g^{-1} d^{-1}$ \\
\hline Kadpom & Hgll adsorption coefficient for POM in water & $L \mu g^{-1} d^{-1}$ \\
\hline Kdaap & Hgll desorption rate for algae in water & $d^{-1}$ \\
\hline Kdapom & Hgll desorption rate for POM in water & $d^{-1}$ \\
\hline Kadn2 & Hgll adsorption coefficient for solid " $n$ " in sediment & $L \mu g^{-1} d^{-1}$ \\
\hline Kadpom2 & Hgll adsorption coefficient for sediment POM & $L \mu g^{-1} d^{-1}$ \\
\hline Kdan2 & Hgll desorption rate for solid " $n$ ” in sediment & $d^{-1}$ \\
\hline Kdapom2 & Hgll desorption rate for sediment POM & $\mathrm{d}^{-1}$ \\
\hline$k_{12}(T)$ & HgO oxidation yield rate in water & $d^{-1}$ \\
\hline$k_{d 21}$ & Hgll dissolved Hgll photoreduction rate in water & $d^{-1}$ \\
\hline$k_{d o c 21}$ & DOC adsorbed Hgll photoreduction rate in water & $d^{-1}$ \\
\hline$k_{d 23}(T)$ & dissolved Hgll methylation rate in water & $d^{-1}$ \\
\hline$k d 23-2(T)$ & dissolved Hgll methylation rate in sediment & $d^{-1}$ \\
\hline$k_{d o c 23}(T)$ & DOC adsorbed Hgll methylation rate in water & $\mathrm{d}^{-1}$ \\
\hline$k_{d 31}$ & dissolved MeHg photoreduction rate in water & $d^{-1}$ \\
\hline$k_{\text {doc31 }}$ & DOC adsorbed MeHg photoreduction rate in water & $d^{-1}$ \\
\hline$k_{d 32}$ & dissolved MeHg demethylation rate in water & $d^{-1}$ \\
\hline kdoc32 & DOC adsorbed MeHg demethylation rate in water & $d^{-1}$ \\
\hline$k d 32-2(T)$ & dissolved MeHg demethylation rate in sediment & $d^{-1}$ \\
\hline LHgll & Hgll areal air deposition rate & $m g \mathrm{~m}^{-2} \mathrm{~d}^{-1}$ \\
\hline$L_{\text {MeHg }}$ & MeHg areal air deposition rate & $m g \mathrm{~m}^{-2} \mathrm{~d}^{-1}$ \\
\hline $\mathrm{MeHg-->HgO}$ & MeHg photodegradation yield into HgO in water & $n g L^{-1} d^{-1}$ \\
\hline MeHg-->Hgll & MeHg demethylation yield into Hgll in water & $n g L^{-1} d^{-1}$ \\
\hline $\mathrm{MeHg}{ }_{2-->H g l l}$ & MeHg demethylation yield into Hgll in sediment & $n g L^{-1} d^{-1}$ \\
\hline MeHg-->Bed & MeHg settling in water & $n g L^{-1} d^{-1}$ \\
\hline $\mathrm{MeHg}_{2}$ burial & sedimate MeHg burial in water & $n g L^{-1} d^{-1}$ \\
\hline $\mathrm{MeHg}<-->\mathrm{MeHg}_{2}$ & MeHg sediment-water transfer & $n g L^{-1} d^{-1}$ \\
\hline MeHgo & air concentration of $\mathrm{MeHg}$ & $n g L^{-1}$ \\
\hline $\mathrm{MeHg}$ & concentration of total MeHg in water & ng L-1 \\
\hline $\mathrm{MeHg}$ & concentration of dissolved MeHg in water & $n g L^{-1}$ \\
\hline MeHgdoc & concentration of DOC adsorbed MeHg in water & $n g L^{-1}$ \\
\hline $\mathrm{MeHgp}$ & total concentration of solids adsorbed $\mathrm{MeHg}$ in water & $n g L^{-1}$ \\
\hline MeHgpts & total concentration of solids adsorbed $\mathrm{MeHg}$ in water & ng kg-1 \\
\hline $\mathrm{MeHg} 2$ & concentration of total MeHg on in sediment & $n g L^{-1}$ \\
\hline $\mathrm{MeHg}_{d p 2}$ & concentration of dissolved MeHg in pore water & $n g L^{-1}$ \\
\hline
\end{tabular}




\begin{tabular}{|c|c|c|}
\hline Symbol & Definition & Units \\
\hline $\mathrm{MeHg} d o c p 2$ & concentration of DOC adsorbed $\mathrm{MeHg}$ in pore water & $n g L^{-1}$ \\
\hline MeHgp2 & total concentration of solids adsorbed $\mathrm{MeHg}$ in sediment & $n g L^{-1}$ \\
\hline MeHgpts2 & total concentration of solids adsorbed $\mathrm{MeHg}$ in sediment & ng kg-1 \\
\hline$q_{\mathrm{cn}-\mathrm{Hg} \|}$ & maximum amount of Hgll adsorbed by solid " $n$ " in water & $\mu g g^{-1}$ \\
\hline$q_{c n-H g \| 2}$ & maximum amount of Hgll adsorbed by sediment solid " $n$ " & $\mu g g^{-1}$ \\
\hline qcap-Hgll & maximum amount of Hgll adsorbed by algae in water & $\mu g g^{-1}$ \\
\hline qcpom-HgIl & maximum amount of Hgll adsorbed by POM in water & $\mu g g^{-1}$ \\
\hline$q_{\text {cpom-HgII2 }}$ & maximum amount of Hgll adsorbed by sediment POM & $\mu g g^{-1}$ \\
\hline$q_{c n-H g l l}$ & maximum amount of Hgll adsorbed by suspended solids & $\mu g g^{-1}$ \\
\hline$q_{c n-H g \| 2}$ & maximum amount of Hgll adsorbed by sediment solids & $\mu g g^{-1}$ \\
\hline qcap-MeHg & maximum amount of MeHg adsorbed by algae in water & $\mu g g^{-1}$ \\
\hline$q_{c p o m-M e H g}$ & maximum amount of MeHg adsorbed by POM in water & $\mu g g^{-1}$ \\
\hline$q_{\text {cpom-MeHg2 }}$ & maximum amount of MeHg adsorbed by sediment POM & $\mu g g^{-1}$ \\
\hline$q_{\mathrm{cn}-\mathrm{MeHg}}$ & maximum amount of MeHg adsorbed by solid " $n$ " in water & $\mu g g^{-1}$ \\
\hline qcn-MeHg2 & maximum amount of MeHg adsorbed by sediment solids & $\mu g g^{-1}$ \\
\hline$r_{m s 04}$ & ratio of sediment methylation rate and sulfate reduction rate & $\mathrm{L} \mathrm{mg}^{-1}$ \\
\hline $\mathrm{SO}_{2}$ & sediment pore water sulfate & $\mathrm{mg}-\mathrm{O}_{2} \mathrm{~L}^{-1}$ \\
\hline $\mathrm{SS}_{\mathrm{HgO}}$ & sum of internal source and sink terms of $\mathrm{HgO}$ in water & $n g L^{-1} d^{-1}$ \\
\hline SSHgll & sum of internal source and sink terms of total Hgll in water & $n g L^{-1} d^{-1}$ \\
\hline SS HgIlld $_{1}$ & $\begin{array}{l}\text { sum of internal source and sink terms of dissolved Hgll in } \\
\text { water }\end{array}$ & $n g L^{-1} d^{-1}$ \\
\hline SS Hglldoc & $\begin{array}{l}\text { sum of internal source and sink terms of DOC adsorbed HgIl } \\
\text { in water }\end{array}$ & $n g L^{-1} d^{-1}$ \\
\hline $\mathrm{SS}_{\text {Hgllap }}$ & $\begin{array}{l}\text { sum of internal source and sink terms of algae adsorbed } \\
\text { Hgll in water }\end{array}$ & $n g L^{-1} d^{-1}$ \\
\hline $\mathrm{SS}_{\text {HgIllpom }}$ & $\begin{array}{l}\text { sum of internal source and sink terms of POM adsorbed Hgll } \\
\text { in water }\end{array}$ & $n g L^{-1} d^{-1}$ \\
\hline $\mathrm{SS}_{\mathrm{Hg} \| \mathrm{l}}$ & $\begin{array}{l}\text { sum of internal source and sink terms of solids adsorbed } \\
\text { Hgll in water }\end{array}$ & $n g L^{-1} d^{-1}$ \\
\hline $\mathrm{SS}_{\mathrm{Hg} / 2}$ & sum of source and sink terms of total Hgll in sediment & $n g L^{-1} d^{-1}$ \\
\hline SSHglld2 & sum of source and sink terms of dissolved Hgll in sediment & $n g L^{-1} d^{-1}$ \\
\hline SSHglldoc2 & $\begin{array}{l}\text { sum of source and sink terms of DOC adsorbed Hgll in } \\
\text { sediment }\end{array}$ & $n g L^{-1} d^{-1}$ \\
\hline SS Hgllpom2 & $\begin{array}{l}\text { sum of source and sink terms of POM adsorbed Hgll in } \\
\text { sediment }\end{array}$ & $n g L^{-1} d^{-1}$ \\
\hline $\mathrm{SS}_{\text {Hgllp2 }}$ & $\begin{array}{l}\text { sum of source and sink terms of solids adsorbed Hgll in } \\
\text { sediment }\end{array}$ & $n g L^{-1} d^{-1}$ \\
\hline $\mathrm{SS}_{\mathrm{MeHg}}$ & sum of internal source and sink terms of total MeHg in water & $n g L^{-1} d^{-1}$ \\
\hline $\mathrm{SS}_{\mathrm{MeHg} 2}$ & sum of source and sink terms of total MeHg in sediment & $n g L^{-1} d^{-1}$ \\
\hline
\end{tabular}




\begin{tabular}{|c|c|c|}
\hline Symbol & Definition & Units \\
\hline$v_{b}$ & sediment burial velocity & $m d^{-1}$ \\
\hline$V_{m}$ & sediment-water transfer velocity & $m d^{-1}$ \\
\hline$V_{r p n}$ & re-suspension velocity for solid " $\mathrm{n}$ " & $m d^{-1}$ \\
\hline$V_{s p n}$ & settling velocity for solid " $\mathrm{n}$ " & $\mathrm{m} \mathrm{d}^{-1}$ \\
\hline Vsap & algal settling velocity & $m d^{-1}$ \\
\hline Vsom & POM settling velocity & $\mathrm{m} \mathrm{d}^{-1}$ \\
\hline$V_{v-H g O}(T)$ & volatilization velocity of $\mathrm{HgO}$ & $m d^{-1}$ \\
\hline$V_{V-M e H g}(T)$ & volatilization velocity of $\mathrm{MeHg}$ & $\mathrm{m} \mathrm{d}^{-1}$ \\
\hline$Y_{12}$ & HgO oxidation yield coefficient in water & unitless \\
\hline$Y_{21}$ & Hgll reduction yield coefficient in water & unitless \\
\hline$Y_{23}$ & Hgll methylation yield coefficient in water & unitless \\
\hline$Y_{31}$ & MeHg photodegradation yield coefficient in water & unitless \\
\hline$Y_{32}$ & MeHg demethylation yield coefficient in water & unitless \\
\hline \multicolumn{3}{|c|}{ Greek } \\
\hline$\lambda_{\max }$ & maximum light extinction coefficient & $m^{-1}$ \\
\hline$\theta$ & temperature correction coefficient & unitless \\
\hline$\phi$ & sediment layer porosity & unitless \\
\hline
\end{tabular}




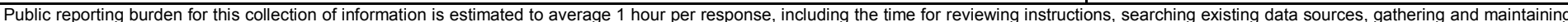

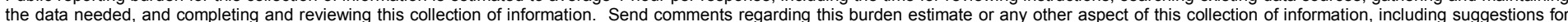

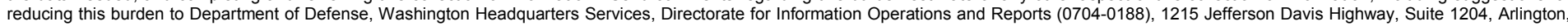

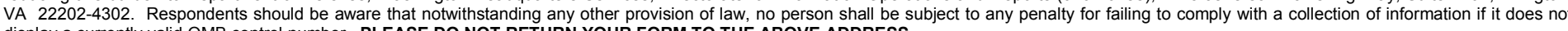
display a currently valid OMB control number. PLEASE DO NOT RETURN YOUR FORM TO THE ABOVE ADDRESS.
1. REPORT DATE (DD-MM-YYYY) 2. REPORT TYPE
3. DATES COVERED (From - To)

July 2016

Final report

Aquatic Contaminant and Mercury Simulation Modules Developed for Hydrologic and Hydraulic Models

\section{TITLE AND SUBTITLE}

5a. CONTRACT NUMBER

5b. GRANT NUMBER

5c. PROGRAM ELEMENT NUMBER

5d. PROJECT NUMBER

5e. TASK NUMBER

5f. WORK UNIT NUMBER

8. PERFORMING ORGANIZATION REPORT NUMBER

ERDC/EL TR-16-8

U.S. Army Engineer Research and Development Center

Environmental Laboratory

3909 Halls Ferry Road, Vicksburg, MS 39180-6199

9. SPONSORING / MONITORING AGENCY NAME(S) AND ADDRESS(ES)

10. SPONSOR/MONITOR'S ACRONYM(S)

Headquarters, U.S. Army Corps of Engineers

Washington, DC 20314-1000

11. SPONSOR/MONITOR'S REPORT NUMBER(S)

\section{DISTRIBUTION / AVAILABILITY STATEMENT}

Approved for public release; distribution unlimited.

\section{SUPPLEMENTARY NOTES}

\section{ABSTRACT}

This report offers details regarding the theory and mathematical formulations implemented in the newly developed general constituent simulation module (GC), contaminant simulation module (CSM), and mercury simulation module (HgSM). The GC models simple kinetics for multiple size classes of solids and user-defined constituents in the water column. The CSM models the kinetics of user-defined contaminants in aquatic systems. The kinetic processes modeled in CSM include: ionization, multi-phase partitioning, degradation, photolysis, hydrolysis, volatilization, generalized second-order reaction, and transformations where one chemical species undergoes a reaction and is transformed to a daughter product. The HgSM models mercury species (elemental mercury, inorganic mercury, and methylmercury) and their cycling in aquatic systems. The three water quality modules only compute internal sources and sinks of each state variable for both water column and an underlying sediment layer. The GC, CSM and HgSM modules are written as "plug in" dynamic link libraries and compiled as GC.dll, CSM.dll and HgSM.dll respectively. These modules have been integrated into the HEC-RAS model and will also be integrated into other hydrologic and hydraulic models (e.g. AdH and SRH-2D).

\begin{tabular}{|ll}
\hline 15. SUBJECT TERMS & Mercury Species \\
Water Quality & Contaminant Simulation Module (CSM) \\
Solids & Mercury Simulation Module (HgSM) \\
Contaminants &
\end{tabular}

HEC-RAS

Hydrologic and Hydraulic (H\&H) Models

Contaminants

\section{SECURITY CLASSIFICATION OF:}

a. REPORT

UNCLASSIFIED

b. ABSTRACT
UNCLASSIFIED

17. LIMITATION
OF ABSTRACT

\begin{tabular}{l|l} 
18. NUMBER \\
OF PAGES
\end{tabular}

c. THIS PAGE

UNCLASSIFIED

\section{OF PAGES}

136 19a. NAME OF RESPONSIBLE PERSON

19b. TELEPHONE NUMBER (include area code) 